Communication Research and Broadcasting No. 9

Editor:

Internationales Zentralinstitut für das Jugend- und Bildungsfernsehen (IZI) 


\section{Media Communication in Everyday Life}

Interpretative Studies on Children's and Young People's Media Actions

Edited by

Michael Charlton and Ben Bachmair

$\mathrm{K} \cdot \mathrm{G} \cdot$ Saur

München · New York · London · Paris 1990 
Editor of the series:

Internationales Zentralinstitut für das Jugend- und Bildungsfernsehen (IZI)

Rundfunkplatz 1, D-8000 München 2,

Tel. (0 89) 59 00-21 40, Telex 52 107-0 brmd, Telefax (0 89) 59 00-23 75

Responsible:

Paul Löhr

Editorial Assistant:

Rosemarie Hagemeister

Translation of the three contributions by Bachmair (et al.):

Richard Kilborn

Translation of all other contributions:

Geoffrey P. Burwell

CIP-Titelaufnahme der Deutschen Bibliothek

Media communication in everyday life : Interpretative studies

on children's and young people's media actions /

ed. by Michael Charlton and Ben Bachmair.

[Transl. of the 3 contributions by Bachmair (et al.):

Richard Kilborn. Transl. of all other contributions:

Geoffrey P. Burwell]. - München ; New York ; London ;

Paris : Saur, 1990

(Communication research and broadcasting; No. 9)

ISBN 3-598-20208-3

NE: Charlton, Michael, [Hrsg.]; GT

Printed on acid-free paper

(C) 1990 by K. G. Saur Verlag GmbH \& Co. K. G., München

Phototypesetting: Fotosatz H. Buck, 8300 Kumhausen b. Landshut

Printed by: grafik + druck GmbH \& Co., München

Bound by: Attenberger $\mathrm{GmbH}$, München

ISBN 3-598-20208-3 


\section{Contents}

\section{Paul Löhr}

The Internationales Zentralinstitut für das Jugend- und Bildungsfernsehen (IZI): 25 years as a mediator between theory and programme

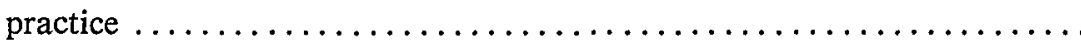

Ben Bachmair, Michael Charlton

The editors' preface $\ldots \ldots \ldots \ldots \ldots \ldots \ldots \ldots \ldots \ldots \ldots \ldots \ldots$

Theoretical and methodological frame of reference

Michael Charlton, Klaus Neumann

Reception research as structure analysis $\ldots \ldots \ldots \ldots \ldots \ldots \ldots \ldots \ldots, 21$

Ben Bachmair

Everyday life as the subject of television research . .

Stefan Müller-Doohm

Media research as symbol analysis

\section{Projects and studies}

Ben Bachmair

The function of interpretation and expression in television experience

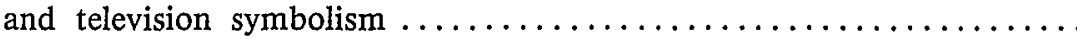

Ben Bachmair, Burkhard Hofmann, Michaela van Waasen, Martina van den Hövel

Media analysis within an activity context - Understanding a girl's

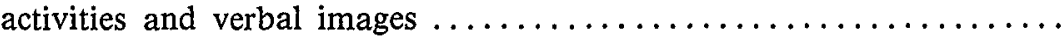

Waltraud Orlik, Michael Charlton, Klaus Neumann

Media symbols and self-symbolisation - Steps taken by the child to

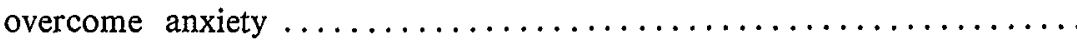

Heinz Hengst

Change of scene - The scripts of the media industry in children's culture

Stefan Aufenanger

Hermeneutic case reconstruction in media research

Michael Charlton, Klaus Neumann, Mara Niemann

Children write viewers' letters $\ldots \ldots \ldots \ldots \ldots \ldots \ldots \ldots \ldots \ldots$ 
Jan-Uwe Rogge

Media-related education for parents and family counselling as an aid to socialisation in practical life - Some essentials .................

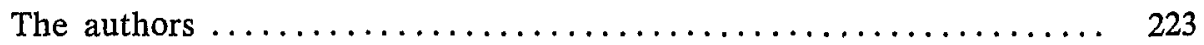




\section{The Internationales Zentralinstitut für das Jugend- und Bildungsfernsehen (IZI): \\ 25 years as a mediator between theory and programme practice}

\section{Introduction}

The IZI 25 years old - an occasion to review the work performed, which is what this volume intends to do, since in about the last ten years an interpretative research into the media and communication has established itself at the universities in the Federal Republic of Germany. The promotion of television for children and young people and for educational purposes by the IZI and the research at the universities into media reception by children and young people are committed to the same aims. From the beginning there has been a close exchange between the institutions involved.

The mid-sixties were a time of complete reorientation - great value was attached to education, training and further education. In those days the medium of television was thought capable of a great deal, and this included these areas. The socalled Third Programmes here in Germany were launched in the confident hope that they could provide education for all. It was at this time that the Internationales Zentralinstitut für das Jugend- und Bildungsfernsehen (International Central Institute for Youth and Educational Television) was founded, and from the beginning it has been supported by the Gesellschaft zur Förderung des internationalen Jugend- und Bildungsfernsehens e.V. Members of this society are: the Free State of Bavaria, the City of Munich, the Bayerischer Rundfunk (Bavarian Broadcasting Corporation) for the Arbeitsgemeinschaft der offentlich-rechtlichen Rundfunkanstalten der Bundesrepublik Deutschland (ARD - public-service broadcasting) and the Zweites Deutsches Fernsehen (ZDF).

As a documentation and information centre which, however, not only reports on research but also initiates and supervises it, the IZI has set itself the following tasks: the IZI finds and supplies chiefly information on television for children and young people and educational television from the national and international research into television and the effects of the media. Through its work the IZI wants to contribute towards helping to show and to clarify the cultural significance of television and its incorporation into the everyday world of its audience. "This means that the IZI's most important objective is to pass on information, in particular scientifically obtained data and arguments, to those who, as researchers, pro- 
gramme producers and specialised journalists, but also as parents, teachers and academically qualified social workers, are involved with audiences of children and young people." The IZI has pursued this objective in the last 25 years and has increasingly developed into an accepted mediator between theory and practice that has provided new impetus - in this connection the intensive cooperation with the programme staffs of the broadcasting stations should be especially emphasised. The IZI's activities as a mediator are not only evidenced by the numerous contributions to national and international conferences and congresses, and the organisation of seminars and symposiums of experts, but also the publications issued in the "Schriftenreihe", the "Offene Reihe", the series "Communication Research and Broadcasting", the review "Fernsehen und Bildung" (up to 1982), the review "TelevIZIon" (from 1988) and in the IZI's "Bibliographischer Dienst" testify to its work in this area.

A selection of research works carried out under the aegis of the IZI: 1965 - 1989:

M. Keilhacker/G. Vogg: Gesetzmäßigkeiten des Fernseherlebens bei Kindern und Jugendlichen. Dargelegt am Beispiel der preisgekrönten Sendungen des Prix Jeunesse 1964. Munich: IZI 1965 (empirical study)

H. Sturm/R.v.Haebler/R. Helmreich: Medienspezifische Lerneffekte. Eine empirische Studie zu Wirkungen von Fernsehen und Rundfunk. Munich: IZI 1972 (empirical study)

M. Schmidbauer/P. Löhr/A.O Schorb: Schulfernsehen in Bayern. Eine Untersuchung über den Einsatz von AV-Medien in bayerischen Schulen. Munich: Ehrenwirth 1974 (empirical study)

H. Sturm/K. Holzheuer/R. Helmreich: Emotionale Wirkungen des Fernsehens Jugendliche als Rezipienten. Munich: Saur 1978 (empirical study)

S. Jörg: Unterhaltung im Fernsehen. Show-Master im Urteil der Zuschauer. Munich: Saur 1984 (empirical study)

P. Löhr: Arbeitslose Jugendliche - eine Zielgruppe für Fernsehen und Hörfunk? Munich: Saur 1985 (empirical study)

M. Schmidbauer/P. Löhr: Der Markt der kommerziellen Kindermedien. Munich: Saur 1985 (literature review)

M. Schmidbauer: Die Geschichte des Kinderfer jehens in der Bundesrepublik Deutschland. Munich: Saur 1987 (secondary analysis)

M. Schmidbauer/P. Löhr: Jugend und Fernsehen. Plädoyer für ein jugendgeeignetes Programm. Munich: Saur 1989 (literature review)

If the activity of mediating - as described above - is not to take place aimlessly, 
it must relate to a perspective, must be assessed with regard to the data documented, the arguments advanced, the research carried out and its findings estimated. For the IZI the reason for this perspective was and is to be found in the conditions which shape the young people's and children's day-to-day television routine ${ }^{1}$ summed up in the dual question: How, and motivated by what, do young people and children handle television and its programmes? How, and promoted by what, do television and its programmes handle the needs and demands of the young people and children? The contours and contents which nowadays characterise this perspective - with the rapid changes in day-to-day habits and in science the way it is conceived has varied considerably in the last 25 years - have been set down in a study recently published by the IZI. ${ }^{2}$ This work is to be presented below in rather more detail as an example of the IZI's studies. Two of the things the study tries to make clear are: firstly, the way in which the IZI relates to the current discussions on theory and research with its informational, documentational and research work; secondly, the principal specific considerations on the triangle 'youth, education, television'3 which serve as guidelines for the activities of the IZI.

\section{The phase of life 'youth' and the development necessity 'education'}

To determine what is described as the phase of life 'youth' it is useful to take the term socialisation as a point of departure. If socialisation is understood as the "process in which the personality comes into being and develops in mutual dependence on a person's social and material environment as it is imparted by society" , 4 this means for the phase of life 'youth': socialisation in this phase, too, is based on the correlation between the subjects (to be socialised) and the (social and material) environment imparted by society, since the young people also find themselves in and move in a social context which, on the one hand, they absorb and process, but, on the other, are (partly) responsible for, influence and change. This interpretation of the phase of life 'youth' is based on the so-called interactive model of socialisation, which rests on the following assumptions. ". . . human developments and the development of the social and objective environment (are) seen in mutual dependence. The human subject finds himself in a productive process of adapting to and coping with the environment. The human subject can consciously reflect his own situation and include it in the sequences of his own actions. He selects certain means to achieve certain goals, thinks over the consequences of acting accordingly and takes into consideration that these consequences change the contextual conditions for his own actions . . . (It) is a matter of acquiring certain basic qualifications of actions and of a general competence, of being capable of acting autonomously in the social environment and of disposing of an identity of one's own, as a criterion for a successful development."s 
It is against this kind of background that the specific educational process has to be examined which the young people go through in the phase of life 'youth' and in the course of which they, on the one hand, gain an ego identity, and, on the other, (should) cultivate the ability and the willingness to integrate themselves into the societal context (of values and norms). By the formation of an identity (or individuation) is understood - the "process of building up an individual personality structure with complex cognitive, motivational, linguistic, moral and social features and competences as well as of having subjective experiences as a unique personality."6 By integration is understood - "adaptating to societal values, norms and standards of behaviour and taking a place in the economically conditioned structure of chances, (which) forms the basis for the social identity of the young person, that is for the subjective experiencing of a recognised social membership role."7 The socialisation process can be described as successful if "a synthesis of individuation and integration is achieved which results in a competence for autonomous actions and an ego identity balanced between personal and social identity.",8

The major problems associated with this process of providing an identity and promoting integration can be described as follows:

- The youth phase is the period of time in which an ego identity and social competences for acting and economic work are (should be) acquired in equal measure. The young people themselves are, although they have developed neither the complete degree of autonomy for acting nor a fully developed ego identity, understood as subjects who are capable of a productive processing of reality and a constructive way of dealing with themselves and the world they live in.

- The young people are faced with a dual task, which has not only a stimulating but also a - in some cases very - stressful effect. They must, firstly, radically change the structures of their motives, feelings, ways of thinking and action patterns and thus cope with a fundamental reshaping of their personal identity. They must, secondly, - and at the same time - achieve immense sociocultural adaptations and meet economically significant demands to acquire qualifications. Here society, or rather the institutional system of society, is confronted with two functions. On the one hand, the institutional system has to give aid and support to the young people in restructuring in the area of emotion, cognition and action and to enable them to acquire those competences which are absolutely essential prerequisites for being 'admitted' into adult society. On the other hand, the institutional system - especially with regard to the future conditions in which the young people are going to live - has the duty to guarantee scope for, in particular, creative competences. The fact that competences of this kind may possibly contradict the received norms not only has to be tolerated, but it must, moreover, be accepted as an important objec- 
tive by the institutional system, as it is only with the help of these competences that the young people can innovatively respond to the apparent "completeness"9 of an "administered, institutionalised world which withholds selfdetermined actions" 10 as well as to its actual problem character.

- The decisive question which the young people face is whether they can consistently withstand the process of identity formation and integration (demanded of them) and can, at the same time, produce a synthesis of identity formation and integration into the context of the values and norms of society. Only when this condition is fulfilled can a successful socialisation take place. That means: only then are the young people in a position to perform "the construction of an ego" which can reconcile the values of society with its structure of instincts and is in a position to establish a socially integrative stability of their own person in this synthesis." 11

- The process of individuation and of integration represents a sequence of transitional processes which lead from simple to complex personality organisation and from simple to complex status configuration. Both of these developmental paths mutually determine and influence each other. When a social status is taken over ('trainee', 'secondary school pupil') new fields of interaction open up; new competences for action are called for; the repertoire of psychological and social skills already existing has to become more sophisticated; the demands made on autonomously controlled and coordinated action increase. With regard to the quality of the status transition ('status passage') the young people see themselves subjected to a considerable difficulty, as they not only have to live up to the 'new' expectation structures which their environment confronts them with, but they also have to fight their way through the contradictions and inconsistencies of these expectation structures in order to be really in a position to cope with individuation and integration. Contradictions and inconsistencies of this kind result from the fact that the recommendations and expectations (presented to the young people by adult society) are often unclear and equivocal and are not rarely endowed with 'double standards of morality'. And they result from the fact that achievements are always being demanded from the young people for the fulfillment of which they have neither the appropriate individual nor the appropriate social prerequisites.

- That grappling with these contradictions and inconsistencies, as well as with other problems too, has a far-reaching influence on the young people's consciousness and actions is quite obvious. Whether or not during this tussle conflict potential resulting in a crisis accumulates and behaviour which destroys identity and is inimical to integration is provoked is likely to depend on three factors (the points given are to be related in each case to the socially and situationally specific conditions of the young people): 
- firstly, on the extent to which the young people are able to cope with the decisive problems that trigger anxiety (irritations about their own physical nature; replacing the family (of origin) with groups of peers; contradictions between the standardisations of society and the demands made on their own actions; the pressure to achieve and consume; confrontation with the problem of finding a job and unemployment, with destruction of the environment and nature, exploitation and poverty);

- secondly, on whether the young people can resort to anxiety-processing mechanisms and strategies for coping with problems (also alternative ones that deviate from the norm) which, on the one hand, prevent them from becoming apathetic and excessively active, and, on the other, introduce them to politico-social activities;

- thirdly, on whether and, if so, which support, which help, is offered to the young people by their social environment, that is, primarily by the socioinstitutional system.

It is particularly in the light of the last mentioned that it again becomes clear which - positive or negative - importance the institutional authorities of the socio-institutional system have for the formation of an identity and integration into the societal context. This applies not only to the family and educational institutions. But it also, and in particular, applies to the media. For "young people construct reality and identity ... - - whether 'successfully' or not in their everyday actions to a growing extent less alone and by direct interaction, but rather in conjunction with and mediated by the media."12

\section{Television as a socialisation factor}

With regard to the use and effect of the media, television plays a "dominant role" ${ }^{\prime 13}$ in young people's activities. It must, however, be conceded that - related to the group of the young people - television has been reaching fewer of them in recent years. The reasons for this can probably be found in the specific processes and activities which have developed in precisely this age group - with regard to the severance from the family, on the one hand, and to the expansion of activities outside the home connected with this, on the other hand. The extent and the direction of the assessment the young people make of television (truth, completeness, objectivity, an aid in orientation) contain an element that ist clearly critical of television.

With regard to the above-mentioned demands and burdens which characterise the young people's situation in life and which they have to overcome, the relationship between 'youth and television' is decisively determined 
- by the great demands and the strains made on the emotionality, the knowledge, the ability to act and, not least, the young people's skills relevant to communication and television;

- by the conditions peculiar to society and the situation under which the young people have to come to grips with these demands and strains;

- by the extent of the support which the young people receive in this connection from people and institutions (including the media);

- by the opportunities of access to and reception of media programmes in general;

- by the contents, forms and qualities of the television programmes in particular.

If such a frame of reference is taken as a basis, the subject of 'youth and television' can be summed as follows:

- The relationship of 'youth to television' has its place in a context of social relations which - grouped around the young people's centre of their everyday world - are to be understood as a network of "socio-ecological cross-related spaces." 14

- As a socio-communicative element of the everyday world experienced and realised by the young people, the relationship of 'youth to television' plays a decisive part in the constitution of social reality and in the process of shaping the environment.

- The relationship of 'youth to television' first shows its concrete quality when the "young people's way of looking at things is opened up as a major orientation constituting the world they live in." 15 Taking this conception as a starting point, the young people's use of television can be dealt with from four points of view: ${ }^{16}$

\section{Youth as a psycho-social phase}

The use of television is characterised by the specific constellation and the specific "psycho-social peculiarities" "17 which are typical of the age of youth as a transitional phase between childhood and the adult world. This sphere is particularly characterised by the fact that the young people, on the one hand, begin to take over adults' roles, and, on the other, are exposed to the turmoils of the adults' world as burdens they and their future are saddled with.

\section{Structural changes in the youth phase}

Since the period of youth as a socially determined phase is dependent on the movements and developments which take place in society as a whole, they always have an effect in the youth phase as well. Thus the social processes of change that have occurred in the last few years result in the border between the age of youth and the adult world becoming increasingly porous. For these processes - see the indi- 
vidualisation and simultaneous pluralisation of the forms of life or the fact that science is being increasingly applied to production and administrative processes - have had a lasting influence on the relation between (the age of) youth and the adult world (lengthening of the training and educational careers, an increase in orientation patterns and behavioural models, propagation of alternative life styles, distortions of the labour market). It is obvious that such events have a radical effect on the ways in which young people turn to the media in general and television in particular and how they use them.

\section{The use of television as a social act}

The young people thus do not relate to television quasi-automatically. They do so, rather, indirectly through their needs and problems, their motivations and values, which are shaped by the psycho-social quality of the age of youth and the young people's concrete everyday conditions of life formed by it. (Added to this are the specific situational conditions which influence the way they turn to and deal with television.) If we take into account with which demands and strains the young people are confronted in the phase of life 'youth' under the pressure of immense processes of change in society, it is to be assumed: the usefulness of television (as of the other media) obviously lies in its relation to the considerable achievements of seeking and orientation which are demanded from the young people on their way to a personal identity and integration into society's context of values and norms. Here the crucial question concerning the core of the relationship between 'youth and education' is: Is, in this relation, a rational way of dealing with those achievements that is aware of the problem achieved, or a way that serves to conceal and compensate for the tasks and strains imposed on the young people?

\section{The television programme as an offering factor}

The expectations and demands which the young people show for television by reason of their psycho-social state of mind encounter a programme which, on the one hand, presents itself as an offering, and, on the other, also helps to structure those expectations and demands. In this connection the fact that the young people are a 'television generation' is important: they have grown up with the medium and handle it as a "self-evident and unobtrusive ingredient of everyday life." much for the findings of this recently completed IZI study. 


\section{Why is the relationship between youth, education and television that has been outlined of importance for the activities of the IZI?}

When at the beginning of this article there was mention of the perspective with which the IZI carries out its research, documentation and information work, that was not intended as the final formulation of a concept, let alone a recipe, for research and - with regard to documentation and information - for educational policies intended for direct 'application'. What is meant is, rather, a framework which is loose - although it does relate to problems, arrange them, generate them - on which the IZI's activities can be based, sometimes more closely and sometimes less closely. It is thus a framework, however, which offers starting points not only for fields of study and research concepts but also for documentation and information projects and makes it possible:

- firstly, to link up the IZI's activities with the latest developments in the discussion on theory and (educational) policies;

- secondly, to formulate practical and theoretical points of reference - giving reasons for their relevance - from which research, documentation and information can take their bearings;

- thirdly, to have a chance to specifically influence the demands made by the practice of society in general and the practice of television (programmes) in particular.

\section{Notes}

1 young people $=14$ - to 19 -year-olds; children $=3$ - to 13 -year-olds

2 M. Schmidbauer, P. Löhr: Jugend und Fernsehen. Plädoyer für ein jugendgeeignetes Programm. Munich: Saur 1989. (Schriftenreihe Internationales Zentralinstitut für das Jugendund Bildungsfernsehen. 23)

3 On the subject of 'childhood', which is not dealt with here in any further depth, compare the basic theoretical argumentations. In: M. Charlton/K. Neumann (in collaboration with $M$. Barth, H. Benzinger, B. Braun, U. Dörler, U. Münssinger, A. Pohrt, R. Rapp, B. Siegrist, R. Stich): Medienkonsum und Lebensbewalltigung in der Familie. Methode und Ergebnisse der strukturanalytischen Rezeptionsforschung - mit fünf Fallbeispielen. Munich 1986. And in:

J.-U. Rogge: Objektive und subjektive Hintergründe der Medienrezeption. In: K. Jensen/J.U. Rogge: Der Medienmarkt für Kinder in der Bundesrepublik. Tübingen 1980.

4 D. Geulen/K. Hurrelmann, Zur Programmatik einer umfassenden Sozialisationstheorie. In:

K. Hurrelmann/D. Ulich (Ed.), Handbuch der Sozialisationsforschung, Weinheim 1980, p. 51

5 K. Hurrelmann/B. Rosewitz/H.K. Wolf, Lebensphase Jugend, Weinheim 1985, p. 23)

6 K. Hurrelmann/B. Rosewitz/H.K. Wolf, p. 28

7 ibid.

8 ibid. 
9 D. Baacke: Die 13-bis 18jährigen, Weinheim 1985 (4th edition), p. 227

10 ibid., p. 224

11 H. Rust: Jugendprobleme im Fernsehen. Eine Studie über Darstellung und Rezeption. Tübingen 1981 , p. 15

12 M. Radde: Die Mediatisierung des Jugendalltags als Herausforderung an die Jugendarbeit (im Blickwinkel des sozialökologischen Ansatzes der Jugendforschung). In: M. Radde/U. Sander/R. Vollbrecht (Ed.): Jugendzeit - Medienzeit. Daten, Tendenzen, Analysen für eine jugendorientierte Medienerziehung. Munich 1988, pp. 119 et seq.

13 K.-H. Müller-Sachse: Multimedia-Generation. Die Jugend/Medien-Studie. In: W \& M (Weiterbildung \& Medien) 3/1986, p. 35

14 U. Sander/R. Vollbrecht: Kinder und Jugendliche im Medienzeitalter. Opladen 1987, p.35

15 ibid, p.65

16 Cf.H. Bonfadelli: Jugend und Medien. Befunde zum Freizeitverhalten und zur Mediennutzung der 12- bis 29jährigen in der Bundesrepublik Deutschland. In: Media Perspektiven $1 / 1986$, p. 1 et seq.

17 J.-U. Rogge: Jugendkultur, Medienkultur, Alltagskultur - einige Beschreibungs- und Deutungsversuche. In: M. Radde/U. Sander/R. Vollbrecht (Ed.), p. 62

18 R. Vollbrecht: Die Herausforderung der Medienforschung angesichts gesellschaftlicher Individualisierungsprozesse - Ein Plädoyer für medienökologische Ansätze. In: Deutsches Jugendinstitut (Ed.): Medien im Alltag von Kindern und Jugendlichen. Methoden, Konzepte, Projekte. Munich 1988, p. 382 


\section{The editors' preface}

"There was a film on telly the other day. . ." is how quite a few casual conversations begin between schoolchildren in the playground and in the classroom. In our case it is a literal quotation recorded by scientists. A 17-year-old Turkish girl, who was growing up in Germany, used this reference to a recently transmitted film in order that she was better able to explain to her friends what she meant when she talked about a smiling witch (details in Bachmair: Media analysis within an activity context; in this volume). Media experiences, especially those from television, are so much a part of children's and adolescents' everyday life that they represent a fund of knowledge shared in common, of shared experiences and images, on which it is always possible to draw whenever it is a matter of making oneself understood with regard to this everyday life.

Scientific research has hardly reacted to the way that television has been turned into part of everyday life. The conventional research into the effects of the media pretends that media use and media experiences can still be separated from their close interconnection with daily life, effects can be determined, or at least the ways and the networks of effects can be causally explained. But once social institutions are incorporated so much into everyday life that people have begun to shape their conduct of life with the help of these institutions and symbols, the tool of research orientated towards the ideal of natural sciences becomes blunt. People's speech and actions comply with other conditions, and they have to be reconstructed in their societal significance according to the logic of language and actions.

This is performed by the interpretative research methods, provided that they are applied with the same care and with a comparable methodological know-how as is the case in the meantime in quantitative media research. Because this is so, because research into children's and adolescents' everyday media life is not only a terra incognita in large areas as far as contents are concerned, but is also largely unclarified methodologically, this book deals with both the findings of research into everyday life carried out by the media sciences and their theoretical and methodological fundamentals.

With regard to contents we have endeavoured to take into account all the age levels and life-worlds in which children and adolescents connect media experiences with everyday actions. Studies are presented on the use of the media at pre-school age (Charlton/Neumann; Orlik/Charlton/Neumann), at primary school age (Bachmair; Charlton/Neumann/Niemann) and in adolescence (Aufenanger; 
Bachmair/Hofmann/v. Wasen/v. den Hövel; Hengst). At the same time the action areas that are preferred (family, peer group, school, the public of the consumer and leisure industry) are also considered in these works in addition to individual age groups. The article by Rogge completes these locales with the counselling centre for the education of parents and families.

All the authors describe in detail the theoretical approach on which their work is based. The articles have in common that they rest on a theory of symbolically mediated interaction. As is known, there are two broad trends in this area: the one which tends to see its origin in Alfred Schuitz's work on the construction of the social world, and the other in George Herbert Mead's theory of the subject and society. Neither of these traditions can be carried over into the other, but they do share the common aim of making a contribution to an understanding of the meaningful structure of the social world and to the logical reconstruction of communication processes in terms of meaning. From this theoretical point of view, closer connections arise between the work of Bachmair et al., Hengst and Rogge, on the one hand, and of Aufenanger, Charlton et al. and Müller-Doohm, on the other.

With regard to the methodology underlying the studies, too, the effects of internally belonging to one of these 'schools' are revealed. Whereas, for example, the work of Bachmair or Hengst, influenced as it is by ethnomethodology, primarily wants to understand the aspect of producing social order here and now, the authors orientated towards reconstruction logic or structural hermeneutics (Aufenanger, Charlton, Müller-Doohm, Neumann, Niemann, Orlik) are more concerned with the pragmatic analysis of a societally shared meaning of action.

Part I presents the object areas dealt with and the methods appropriate to the object. The arrangement of the three articles alone is intended to make it clear that the individual reception process can be seen only in connection with the action practice in everyday life and with the cultural tradition into which it is integrated. In Part II individual projects and studies are presented, arranged according to the research methods used: the beginning is made up of four articles which have worked with the method of participatory observation in different fields of action. After that the structural-analytical reconstructive procedure is presented in two examples of studies. A practice-related recommendation to counsellors who are engaged with children and families in the area of the media forms the conclusion.

The editors hope that, in spite of the specific interests in the findings existing in the works, the principal and promising common basis of the interpretative works presented here will become clear.

Why the restriction to national research when this work is published by the Internationales Zentralinstitut für das Jugend- und Bildungsfernsehen (IZI)? Certainly not because the editors are of the opinion that it is only in the Federal Republic 
of Germany that media research related to everyday life is being pursued. The ideas of Mead and Schütz are by no means adopted here to any greater extent than elsewhere. But it is precisely with the aid of the good international contacts of the IZI and its facilities for documenting the development of media research throughout the world that it has become clear to the editors how important a signal is in the direction of a communication research orientated towards action and language theory at the present point in time. The opinion dominant both nationally and internationally that only quantitative media rersearch is good media research can only be called into question if it is possible to present interpretative works which are thought out theoretically and methodologically.

In spite of the first promising attempts by some colleagues to organise a regular exchange of ideas on questions of interpretative media research within the framework of the International Communication Association, up to now the form of national cooperation has prevailed such as exists, for example, in the Gesellschaft für Kommunikationskultur und Medienpädagogik (Society for Communication Culture and Media Pedagogics). The authors whose works are presented in this volume have been collaborating with other colleagues on the further development of interpretative media research for over ten years. By publishing an English edition of this book we also want to stimulate a fruitful and more intensive cooperation beyond the borders of the countries where German is spoken and beyond existing contacts.

We owe a special debt of gratitude to the Internationales Zentralinstitut für das Jugend- und Bildungsfernsehen, which has long been supporting our work and which made it possible for this book to materialise. Here we should like to mention in particular Paul Löhr, who from the initial planning of the volume up to its publication personally devoted himself to the work, Rosemarie Hagemeister, who very conscientiously carried out the final editing, and Manfred Meyer, who gave us valuable references to current research literature. The logistical, publishing and financial contributions of the IZI to the promotion of media research appropriate to the object were of great help to us. 



\section{Theoretical and methodological frame of reference}

Michael Charlton, Klaus Neumann

\section{Reception research as structure analysis ${ }^{1}$}

Discussion of a research method using the example of the Freiburg Longitudinal Study on Media Reception by Children

\section{Questions of a language and action theoretical media science}

Although media science is not a very young discipline, there is still no consensus in research on its basic assumptions and research methods. Media scientists, depending on their scientific discipline of origin, represent very different ideas on the processes on which mass communication is based and on the methodology appropriate to the subject. In the Federal Republic of Germany the social scientific questions and methods such as have been developed in journalism, psychology and sociology predominate (compare the inquiry of the Senate Commission of the Deutsche Forschungsgemeinschaft: DFG, 1986). But literary and theatre scholars, too, as well as philologists are increasingly occupying themselves with non-literary kinds of texts and with their reception (compare, for example, Bohn, Müller and Ruppert, 1988). These research traditions result, in their turn, in fundamentally different interests in knowledge and ways of access.

Mass communication scientists, psychologists and sociologists tend to ask about the "effect" of mass communication: Here it should be taken into account that every recipient possesses different prerequisites for understanding the media's messages, and it is usual to cover the fringe conditions of media reception. Basically, however, it is the means of communication themselves in this approach which are seen as the actual causes of the reception result. The research follows the pattern of causal analyses, such as we are familiar with from the research framework of natural sciences: "What is the effect of the medicine $X$ on a group of persons P suffering from the symptom A?" The properties of the medicine, 
the regularity with which it is taken, the duration of the treatment, other therapeutic measures carried out at the same time, and finally the symptoms and course of the illness in the group of patients have to be controlled. Then - so it is hoped - the effect of the medicine can be determined, and recommendations for its area of application can be worked out. What applies to medical research also claims validity for the investigation into the "effects" of the media: here we are concerned with information which has an "effect" on people in a corresponding way.

There is no question that such a view of mass communication has its societal significance. Advertisers in daily newspapers want to know what effect their advertisement has, politicians would like to run an efficient election campaign, the population should be enlightened as quickly as possible about the dangers of AIDS infections, and school textbooks aim to give schoolchildren access to a new area of knowledge. Here mass communication is examined from the point of view of the political decision-maker, the communicator or his adviser. The fact that different sections of the public have different reading habits, different education and different social interests has to be taken into account. But the individual recipient, in his endeavours to do justice to the demands of everyday life, cannot be at the centre of this research. Laws have to formulate the general and not the particular; administrative decisions are only possible if the citizen's behaviour is predictable to some degree.

This form of media research does not interest the individual readers, listeners and viewers in the same way. They can, it is true, read in the newspaper or in specialised publications which non-fiction book sold the most copies in the previous month, or they learn something about the net audience rating of the children's programme "Sesame Street". But as they themselves do not as a rule want to offer something on the media market, there is only a limited interest in sales figures and audience ratings. For the recipients themselves the media are a problem in another way - when they ask, for example, what importance individual media have for their lives: To what extent is my opinion manipulated by the media? How much of my leisure time is taken up by watching television, listening to the radio etc., and is that what I want? From which media can I get help in everyday problems? How can I educate my children so that they can deal responsibly with the media offerings, which are still on the increase?

These consumers' questions indicate subjects which have mostly received less attention in the established media research than those mentioned at the beginning to the questions orientated to the interests of communicators or producers. But even when producers and recipients are equally interested in a problem (e.g. the phenomenon of 'heavy TV viewing'), both, however, do differ in the direction of their questions. While at present the extent and distribution of watching a lot of television are discussed in individual sectors of the population predominantly 
from the producers' perspective (cf. Buss, 1983) or its political effects ('mainstreaming', increase in anxiety, cf. Gerbner et al., 1976), studies are still rare which inquire into the personal motivation for spending a lot of time watching television and the function of frequent television viewing for the everyday situation in life (e.g. Charlton, Rapp and Siegrist, 1986).

The model of the media 'effects' outlined at the beginning is not in keeping with the experiences which consumers have in their dealings with mass media. Of course, they know that, for example, commercials on television or a political magazine aim at giving rise to certain opinions and convictions in the viewer. But they do not feel that they are completely at the mercy of these attempts to influence them. For them mass media are an established component of their everyday life. They use media in the same way as they use other necessities of everday life, namely to help them cope with life.

Nowadays, more than ever, mass communication processes are an integral part of everyday actions which are used while coping with life. In order to be able to estimate the specific nature of this form of shaping and coping with everyday life it is useful to relate the structures and functions of mass communication to those of interpersonal communication. What similarities and what differences are there between medial, i.e. technologically mediated, forms of communication and direct dialogue situations? The idea of closely and systematically connecting the form of the mass-medial dialogue with that of the social dialogue is not an altogether new perspective: the conception of the media reception as a "para-social dialogue" (Horten and Wohl, 1956) of the producer with the recipient and vice versa has repeatedly been the subject of theoretical and empirical works. We have presented a detailed account of the current point reached in the discussion elsewhere (Neumann and Charlton, 1988).

The form of the social dialogue is tied to specific prerequisites. Whoever wants to talk to other people in an everyday situation must first have learnt how to distinguish between his own views and those of his interlocutor. Hörmann (1977) characterises speaking as an attempt to direct one's interlocutor's consciousness to certain matters and contexts, and to win him over to one's own perspective. In order to take part profitably in a conversation it is necessary to master both these things: becoming involved in the other person's arguments as well as putting up resistance and insisting on one's own position.

Seen ontogenetically, the child first learns to oppose his mother's attempts to influence him with a 'No'; only later does he learn to say 'Yes' (Spitz, 1970). Hand in hand with learning to speak, the child makes progress in differentiating between his own self and non-self (Mahler, Pine and Bergman, 1978). The child is therefore long familiar with the struggle for autonomy and self-assertion when he begins to come to grips with media stories. But where does the infant's capabil- 
ity for self-assertion reach its limits? What help and guidance does the pre-school child require in the "media network" (Bachmair, 1984)? The experts' answers to these questions depend on their particular ideological viewpoint rather than on the latest developments in scientific research. There are, it is true, some empirical studies on the ontogenesis of the socio-cognitive preconditions for an appropriate media relationship (summary of the latest research developments in Bonfadelli, 1981; Böhme-Dürr, 1988; Charlton, Neumann and Niemann, in this volume; Collins, 1987). But there are practically no studies on the nature and effectiveness of the action strategies which children use to protect themselves from media influences or to check the reception process.

If mass communication is understood as social action, it seems obvious to transfer in depth the questions developed in the discourse research to media research as well. Do the strategies for steering the dialogue such as listeners can apply in a face-to-face dialogue (cf. Henne and Rehbock, 1982) find their parallels in the process of media reception? In addition to the viewers' reaction by writing letters as a "follow-up communication" (Huth and Krzeminski, 1981), here one has in mind particularly social and inner psychological regulatory actions which the viewer can use against the persuasive pressure of what the media offer. Just as in media research, in the more recent, socio-psychological persuasion research as well there are the beginnings of a reformulation in action theory of this phenomenon which up to now has been mainly examined from the point of view of its effect (cf. Smith, 1982).

When children of a pre-school age use the media, they have long since developed a variety of routines for achieving their interests in their dealings with familiar members of the family and friends. Knowledge about whether and how these children's techniques also prove successful in dealing with the media are extremely important for the media education of children.

\section{Methodological consequences}

From the point of view of someone acting in everyday life the reception process and its social incorporation can be described as a succession of comments and decisions in the light of the framework of material, social and personal conditions. The subject does not necessarily always have to be conscious of the objectives and solution strategies pursued in actions. The analysis of the action conditions and of the available and the chosen alternative actions can make visible the motives for use which could not have been named by the person acting himself, and it can bring out use routines which under circumstances elude everyday self-perception. 
What has been said here applies especially to children. It is certainly sensible to assume that children can act competently in familiar situations, and that they can do so long before they are in a position to describe their action patterns selfreflectively.

Which methods are available for an analysis of the recipients' actions? Traditionally two very different methodological accesses are discussed in the social sciences: the quantitative, causal-nomological research approach and the qualitativeunderstanding ("verstehende") approach. Below it will be pointed out why both methods - not only the quantitative one but also the qualitative method of media research - appear to be unsuitable for an analysis of mass communication according to language and action theory. On the other hand, for the analysis of mass communication a method developed only in the last few years presents itself in an almost ideal way: the reconstructive method, such as, for example, Oevermann (1986) worked out for formulating sociological questions as objective or structural hermeneutics. We have suggested calling research into media sciences which follows this approach 'structure-analytical' reception research (Charlton and Neumann, 1986).

If one makes the methodological claim to be able to explicate media effects causally with the help of laws, one must at the same time also take a certain subject conception as a basis. The media must be regarded as things, or more precisely as stimulus configurations, and the recipients' actions must be capable of description as the changes of the state of bodies, i.e. as material events. Communication must be definable in this physicalistic concept as an exchange of information. Under certain circumstances a media stimulus triggers a response in the viewer which can be described in precise terms.

In doing so, some important aspects are bound to be lost compared with a concept of communication understood in terms of everyday language. Media, is the conviction in everyday life, do not represent signals to which a recipient has to react. According to how we see ourselves, with regard to symbolic statements we have the possibility or freedom of action to follow them or not, and to share the views offered or not. Neither the speaker nor the listener behave towards a symbol in the same way as a technical system indicates or 'follows' a control quantity. A message can be true or false. Measured against societal norms, it can be correct or incorrect. The speaker can truthfully mean what he says or he can tell a lie. Signals, on the other hand, cannot behave inappropriately and cannot lie.

In the modern information processing theory to explain media effects, although a number of cognitive parameters are taken into consideration as an additional condition for predicting the stimulus effect by the individual taking in the information, the fundamental discrepancy between the technical transmission of information and human communication cannot be eliminated in this way. The price 
that has to be paid for the scientific exactitude of the method is a considerably changed subject definition of mass 'communication' compared with usage in everyday language.

Comparable difficulties arise when the attempt is made to integrate the activity of the subject into a causal-nomological effect model, such as, for example, has been attempted with the aid of the 'dynamic-transactional approach' (Früh and Schönbach, 1982). The free comment of the subject cannot be anchored in a traditional causal model, unless central elements in the definition of causality are changed (cf. Harré and Madden, 1975).

How can these contradictions be avoided? Representatives of a qualitativeunderstanding approach hold the view that both the meaning of the symbolic contents used in the process of mass communication and the evaluation of the consequences of reception can only be deciphered by means of an intuitive assessment process. To this end the recipients are either asked to say what the effect on them is of a particular film, picture or text, or the scientist records the media effect himself, in a self-experiment, so to speak, or a number of people have to estimate the quality of the media message on the basis of their "common sense". The influence of the media experience on the viewers' mood or actions can also be characterised by an observer's intuitive judgement.

How is this approach to be assessed? One advantage of the understanding compared with the physicalistic approach can be seen in the fact that in this way no reductionistic assumptions have to be made about the communication process. One disadvantage is obvious: the appropriateness of intuitive judgements can be disputed, even when several people arrive at the same judgement by guessing. The introspective ascertainment of media effects by observing one's own experience also reaches its limits where emotional attitudes on the symbolic message occur which cannot be represented by language.

In view of this method problem, many researchers choose a compromise solution between a purely understanding and a quantitative-causalnomological procedure. They use the intuitive judgements obtained in the course of their observations or other people's observations, such as measured values, which can subsequently be subjected to a statistical analysis with the help of the general linear model . Differences between those making a judgement then enter the calculation as error variances. The aim of the analysis is the same as that in quantitative-nomological research. The determination of the communication process by the factors examined is meant to be proved, and the variance explained by external and internal conditions is meant to be maximised.

Although this analysis model is the basis for most of the studies into the media effects (e.g. all studies using questionnaires on subjectively experienced media in- 
fluences), it is unconvincing from the point of view of communication theory. The disadvantages of both procedures - on the one hand, the reduction of the communication process to the elements that can be represented in an information transfer theory, and, on the other, the problems connected with the introspection or intuitive explanation of the meaning of symbols and actions - enter into this combined method.

Wherever it is a question of the appropriate interpretation of the consequences of human communication and interaction, for example in court trials, it would be impossible to imagine leaving out the examination of certain claims to validity of a witness's testimony or an expert's opinion in favour of empirical exactitude (truth, normativity, truthfulness; Habermas, 1976) or to restrict oneself to the statements of those concerned as a means of establishing the facts. Coming to a judgement in the dispensation of justice is based on a rational reconstruction of the crime committed. Constellations of the events and testimony from those involved are only aids in making this reconstruction, they cannot replace it.

To rationally reconstruct an action is something different from explaining behaviour causally (e.g. as a consequence of an individual's learning history and of an annoying situation at the present moment). Rational reconstructions reveal the logic of the course of an action; causal explanations must be accounted for empirically, not logically (cf. Brandtstädter, 1982, 1984). To understand the reconstructive procedure it is helpful to distinguish between the (logical) reasons and the (causal) causes of an action. An explanation for reasons presupposes that the acting subject is regarded as being free to form an attitude about the situative conditions. It is true that his material, social and personal prerequisites impose narrow limits on the person acting, but there does remain a remnant of scope for decisions. Only someone who recognises this picture of man can, as is usual in the administration of justice, attribute the action to a person and examine his capability of guilt (i.e. his possibility of refraining from a criminal act).

It would be a misunderstanding to assume that the validity of natural laws is disputed by the rational explanation. In philosophy very controversial negotiations have been conducted on whether causes are also reasons and vice versa (cf. Davidson, 1963; Hamlyn, 1953; Kenny, 1975; Peters, 1958; Toulmin, 1970). The usual argument against distinguishing between reasons and causes is that every action must, after all, also have a cause. In the case of human actions this cause is identical with the reason for the action (or the motive or intention). Lenk (1978a, b) raises the objection to this that motives for actions are not material states or events, but interpretative constructions of a semantic character (cf. also Thalberg, 1977). To explain an action by its reasons means doing nothing else but reconstructing the actions with regard to their social meaning. The same body movement (doubtless resulting somehow causally) can have quite different social 
meanings (a push can mean aggression but also an aid when danger threatens; doing nothing can mean failing to provide help etc.). ${ }^{2}$

A further misunderstanding with regard to the reconstructive method of explanation consists in assuming that with its help only the reasons of which the actor is aware can be given. From a societal perspective even such actions can be logically reconstructed which the actor himself does not understand (does not perceive, does not want to be interpreted in this way). Even so-called 'irrational' actions can be rationally explained when it is possible to show under which action conditions that are assumed by the subject against the facts and, under circumstances, unconsciously the action makes sense. Psychoanalysis, as is known, avails itself of this method of explanation.

In the case of non-linguistic actions the reconstruction of the meaning frequently poses a problem. How is one to know whether someone has really not seen the helpless victim of a traffic accident, or whether his own affairs were simply more important than giving help? The matter is simpler in the case of spoken actions. The modern speech act theory, so Habermas argues (1988), has shown that speech acts show a self-relating structure. Texts give us to understand by themselves how they are meant. The validity claims raised by an assertion can be tested on the basis of the context in which the utterance appears. The rational reconstruction opens up a method of analysing social actions which does not force the researcher to describe the action as a physical event or to purchase the consideration of intentionality and sociality of man at the price of a subjectivity of interpretation.

Oevermann, too, (1983; 1986; Oevermann, Allert, Konau et al., 1979), whose structural hermeneutics constitutes at present the most highly developed variant of a reconstructive procedure, stresses the possibility of an objective analysis of meaning structures from interaction texts. Human communication and interaction are understood as being guided by rules. In socialisation every person has internalised a canon of interaction rules. He cannot, it is true, explicate this knowledge of rules with general validity, but he is in a position to say in each individual case whether a way of acting is possible or not in a given context. This everyday knowledge serves the researcher as a criterion when he wants to explain a concrete case with the help of a certain interaction rule. The assumptions of rules undisputed according to the tacit knowledge serve like clear cases to build up an interaction grammar - more precisely: a structure-genetic competence theory of acting.

The logic of a sequence of actions manifests itself only over a succession of interacts. A single utterance can make sense in a large number of quite different contexts (it being the expression of another specific rule of the interaction sequence depending on the context). In an interaction sequence which is pursued over several utterances or a change of speakers, however, (about 7 to 12 interacts are usually 
needed for an analysis), the relevant, only valid action structure of the case develops. A structural case reconstruction on the basis of a 'detailed analysis' (Oevermann, Allert, Konau et al., 1979) is presented in the article by Charlton, Neumann and Niemann in this book.

A research project lasting over several years that was carried out at the University of Freiburg under the guidance of the authors is presented below as a good example from the programme of structure-analytical reception research.

\section{Formulating questions and conducting the Freiburg Longitudinal Study}

In our research project we investigated two questions: firstly, we wanted to identify partial processes of the reception sequence from the point of view of media theory. If mass communication is to be literally understood as 'communication' the following questions are of interest: Which elements of a symbol-mediated exchange process do the face-to-face interaction and the media reception have in common? Which specific conditions take effect during participation in the reception process? To what extent do everyday communication and mass communication complement and compete with one another? And what different use patterns are result from the type of medium?

Secondly, we were especially interested in the significance of media reception in socialisation theory. Do media experiences in the lives of pre-school children represent more of a help or more of a burden? Can contact with the media promote the development of children? What is the importance of the media for the relationship between parents and child and child and siblings? Here, however, questions should not be asked unilaterally about an influence of the medium on the child recipient (the media as hidden persuaders), but it was a matter of at least equal importance to ask in how far children can use the media as instruments to pursue their aims.

Both these question complexes were to be treated from a common theoretical point of reference. A basis for this were Habermas's works on a theory of communicative actions (especially 1981a, b, 1984a, 1988) and Habermas's considerations of socialisation theory (esp. 1976, 1983, 1984b; Döbert, Habermas and Nunner-Winkler, 1977) and Oevermann (1979; Oevermann et al., 1979: cf. also Aufenanger, 1989). According to Habermas, three world references must be negotiated in every communication process: the meaning of what is said with regard to the objective world of things, with regard to the world of social norms and interaction relations and with regard to the subjectivity of the speaker. Each com- 
municative action says something about facts in the world, about the relationship between speaker and listener and about the person of the speaker (cf. also Bühler, 1969). It might easily be supposed that in the reception process, too, the aspects of coming to terms with things, society and one's self play a central role. Our examination of the dialogue-theoretical approaches in mass communication research (see Neumann und Charlton, 1988) has very clearly corroborated this hypothesis.

In the above-mentioned works by Habermas and Oevermann on the socialisation theory it is shown that the development of the child can be described with three broadly understood competence theories which correspond to these world relations: the theory of cognitive development in the tradition of Piaget, the theory of social development in the tradition of Mead and Kohlberg, and the theory of the ego development as a further development of the action and subject theory in Freud's psychoanalysis. The level of development attained in the three areas forms the basis for the child's communicative competence. The authors regard as important the statement that this conception is not a loose, eclectic collection of theories but that the theory of communicative action accounts for and presupposes a coordination of the partial competences mentioned.

The Freiburg Longitudinal Study therefore deals with the question of how children use the media a) depending on their cognitive abilities and in the course of the development of their competence with regard to things, b) in the context of their social abilities and as a means for developing satisfactory social relations and c) in connection with their emotions and ego-achievements conditioned by their development, the ego-structure at the same time being seen as a condition and developmental aim of media reception. These questions can only be examined against the background of a well-grounded context knowledge of a child's level of development, its personality and social situation. Apart from the media use routines and the family's attitude to education, the interaction structure in the family was therefore analysed with the help of participatory observation (cf. Schütze, 1977), e.g. the family themes (Hess and Handel, 1975), the role distribution and the modes of attachement. The demands made of the child were described as 'developmental tasks' (cf. Havighurst, 1953; Oerter, 1986), the child's specific forms for coping with life were reconstructed. Each individual act of media use was, moreover, evaluated in its current context (e.g. events of the day, relation to the observers and family members present). The child's salient themes and psychodynamics were recorded by means of clinical-psychological methods (e.g. Sceno-Test, v. Staabs, 1978).

The study was carried out on six children aged between 2 and 6 years. In the course of almost two years the children were visited by two observers at a time for several hours at intervals of about three weeks. The observations during 
participation in everyday family life, at play with the child concerned and while using the media together (picture books, sound tapes, television programmes) were recorded and evaluated in a very complicated interpretation procedure going through several stages (see table).

Table:* Inquiry and evaluation steps in the Freiburg Longitudinal Study

\begin{tabular}{lll}
\hline $\begin{array}{l}\text { Inquiry/eval- Number/frequency } \\
\text { uation steps }\end{array}$ & Description/aim & $\begin{array}{l}\text { Analysis material/ } \\
\text { evaluation sheets }\end{array}$
\end{tabular}

(1)

(2)

(3)

(4)

(5)

(6)
6 children visited in 3-week rhythm for one afternoon by 2 observers for a period of 18-24 months; sum of contacts: 107

$3-6$ evenings talking to parents, including participatory observation of family life

Weekly

About 20

Twice (at beginning and end of field phase) half a day per case 6
Talks with parents according to guidelines

Field observation; play contact with child accoring to guidelines

Tape recordings; photos of play situations (Scenotest), copies of media used, children's drawings produced etc. Report on session by observers.

Tape recordings, report of talks, documentation of media available in the family, media diary for child, media questionaires

Transcripts and material from (1) and (2), supervision reports liminary interpretation of field contact, working out proposals for play stimulation

Play stimulation: planned arrangement in play contact to check a version/interpretation

External case supervision by family therapist for comparative analysis Case documentations: description of family themes and dynamics, development logic and dynamics of child, rough analysis reception situations with regard to child's development

As in (1), (2)

As in (1), (2), (3)

As in (1), (2), (3), thematically uniform grid for the individual cases

* According to Charlton and Neumann, 1986 


\begin{tabular}{|c|c|c|c|}
\hline $\begin{array}{l}\text { Inquiry/eval- } \\
\text { uation steps }\end{array}$ & Number/frequency & Description/aim & $\begin{array}{l}\text { Analysis material/ } \\
\text { evaluation sheets }\end{array}$ \\
\hline (7) & About 200 & $\begin{array}{l}\text { Structure generalisation } \\
\text { for reception situation: } \\
\text { interaction analysis of } \\
\text { circumstances accompa- } \\
\text { nying reception (transi- } \\
\text { tions play/media } \\
\text { use/play, family } \\
\text { dynamics, child-observer } \\
\text { dynamics, media traces } \\
\text { in later contacts) }\end{array}$ & $\begin{array}{l}\text { Text-Kontext-Korpus } \\
\text { (see Braun et al., 1989) }\end{array}$ \\
\hline (8) & About 200 & $\begin{array}{l}\text { Structure generalisation } \\
\text { for reception process: } \\
\text { forms of occupation } \\
\text { with and distancing from } \\
\text { the medium, meaning } \\
\text { for the child's coming to } \\
\text { grips with itself, things } \\
\text { and society }\end{array}$ & $\begin{array}{l}\text { Text-Kontext-Korpus } \\
\text { (see Braun et al., 1989) }\end{array}$ \\
\hline (9) & 6 & $\begin{array}{l}\text { Reconstruction of the } \\
\text { media biography of the } \\
\text { case, new formulation of } \\
(6) \text { on the basis of find- } \\
\text { ings from ( } 7 \text { ) and ( } 8)\end{array}$ & $(6),(7),(8)$ \\
\hline
\end{tabular}

* According to Charlton and Neumann, 1986

The reconstructive method differs from the traditional logic of research (Popper, 1969) in the way in which the relation between theory and observation is understood. Whereas in the hypothetical-deductive model empirical facts are used to falsify hypotheses, the logical conclusion in the reconstruction of competence theories can be understood rather as abduction. ${ }^{3}$ The group of interpreters decides by reason of their implicit knowledge of the rules which action rule is followed by an observed interaction sequence. Only in a second step is it then possible to check whether the presupposed competence theory covers the case analysed, or whether - abductively - a corollary rule has to be introduced by way of explanation. Scientific hypotheses therefore have no central status in the knowledge process, since the 'matter itself' is to be made to speak (cf. Oevermann, 1983). The specific formulation of the questions does not find its expression in observation instruments or a concrete system of categories. It simply serves to lay down which observation is to be rated as context and which as an expression of the defined case structure. 
In the case under discussion both the socio-dynamics in the family and the needs thematised by the child only formed the foil against the background of which it was possible to bring out the actual 'case', viz. the reception process in its partial phases and the sequences of the reception for the child's coping with life and identity formation. The observation objects were therefore the 200 reception processes including their presuppositions and consequences. The aim of the analysis were generalised (partly universal and partly typical) process elements and partial structures of this occurrence (for a detailed account see Charlton, 1987; Charlton and Neumann, 1988).

\section{Results of the Freiburg Study: options for action in the reception process}

In this article not all the results of the Longitudinal Study can be presented. We shall restrict ourselves to describing some important aspects of the reception process. The theoretical arrangement of these and further results, the elucidation and documentation of the case reconstructions using selected examples and the important question of the significance of the use of the media in socialisation theories in infancy are to be dealt with in detail elsewhere. (The complete observation material is available in Braun, Charlton, Neumann et al., 1989. A comprehensive account of the results will be made available in Charlton, Neumann et al., in preparation/1990.)

The result of the seventh and eighth evaluation step (cf. Table) is a list of decision points which are gone through in the course of a normal reception process. In spite of changing external circumstances, children's requirements, competences etc., there are quite a number of optional situations which open up for the recipient the decision between two and more choices. We intend to deal below with these decision points or "coordinating points" in the course of the action in somewhat greater detail.

Of the altogether about 200 reception situations which were recorded by the group of observers in the course of the study of the six children it was possible to reconstruct 78 to 110 situations in their action structure depending on how the question was formulated.

\section{Initiative for using the media}

How and on whose initiative was the decision taken to use a certain medium on the afternoon for play? In $81 \%$ of the situations (65 out of 80 ) the decision to use the media came from the child. This result is certainly to be interpreted as situation-specific: both the family members and the observers exercised restraint with their suggestions in the non-directive play situation. The media customarily used at a certain time (e.g. afternoon television programme) or in a certain situation (e.g. reading a bedtime story) also played a minor part in the observation si- 
tuations. The distribution of the use initiatives among the persons present was therefore conditioned by the study. For this reason this result is hardly generalisable for other situations. The more far-reaching result that the decision to use the media is a logical constituent of the use situation is also trivial. Is this already an indication of a serious limitation of the scope of the results through the specific framework of the study? We believe not. As we want to show below, it is also possible to identify less trivial decision moments; moreover, the influence of the observation situation refers as a rule to the frequency with which an option is realised, but far less often to the fundamentally possible variants.

\section{Social significance of the media use}

The decision to use the media changes the field of action in two respects. On the one hand, the interaction with persons present is newly ordered, and, on the other, the content focus of the activity frequently changes. With regard to the first aspect of social interaction, the media consumption is frequently regarded by representatives of the 'uses approach' as a surrogate for a lack of social contact (Rosengren and Windahl, 1977). In this point, too, our research procedure does not allow an examination of this hypothesis: the observers were much appreciated play partners for all the children. It is clearly shown, however, that the partner substitute does not constitute the sole social function of media use. While logically reconstructing the meaning of the reception sequences, we came across three dimensions of social interaction forms which were relatively independent of each other and which are influenced by media consumption (cf. Neumann and Charlton, 1989):

\section{Dimension I: "Action coordination"}

In $59 \%$ (65 out of 110) of all the situations evaluated the child concerned brought about a change (or a strengthening) of existing forms of cooperation through using the media. Very often ( 35 times) the child changed or strengthened the common focus of attention through reception. So here the medium served to give a cue for the re-arrangement of the cooperation. Quite frequently media were employed to steer the dialogue. Altogether 23 times the child entered into an ongoing dialogue by referring to a media story or called on someone present to say something about a (media) theme. Occasionally the use of the media also served to build up or maintain usual family role distributions spanning more than one situation (7 times).

Dimension II: "Power and self-assertion"

In $57 \%$ of the cases observed (63 out of 110 ) the child used the media for purposes of self-assertion or subordination. In one case the occurrence was checked out 
by an adult; in the other cases the mutual control was balanced. It was possible to distinguish five forms of children's control and subordination strategies: a) proving competence or superiority (19 times), b) controlling the mood (mood control, cf. Brown, 1979; 14 times), c) exerting social pressure (19 times), d) withdrawing from the influence of the others in connection with using the media (9 times), e) submitting to the observers' interest in media (twice). ${ }^{4}$

Dimension III: "Affectively shaping relations"

With surprising regularity (in $93 \%$ of the cases, 102 out of 110 situations observed) there were elements of an emotional regulation of relations during reception. The children used the media reception to a) establish physical closeness (21 times), b) to avoid closeness (twice), c) to inform themselves with regard to the subject (29 times), d) to divert from themselves or from their own subject ( 3 times), e) to establish emotional mutuality (23 times), and f) to let themselves be provided (spoilt) with media stories (24 times). ${ }^{5}$

The three dimensions of the interaction forms and of their reorganisation in media use can be well substantiated theoretically (cf. Neumann and Charlton, 1989) and have been empirically established in, for example, the numerous works of Bales' Working Group (Bales, 1950, 1970; Bales and Cohen, 1979) for many other areas of life as well in which small groups cooperate with one another. Through conversations during media use, but especially through turning to or away from the media, the recipients can redefine their relationships among themselves. Media consumption can be understood from this perspective as a means of social control.

This statement must not be misunderstood: we are by no means of the opinion that media consumers, especially when children are involved, consciously employ media as control instruments, for example for regulating the role distribution in the family. Nevertheless, there are a large number of use strategies which are mostly realised unconsciously (for example, when somebody 'hides' behind his newspaper) which in reality entail a re-arrangement of interaction. As we have shown in our detailed descriptions of cases (Braun, Charlton, Neumann et al., 1989), children use this intentionally.

The importance of media use for dealing with one's own development themes

People see the world perspectively. They understand situations from the point of view of their personal requirements and desires; they are biased with regard to themes. This concept of the personal 'theme' to describe this perspectivity of perceiving and acting in everyday life has quite a long tradition in psychology (cf. Charlton, Neumann et al., in preparation/1990). It is precisely in infancy that it is necessary to come to grips with the ever new demands of life: with personal or 
normative 'developmental tasks' (see above). Such tasks are represented, for example, by severance and individuation, the acquisition of a generation and sex role or settling down in the institution of kindergarten. In their games, too, children show that they are fascinated and "caught up" by these themes (playing father-mother-child, adventure games).

We observed in our study whether the initiative for using the media, the choice of the subject, the person's specific way of understanding the media story, but also breaking off reception, can be connected up with these development subjects (cf. also Charlton and Neumann, being printed/1990). For this purpose the thematic connections between the child's play and the media stories selected were examined.

The evaluation resulted in the following picture: Do the child's personal themes emerge in the course of play before using the media? This is the case in $84 \%$ of the cases ( 67 out of 80 reception situations). Is the theme that has prevailed so far continued by the selection of the media theme? This question can be answered in the affirmative in $75 \%$ of the cases (60 out of 80 reception situations). Does the media story correspond to the child's development theme from the point of view of the interpreters? The answer is an unequivocal 'yes' for $51 \%$ of the cases (41 out of 80 reception situations, and 'yes, partially' in $26 \%$ of the cases (i.e. in another 21 out of 80 situations). Does the media story correspond to the child's own development theme from its point of view? In $80 \%$ of the cases (64 out of 80 reception situations) this is "very clearly" the case, and in $13 \%$ of the cases (i.e. in another 10 out of 80 situations) "partially" so.

Analysis in greater depth of the thematic views of the subject by the children shows that in altogether 31 situations the media stories were allocated to the child's own themes by the recipients more closely than this had been assessed from the observers' point of view. Forms of assimilating perception are a phenomenon known in cognitive psychology (Neisser, 1979), but it is difficult to detect them in studies that are close to everyday life. With the help of the reconstructive procedure it was possible to infer the thematic prejudice from the use of the media material, in the utterances accompanying reception or from the child's games.

Like the reception beginning, the reception end can also be interpreted as a prominent "decision knot" for the thematic shaping of the situation. In 38 out of 80 situations analysed $(48 \%)$ the media theme is also continued after reception. In 29 cases $(36 \%)$ a new theme is introduced or the one that previously predominated is interrupted, and only in 13 cases $(16 \%)$ does the steering of the theme have no connection with the end of reception.

The (subjectively perceived) media theme is not just limited in certain points to the transitional situation but also remains decisive for subsequent play for a period of intermediate length. In 62 out of 80 cases $(78 \%)$ the media theme is taken 
up in play with varying degress of clarity. Only in the remaining 18 cases was it not possible to detect any thematic continuity.

If one follows throughout the whole reception cycle which changes the child's theme undergoes, the most frequent sequence form is characterised by the fact that the child's development theme predominates to the same extent before, during and after reception (altogether 14 thematically homogeneous sequences, which is $18 \%$ of the 80 situations). The second most frequent reception pattern is a preoccupation with the child's own theme, which is briefly interrupted only at one point, viz. directly at the end of reception (altogether 12 sequences or $15 \%$ ). We interpreted this phenomenon as indicating that the children took a quick 'breather' in this case before they could or wanted to return to occupying themselves with their own situation. The third most frequent sequence is the pursuit of a continuous, self-related theme, in which case the media theme was subjectively reinterpreted according to the child's own requirements, since from an objective point of view it did not or did not clearly represent the child's theme ( 5 cases, i.e. $6 \%$ ). All other sequence patterns occur in fewer than 3 cases (for further sequence patterns see Charlton and Neumann, being printed/1990).

\section{Strategies of reception steering}

In the analysis of the discourse the speakers' strategies to steer the discussion constitute an important area of study (Schwitalla, 1976; Henne and Rehbock, 1982). The listener, too, can in his turn exert an influence on the speaker, for example by means of listener's signals expressing agreement or contradiction, or by starting up a change of speaker. Recipients as the participants in mass communication, who at first sight appear to be 'passive', find it considerably more difficult to influence the communication process. Apart from the rare form of participation by writing readers' letters, the principal form of steering probably consists in the selective approach to the offerings of the media. Mediated by the sales figures and audience ratings, to which the media 'makers' pay great attention, recipients can in this way exert a very effective influence, albeit indirect and with some delay, on the media offerings.

The attempt to influence the producer is, however, not the only reason why recipients want to gain some control over the communication happenings. Much more important are the 'private' reasons. The recipient has to deal with a large number of tasks in his everyday life. Electronic media in particular can be easily consumed at the same time, while the listener or viewer gives most of his attention to another activity (cf. Fritz, 1984 for the discussion of this phenomenon in communication sociology; Reid and Frazer for the aspect 'Children's Play and Television', 1980). Added to this is another reason why the media are not always given the recipients' undivided attention. As we have already seen in the analysis of the thematic preju- 
dice, for the recipients the subject presented and its relation to their own opportunities and tasks for acting are of central significance. Apart from the quality of the contents, the intensity of the stimuli for coming to grips with themselves as well has to be given in the right doses. After having analysed the function of children's control strategies above, below we intend to deal in more detail with the forms of reception steering by children.

The formal analysis is based on 78 reception situations. The study goes into the forms of the transition to reception (entry) and to the subsequent activity (exit) as well as the involvement and distancing during reception. A look at the beginning of the reception phase shows that agreement as to a certain reception medium is by no means always reached without difficulties. In 24 out of the 78 situations $(31 \%)$ the entry into reception takes place gradually. The child and the observer have to negotiate with one another as to whether a medium should be used or not and which specific theme is of interest.

When both sides have managed to agree on a certain medium the child has several possible ways at its disposal of becoming involved with the subject presented. Rapp (1973) described two forms of inner participation in events on the stage for the spectator in the theatre: the illusive and the in-lusive reception modes. The spectator can either allow himself to be captivated by the play, and can be completely taken up with the action of the play (illusion). Or he can deal with the play reflectively by remaining conscious of the distance between himself and his person to what is presented on stage (inlusion).

We have tried to transfer both these aspects to the area of media reception. During the reconstruction of the reception sequence it emerged that an inlusive attitude in the child usually went hand in hand with a focusing on individual action or meaning strands in the media events. If the child wants to relate its own experience to the media story, then it perceives what it sees or hears from a particular point of view. For us as observers the focusing performances were recognised by the child's comments to events in the film (in 41 out of 78 cases, that is $53 \%$ ). In other cases the focusing showed itself in that the child put on a role play parallel to reception into which structural elements of the media story were incorporated (16 cases, $20 \%$ ). Thus, for example, a four-year-old girl played a departure scene with the Sceno dolls parallel to the radio fairy-tale of 'Hansel and Gretel': the doll child goes to school, no longer needs its parents, is already grown up etc. Altogether the children exhibited an inlusive focusing reception style 57 times $(73 \%)$, they followed the story non-selectively and generally attentively 17 times $(22 \%)$, and once $(1 \%)$ we obsereved a passive-regressive reception behaviour. In 3 other cases $(4 \%)$ it was not possible to clearly reconstruct the way the child dealt with the media. 
In addition to the verbal comments on the media events and the inlusive play, we were also able to register a number of other reactions by the children which made it easier for us to reconstruct the reception mode: mimicking and expressive signals, cuddling up to the observers or toy animals, sucking, fiddling around with themselves, jumping about, romping.

What is no doubt the most important instrument for steering reception by the viewers is interrupting or breaking off reception. The 78 reconstructed situations included the following forms of distancing: no distancing (30 cases, $38 \%$ ); completely breaking off reception before the story was ended (12 cases, $15 \%$ ); an interlude with subsequent return to reception ( 9 cases, $12 \%$ ); parallel action unrelated to the media (15 cases, $19 \%$ ); manipulation of the medium (of the book, cassette recorder, TV set: 10 cases, $13 \%$ ); withdrawing attention (through conversation, falling asleep: 2 cases, $3 \%$ ). We can state that reception without distancing was not the rule in the cases observed. Far more frequently the children measured out or regulated the extent of (emotional) influencing through the medium (in altogether $62 \%$ of the situation).

The child's scope for action in the use situation also expresses itself in the initiative for ending reception: 35 times $(45 \%)$ the child ended the use of the medium on its own, and 18 times ( $23 \%$ ) the initiative came from the observer. In 25 cases $(32 \%)$ ending occurred as a result of the technical course or the contents sequence of the media presentation (cassette or television film came to an end, book was finished etc.). In 27 out of 78 cases ( $35 \%$ ) another reception was begun after the first was over (new book etc.), in 42 cases $(54 \%)$ the child and observer turned to playing, in 9 cases $(11 \%)$ the time for the play session was over.

\section{Discussion of the results of the study}

In our study we have pointed out social and personal possibilities for using media reception and we have presented some techniques which children employ in pursuing these aims.

Even pre-school children use the mass media as social regulators. They avail themselves of the media to influence their current social situation, to think over again earlier social experiences and to prepare themselves for future interactions. Culture essentially serves man's social requirements. It is made by people for people and anyone wishing to partake of it must do so in a dialogical attitude.

Of course, we do not deny that information about non-social matters as well can be gathered from the mass media and that this knowledge can also be used quite individualistically. Nevertheless we suspect that the attraction of dealing with symbolic culture consists precisely in the fact that it is here that socially preinterpreted experience is imparted and not just technical knowledge about actions, 
such as can already be acquired by a child that cannot yet speak in the nonsymbolic interaction with the world of things. Because this interpreted world includes not only information about matters of fact but also the author's comments on these things and events and his offer to the reader of a relationship, the recipient is prepared for participation in social reality. In the symbolic representation he encounters a world that is perspectively thought up in advance, which includes the world of things, man's social relations and the place in this society allocated to him.

Compared with actions in face-to-face situations, the para-social dialogue with media differs chiefly through the restrictedness of the recipient's influence on the communicator (author, producer, speaker etc.). But this restrictedness also entails advantages. The release of the reader from communicative obligations is of particular importance. The reader does not have to present himself, he can keep his opinion to himself and yet does not risk that his vis-à-vis will stop explaining himself. The author's possibilities of influencing the reader are limited. He only has his word or image symbols at his disposal to guide the recipient's consciousness - if we disregard for the moment the possible sanctions which can occur in the social context of reception, for example when the teacher rewards his pupils for having worked with a book according to his ideas. One of the ways that the written form as the 'language of distance' (Koch and Österreicher, 1985) differs from the oral 'language of closeness' is the extent of the reader's social obligation and the author's power of sanction.

Now this double release of the reader from an obligation makes it possible for him, however, to give up distancing himself in quite a different way - namely in dealing with himself, with his own position in the societal action structure. If language helps man to take up his eccentric positionality (Plessner, 1976) this applies in special measure to the language of the media. In his largely selfdetermined comments on the interpretations offered by the author the reader can sort himself out, can experience himself in the mirror of the media message.

A subject-related, longitudinal analysis of the results - so much is only mentioned briefly here - shows how important the influence of media reception is on the child's identity formation. This is especially valid in view of the increasing demands which modern societies make on the individuation of their members (cf. Neumann, 1989).

Over and beyond the mere presentation of the findings of the study it was also the aim of the present work to point out the possibilities of a structure-analysis approach for media research. In the form submitted here the findings have a certain similarity with categorial descriptions of interaction sequences, such as are known from social psychology, for example. It emerges on closer examination, however, that the elements and decision knots described in the reception sequence 
could have been identified neither with the classical method of questioning recipients nor with the help of a traditional behaviour observation with given evaluation categories or rating scales.

Only by using the reconstructive method can action rules be identified which although they actually structure the interaction sequence - can neither be preformulated hypothetically by the researcher nor consciously reflected by the actor himself. Even the raters usually used in social science to estimate the parameters in complex situations are bound to fail here when it is a question of (just) indicating which way of acting is involved in a given observation section. Only if the raters become familiar with the hermeneutics of structure analysis by endeavouring, on the basis of a broad knowledge of context, to argue the reasons for the logic of the sequential interaction sequences and the possibilities open for action at every point of decision, will it be possible to solve this problem. Only the laborious logical reconstruction of the meaning in which every individual case is first examined with regard to its own particular rules allows a generalisation of the structure in a later step. We are of the opinion that it is worth the effort.

\section{Notes}

1 This study was funded by the Deutsche Forschungsgemeinschaft as part of the main programme "Publizistische Medienwirkungen" (Ref.: Ch 73/2-4) and, in a second phase, as a part project B7 of the Special Research Area 321 ("Mündlichkeit und Schriftlichkeit"). The study was carried out by - in addition to the authors - Barbara Braun, Ruth Franck, Ruthild Rapp and Waltraud Orlik, the latter having also prepared the quantitative evaluation of the material.

2 A detailed presentation of this argumentation can be found in Charlton (1987).

3 Following considerations by Pierce, Oevermann et al. (1979) understand by the abductive conclusion a procedure in which knowledge progress consists in the empirically conducted further development and expansion of a system of rules for describing social reality.

4 The individual strategies observed exceed the total number of children's action forms because some children pursued two strategies at the same time.

5 See note 4

\section{References}

Aufenanger, St.: Entwicklungspädagogik - die soziogenetische Perspektive. Habilitationsschrift. Mainz 1989.

Bachmair, B.: Symbolische Verarbeitung von Fernseherlebnissen in assoziativen Freiräumen. 2 vols. Kassel: Gesamthochschul-Bibliothek 1984.

Bales, R.F.: Interaction process analysis. Reading, Mass: Addison-Wesley 1950.

Bales, R.F.: Personality and interpersonal behavior. New York: Holt, Rinehart and Winston 1970.

Bales, R.F.; Cohen, St.P.: Symlog. A manual for the case study of groups. New York: The Free Press, 1979.

Bohn, R.; Mutler, E.; Ruppert, R. (Ed.): Ansichten einer künftigen Medienwissenschaft. Berlin: Edition Sigma 1988. 
Bonfadelli, H.: Die Sozialisationsperspektive in der Massenkommunikationsforschung. Berlin: Spiess 1981.

Böhme-Dürr, K.: Die kleinen Plastikleute im Fernsehen: Wie Kinder Fernsehrealität wahrnehmen. In: Kreisjugendring Nürnberg-Stadt (Ed.): Medienwirklichkeit - Wirklichkeit. Nürnberg: Selbstverlag 1988, p. 61-80.

Brandstädter, J.: Apriorische Elemente in psychologischen Forschungsprogrammen. In: Zeitschrift für Sozialpsychologie, 13/1982/-, p. 267-277.

Brandstädter, J.: Apriorische Elemente in psychologischen Forschungsprogrammen. Weiterführende Argumente. Zeitschrift für Sozialpsychologie, 15/1984/-, p. 151-158.

Braun, B.; Charlton, M.; Neumann, K.; Orlik, W.; Rapp, R.: Freiburger Längsschnittuntersuchung der Medienrezeption durch Vorschulkinder im familialen Kontext (TextKontext-Korpus). Forschungsberichte des Psychologischen Instituts der Universität Freiburg. No. 53. 7 vols. Freiburg 1989.

Brown, J.R.: Wie Kinder das Fernsehen nutzen. In: Sturm, H.; Brown, J.R. (Ed.): Wie Kinder mit dem Fernsehen umgehen. Stuttgart: Klett-Cotta 1979, p. 177-197.

Bühler, K.: Die Axiomatik der Sprachwissenschaft. Frankfurt: Klostermann 1969.

Buß, M.: Die Vielseher. Zur Theorie und Praxis der Fernseh-Zuschauerforschung in der BRD zu Beginn der 80er Jahre: Dissertation. Universität Hohenheim 1983.

Charlton, M.: Möglichkeiten eines sozialwissenschaftlichen Handlungsbegriffs für die psychologische Forschung. Zeitschrift für Sozialpsychologie $18 / 1987 /-$, p. $2-18$.

Charlton, M.; Rapp, R.; Siegrist, B.: Vielsehen: Wie eine Familie versucht, sich sprachlos nahe zu sein. In: Charlton, M.; Neumann, K.: Medienkonsum und Lebensbewältigung in der Familie. München-Weinheim: Psychologie Verlags Union 1986, p. 161-188.

Charlton, M.; Neumann, K.: Medienkonsum und Lebensbewältigung in der Familie. Methode und Ergebnisse der strukturanalytischen Rezeptionsforschung - mit fünf Falldarstellungen. München-Weinheim: Psychologie Verlags Union 1986.

Charlton, M.; Neumann, K.: Mediensozialisation im Kontext: Der Beitrag des Kontextualismus und der Strukturanalyse für die Medienforschung. Publizistik 33/1988/2 - 3, p. $297-315$.

Charlton, M.; Neumann, K.: Medienthemen und Rezipiententhemen. Einige Ergebnisse der Freiburger Längsschnittuntersuchung zur Medienrezeption von Kindern. In: Schulz, W. (Ed.): Publizistische Medienwirkungen. Weinheim: Verlag Chemie (in print/1990).

Charlton, M.; Neumann, K. u.a.: Medienrezeption und Identitätsbildung. Schriftenreihe: SkriptOralia. Tübingen: Narr (in preparation/1990).

Collins, W.A.: Fernsehen: Kognitive Verarbeitungsprozesse. Unterrichtswissenschaft, 15/1987/4, p. 410-432.

Davidson, D.: Action, reasons, and causes. Journal of Philosophy, 60/1963/- , p. $685-700$.

Deutsche Forschungsgemeinschaft (Ed.): Medienwirkungsforschung in der Bundesrepublik. 2 vols. Weinheim 1986.

Döbert, R.; Habermas, J.; Nunner-Winkler, G.: (Ed.): Entwicklung des Ich. Köln: Kiepenheuer and Witsch 1977.

Fritz, A.: Die Familie in der Rezeptionssituation. München: Minerva 1984.

Früh, W.; Schönbach, K.: Der dynamisch-transaktionale Ansatz. Publizistik, $27 / 1982 / 1-2$, p. $74-88$. 
Gerbner, G.; Gross, L.: The scary world of TV's heavy viewer. Psychology Today 9/1976/-, p. $41-45$.

Habermas, J.: Was heißt Universalpragmatik? In: Apel, K.O. (Ed.): Sprachpragmatik und Philosophie. Frankfurt: Suhrkamp 1976, p. 174-272.

Habermas, J.: Theorie des kommunikativen Handelns. Vol. 1: Handlungsrationalität und gesellschaftliche Rationalisierung. Frankfurt: Suhrkamp 1981a.

Habermas, J: Theorie des kommunikativen Handelns. Vol. 2: Zur Kritik der funktionalistischen Vernuft. Frankfurt: Suhrkamp 1981b.

Habermas, J.: Moralbewußtsein und kommunikatives Handeln. In: Habermas, J.: Moralbewußtsein und kommunikatives Handeln. Frankfurt: Suhrkamp 1983, p. 127-206.

Habermas, J.: Notizen zur Entwicklung der Interaktionskompetenz. In: Habermas, J.: Vorstudien und Ergänzungen zur Theorie des kommunikativen Handelns. Frankfurt: Suhrkamp 1984a, p. 187-225.

Habermas, J.: Aspekte der Handlungsrationalität. In: Habermas, J.: Vorstudien und Ergänzungen zur Theorie des kommunikativen Handelns. Frankfurt: Suhrkamp 1984b, p. $441-472$.

Habermas, J.: Nachmetaphysisches Denken. Frankfurt: Suhrkamp 1988.

Hamlyn, D.W.: Behaviour. Philosophy, 28/1953/-, p. 132-145.

Harré, R.; Madden, E.H.: Causal powers. A theory of natural necessity. Totowa, N.J.: Littlefield Adams 1975.

Havighurst, R.J.: Developmental tasks and education. New York: McKay 1953.

Henne, H.; Rehbock, H.: Einführung in die Gesprächsanalyse. 2. ed. Berlin: De Gruyter 1982.

Hess, R.D.; Handel, G.: Familienwelten - Kommunikation und Verhaltensstile in Familien. Düsseldorf: Schwann 1975.

Hörmann, H.: Meinen und Verstehen. Frankfurt: Suhrkamp 1977.

Horten, D.; Wohl, R.R.: Mass communication and para-social interaction. Observations on intimacy at a distance. Psychiatry $19 / 1956 /-$, p. $215-229$.

Huth, L.; Krzeminski, M.: Zuschauerpost - ein Folgeproblem massenmedialer Kommunikation. Tübingen 1981.

Kenny, A.: Will, freedom, and power. Oxford: Basil Blackwell 1975.

Koch, P.; Oesterreicher, W.: Sprache der Nähe - Sprache der Distanz. Romanistisches Jahrbuch. Berlin: de Gruyter, 1985, p. 15-43.

Lenk, H.: Handlung als Interpretationskonstrukt. In: H. Lenk (Ed.): Handlungstheorien interdisziplinär. Vol. 2/1. München: Fink 1978a, p. 279-350.

Lenk, H.: Motive als Interpretationskonstrukte. Zur Anwendung der interpretationstheoretischen Handlungsphilosophie in der Sozialwissenschaft. Soziale Welt 29/1978/-, p. $201-216$.

Mahler, M.; Pine, F.; Bergman, A.: Die psychische Geburt des Menschen. Frankfurt: Fischer 1978.

Melden, A.I.: Free action. London: Routledge and Kegan Paul 1961.

Neisser, U.: Kognition und Wirklichkeit. Stuttgart: Klett-Cotta 1979.

Neumann, K.: Kindlicher Medienkonsum im 20. Jahrhundert. Über die These der Gleichzeitigkeit von Universalisierung und Individualisierung. In: Erlinger, H.D. (Ed.): Kinderfernsehen II. Reihe: Siegener Studien, No. 45. Essen: Verl. Die Blaue Eule 1989, p. $55-93$. 
Neumann, K.; Charlton, M.: Massenkommunikation als Dialog. Zum aktuellen Diskussionsstand der handlungstheoretisch orientierten Rezeptionsforschung. Communications, $14 / 1988 / 3$, p. 7-38.

Neumann, K.; Charlton, M.: Massen- und interpersonale Kommunikation im Alltag von Kind und Familie. Ergebnisse der Freiburger Längsschnittuntersuchung zur Medienrezeption von Kindern. In: Kaase, M.; Schulz, W. (Ed.): Massenkommunikation. Special issue of Kölner Zeitschrift für Soziologie und Sozialpsychologie. Opladen: Westdeutscher Verlag 1989, p. $364-378$.

Oerter, R.: Developmental tasks through the life-span: a new approach to an old concept. In: Baltes, P.B.; Featherman, D.L.; Lerner, R.M. (Ed.): Life-span development and behaviour. Vol. 7. Hillsdale, N.J.: Erlbaum 1986. p. 233-271.

Oevermann, U.: Sozialisationstheorie. Kölner Zeitschrift für Soziologie und Sozialpsychologie. Special issue 21: Lüschen, G. (Ed.): Deutsche Soziologie seit 1945. Opladen: Westdeutscher Verlag 1979, p. 143-168.

Oevermann, U.: Zur Sache. Die Bedeutung von Adornos methodologischem Selbstverständnis für die Begründung einer materialen soziologischen Strukturanalyse. In: Friedeburg, L.v.; Habermas, J. (Ed.): Adorno Konferenz, 1983, p. 234-289.

Oevermann, U.: Kontroversen über sinnverstehende Soziologie. In: Aufenanger, S.; Lenssen, M. (Ed.): Handlung und Sinnstruktur. München: Kindt 1986, p. 19-83.

Oevermann, U.; Allert, T.; Konau, E.; Krambeck, J.: Die Methodologie einer ,Objektiven Hermeneutik ${ }^{\prime}$ und ihre allgemeine forschungslogische Bedeutung in den Sozialwissenschaften. In: Soeffner, H.G. (Ed.): Interpretative Verfahren in den Sozial- und Textwissenschaften. Stuttgart: Metzler 1979, p. 352-434.

Peters, R.S.: The concept of motivation. London: Routledge and Kegan Paul 1958.

Plessner, H.: Der Mensch als Lebewesen. In: Plessner, H.: Die Frage nach der conditio humana. Frankfurt: Suhrkamp 1976, p. 111-123.

Popper, K.R.: Logik der Forschung. Tübingen: Mohr 1969.

Rapp, U.: Handeln und Zuschauen. Untersuchungen über den theatersoziologischen Aspekt in der menschlichen Interaktion. Darmstadt: Luchterhand 1973.

Reid, L.N.; Frazer, C.F.: Television at play. Journal of Communication, 30/1980/4, p. $66-73$.

Rosengren, K.E.; Windahl, S.: Mass media use: causes and effects. Communications, 3/1977/3, p. 336-352.

Schütze, Y.: Innerfamiliale Kommunikation und kindliche Psyche. Eine exemplarische Analyse der Kommunikations- und Rollenstrukturen zweier Familien. Berlin: Schriften des Max-Planck-Instituts für Bildungsforschung 1977.

Schwitalla, J.: Dialogsteuerung. Vorschläge zur Untersuchung. In: Berens, F.-J.; Jäger, K.H.; Schank, G.; Schwitalla, J.: Dialogstrukturen. München 1976.

Smith, M.J.: Persuasion and human action. Belmont, Ca.: Wadsworth 1982.

Spitz, R.: Nein und Ja. Die Ursprünge der Kommunikation. 2. ed. Stuttgart: Klett 1970. Staabs, G. von: Der Scenotest. Bern: Huber 1978.

Thalberg, J.: Perception, emotion, and action. Oxford: Basil Blackwell 1977.

Toulmin, S.: Reasons and causes. In: Borger, R.; Cioffi, F. (Ed.): Explanation in the behavioral sciences. Cambridge: Cambridge Univ. Press 1970, p. 1-26. 


\section{Everyday life as the subject of television research}

With television having become a common feature of everyday life at the end of the sixties and the beginning of the seventies, it was no longer possible to describe television in the simple terms of a cause and effect model as it was with the mediachannelled transfer of information. The fact that television was seen as something usual, indeed something taken for granted, in the flow of everyday events and relationships initiated a change in "television" as a subject for research. What were, for instance, the methodological consequences? It was, and still is, necessary to develop a research methodology which is capable of assessing the complexity and meaningfulness of everyday life and the role of television within it.

The following article begins with a historical survey of two of the methodological contributions from the beginning of the seventies. In one of these, Teichert attempted to understand television reception from the standpoint of the "theory of action', in the other, the "longitudional study" emphasised the mutual "link up" of television and action as a normal feature of television use. With the support of Schütz's 'Theory of Action' in a social world, the subject "everyday life" will be systematically marked out, with the help of the concepts "Action" and "Reality".

\section{Conceptual response to television becoming part of everyday life}

\subsection{The need to integrate the theory of action and mass communication theory}

In 1972/73 Teichert undertakes a study of the approaches of reception research, which he classifies under the title "Television as Social Action". His concern is to investigate the "Mediation of Reality by the Media" (1972, p. 421), which the approaches available at that time were not able to achieve because of their conceptual limitations and their fragmentary methods (1972, p. 424). His criticism is that social action, in its significance for the "present social system " $(1972$, p. 421) and for the "social personality of the recipient" (1972, p. 421) is not considered alongside television reception. This conceptual narrowness is shown up, according to Teichert's observations, by among other things the procedures of "professional listener and viewer research" which categorises the recipient only "as a statistical association, that is, as the bearer of certain characteristics" (1972, p. 422). Thus the researcher fails to take account of the "social reality of the recipient"; instead attention is paid to media oriented standardisations. The "only linking characteristic" available in the description of the relationship between "communicator and 
recipient" is "merely the fact that they share television reception" (1972, p. 423). The resultant research strategy is to "structure the dispersed mass of the public in terms of sociographic data such as sex, age, profession etc. or in terms of psychological factors such as cognitive and affective predispositions"' (1972, p. 424). The relationship to the communicator, to the medium, is then explained by means of "a linear causal concept of cause and effect" (1972, p. 424). In this way, the mediation dynamics ("dialectic cause and effect relationship", 1972, p. 425) are "concealed" by the "linear causal conceptual process" (1972, p. 425). A further problem is that the "analytical separation" of cause-and-effect-factors itself becomes a frame of reference. This means that the studies, despite containing a wealth of data, are of little use.

In contrast, Teichert draws up a model ${ }^{1}$ in which "the manner of media use is embedded in a comprehensive theory of interaction", in which the "presentation of mass media subjects is seen as a presentation of realistic material, which the recipient uses in a subjective way as a means of coping with reality and of finding his personal identity"' $(1972$, p. 439). This programme combines the theory of action (by implication in A. Schütz, W. Weber) and communication theory (symbolic interactionism, G. H. Mead, H. Blumer) with a social concept of mass communication and reality (especially the reality concept of Berger and Luckmann). Thus the connection between television reception research to the so-called paradigm of social research was established. ${ }^{2}$

\subsection{The ordinariness* of everyday life and the theoretical attempt to describe and explain the 'link up of action' and mass media}

In 1964, 1970 and 1974, the broadcasting corporations had commissioned studies of media use. The 1974 study, with the publication of its results (Berg, Kiefer 1978), is remarkable in that it goes hand in hand with a methodological positioning "as to the need for a new conception of mass media research in the Federal Republic of Germany" (Langenbucher et al., 1978). It amounts to an adaptation of the "Uses and Gratifications Approach". (The reader is explicitly referred to Blumler, Katz 1974).

Behind the empirical investigation of television use lay the question of the competition between television and the press; more specifically how the use and assessment of television had an effect upon the use and assessment of the daily press and radio. This central question was converted directly into empirical categories, with investigations being made into: the amount of time spent on media use, the scope of the media, the relationship to political information (Kiefer 1978,

\footnotetext{
* The German expression Selbstverständlichkeit is translated by 'ordinariness'.Ordinariness
means 'taken for granted'.
} 
p. $45 \mathrm{f}$.) and attitudes, expectations and personal significance as regards the medium (= "functional significance of the medium", Kiefer 1978, p. 47).

\section{Television and television reception as 'normal' and 'ordinary'}

The 1974 study could start from the assumption that "all homes" have a television, compared to the 1964 study which spoke of "a good $50 \%$ of homes". The time spent on total media use between the 10 years from 1964 to 1974 had risen to almost $41 / 2$ hours a day. A situation in which one of the media being considered in the study (television, newspapers, radio) had ousted the others had not taken place. Rather a complementary media use had developed, with over 2 hours of television, almost two hours of radio, and over half an hour spent on a newspaper.

The important point is that, with the spread of television into almost all homes and with more than 2 hours daily of viewing time (the next largest amount of time per day after sleep and work, Kiefer 1978, p. 60), a "change in the attitudes towards television" (Kiefer 1978, p. 60 ) came about, described by Kiefer as a "coming down to earth": "The idea - obviously exaggerated - of the new medium's ability to perform a journalistic function has, as people grow more used to its daily accessibility and to its daily use, given way to a differentiated attitude" (Kiefer 1978, p. 60).

This German finding is to be seen parallel to that of an American study (Bower 1973 , p. 14) in which, as Kiefer states, television in 1970, in comparison to 1960 , was "clearly classified - and indeed also experienced - as less 'exciting', 'interesting', 'wonderful', and all in all less 'excellent' (Kiefer 1978, p. 60). In assessing television's informative role, Kiefer detects, as does the American study, a "growing significance of the role played by the recipient" (Kiefer 1978, p. 61) and, at the same time " a general cooling off in attitude towards the medium (television)" (Kiefer 1978, p. 61).

To summarise these findings, television in 1974 has come to be seen as a everyday, a 'normal' experience, something which has been more or less integrated as an accepted, 'ordinary' part of daily life - with people viewing for a large amount of time.

\section{The combination of mass communication, reception and everyday life}

This acceptance of television as a normal and inconspicious part of everyday life since the beginning of the seventies cannot - and could never - be adequately described in terms of simple or complex models of mass media information transfer. This methodological inference was also drawn at the beginning of the research report "The necessity of a new approach". . . (Langenbucher et al., 1978). The 
Lasswell concept and his statement (Who says what in which channel to whom with what effect?) is no longer appropriate to the research subject. As long as a new medium is regarded merely as something which supplements and enriches everyday life, the thing and its consequences for people can be explained by means of a simple cause-and-effect-model. There are two reasons for this: the first is that an innovation like television sets something in motion which - as long as the innovation catches on - can be determined in terms of cause and effect. The other reason is that thinking in terms of cause and effect corresponds to the logic of mass communication as a means of information transfer. The relationship can be understood and explained by being classified as cause and effect.

But how can those completely different functions of television from those of the reproduction of picture and sound be described? Everyday television is integrated into the flow of everyday events and everyday experiences and takes on, within this flow, communicative functions for people, functions which do not fall into the pattern of information transfer or cause and effect. In order to reach a closer understanding, the "Uses and Gratifications Approach" and the Agenda Setting Hypothesis were used: What do people do with television? What topics are dealt with or structured by television? It is a question here of a fundamental change of theoretical perspective, which Renckstorf (1978) classifies as a new research subject: from a "media-oriented" to an "audience-oriented model to describe the process of mass communication"' (Renckstorf 1978, p. 325 ff.). The crucial factor here is an approach which places people and their actions in the centre of mass communication research: "The recipients decide if, when and how they deal with the topics disseminated by mass media, which they use and employ within the context of their aims, needs and interests" (Renckstorf 1978, p. 327 f.). You could add: (because) this is why people, now that television has become a regular feature of everyday life, treat television in the same way as they treat the other things which they take for granted on a day to day basis.

Along with the attempt to change the theoretical perspective from the medium to the addressees, the ordinariness of television and all the other kinds of media appears as a process which is integrated in the fields of people's actions and experiences. In spite of the change of emphasis in theory to the active media user this approach does not provide an identification or explanation of the combination of action and specific communicative forms of television.

\subsection{Analogies, arguments and concepts concerning the everyday relation between the subject and the mass communication}

On the other hand, however, there have been, and still are a number of theoretical attempts to throw light on and explain the relationship between the mass communication and action. Comparable to the "Uses and Gratifications Approach" they 
are formulated, at least in the first instance, on a similarly concrete level of reflection using analogies to form the frame of reference for the arguments.

It is in this way that Hengst explores for example, in his book "Second-hand reality - Childhood experiencing the world of toys and media products" (Bauer, Hengst 1980) the various structural conditions in the relationship of children, regarded as subjects to the objects of reality. This is what he identifies as the relation between experience and reality. This experience-oriented subject-object relationship is radicalised in images such as those of the "Disappearance of Reality" (v. Hentig 19812), and that emphasises at the same time the threat the mass communication poses to the subject. The metaphor of the "plug-in drug in the living room" (Winn 1977) describes this threat as a danger of addiction in a flight from reality on a daily basis by means of television image consumption.

The abstractly formulated concept of "Symbolic Mediation" (Bachmair 1989a) deals with a specific subject-object relationship which goes with television. The idea of the symbolic mediation reaches beyond a sense of reality which is built on experience and related to reason. It places television within the relationship to every cultural, symbolic mediation between subject and reality. The symbolic relationship between subject and reality includes experiences, emotions, fantasies, associative utterances and activities etc. The metaphor of the "Media and Consumer Network" , of which television is the leading medium, refers to the risk of alienation within a symbolic mass media mediation. The possibilities for action on the part of children in a network-like everyday world can be described, in a loose relationship to active or passive media use, as entangled or as freeing themselves from it (getting caught up in the media and consumer network and freeing oneself from it).

Eurich (1980) extends the metaphor of the network and speaks of the "cabled up life". This metaphor makes the idea of alientation appear direct and obvious.

The metaphors which emphasise a media-oriented subject-object relationship allow little room or chance to think about the meaning of watching television as a everyday activity. This nevertheless highlights the classification of "coping with life", as it is used by Charlton and Neumann (1986) as a concept for the interpretation of a family-based study. This meaning of all television related family activities, follows on from the link between family life and television, which, as a result, also forms a unified whole with the meaning of family activities. 


\section{Everyday life as action and as reality - action theory outlines of everyday television}

Along with the development of theories about everyday television or everyday mass communication, there was, stemming from sociology, an intensive evaluation about 'forgotten' action theories and communiction theories. The impetus came from among others, the Bielefeld Sociologists' Working Group (1973). ${ }^{3}$ It focussed on theories from the first half of this century which concentrated on action and communication in modern society. Central here were the works of Alfred Schütz, which are also useful in understanding the link which exists in everyday life between television and action as constituting reality. Two concepts are important here: everyday life is the sphere in which one can join in actively and everyday life has an outstanding significance as a social reality.

As regards the relationship between people and television, the everyday occurrence of television (as something broadcast and as something received) signifies that two very different communication structures have become 'linked up'. This linkup takes place essentially at the time of reception, but more and more too at times of interaction, in which television is spoken about, for example. Especially at the time of reception, the technological communication structure of information transfer coincide with the symbolically mediated interaction of people's actions and experiences. The linkup of two dissimilar, almost contradictory communicative structures, has led to practical as well as theoretical difficulties. The practical difficulties have been the concern of, among others, media education, which has, for example, studied the changing ways in which children have related to reality as a result of television. It looks for, among other things, the qualitatively different ways of experiencing, which form the basis of direct experience and of experience received via television. It also seeks to find out what educational ways there are of intervening and compensating. The theoretical problem as to which communication models are appropriate for television reception and for the processing of television experiences became, indeed becomes, evident at the discussion phase. ${ }^{4}$

The Schütz concept of everyday life and ordinariness provides the frame of reference for a consideration of the phenomena, the problems and the theoretical outlines. "The world of daily life" is, according to Schütz, (Collected Papers I, p. 208 f.) an "intersubjective world, which (is) experienced and interpreted ... as an organized world." It prescribes our experience and our interpretation. "All interpretation of this world is based on a stock of previous experiences." This experienced and interpreted world "is something that we have to modify by our actions or that modifies our actions."

This pragmatic relationship to everyday life means that everyday life as a " world of working" (Collected Papers I, p. 226) has a special status as 'reality'. The mean- 
ing of action, of experience in everyday life ensues as a process of interpretation from a reflective attitude towards the development of everyday reality. The connections between the organized and interpreted reality of everyday life, action and experience must now be examined from the perspective of having become an ordinary medium. Television research is now, therefore, looking to order, interpretation, experience, reflection, meaning and reality.

This is the first of all a task to be empirically settled and, to this end, the present volume presents research results. It is at the same time a historical, analytical task, which essentially still remains to be tackled. ${ }^{5}$

Aspects of action and experience, as well as those of everyday reality, have a part to play in the empirical examination of television as part of everyday life.

\subsection{Everyday life and action}

From the wealth of theoretical aspects of action and experience, which Schütz develops, two concepts which offer immediate help in understanding television are picked out: the ordinariness and familiarity of everyday life (cf. "Some Structures of the Life-World"', Collected Papers III, p. $116 \mathrm{ff}$.); action and its constituting process in everyday life (cf. "Phenomenology of the Social World", action: p. $63 \mathrm{ff}$., constituting process p. $38 \mathrm{ff}$., experience: p. $45 \mathrm{ff}$.).

\section{Ordinariness and familiarity}

For the present generation of researchers, one aspect of everyday life in relation to children's, young people's and families' use of television is hard to understand: television as "the unquestioned reality" (Collected Papers III, p. 116) of current everyday life, as television only became a part of everyday life for the researchers when they were older. Only the present generation of children, teenagers or young adults grew up with television as a quite normal and ordinary matter. Children and young people take for granted this their everyday world, that is in the ubiquitous media and consumer network, as their parents' generation structured and organised their lives around the car. This everyday world of media and consumption as "unquestioned reality" conveys the idea, as it always has, of one's own world being a universal valid constant as it always was: Schütz (Collected Papers III, p. 117) speaks of the ordinariness of the everyday world as a universal constant: the "structures of the world ", the "validity of our experiences of the world" and our chances for influencing the world - all this is accepted as something valid and constant.

This constancy of experience and action - which includes present day television and the way people respond to it - confront the media educationalist with considerable problems: how to handle and reflect something as a problem of special 
meaning and "relevance" (Collected Papers III, p. 117) although its everyday occurrence does not give cause to do so. ("All these stratifications belong as unquestionably given to our naive experience of the socialised world" (Collected Papers III, p. 119). The researcher must equally take fundamental account in his research plan of the constancy of television and its ordinariness in everyday life. This goes beyond questions of research methods, e.g. that television taken for granted as an element of everyday life excludes simple questioning techniques: you do not really know the point at issue. That means that questions about everyday life can only offer superficial explanations, by providing information about watching patterns, e.g. switching on times. Of decisive importance for research, on the other hand, is to take a close look at action and at what people tell researchers, seeing this information as a representation of their complex everyday world. In terms of research strategy, this means using research observation and informative documents to uncover the very varied layers of everyday life and of the mediation process of experience and action in relation to the ordinary everyday reality of mass communication. This leads to interpretation methods in which texts which at first sight appear simple and insignificant (they are after all understandable in an everyday sense) are analysed from very abstract and theoretical perspectives, which make everyday life seem questionable. One question, for instance, then to be asked is, to what extent well-known television genres and young people's patterns of action relate to each other.

\section{Patterns of action and interpretation}

In order to get closer to the symbolic quality of television and its integration into everyday life, it is appropriate to consider Schütz's argument that patterns of "expression and interpretation" (Collected Papers III, p. 119) structure everyday life: although it is an unquestionable reality, we organise the "social world" of everyday life by means of the "socially conditioned schemata of expression and interpretation prevailing in the group to which we belong." These schemata "also co-determine what within our culture is accepted as unquestionable, what can become questionable and what appears as worthy of questioning" (Collected Papers III, p. 119 f.). These schemata of expression and interpretation have, over and above this reflective significance for everyday life, the general function of a "common schema of interpretation of the common world." They are "a means of mutual agreement and understanding" ( Collected Papers III, p. 120). In the relationship of a subject to the world and to other people, which is always mediated via interpretative schemata, television today also plays an interpretative role. The status of television's interpretative role can now be empirically characterised. This interpretative role results from the common origins of interpretative schemata which bring action and experience together in a reflexive fashion. Thus nowadays television watching and those experiences linked with it (e.g. the everyday life 
of the family) enter into structuring interpretative schemata, while this relationship, because it is part of an unquestioned reality, is not reflected upon. One cannot reflect about how and why television experiences, family life, action, other experiences and interpretation should all be linked in a coherent process. (cf. The Phenomenology of the Social World, p. 82).

These interpretative schemata arise because experiences are integrated in the prescribed "total context of experience" (The Phenomenology of the Social World, p. 78, p. 83). In this reflexive process of interpretation and experience in the given framework of a personal biography, television in various sequences has its own role for example as an experience which is integrated, or for example as an interpretative scheme which integrates experiences. Furthermore, television might well structure complex areas of experiences by providing particular patterns of order (The Phenomenology of the Social World, p. 81). Television has, therefore, the cultural function of integrating and developing everyday patterns of action and interpretation in terms of classifying schemes. It is not easy, from a methodological point of view, to work using this complex structure of interpretations, experiences, interpretative schemes and patterns of order as a research object, for these processes relate reflexively the one to the other and do have the quality of ambiguous events and thus are not to be described definitely. This complex relationship is not only dependent on the respective individual and cultural situations but also, as it is a reflexive process, it is always new and also uniquely in a state of flux. The "experience itself decides the scheme into which it is to be ordered" (The Phenomenology of the Social World, p. 85) and thus it serves to determine its own integration.

For the researcher, this means tracing the reflexive character of the interpretative process - and of television which is integrated into it (its topics, images, signs, forms of representation etc). One can then discover the functional relationship between interpretative process and television as an element of mass communication. In the process, general features - that is the dynamics of this reflexive connection - can be recognised from the particular case, whether it be an event or whether it be the interpretative process of an individual or of a group of people. The general structures can be recognised, because the development to the everyday mediation of experiences, events, interpretative schemes and patterns of order, is always a social matter; that is why because these constitute more than simply the perspectives and the experiences of one individual. These processes always take place in a world which is intersubjectively present, a world whose general and symbolic order plays a constitutive part in creating the process of action and interpretation (Collected Papers I, p. 312 ff.). ${ }^{6}$ 


\subsection{Symbolic objectivisations and the reality of everyday life}

Using the arguments of Berger and Luckmann (Sociology of Knowledge 1970), the outline presented above of the important aspects of Schütz' theory of action in the everyday world must now be related to the problem of media and reception, as well as to the educationally relevant link between the generations. ${ }^{7} \mathrm{We}$ now move on to consider everyday reality and action in terms of symbolic objectivisations. Where is the relationship to the media to be found? The technological mass media of industrial society are linked to reality, everyday life and action, because they too are symbolic objectivisations. As such, they are substantially bound up within the cultural mediation process of the construction and acquisition of reality. With the help of the concept of the "social construction of reality" - such is the title of Berger and Luckmann's enterprise - the fact that a communicative apparatus such as television has become a regular feature of everyday life can be dealt with theoretically, from the point of view of the dynamics which go to make up everyday life, culture and communication. Considerations about the function of objectivisations in "subjective" and "objective reality" are decisive here (Berger and Luckmann, p. 49, p. 139).

\section{Symbolic Objectivisations}

Berger and Luckmann start out from the outstanding significance of the everyday life and everyday world (as emphasised by Schütz). This reality ensues from the ordinariness and certainty of the everyday world (p. $21 \mathrm{f} ., 23$ ). However, it takes on this characteristic because action occurs in an "intersubjective world", which arises out of the "objectivisations of subjectively meaningful events". In this way, we hardly experience reality as something made and objectivied by us, but as something "already given": "The reality of the everyday world is already objectivied, that is, constructed by an ordering of objects, which were already declared as objects long before I appeared on the stage" (p. 24). These objects which, through action, have been produced as an "objectivisation of human subjectivity" (p. 37), give the everyday world its realistic quality: "The reality of the everyday world is not only full of objectivisations, it is rather that it is a reality because of this objectivisation" (p. 37).

Because this everyday reality stemming from the objectivisations of human subjectivity is an intersubjective world, shared with other people, the objectivisations are of a symbolic as well as a material kind (p. $37 \mathrm{ff}$ ). Thus the language of the everyday world takes on, as an objectivisation, a special and prominent significance: "The language used in everyday life provides me unceasingly with the necessary objectivisations and creates the order in which these objectivisations have meaning and appear meaningful to me in the everyday world"' (p. 24). 
This statement is always valid, even when language has relaxed its close relationship to what has or can be written and is connected to the pictures or to the production modes of television.

Returning to the concept of television becoming a regular feature of everyday life: everyday television means that television aligns itself with the connection between action and objectivisation, and thus also becomes bound up with man's leading, symbolic objectivisation system, namely with language. One special reason for this link being possible and in principle discernible is that the technological mass media are particularly suited to the typical objectivisations of industrial society and are therefore a part of this reality. They have this much in common with machines, cars etc. Moreover, they are, as objectivisations, primarily symbolic in nature and thus capable of being integrated with language or with other comparable systems of symbolic objectivisations (e.g. arts). This contributes to the creation of reality in many cultural and social fields.

Today everyday reality and culture are already being constituted through television and its links with language and other traditional systems of symbolic objectivisations. It makes sense to undertake psycho-historical and culture-historical analyses in order to trace back its origins in everyday life; e.g. how industrial culture, by means of the objectivisation 'car' and by taking over the light fictional works of the 19th century, sets up specific relation between human subjects and the reality of objects. Research can ask questions such as what emotional function violent depictions play in the 'experiencing of self' and how the experience of reality can thus be prepared for or compensated for. It can also ask how the individualising and equalising mechanisms in a growing complexity of systems are underpinned by television, etc. etc. ${ }^{8}$

\section{Television and the acquisition of reality in the relation of the generations}

The emergence of an objective world can be traced back to action. The integration of this objective world into subjective action is the second constantly recurrent aspect of reality. The hypothesis which has been developed up to now concerning the communicative connection between people and the world is decisive here. In particular it explains the process of children and young people growing up into the world of adults: "The comprehension of the world . . . is not the result of selfsatisfied target setting on the part of an isolated individual; it begins rather with the individual 'taking over' a world in which others already live" (p. 140). The world in which children live is therefore always a world of symbolic objectivisations, and thus a world of things and events, which carry within themselves their meaning and also the ways and means of interpreting or changing this meaning. This meaning relationship is taken for granted especially by the technological mass media, because they originated as communicative media. Thus the processes 
of emergence and acquisition are structured technologically: the emergence of television is organised as an industrial production enterprise, which is geared to consumption and intensive use. The acquisition is always characterised by a reception situation which is familiar to us - sitting more or less silently in front of the television screen. This is enforced by the 'logic' of television, that is the organisation of communication technology as a transfer of information. With the everyday occurrence of television as a symbolic objectivisation moulding the reality of everyday life in industrial society, the acquisition of television has developed away from reception - in the sense of a final 'consumption' of information - to the integrated acquisition and use of television. This acquisition and use of television (independent of the screen itself, for example, as an aid to clarify an interactive situation) is learned through acquisition modes which are specific to generation, age and culture. Television topics, images, language, production modes are all linked - in a subjective integration process of children and young people - to all the other 'cultural messages' of everyday life. This subjective integration process is structured through the patterns of interpretation and action which the children have already acquired or developed themselves. An important task of research is to discover and describe them.It is, however, not easy to cope with, because the subjective patterns of action and interpretation can only be found in the form of a unified combination of television and family life or life in a peer group. Even if, with this theoretical approach to the research subject television, everything connects up with everything else, it is nevertheless possible to identify that which is specific to the media within this amalgam of symbolic objectivisation and action. It is the television experiences and the television symbolism that appear in the language, in the situational interactions etc. of children and young people which remain to be discovered. Television experiences and television symbolism in the actions of children and young people are indicators pointing to the television-oriented functional connections between the reality of everyday life and culture on the one and both experience and television with subjective patterns of interpretation and action on the other hand. This subjective acquisition of reality in the relationship to action and in the link with television can be described in terms of the dynamics of symbolic mediation.

In order that one is, as a researcher, still able to describe and analyse phenomena, despite insolvable complexities, it is necessary to take two steps towards objectivisation: Television as a medium and as a subjective activity is a communicative and meaningful activity in the flow of everyday events, everyday experiences and everyday relationships. This flow can, with the help of the following general categories referring to the "subjective" and "objective realities", be properly described and analysed:

- media experiences and media symbolism (including the emotional acquisition of media symbolism) 
- media symbolism, both in subjective symbolic representations and in the subjective patterns of expressions

- the connection of subjective patterns of interpretation and action (especially the action-determining subjects [themas] which are typical for each age group), with media experiences and media symbolism

- the linking of the situational context with patterns of action and interpretation, media experiences and media symbolism.

These categories are functionally linked by a model of subjective acquisition and communication. Decisive for this is the following idea: action-determining subjects (themas) are representated in the situational context with the help of experienced media symbolism or other symbolic objectivisations of a culture. (The symbolic mediation process is described in this context as an inner-outer relationship and as an impression-expression relationship). The function of television, within the dynamics of symbolic mediation of culture, everyday life and action can be identified by the reception, the processing and the communicative use of television as a system of symbolic objectivisations of a culture being examined on the basis of subjective interpretative patterns in the everyday flow of action and interpretation, in which television is interwoven in language and experiences.

\section{Notes}

1 Summary in Teichert 1973, p. $382 \mathrm{ff}$.

2 cf. Arbeitsgruppe Bielefelder Soziologen (The Bielefeld Sociologlists' Working Group), 1973. See especially the so-called interpretative paradigm, Wilson 1973.Survey of the scientifichistorical works on paradigms of communication and television research is to be found among others in Rogge, Renckstorf 1978, Langenbucher et al.1978. Literature survey of research on the interpretative paradigm, e.g. Auffermann, Bessler.

3 Overview of literature on action theory, for example Soeffner.

4 The discussion extends from the stimulus-response-approach to symbolic interactionism, cf. overview in Kübler 1980, Schenck 1987, Renckstorf 1985, Horn 1985, Habermann 1985, Bledjian 1985.

5 cf. Muller-Doohm's concept of structural analysis in this volume. Well-known theoretical contributions to this historical assignment, cf. Horkheimer/Adorno, Anders, Benjamin.

6 In this structural process 'relevance structures' are important. Schütz, among others, describes these as "thematically relevant". Thematic relevance, however, singles out what has become a task or a problem. Thus the concept of theoretical relevance is hardly suited to describing the aspect of content of everyday patterns of interpretation and action, because these, in fact, belong to those 'taken-for-granted' constituents of everyday life. A more psychological line of questioning is helpful here - one which starts from action-determining subjects (themas) and from age-specific subjects or life subjects.

7 The connection between Berger and Luckmann to Schutz is shown in the introduction to the German edition of Berger/Luckmann.

8 Cf. Bachmair: $1989 \mathrm{~b}$ and 1990. 


\section{References}

Anders, Günther: Die Welt als Phantom und Matrize. In: Die Antiquiertheit des Menschen. vol. 1: Über die Seele im Zeitalter der zweiten Industriellen Revolution. München 1987, $7^{\text {th }}$ ed., p. $97-211$.

Auffermann, Jörg; Bohrmann, Hans; Sülzer, Rolf (Ed.): Gesellschaftliche Kommunikation und Information, 2 vols., Frankfurt 1973.

Arbeitsgruppe Bielefelder Soziologen (Ed.): Alltagswissen, Interaktion und gesellschaftliche Wirklichkeit. 2 vols., Reinbek 1973.

Bachmair, Ben: From the Motor Car to the Television. Media Culture and Society 1990. Bachmair, Ben: Entwicklungslinien für Kindheit - Argumente für kulturspezifische Entstehung medienvermittelter Lebensformen. In: Deutsches Jugendinstitut (Ed.): Kinderfernsehen und Fernsehforschung in Japan und in der Bundesrepublik Deutschland. München 1989(b), p. 165-183.

Bachmair, Ben: Symbolische Vermittlung - Argumente, Beispiele und Stichworte zu einer Handlungs-, Kommunikations- und Medientheorie. In: Conrady, P. (Ed.): LiteraturErwerb. Kinder lesen Texte und Bilder. Frankfurt 1989(a), p. 130-162.

Bauer, Karl W.; Hengst, Heinz: Wirklichkeit aus zweiter Hand. Kindheit in der Erfahrungswelt von Spielwaren und Medienproduktionen. Reinbek 1980.

Benjamin, Walter: Das Kunstwerk im Zeitalter der technischen Reproduzierbarkeit. Frankfurt $1981,12^{\text {th }}$ ed.

Benz, Karl: Alltagswelten von Jugendlichen. Eine empirische Studie über jugendliche Handlungstypen. Frankfurt 1986.

Berg, Klaus; Kiefer, Marie-Luise (Ed.): Massenkommunikation. Eine Langzeitstudie zur Mediennutzung und Medienbewertung, Mainz 1978.

Berger, Peter L.; Luckmann, Thomas: Die gesellschaftliche Konstruktion der Wirklichkeit. Eine Theorie der Wissenssoziologie. English original edition 1966, German edition Frankfurt 19701, $1977^{5}$

Bessler, Hans-Jörg: Hörer- und Zuschauerforschung. München 1980.

Bledjian, Frank: Theoretische Ansätze über den Einfluß der präkommunikativen Einstellungsstruktur der Rezipienten auf Bildung und Änderung von Einstellungen. In: Prokop, Dieter 1985, p. 75- 113 .

Blumler, Jay G.; Katz, Elihu (Ed.): The Uses of Mass Communications. Current Perspectives on Gratifications Research. Beverly Hills, London 1974 (Sage Annual Reviews of Communication Research, Vol. III)

Bower, Robert T.: Television and Public. New York 1973.

Charlton, Michael; Neumann, Klaus: Medienkonsum und Lebensbewältigung in Familien 1986. München 1986.

Coenen, Hermann: Diesseits von subjektivem Sinn und kollektivem Zwang. München 1985.

Eurich, Klaus: Das verkabelte Leben 1980 . Wem schaden und wem nutzen die Neuen Medien. Reinbek 1980.

Habermann, Peter: , Television and Behavior'. Part 2: Kognitive und emotionale Verarbeitungsprozesse. In: Prokop, Dieter 1985, p. 64-74.

Hentig, Hartmut von: Das allmähliche Verschwinden der Wirklichkeit. Ein Padagoge ermutigt zum Nachdenken uber die neuen Medien. Munchen, Wien $1981^{2}$ 
Horkheimer, Max; Adorno, Theodor W.: Kulturindustrie, Aufklärung als Massenbetrug. In: Horkheimer, Max; Adorno, Theodor W.: Dialektik der Aufklärung. New York 1944, Frankfurt 1969, p. $128-176$.

Horn, Imme: ,Television and Behavior'. Part 1. Wirkungen von Fernsehinhalten. In: Prokop, Dieter 1985, p. 55-63.

Kiefer, Marie-Luise: Massenkommunikation 1964 - 1970 - 1974. In: Berg, Klaus; Kiefer, Marie-Luise (Ed.): Massenkommunikation 1978, p. 41-322.

Kübler, Hans-Dieter: Kinder und Fernsehen. Ein Literaturbericht. Zeitschrift für Literaturwissenschaft und Linguistik, Beiheft 11, 1980, p. 136-204.

Langenbucher, Wolfgang R.; Räder, Georg; Weiß, Hans-Jürgen: Zur Notwendigkeit einer Neukonzeption der Massenkommunikationsforschung in der Bundesrepublik. In: Berg, Klaus; Kiefer, Marie-Luise 1978, p. 9-39.

Prokop, Dieter (Ed.): Medienforschung. Vol. 2: Wünsche, Zielgruppen, Wirkungen. Frankfurt 1985.

Renckstorf, Karsten: Zur Hypothese des ,Two-step-flow' der Massenkommunikation. In: Prokop, Dieter 1985, p. 29-52.

Renckstorf, Karsten: Tagesablaufstudien und die Gewinnung neuer Datenqualitäten in der Massenkommunikationsforschung. In: Berg, Klaus; Kiefer, Marie-Luise 1978, p. $323-343$.

Rogge, Jan-Uwe: Zur Kritik der Wirkungsforschung. In: Dichanz, Horst; Kolb, Günter

(Ed.): Beiträge zur Medienforschung, Köln 1979, p. 116-142.

Schenk, Michael: Wirkungsforschung, Tübingen 1987.

Schramm, Wilbur: Grundfragen der Kommunikationsforschung. München 1973, 5th ed.,

English original edition: The science of human communication. New York, 1963.

Schütz, Alfred: Collected Papers I. The Problem of Social Reality. The Hague, Boston, London 1962.

Schütz, Alfred: Collected Papers III. Studies in Phenomenological Philosophy. The Hague 1975.

Schütz Alfred: The Phenomenology of the Social World. Translated by Walsch, George, Lehnert, Frederick. Northwestern University Press 1967.

Schütz, Alfred: Das Problem der Relevanz. Frankfurt 1971.

Soeffner, Hans-Georg: Alltagsverstand und Wissenschaft - Anmerkungen zu einem alltäglichen Mißverständnis. In: Zedler, Peter; Moser, Heinz (Ed.): Aspekte qualitativer Sozialforschung. Studien zur Aktionsforschung, empirischer Hermeneutik und reflexiver Sozialtechnologie. Opladen 1983, p. 13-50.

Teichert, Will: ,Fernsehen' als soziales Handeln. Zur Situation der Rezipientenforschung; Ansätze und Kritik. In: Rundfunk und Fernsehen 20/1972/4, p. 421 - 439; Entwürfe und Modelle zur dialogischen Kommunikation zwischen Publikum und Massenmedien. In: Rundfunk und Fernsehen 21/1973/4, p. 356-382.

Wilson, Th. P.: Theorien der Interaktion und Modelle soziologischer Erklärung. In: Arbeitsgruppe Bielefelder Soziologen 1973, vol. 1, p. 54-79.

Winn, Marie: The plug-in drug. New York 1977. (German edition 1984: Die Droge im Wohnzimmer.) 
Stefan Müller-Doohm

\section{Media research as symbol analysis}

\section{The methodological consequences of the unity of communication and cultural sociology}

"The social science we want to pursue is a science of reality. We want to understand the reality of life that surrounds us, into which we have been placed, in its special nature - the context and the cultural significance of its individual phenomena in their present shape, on the one hand, and, on the other, the reasons why it has turned out as it has and not otherwise."

Max Weber

\section{Communication, the culture industry and symbolic order}

The modern media of mass communication, which Horkheimer and Adorno classified as "culture industry" (1944, p. 144) on account of the connection between cultural communication and capitalist economy and the concomitant standardisations and schematisations of their serial products, are integral parts of society's cultural system. They propagate and shape culture, they are partly responsible for the cultural milieu in society, and they convey cultural interpretations, pictures of the world, life styles, values, opinions etc. by means of mass communicative processes. Seen like this, a cultural sociological way of looking at the mass media, at their textual, visual and acoustic productions and forms of distribution is quite obvious (Soeffner 1988, p. $6 \mathrm{ff}$.). That the culture industry, that press, radio and television are important representatives of what is generally regarded as culture in modern societies, applies to their educational task, which they claim and/or is laid down by law, namely to inform the various groups of the population journalistically in a generally intelligible form and with regard to the typical contents of the mass media which are published under the usual headings of information, commentary, entertainment, culture, knowledge etc. In the journalistic manner of presenting such content forms both the criterion of popularity and mass appeal are taken into consideration.

What is imparted by the mass media is intended to be popular in two senses: presented in a way that is attractive to many and thus intelligible to everyone, and, at the same time, of interest to a mass audience. On account of this dual criterion of selection and presentation the productions of the press, radio and television are 
synonymous with what is usually called popular culture and mass culture. "If the culture industry refers to the production aspect . . ., mass culture refers to the reception aspect. Mass culture is the subjectivity that is undermined . . . by the culture industry, an inter-subjectivity that tends to be deprived of its communicative potential"' (Lövenich 1987, p. 85).

Thus the negative aspect of the relationship between mass communication and culture meant by the critical concept of the culture industry has been more closely identified. For today, following on Horkheimer and Adorno's analyses (Kausch 1988), it is thematised by that apocalyptic (Eco 1984) media criticism which puts the cause for the disastrous decline of culture in post-modernity down to the rapid increase in and the spread of electronic entertainment, to the reception of its trivial presentation patterns and emotionally charged stereotypes of presentation. The triumphant advance of the multimedial telecommunication systems, which are today organised on the level of large expanding, monopolistic and transnational companies, the triumphal advance of this "transnational corporative culture machine" (Schiller 1989, p. 784) is made responsible for the primary loss of experience, for the passivity and apathy of the audience, for the escapism and the decline in fantasy of the first TV generation, and, in the end, for the complete "disappearance of childhood" (Postman 1983), even for the privatistic amusement in front of the television screen resulting in psychological death (Postman 1985). Over and beyond this, the suppression of the culture of oral and written communication by the picture-sound culture, the electronic mixtum compositum, is considered to be the chief cause of the "decline of logocentred narrative structures", and thus for the "radical changes in the mode of cultural reproduction in western societies" in general (Schulte-Sasse 1988, p. 433 f.).

If one disregards the pejorative connotation of the term mass and popular culture, which is not easy in view of the alarming qualitative standard of the overwhelming part of the culture industry's products on the world market of cultural production and distribution, one comes across a more far-reaching link between communication and culture. It implies an aspect that goes more deeply into giving the reasons why media research is bound to move into the horizon of culture-sociological research which does not cut itself off from these global changes in the structure of culture. For communication, whose prototypical and developed elementary shape comes about through the medium of language, not only influences the subjects' identity-forming process (Lüscher 1982), but constitutively refers to culture. Communication on the basis of linguistic and other non-linguistic symbolic forms of expression, presentation and meaning (Cassirer 1960, p. $152 \mathrm{ff}$.) is a cultural achievement and at the same time the condition for the possibility of culture. Conversely, culture, which in the abstract can be understood as a complex structure of symbolic contents of meaning and sense, is nothing other than sedimented communication (Leach 1978). The symbolic contents of meaning and sense have their 
origin in communicative acts of understanding and are related to communication, inasfar as "the complex linkage of processes in a culture (imparts) information to those involved in them" (ibid., p. 8).

\section{Culture and society}

This first explanatory step of media research as culture research, which has drawn attention to the fact of culture-industrial production and to the close connection between culture and communication, requires a second step to clarify the relationship between culture and society. For only then does the postulated culturesociological access to the mass media and their productions become plausible, and this has not only consequences with regard to determining the subject of media and communication research, but also concerning its specific methods.

What is culture more precisely, the communicative qualities of which have already been mentioned? As an autonomous and integral part of society it is an external and internal orientation framework of individuals in the process of social acts. This orientation framework or the cultural structure of sense contains not only cognitive but also normative and expressive interpretation schemes (Rosengren 1984). They assume real shape in speech, in texts or actions, in institutions or ideas, in events or feelings. According to this way of understanding culture, it is a complex "of meanings which occur in a symbolic guise, . . . a system with the help of which people impart, receive and further develop their knowledge" (Geertz 1987, p. 46). Culture is the entirety of symbolic forms, which include, in addition to language as the primary form, for example art, science, law, religion, economy. Here the symbolic is the sphere of those acitivities "through which man organises his own experiences into a system of contents which corresponds to a system of expression. The symbolic is the activity through which experience is not only coordinated but also communicated"' (Eco 1985, p. 199). The culture differentiated in societies describes the "stock of knowledge", incorporated in symbolic forms, "from which the communication participants provide themselves with interpretations by agreeing on something among themselves" (Habermas 1988, p. $96 \mathrm{f}$.). By updating these interpretation schemes in linguistically imparted interactions in practical everyday life they contribute to the change and expansion of cultural stocks. Culture as the symbolic sphere of a more or less institutionalised external structure of sense is transformed in the process of everyday acts by the subjects into an internal orientation scheme, by their being socialised in societies and made familiar with their stock of knowledge. This process of socialisation through which individuals develop into subjects capable of language and actions, acquire action competences, is controlled by socialisation agencies, which include not only family, school, peer group but also the different media of mass commu- 
nication. Their significance, especially that of television and of the so-called new media, has grown to an increasing extent worldwide in the last few decades. This is demonstrated, on the one hand, by the rising time budget for everyday media consumption (Television and Behavior 1982) and, on the other, by the diversification and expansion of the audiovisual media in modern industrial societies, in which "a change from a reading or writing culture to a visually-orientated, telecommunicative culture", is taking place (Schulte-Sasse 1988, p. 435). From functional points of view the mass media are institutions of social integration, i.e. they familiarise the adoloscent and adult subjects with the cognitive, normative and evaluative standards of society valid at a given time and introduce them into the sociocultural context of the symbolic. It goes without saying that the developed mass media, which represent a differentiated system, while performing these socialisation functions, make use of textual, visual and acoustic forms of imparting the symbolic which are specifically orientated to target groups.

If now; against the background of this attempt above to provide clarification, we return to the relationship between culture and society, it becomes obvious that the term culture that has been introduced implies an "extension of the concept of sociality" (Knorr-Cetina/Grathoff 1988, p. 29). Its systematic value as a demarcation from the term society as a system consists in the fact that it brings out the principal communicative mediation and symbolic prestructured nature of social acts. Sociation is a cultural process which must be thought of as understanding sense by the use of symbols and language. Here it is to be assumed that the subjects always find themselves in societies as in a life-world symbolically prestructured for them. The intersubjective relationship in the social context has the same origin as the use of symbolic expressions through subjects capable of acts and language. What is important for a culture-sociological media research at this point on account of their methodological consequences resulting from the logic of the subject is to emphasise the following fact: the cultural sphere of the symbolic forms of expression, presentation and meaning constitutes a reality in its own right.

A third step in the argumentation follows from this premise after placing mass communication in the symbolically structured sphere of culture: communication research which takes the fact seriously that mass media are effective as a factor for distributing knowledge, for imparting a society's symbolic order, must be conceptualised as culture sociology and the latter more precisely as symbol analysis. A "culture analysis" developed from this culture-sociological research perspective "not only presupposes social reality is symbolically constituted, it turns it into a specific interest of the culture-analytical perspective" (Knorr-Cetina/Grathoff 1988, p. 30).

This two-fold attempt to specify that the subject of sociological culture analysis 
is "culture as the symbolically constituted form of life" (ibid., p. 29) and the mass media themselves are located in the symbolic order and are functionally related to their cultural shape, provides central reasons for establishing communication research as symbol analysis, something that hitherto has been based on arguments that have tried to throw light on the concept of the specific nature of the object area of communication research - the cultural forms of expression of the communicative in society. But defining communication research in this way at first gives rise to more problems than it solves. For it gives rise to the methodological question of empirically and practically conducting culture-sociological communication research as symbol analysis. Media research itself, with its customary instruments of analyses of contents, effects and reception, has little to offer for the practical solution to this problem of methods, for it works on a completely different reference level in its basic theory orientated to the conventional research tradition, a deductive-causal, functionalistic way of explaining things. As a "normative paradigm" it principally differs from the "interpretative paradigm" (Wilson 1973) in that here the starting point is not a stimulus-response behaviour but meaningful social actions, i.e. the active role of individuals who interpret their social world and who act within the framework of this meaning-attribution. In sociology, especially in the culture sociology of Pierre Bourdieu, but also in the action theory of Jürgen Habermas, in the genetic structuralism of Ulrich Oevermann and in the psychoanalytical interaction theory of Alfred Lorenzer the concept of symbolic reality or of the textuality of social reality plays a central role. The theoretical work preparing symbol and text concepts in sociology, however, differs to the same extent as the methodological conclusions diverge which are deduced in practical research more or less concretely from the focal point of the analysis of the symbolic. In one point these sociological concepts for explanation agree, however: the analysis of the symbolic presupposes an interpretatively understanding, reconstructively interpretative methodology, because the symbolic reality is itself meaningful. The meaning of a word or a sentence is regarded as a fundamental pattern of such a symbolically fixed and culturally incorporated meaning. The relationship between linguistic expressions and the meaning they symbolise can be comprehended with the aid of specific methods of hermeneutic analysis in the light of its "culture meaning" (Weber 1982, p. 182): the cultural shape of what is social is principally based on sense, which can be reconstructively inferred by means of understanding through interpretation with regard to its meaning, its culture meaning.

Against the background of this emphasis on the interpretative paradigm the quintessence of the above considerations should be set down: the social communication processes of a verbal and nonverbal kind are thus central parts of this symbolic reality, which sociological hermeneutics endeavours to understand through interpretation. On the culture-industrial level of mediation by the mass media as well, meaningful processes are certainly involved. 
The above-mentioned sociological concepts which have the sense structure of the symbolic as their point of departure do, it is true, provide essential impulses for an interpretative method of research into culture sociology which is appropriate to the specific nature of its subject area as a symbolical-meaningfully structured reality. But the analysis strategies deduced from the various hermeneutic conceptions, inasfar as they reach this stage of concretisation at all, must first be integrated to form a uniform model of the understanding of meaning. Which path to such an integration for a culture-sociological communication research can be pursued is to be discussed according to a sketch of those hermeneutic concepts in sociology which, in spite of all the differences, take the matter seriously that "the sense sedimented in their symbolic contexts and self-interpretations . . . (opens itself up) to the understanding access of the interpretation alone"' (Habermas 1988, p. 84).

Only those sociological concepts which do not stop solipsistically at the individual being, the human being as "Homo cultura" or "Animal symbolicum" will analytically do justice to this cultural mediation of what is societal through symbolisation and language - to its culture meaning. For the meaningfulness admitted into language is related to the intersubjectivity of speech, to communication by dialogue, to communicative action practice, which in its turn points to a generality: on the one hand, to the base rule of precisely this language dependence, on the other, to the historically cultural background of the tradition of a symbolic universe. The system of common significant symbols is based on a given system of rules and moves into the horizon of sense of social reality by dint of symbolically and colloquially mediated acts as a continued interaction process.

\section{The structure of the symbolic as text reality}

The conditional relationship between the multifariousness of the sense symbolised in the social world, the cultural meanings manifesting themselves in symbolic forms and the base rules with the speech acts determined by them and which they determine is reduced by Ulrich Oevermann to the instructive formula that social reality is principally textual and "on account of its textual form . . . always describes itself"' (1986, p. 81). This idea of textuality emphasises the fact that social reality is accessible to us only in its symbolically structured form or speech state. Oevermann takes as his starting point a strict division between two levels of reality: the reality of the objective "sense structures of the text", which is of primary importance for sociological analysis, as a level of possible meanings, and the secondary reality of "subjectively intentionally represented meanings of the text". The structural logic has absolute priority in the validity of the text's form of expression - and its hermeneutic analysis. The universal, generative rules which 
take effect as the text's case-specific laws of structure and are based on the latent sense structures are restricted - according to Oevermann - to "grammaticality, logicity, morality, reasonableness" (1981, p. 12). Texts are material vehicles of sense structures. The social content is objectified in them. Social reality is constituted like $a$ text, in which all the rules of a society's meaning constitution are inherent and which writes itself of its own accord, as it were, in the process of social interactions.

Now what is the gain in knowledge of this sociologically expanded text concept?

A sociologically defined text concept aims at making the symbolic aspect of the social terminologically comprehensible as a given fact of structure. This first thesis is followed by another thesis: one and only one symbolic form for meanings is the text and the word language referred to it. It is true that the language's system of rules and its textual form are fundamental symbol systems in which the meaning function is paramount, a phylogenetically and ontogenetically developed, rational meaning mode of the symbolic. Thus language makes it possible not only to "articulate the objective meaning of human interaction", but the symbol organisation of language, according to Oevermann, ensures "context independence par excellence" (Oevermann 1979, p. 430). But the expression and presentation dimensions of the symbolic, already brought up by Ernst Cassirer, which supplement the meaning dimension by no means become apparent in the rational medium of the language and of the text, its discursive meaning function. But, rather, the semiotics of the symbolic order goes beyond the language and text medium, and linguistic signs are only a "special case" of signification (Eco 1987). The decisive insight of Cassirer's symbol theory consists precisely in its crossing the narrow limits of the relation to language understanding and textuality: the language and the text form is only one possibility of symbolisation. Not only verbal utterances on the basis of textual structural logic are valid as a symbolic means of rational understanding but also the ways of articulation fundamental for visual and auditive communication processes, for example, in the form of pictures, sounds and physical gestures. So it is consistent that the American cultural anthropologist Clifford Geertz (1987, p. 253), following on the French phenomenologist Paul Ricoeur (1969, p. 34), pleads for an extension of the concept of the text. They thus find themselves in complete harmony with Oevermann's genetic structuralism. Admittedly, this understanding comes to an end at the moment when both, in agreement with Dan Sperber $(1975$, p. 17) and against any kind of language centrism, insist on a freeing the text from its reduction to language logic and structure laws.

Oevermann assumes that there is a possibility in principle of transforming the non-verbal ways of articulation of the symbolic into language, of converting them into text form and thus making them discursively accessible. Here it has to be ta- 
ken into account that it is "not the language symbols themselves but the interactions in their entire materiality which constitute the meaning content' (1979, p. 430). It is true that Oevermann emphasises with regard to works of art their "constitutive relatedness to the sensual presence of the material of expression and the non-reduceability to another . . . materiality of expression" (1986, p. 79). But an expression of this kind prelinguistically realised can nevertheless be expressed in language in its objective meaning structure. "Expressed in language means . . . only a different realisation of what . . . was constituted by language anyway" (ibid.). In a very similar way Cassirer in his philosophy of human culture and also Arnold Gehlen in his anthropology $(1970$, p. $240 \mathrm{ff}$.) have pointed out the meaning quality of language as the highest level of development of the symbolic which is attained in the history of language after the "mimetic" and "analogical" stage. But when both insist that the symbolic consists not only of discursive language components, but that these are only one form in which "symbolic pregnancy" appears, are one symbolic form with particular nuances of the qualities of expression, presentation and meaning (Cassirer 1960, p. 152), then attention is thus drawn to complementary qualities of the symbolic. In the case of the fully developed language their conceptually discursive meaning function is undoubtedly of major importance. Nevertheless, the pictorial, non-verbal presentation and expression function of the symbol system is retained as the sphere of sense understanding. Susanne K. Langer, following on Cassirer, has distinguished between the discursivity of verbal symbolism and presentative symbolics as an independent type of semantics (1965). The visual and acoustic objectivations of culture contain first and foremost such presentative qualities of presentation and expression. Inasfar as language is a specific phenomenon of the use of signs and imparting sense, the symbolic cultural activity takes place primarily, it is true, in the discursive medium, but it also contains presentative parts. Only recently Anthony Giddens has come out against an abbreviated concept of sense and meaning in sociology by conceptually differentiating between symbolic orders and discursive ways, which both constitute the cultural aspects of social systems. He points out in this connection the symbol's own "surpluses of meaning which are contained in the polyvalent character of the signs"' (1988, p. 86).

This symbol-theoretical expansion of the cultural facts of communication and textual form of the social mediated by language makes it possible to overcome structuralistic or language-rationalistic one-sidednesses, which are common to the conceptualisation of text and language both by Ulrich Oevermann and by Jürgen Habermas. Despite all the divergences of the two authors they share the fixation on the regular or discursive meaning function of the text and language forms of social reality. "Making this preliminary assumption, the status of non-significantgestic" interaction in social intercourse can no longer be adequately defined (Busch 1985, p. 210 and 1988). 


\section{The non-linguistic as a form of decline}

In his theory of linguistic communication, which Jürgen Habermas has conceptually developed on the basis of "fundamental norms of possible speech" in the last two decades (1971, p. 141), he concedes, it is true, on the one hand, symbolic forms of presentation and expression of a non-lingusitic nature which belong to a genetically older phase and which as body-bound expressions are emotionally charged and context-dependent to a high degree; they lose their inherent sense when they are transformed into language or adapted to their grammatical logic. To this extent Habermas recognises their meaning quality and admits that "the palaeosymbolically-bound meaning potential . . . in creative language usage (is) publicly made up for and made available for a grammatically regulated use of symbols " $(1982$, p. 355). On the other hand, this extension of symbolic possibilities of expression, presentation and meaning remains tied after all to the specific medium of linguistic discursivity. For, according to Habermas, it is solely understanding-orientated actions that set off the process of the symbolic reproduction of a society which moves within the three dimensions of cultural transmissions, of social integration and individual socialisation.

Texts in the sense of the extended definition of the concept explained at the beginning are sediments of language acts or of understanding-actions. Basically three meaning-components of the same origin come to fruititon in them: apart from the literal message on factual matters, they contain intentions and finally interpersonal modes of reference. What is "meant" in the text and the "way it is used in the act of speaking" combines with what is "said" and represented in the text (Habermas 1988a, p. 77 and 106). When accordingly, apart from the semantic messages of texts, the intentions and the normative contents incorporated in them, when apart from the propositional constituents their performative sense is to be analysed, then there is indeed a need for a specially developed type of interpretation that understands the sense, for a specific "methodological effort" (ibid., p. 91). Habermas outlines this methodological effort admittedly only in the context of his explanations of the pragmatic extension of the meaning-theory, but not with the concrete prospect of applying it to practical research in culture sociology.

He takes as his point of departure the systematic linkage of questions of meaning and validity (1981, p. $158 \mathrm{ff}$.). He insists in principle on hermeneutics as a rational interpretation; its aim consists in understanding the sense as a communicative experience, in opening up meaning from the inner perspective of the sense context of a life-world. Understanding a text sociologically means to take part intersubjectively and discursively in producing that life-world context which represents the space-time apriori of social scientific subject areas. In this form of sociological sense understanding the decisive first step is the "presupposition analysis", which 
is carried out on the basis of formal pragmatics. With its help the life-world background should, in the methodological attitude of the sociological researcher, be reconstructed as the "depth layer of unthematic knowledge, that background against which meanings as such can be opened up from a participant's perspective and be assessed as true, right or truthful. When the interpreter of a speech act or a text in the performative attitude of a virtual interaction participant comprehends under which contextual conditions it can be accepted as valid, its meaning opens up to him. Understanding a text aims at examining what makes it acceptable, it being possible to assess the acceptability according to the reason for the validity of the truth, rightness or truthfulness $(1981,1$, p. $190 \mathrm{ff} ., 1983$, p. 39 ff.). In the next step of the analysis it is for Habermas a question of clarifying the pragmatic and semantic prerequisites by explaining the "horizon of situated knowledge" and the "subject-dependent context knowledge" (1988a, p. 89).

As Habermas supposes that the understanding-orientated acts, which are essential for the symbolic reproduction of the horizon of intersubjectively shared background assumptions, have a rational internal structure, sociological sense-understanding must be carried out as a rational interpretation. A review of Habermas's diverse remarks on hermeneutics and interpretative social research give rise to the impression that he oscillates irresolutely between recognising the hidden but indisputably communicative sense of the palaeosymbols and capitulating before the separately individualistic, paradoxically unusual use of the signs of grammatically symbolic articulation modes out of a "wild way of thinking" which have not already been flattened out (Lévi-Strauss). The use of signs by the wild way of thinking as one meaningful form of interpreting the world recognised as valid - also by Habermas - only becomes accessible to the pragmatic theory of meaning when not only the semantic function of language but also the presentation and expression form of representative symbolics is systematically taken into consideration in it. On the other hand, everything that is non-verbal, whose real existence Habermas by no means denies, is, in the last analysis, a prefigurative or degenerative form of discursive symbolisation and as such a palaeosymbol or desymbolisation: the semantic contents of non-verbal expression is at bottom principally of a verbal nature and, according to Habermas, refers to language (1984, p. 12, p. 501 ff.). Sense only exists as verbal sense.

Centring sense understanding in this way on the rational language elements of the symbolic (cf. 1981, I, p. 197) ignores the "meaning of the expression model of acts"' (Joas 1988, p. 279), centring on language in this way disregards the production of social sense by gestic communication, rules out the motivational meaning of significant gestures and other non-verbal expressions in the action text; because of their non-linguistic, merely presentative-visual symbol quality they are regarded as particularistic and as an epiphenomenon. For this reason it can rightly be held 
against Habermas's language paradigm that, in addition to neglecting bodily-physical dimensions of social acts and their sediments, it suppresses the visual as well as the musical-acoustic ways of presenting and expressing symbolically prestructured reality (cf. Honneth 1984, p. 310). Thus Habermas, however, leaves unused, from the beginning, possibilities of interpreting a sense-understanding analysis.

In the theory of communicative acts he responds to this shortcoming by introducing a "subjective world as the totality of experiences to which, in each case, only one individual has a privileged access"' (1981, I, p. 84). But the expressive dimension of interactions and their objectivation only attains the level of symbolisation, according to Habermas, when the symbolic forms of expressing inner experiences are constituted according to the rules of understanding-orientated, argumentative speech, so that then they can be judged by the validity reason of truthfulness or authenticity. Consequently, expressive forms of expression, experience sentences, must be measured by the yardstick of consensus-rational validity claims just like assertory statements about the world of existing matters of fact and normative statements about the world of legitimately regulated personal relations. If a sense content hidden in the pictorialness of the symbolic is thus to be explained through the criterion of the truthfulness or authenticity of expressions, a grammatical rightness and linguistic logic is pretended for this expression quality, although it is dubious whether it is at all appropriate for it. It is implicitly supposed that a culture-sociological analysis of, for example, the world of pictures and of its primary presentative-visual symbolics can be deduced directly from the methodology of understanding verbally communicated interactions.

It has to be asked, however, whether the symbolisation, for example in dream occurrences through "condensing" and "shifting", as well as analogous aesthetically alienating presentations in art and the manipulative techniques in popular culture, but also the unconsciously conditioned, ambiguous and equivocal sign formations hidden under the syntactical, semantic and pragmatic language layer and customs of speech, and, finally, what is unspeakable but capable of symbolisation, whether all these expression qualities can be analytically opened up at all as negative deviations from the normative model of argumentative speech. In this perspective the empirically extremely topical question of mass communication research, for example, remains excluded, namely whether, complementary with the shifting of "production from the area of material goods to that of symbolic goods" (Touraine 1986, p. 23), a tendency to delinguify the symbolic can be detected in the course of a growing visualisation of the socio-cultural sphere through popular culture and the post-industrial information and communication technological development dynamics. It is here a matter of answering the question raised at the beginning as to which consequences result from this trend of a kind of nonnarrative, non-linguistic communication reduced to visual set pieces and sign par- 
ticles for the identity of language and identity, for the interaction and communication relations, for the mode of social integration.. These questions are only accessible to in-depth research in culture and media sociology when the non-linguistic presentative aspect of the culture of symbolic forms of mediation are not ignored, but these visual materials are looked at with regard to their cognitive and psycho-social impact (Kuhns 1986).

\section{Depth hermeneutics}

With reference to these complexes of problems Alfred Lorenzer's psychoanalytical theorem of "desymbolisation" offers a useful terminological frame of reference. He calls the mutilation of the symbol "desymbolisation". Such desymbolised representatives are "degraded to clichés and are eliminated from the language", but nevertheless exercise a behaviour-regulating function as clichés (1971, p. 38). His psychoanalytically supplemented action theory with the basic categories symbol, interaction and practice (Lorenzer 1977) claims to make the sensual-bodily components, the affective expression gestures of symbolically conveyed interaction forms, accessible to sense understanding. Thus the research programme of depth hermeneutics as the methodological means of scenic understanding furnishes pioneering arguments for a two-dimensional, namely language and picture hermeneutical, culture analysis. It, too, is centred around the symbolic as a subject definition of the social and takes as its starting point - inspired above all by Freud's "Interpretation of Dreams", his distinction between dream thoughts and dream content - the premise of an interplay between the manifest meaning level (discursive-denotative), which is presented in language, and the latent sense level (scenic-pictorial), which is presented in pictures: every "text lives from the ambiguity of the text's sense. Manifest-latent, they are the two aspects of a symbol connection which can be separated from one another" (1986, p. 57).

Lorenzer's "Hermeneutics of the Body" (1988b) adopts the view that the concealed traces of the unconscious (instinct representatives) are, it is true, effective sediments of the symbolic, but "the unconscious is what is removed from language" (ibid., p. 848), is therefore a sign-like means of representing symbolic reality. To decipher hermeneutically these unconscious, verbally unformed, but symbolically coagulated sense substances (scenes) an understanding interpretation process is necessary which advances from the obviously discursive language figures and their semantic contents to the latent layer of picture writing, those sensual symbolic expression forms, as far as the unconscious forms of practice. This depth hermeneutics in the sense of a "deciphering of the unconscious meaning of a text" (1986, p. 26) is seen as "scenic deciphering of the pictures which are written into the symbolic forms to a varying extent and scope and are expressed as visual signs. 


\section{The unconscious as habitualised historicity}

Pierre Bourdieu, in his dispute with Erwin Panofsky's method of art history, expressly refers to the structural complexity and diversity in the socio-cultural world of the symbolic by availing himself methodologically of Panofsky's differentiation between a primary sense layer with the two dimensions "factual sense" and "expression sense" and a secondary sense layer.

Panofsky does indeed lay the foundation for a general method of culture analysis which cuts across the disciplinary borders of the science of art and which is appropriate to the complex symbolic form, the polymorphia of the meaning levels of cultural objectivations. Panofsky's method of proceeding first covers not only the factual meaning but also the expressive sense contents, for example of picture materials. This iconographical method of access then aims at revealing the metaphorical way of shaping picture components as a historically coagulated, conventionally characterised visual form of presentation. Over and beyond this, it is the aim to decipher the depth structure of the particular cultural meaning objectivation in corresponding relationship to other cultural objectivations. Here Panofsky is speaking of the method of iconoloy as an addition to iconography. This is a kind of multi-methodological-interdisciplinary synthesis of meanings. It allows the special message contents in each case to be understood as elements of the overall cultural process: as "a symptom of something different which articulates itself in an immense variety of other symbols" (1978, p. 41).

Bourdieu's principal methodological interest focuses on the depth layer of the symbolic that is to be fathomed iconographically and iconologically, a knowledge of which is the prerequisite for the interpretation of the formal and expressive surface structure. He assumes that all experiences of the social world are mediated basically symbolically. Social perception results, on the one hand, from the structure context of the economic, social and cultural constellation and, on the other, from the implicit and explicit influencing of the symbolic order: from the "state of the symbolic relations of force"' $(1985, \mathrm{p} .16)$. The symbolic order is not constituted by the grammar of its textual form and the universal validity of rules of intersubjective understanding alone, but what is decisive about it is the non-verbal symbolic practice and expression forms located below the surface structure, routinised gestures, body postures etc. This lower layer of meaning of the symbolic is first opened up with the help of the habitus concept taken over by Panofsky and worked out theoretically and tested empirically by Bourdieu, a term he uses as an explicative principle. The habitus as a system of dispositions, "as a system of internalised patterns ..., which allow all the typical thoughts, perceptions and acts of a culture to be produced"' (1974, p. 143), unconsciously connects the social actor acting symbolically and at the same time orientating himself to symbols with 
the historical totality of an objective structure context. The depth structure of the socially highly differing culture of symbolic life forms is the result of the habitus: the depth structure is incorporated into the habitus by the continuous process of social interactions. At the same time, "this generative grammar of action patterns" (ibid., p. 150) guides the orientation achievements and interaction processes. Accordingly the habitus concept as a category of structure, structuring and mediating practically explains "the solution of the paradox of objective sense without subjective intention" (1981, p. 170). The unconscious schemes of thought, perception and actions of the habitus correspond with unconscious depth structures of the symbol system. This mediation between the culture of the symbolic and the social action practice is called unconscious by Bourdieu because through this mediation what has historically sedimented is created in the form of cultural things we take for granted and practical life-styles. Accordingly Bourdieu (similar to Oevermann and Habermas) also uses the concept of the unconscious 'purged' of psychoanalytical connections. It is not characterised by its own instinctdynamic weight but its historic constitution.

\section{Stimulation potentials}

The extremely elaborate reconstruction methodology of structure-genetic hermeneutics contributes to interpretatively revealing the textuality of social reality in concepts of its latent sense structure. Correspondingly, the culture-sociological and communication-sociological research is encouraged, on the basis of this method of reconstructing the meaning tested in practical research, to take the level of the text, its inner structure of rules, as the starting point of hermeneutic analyses in order to decipher in this way the "how" of the coding of social reality. Through practical research resorting to the latency of text structures that guide actions using the method of the sequential fine analysis of text material of the concrete case available in the form of an interaction sequence, the sense structures are revealed which determine the process of interaction sense-logically. Here, in thought experiments a large number of context types are first constructed which are in harmony with the latent sense structure of the action text in order to determine in this way the normal type of everyday action appropriate to the situation. Through this procedure the scope of possible meanings of the action text is successively restricted in order then to completely decipher the latent sense of the sequence with the aid of an abductive conclusion by the researcher as "a distanced third person".

The methodology of the rational reconstruction by Habermas shifts the culture of symbolic mediation into the research horizon of the theory of communicative actions inasfar as the symbolic has assumed the rationality form of propositional 
and at the same time illocutionary speech acts. On the basis of concentrating the analysis on the semantic and pragmatic symbol form of language, on the basic modes of language use, Habermas makes generalisable principles of senseunderstanding culture analysis plausible. They can be derived from the premise that the socio-cultural reality of the symbolic can "only be opened up from within" (1981,I, p. 165 and 1988, p. 84). Taking this as a starting point is admittedly to seek for methodologically feasible ways of how sense understanding can be transferred "as communicative experience" or as participation in the process of understanding in practical research . In this connection the action-theoretical model of the validity reasons with the criteria of propositional truth, the normative rightness and the authenticity or truthfulness is able to provide central criteria of interpretation. On this foil cultural objectivations can "be criticised as invalid from three points of view: as untrue with regard to a statement made (or the existence presupposition of the contents of the statement); as incorrect with regard to the existing normative contexts (or the legitimacy of the presupposed norms); and as untruthful with regard to the speaker's intention" (1988a, p. 79). If the meaning of the culture of symbolic forms of mediation is to be opened up according to these criteria of assessment, such a comprehensive sense understanding presupposes, however, that the researcher makes the overall socio-cultural context of symbolic forms accessible to himself, on the one hand, by interpretative comparative analysis of their internal components and, on the other, of their constellation in the totality of a historical interval of space and time.

It is precisely this complex objective that the Bourdieu's cultur-sociological research work has adopted. Measured by the breadth of the theoretical reflections and categorial clarifications the statements on the methods turn out, however, to be relatively brief. Bourdieu only refers explicitly to the methods of ethnographical observation, the intensive interview and the analysis of correspondence. All the data material collected is subjected to the latter, because it is, he says, best suited "to gaining control of the totality of the observations and laying open their structures without imposing any presuppositions on the material" (1982, p. 403). Moreover, the concept of symbolic power in conjunction with the menatalityhistorical category of the habitus inspires the culture-sociological symbol analysis in two respects. On the one hand, Bourdieu leaves no doubt that the analysis of the culture of symbolic mediations, also in the perspective of power sociology, class specifics and sex specifics, must be carried out as a system of rules, as the performance of interpretation patterns. On the other hand, he convincingly integrates the socio- and psycho-historical dimension of the particular culture recognised as legitimate of symbolic self-representation into culture-sociological research. Compared with Oevermann's static text concept and Habermas's discursive language concept, Bourdieu introduces new features inasfar as he, firstly, directs his attention towards the social disputes on the political production of the 
symbolic, the public control of the symbolic sphere, and, secondly, thematises the space-time plane of the underlying historicity of the symbolic. The generative action grammar of the habitus is, for its part, characterised by historicity and determined by variation in time and space; it is nothing else but the absorption of collective history. This history is not simply the history of culture in the sense of a change in the symbolic ways of perception and interpretation, but the cultural life forms represent symbolic power through the regulatively effective definition of what has to be regarded as legitimate culture. He thus methodologically recalls the dynamic aspect of the historical change, which does not seem to be systematically worked out either in Oevermann's theory of the transformation laws or in the concept of universal rules of argumentative speech.

\section{Constellation research}

The above discussions of the methodological potential of the various positions of sense understanding in sociology have their constructive yield in the fact that they can be used productively for the model of a culture-sociological hermeneutics. The term constellation research is suggested for this culture-sociological research programme (Englisch 1989). This term is not introduced with any claim to have created a terminological neologism. On the contrary, it arouses quite definite associations, which in itself make it necessary to explain what is meant by it, because they cannot by any means be directly connected with the methodological justification programmes of Oevermann, Habermas, Lorenzer and Bourdieu discussed above. There are, nevertheless, interesting connection lines (Bonss 1982 and 1983, Uhle 1984) between the - as we maintain, complementary - sociological hermeneutic concepts and the aim of understanding object knowledge as "unreduced experience", which Theodor W. Adorno characterised as utopian, one of his main reasons being that he wanted to make it clear without any illusions that this form of sense understanding constituted a tremendous challenge to social research. Adorno describes this utopian knowledge aim in the introduction to "Negative Dialectics" in abstract terms as an attempt "to open up with concepts what is without concepts without making the one equal to the other" $(1966, \mathrm{p}$. 19). In the second part of his main work this "Utopia of Knowledge" is described more precisely by being reduced to the term "constellation" (ibid., p. $162 \mathrm{ff}$.) by recourse to Max Weber's principle of sociological understanding through the formation of ideal types. By this is meant a (non-classifying) understanding of individual phenomena which immerses itself in the object, is immanent. This understanding is obtained from the confrontation of the individual object of study with the totality of its reference context. More precisely it is a matter of making what is specific about the singular understandable from the constellation of the overall phenome- 
na of the object: it has to be deciphered by a two-fold 'comparative' analysis: 1. by analysing the meaning and sense elements inside the text of the cultural objectivation, 2 . by analysing their contextual connection with the totality of the selected area phenomenon. In terms of practical research this is undoubtedly a constructive or reconstructive act. For this reason Adorno calls for methods which allow the researcher to think in models, so that at the end of the material research process he can establish an "ensemble of model analyses" (ibid., p. 37). By connecting the micrological analysis of the object's structure in its presence and latency, the "interiorisation", with the horizon of the meaning totality in which the text appears, the historicity of the object analysed becomes, according to Adorno, evident, for "to become aware of the constellation in which the matter is located is tantamount to deciphering that one which it contains as what has arisen historically within itself'' (1966, p. 163).

From this - for Adorno's theory of knowledge central - thought of setting up constellations, of model analyses and their constrasting combination there emerge methodological impulses (Thyen 1989) for a generalisable empirical method of culture-sociological analysis, for which the above-mentioned term constellation research is proposed. Constellation research implies a methodology which relates to a selected total area of the culture of symbolic mediation forms. At the same time it analyses a constellation of variation forms within the cultural sector that is studied. For example, the different political ways of presenting the news in press, radio, television etc. With the aid of the contrasting technique originally introduced by Glaser and Strauss (1973, 1984, p. 97 ff.) as a qualitative research procedure and by forming multiple comparative groups, by confronting the material with itself, the insight can be deepened into an object's meaning-creating whole (e.g. the political culture of publicly providing information through the various types of press - popular papers, local press, serious national dailies, weeklies, the various public service and commercial radio and television stations, magazines and so on). Analogous with the "configurational analysis" of Norbert Elias (1965), the procedure of constellation research aims to link interpretations on the basis of individual observations to form a complex of interpretations which has a strong message in order thus to arrive at an overall interpretation of the phenomenon area (e.g. political culture of a country). Apart from this "context research" (Knorr-Cetina/Grathoff 1988, p. 33), setting up constellations in this way aims at methods of individual model analyses which take into account the inherent differentiation of the elements of expression, presentation and meaning of the symbolic. At the same time it makes it possible to look into the correspondence between the surface structure of the manifest structure of the meaning and depth of latent sense contents, and examines these analyses of individual cases by contextual back reference to the socio-cultural overall context of the symbolic order which successively crystallises by recording individual phenomena. 
The decisive first preliminary phase of the analysis of those complex meaning and sense dimensions of individual phenomena of symbolic reality consists in the method of constellating. To this end a meaningful cultural objectivation is made accessible through the systematic recording of a body of individual examples or generic types, proceeding according to the principle of selecting feature vehicles of a period of time for a study according to an operationalisable criterion, for example that of social presence and relevance. The constellation thus obtained is, so to speak, "the field of force . . . through which things are charged with meaning" (Bude 1989, p. 11). For precisely this reason the constellation is the actual key to the subsequent interpretation process, which comprises two further phases of analysis. The first main phase contains the detailed structure analysis of the examples of a class of features with the aid of a hermeneutic procedure which avails itself of the methodological insights and empirical procedures of concepts based on language analysis and psychoanalysis as well as the habitus theory. This step in the procedure in continuation of the constellation research extends, firstly, to the internal rule-based structure laws of the symbolic as a meaning level of latency; secondly, it focuses on the knowledge of the dual structure of aspects of content and relation aspects of the symbolic action texts and interprets them in the perspective of their informative, regulative and expressive validity aspects, their discursive and presentative contents; thirdly, it avails itself of the habitus concept to reveal the historical emergence as well as the dispositive and regulative force of the symbolic order; fourthly, it radicalises the analysis in the direction of psychoanalytical text interpretation and of the depth-hermeneutic permeation of symbolic forms in order to make statements about the corresponding relationship between manifest meaning and latent sense contents.

The research phase that follows this leads from the text and picture hermeneutic case reconstruction back to the constellation, which is now illuminated in the light of the relationing of the individual case analyses "by showing up exactly the many similarities and differences of the various comparative groups" (Glaser/Strauss 1984, p. 97) and thus more clearly indicates their structural pattern: a significant excerpt from culture as a symbol system becomes transparent; the research results thus obtained allow the formation of a theory that is empirically rich in content, i.e. object-related, on the inner and outer mediation connection of the meaning and sense relations on the level of different symbolic, textual and visual ways of presenting reality. By relating the symbolic forms of expression, presentation and meaning contrastively that "typological space" first becomes empirically tangible "in which the individual case develops its typical aspects" (Bude 1988, p. 423). This procedure made valid for culture-sociological research certainly makes a great claim, for it is supposed to furnish culture-sociologically generalisable statements about the "cultural strategies" (Goffman) of a society on the data basis of nonindividual, qualitative principles of inquiry and evaluation. 


\section{References}

Adorno, Theodor W.: Kritik, Frankfurt 1971.

Adorno, Theodor W.: Negative Dialektik, Frankfurt 1966.

Barton, Allan H.; Lazarsfeld, Paul F.: Einige Funktionen von qualitativer Analyse in der

Sozialforschung. In: Hopf, Christel; Weingarten, Elmar (Ed.): Qualitative Sozialforschung, Stuttgart 1984.

Bonß, Wolfgang: Empirie und Dechiffrierung von Wirklichkeiten. In: Friedeburg von,

Ludwig; Habermas, Jürgen (Ed.): Adorno-Konferenz 1983, Frankfurt 1983.

Bonß, Wolfgang: Die Einübung des Tatsachenblicks, Frankfurt 1982.

Bourdieu, Pierre: Die Objektivität des Subjektiven. In: Merkur, 41/1987/5, p. 459

Bourdieu, Pierre: Men and Machines. In: Knorr-Cetina, Karin; Cicourel, Aaron (Ed.): Advances in Social Theory and Methodology, Boston and London 1981. (Zit. n. Müller, Hans-Peter: Kultur, Geschmack und Distinktion. In: KZfSS, Sonderheft Kultur und Gesellschaft, p. 27.)

Bourdieu, Pierre: Sozialer Raum und ,Klassen`, Frankfurt 1985.

Bourdieu, Pierre: Die feinen Unterschiede, Frankfurt 1982.

Bourdieu, Pierre: Zur Soziologie der symbolischen Formen, Frankfurt 1974.

Braun, Hans-Jürg; Holzhey, Helmut; Orth, Ernst Wolfgang (Ed.): Über Ernst Cassirers

Philosophie der symbolischen Formen. Frankfurt 1988.

Brown, Richard Harvey: Society as Text, Chicago and London 1987.

Bude, Heinz: Auflösung des Sozialen? In: Soziale Welt, 1/1988c.

Bude, Heinz: Deutsche Karrieren, Frankfurt 1988a.

Bude, Heinz: Der Fall und die Theorie. In: Gruppendynamik, 19/1988b/1..

Busch, Hans Joachim: Wider die Auflösung von Psychoanalyse in (Sprach-)Soziologie. In:

Belgrad, Jürgen et. al. (Ed.): Sprache - Szene - Unbewußtes, Frankfurt 1988.

Busch, Hans Joachim: Interaktion und innere Natur, Frankfurt 1985.

Cassirer, Ernst: Was ist der Mensch? Philosophie der menschlichen Kultur, Stuttgart 1960. Cassirer, Ernst: Philosophie der symbolischen Formen, 3 vols. 1973-1975.

Eco, Umberto: Semiotik, München 1987.

Eco, Umberto: Semiotik und Philosophie der Sprache, München 1985.

Eco, Umberto: Apokalyptiker und Integrierte. Zur kritischen Kritik der Massenkultur, Frankfurt 1984.

Elias, Norbert: The established and the outsiders, London 1965.

Englisch, Felicitas: „Konstellation" als Leitbegriff kultursoziologischer Forschung - eine Skizze. In: Müller-Doohm, Stefan; Neumann, Klaus (Ed.): Medienforschung und Kulturanalyse, Oldenburg 1989.

Geertz, Clifford: Dichte Beschreibung, Frankfurt 1987.

Gehlen, Arnold: Der Mensch, Frankfurt 1971.

Giddens, Anthony: Die Konstitution der Gesellschaft, Frankfurt 1988.

Glaser, Barney G.; Strauss Anselm L.: Die Entdeckung gegenstandsbezogener Theorie. In:

Hopf, Christel; Weingarten, Elmar (Ed.): Qualitative Sozialforschung, Stuttgart 1984. Glaser, Barney; Strauss, Anselm L.: The discovery of grounded theory, Chicago 1967. Gross, Peter: Ist die Sozialwissenschaft eine Textwissenschaft?. In: Winkler, Peter (Ed.): Methoden der Analyse von Face-to-Face-Situationen, Stuttgart 1981. 
Habermas, Jürgen: Nachmetaphysisches Denken, Frankfurt 1988a.

Habermas, Jürgen (1988b): Die neue Intimität zwischen Politik und Kultur. In: Merkur, $42 / 1988$ b/2, p. 468.

Habermas, Jürgen: Vorstudien und Ergänzungen zur Theorie des kommunikativen Handelns, Frankfurt 1984.

Habermas, Jürgen: Theorie des kommunikativen Handelns, 2 vols., Frankfurt 1981.

Habermas, Jürgen: Zur Logik der Sozialwissenschaften, Frankfurt 1982.

Habermas, Jürgen: Vorbereitende Bemerkungen zu einer Theorie der kommunikativen Kompetenz. In: Habermas, Jürgen; Luhmann, Niklas: Theorie der Gesellschaft oder Sozialtechnologie, Frankfurt 1971.

Heinrich, Klaus: Zur Geistlosigkeit der Universität heute, Oldenburg 1987.

Honneth, Axel: Kritik der Macht, Frankfurt 1985.

Informationszentrum Sozialwissenschaften: Kultur und Gesellschaft, Bonn 1988.

Joas, Hans: Praktische Intersubjektivität, Frankfurt 1980.

Joas, Hans: Die Antinomien des Neofunktionalismus. In: Zeitschrift für Soziologie, 17/1988/4..

Kaemmerling, Ekhard (Ed.): Bildende Kunst als Zeichensystem, Köln 1979.

Kleinspehn, Thomas: Der flüchtige Blick, Reinbek b. Hamburg 1989.

Knorr-Cetina, Karin; Grathoff, Richard: Was ist und was soll Kultursoziologische Forschung?. In: Soeffner, Hans-Georg (Ed.): Soziale Welt, Sonderband 6, Kultur und Alltag, Göttingen 1988.

Kuhns, Richard: Psychoanalytische Theorie der Kunst, Frankfurt 1986.

Langer, Suzanne K.: Philosophie auf neuen Wegen, Frankfurt 1965.

Leach, Edmund: Kultur und Kommunikation. Zur Logik symbolischer Zusammenhänge, Frankfurt 1978.

Lévi-Strauss, Claude: Strukturale Anthropologie I, Frankfurt 1977.

Lövenich, Friedhelm: Integration durch Kultur. In: Ästhetik und Kommunikation, 1987, No. $67 / 68$.

Lorenzer, Alfred: Sozialisationstheorie und die Frage nach dem Unbewußten. In: Bergrad, et al. (Ed.): Sprache - Szene - Unbewußtes, Frankfurt 1988a.

Lorenzer, Alfred: Hermeneutik des Leibes. In: Merkur, 42/1988b/2, p. 475/476.

Lorenzer, Alfred: Tiefenhermeneutische Kulturanalysen. In: Lorenzer, Alfred (Ed.): Kultur-Analysen, Frankfurt 1986.

Lorenzer, Alfred: Sprachspiel und Interaktionsformen, Frankfurt 1977.

Lüscher, Kurt: Medienwirkungen und Gesellschaftsentwicklung. In: Media Perspektiven 9/1982.

Müller-Doohm, Stefan: Soziologie ohne Gesellschaft? Notizen zum Gegenstandsverlust einer Disziplin, Ms, Oldenburg 1988 (printed version in preparation)

Oevermann, Ulrich: Kontroversen über Sinnverstehen der Soziologie. In: Aufenanger, Stefan et. al. (Ed.): Handlung und Sinnstruktur, München 1986.

Oevermann, Ulrich: Beiträge zur Fallrekonstruktion, Ms, Frankfurt 1981.

Oevermann, Ulrich: Zur Sache. In: Friedeberg, Ludwig v.; Habermas, Jürgen (Ed.): Adornokonferenz 1983, Frankfurt 1983.

Oevermann, Ulrich et. al.: Die Methodologie einer objektiven Hermeneutik und ihre allgemeine forschungslogische Bedeutung in den Sozialwissenschaften. In: Soeffner, HansGeorg (Ed.): Interpretative Verfahren in den Sozial- und Textwissenschaften, Stuttgart 1979. 
Panofsky, Erwin: Sinn und Deutung in der bildenden Kunst, Köln 1978.

Postman, Neil: Das Verschwinden der Kindheit, Frankfurt 1983.

Postman, Neil: Wir amüsieren uns zu Tode, Frankfurt 1985.

Ricoeur, Paul: Die Interpretation, Frankfurt 1974.

Schiller, Herbert J.: Disney, Dallas und der elektronische Informationsfluß. Die weltweite

Kommerzialisierung der Kultur. In: Media Perspektiven 12/1988.

Schulte-Sasse, Jochen: Von der schriftlichen zur elektronischen Kultur. Über neue Wechselbeziehungen zwischen Mediengeschichte und Kulturgeschichte. In: Gumbrecht, Hans U1rich; Pfeiffer, K. Ludwig: Materialität der Kommunikation, Frankfurt 1988.

Schluchter, Wolfgang: Gesellschaft und Kultur. In: Schluchter, Wolfgang (Ed.): Verhalten, Handeln, System, Frankfurt 1980.

Sperber, Dan: Über Symbolik, Frankfurt 1974.

Soeffner, Hans-Georg: Interaktion und Interpretation. In: Soeffner, Hans-Georg (Ed.): Interpretative Verfahren in den Sozial- und Textwissenschaften, Stuttgart 1979.

Soeffner, Hans-Georg: Kulturmythos und kulturelle Realitäten. In: Soeffner, Hans-Georg (Ed.): Soziale Welt, Sonderband 6: Kultur und Alltag, Göttingen 1988.

Television and Behavior. Ten Years of Scientific Progress and Implications for the Eighties. 2 vols., National Institute for Mental Health (Ed.), Washington 1982.

Thyen, Anke: Negative Dialektik und Erfahrung. Zur Rationalität des Nichtidentischen bei Adorno, Frankfurt 1989.

Touraine, Alain: Krise und Wandel des sozialen Denkens. In: Berger, Johannes (Ed.): Die Moderne, Soziale Welt, special issue No. 4, 1986.

Uhle, Reinhard: Zur Erschließung von Einzelnem aus Konstellationen. In: Naeher, Jürgen (Ed.): Die Negative Dialektik Adornos, München 1984.

Weiß, Johannes: Kultur als soziale Lebenswelt. In: Soziologische Revue, 4/1981/4. White, Hayen: Auch Klio dichtet oder Die Fiktion des Faktischen, Stuttgart 1986.

Wilson, Thomas P.: Theorie der Interaktion und Modelle soziologischer Erklärung. In: Arbeitsgruppe Bielefelder Soziologen (Ed.): Alltagswissen, Interaktion und gesellschaftliche Wirklichkeit, Opladen 1981. 


\section{Projects and studies}

Ben Bachmair

\section{The function of interpretation and expression in television experience and television symbolism}

\section{The context of the investigation}

In 1982 a teaching project entitled "Space Travel" was carried out in a third year class of nine-year-old boys and girls in a primary school. ${ }^{1}$ This project took the form of an associative "fantasy space", 2 which gave the children, within the context of school, the opportunity to develop group skills and play through their own fantasy stories. On six school mornings, the children made props for the "Space Travel" play. While doing this, they had a lot of time and opportunity for their own thoughts and associations, for casual conversations and for the development of ideas for the play. On the fourth school morning, the individual groups acted out their respective "Space Travel" plays in front of the class, using the props they had made. On the fifth morning, the plays were discussed in class; on the sixth school morning, after a holiday of about three weeks, the children stuck the photos of their play onto the wall.

The purpose of choosing the subject "Space Travel" was to link it with a television series on at the time called "Captain Future". "Captain Future" is a cartoon series in which the shining figure of the space-policemen is threatened by wicked people and evil forces. With the help of a lot of technical equipment which he uses to fight and wage war, he is able to free himself and his crew, even the whole of mankind, from the deadly threat. The series ran throughout the winter, once a week in the late afternoon, at a time well-known to the children for showing cartoons. ${ }^{3}$ 


\section{Subject of inquiry}

From the results of our observations, we intend to select and present those tendencies and developmental patterns discerned in the group, and from these the thematic function of television symbolism and television experience can be identified. The category 'thematic function' relates to the 'action-determining subjects (themas)'* chosen by the children. The issue here is the arrangement of the plot, which has a structuring impact both on the way in which TV programmes are received and on the relationships within the group of children. The plot arrangement also establishes connections between television and the relationships within the group.

Three examples were chosen (points 2-4) which underline the typical aspects of symbolic mediation. The major questions concern:

- Interpretation: including questions such as "What significance do the actiondetermining subjects (themas) have as the interpretative background for the reception of TV programmes?"

- Subjective expression and creativity including such questions as "How do television symbolism and television experience contribute to the way in which children create symbolic representations of their action-determining subjects (themas)?"'

More specifically, the study concerns the connection between action-determining subjects (themas), group dynamics and the clusters of symbols and topics in the television series "Captain Future".

\section{Communication theory and methodological outline: symbolic mediation, representation and creativity, interpretation and media traces}

Working with the categories of symbolic mediation or symbolic treatment (in the form of their subjectively acting components), one is able to unveil a programme which has a bearing on communication theory and methodology. The programme

\footnotetext{
* The term "handlungsleitendes Thema" has been translated by " action-determining subject". In the English translation "thema" has been additionally introduced as a literal translation of the German term to avoid terminological misunderstandings.

Action-determining subjects (themas) are people's motives and aims determined by contents which give sense and meaning to actions by structuring. This is especially useful in order to be able to explain the relationship of people to the media. To distinguish energy-orientated concepts from what initiates and structures human actions (for example, drive, needs) "thema" is used to attach importance terminologically to the contents of actions.
} 
does not - in the first instance - fall in line with the theoretical interpretation of television reception as a simple transporting of information from a sender to a receiver. ${ }^{4}$ By defining the research object as a category of "dialectical mediation" (i.e.symbolic mediation), we are also moving away from a research method at the basis of which lies a representational model with prescribed variables. Instead of this, we are beginning to inquire about the cultural and subjective meanings of "media traces" in what the children presented symbolically in their plays.

\subsection{The symbolic quality of television both as a cultural medium and as a subjective activity}

For an educationalist whose primary research interest is the cultural and everyday behaviour of children, it is natural to understand television as an activity which is linked in a communicative chain of cultural objectivisation ( = medium) and subjective action. Television as an event on the screen takes its place alongside an unending number of these cultural objectivisations, which extend from language and curriculum to the houses where children live. Television as hearing and seeing - that is as an activity - is then also a part of a process of cultural acquisition, which is always symbolic in nature. For this reason, it is integrated into the diverse, subjective process of learning and representation. With the classification of television as a medium in the context of cultural objectivisation and of television as hearing and seeing in the context of subjective acquisition and representation, we confront a diverse range of phenomena, for the systematic elucidation of which there already exists an abundance of theoretical aids. ${ }^{5}$ The investigation which is mapped out here relates to concepts of symbolically mediated acquisition, which seeks the subjective sense of actions in an objective world of social and cultural meaning. ${ }^{6}$ The important point here is that with the categories "objective world of social and cultural meaning" and "actions and experience as symbolic acquisition and representation", a subject-reality-relationship is formulated, which to a substantial extent is mediated symbolically: the social and cultural world has this social-cultural quality only because this quality can be defined symbolically. The process of acting, thinking, feeling, experiencing within this world necessitates a series of symbolic objectivisations, in order that the relationship of the subject to the outside world, that is to reality, and to itself and the series of symbolically mediated events, experiences, emotions, perceptions and aims can be created. The way in which the dynamic of this internal/external relationship ${ }^{7}$ functions by means of cultural objectivisation has been described among others by Bettelheim ${ }^{8}$ as the "archaic medium" of the fairy tale. Fairy tale figures, fairy tale plot patterns etc. offer children the symbolism, so that they can come to terms with and have an understanding of their fears, wishes, contradictory feelings and experiences. This includes the possibility of working through fears, wishes, etc. by means of fantasy or some form of action. A fairy tale functions 
in this way, among other things, as a model for interpretation. Thus, for example, the plot and structure of the fairy tale are (almost exclusively) geared toward a happy ending. In this way they can offer encouragement for children and determine the pattern of their fantasies and actions. The subjective structuring of plot elements is of crucial importance in the reception of a fairy tale, as it is with almost every other medium. This plot structuring is given tangible form - in terms of content - by using the category of action-determining subjects (themas). It will therefore not be defined functionally as for example with the categories of "motivation" or "needs".9 Bettelheim, within the context of his theories on fairy tales or media, spoke - psychoanalytically and colloquially - of subjects such as "wanting to grow up", "gaining autonomy" etc.

The symbolic mediating function of the fairy tale is of course to be distinguished from that of television. There is a historical development in this dynamic of the symbolic mediating of cultural objectivisation and subject. There is naturally a (sizeable) difference if a child is told a tale by his grandmother or if he is watching television. The cultural objectivisations always bring a specific and essential 'inner dynamic' into the subject-reality-relationship. The integration of television in a media and consumer network plays a central role in today's world in the relationship of children to television. ${ }^{10}$ Television, as the leading medium in this media and consumer network has consequences for symbolic acquisition and representation forms, especially for interpretational mechanisms as well as for creativity and expression.

The categories of "interpretation" as well as "creativity" / "expression" are ones which highlight subjective possibilities of action and which open up a pedagogical dimension. This pedagogical dimension is made up of binary opposites expressed in everyday terms. These include pairs such as: "being locked in"/ "freeing oneself"; "succeeding"/ "failing". These two opposing pairs attempt to demonstrate the risk of alienation for a subject-object-relationship mediated by television, thereby revealing its practical significance and establishing empirical evidence for it.

1. Sphere of inquiry: Subject-object-relationship as an interpretation guided by action-determining subjects (themas)

\section{Illustrative questions}

What is the relationship between television ${ }^{11}$ and action-determining subjects (themas)? Do television experiences or the symbolic structure of a television film (figures, distribution of figures within the plot, direction of the film etc.) become an interpretation model for the child's way of experiencing and behaving. Do the particular action-determining subjects (themas) of the children take on a different meaning through television experiences or television symbolism? The alternative 
questions to these highlight the dominance of the action-determining subjects (themas) in their interpretative function for the reception of television and for the processing of television experiences: Are television experiences, television symbolism, the situations in which television programmes are received interpreted through the action-determining subjects (themas) of the children? What role in this do the relationships between members of the group and the topics discussed by the group have for the ways in which children process television experiences or symbolism?

\section{Hypotheses}

These questions provide a concrete basis for the following hypotheses concerning the interpretative function or the interpretative preferences of television as an objectivised form of cultural interpretative relationships. In addition the hypotheses concerning the interpretational function and preferences of the action-determining subjects (themas) can be viewed as the dynamic focal point of a subjective interpretational model.

(1) The interpretational dynamic is generated from a complex structure of internally-reinforcing elements. These are: experiences - including media experiences - and the experience of media production and direction mode/language, including media symbolism/situational plot context including the group relationships/action-determining subjects (themas).

The action determining subjects (themas) thereby have a mediating function and relate these events interpretively and interdependently the one to the other.

(2) The group relationships and the situational context form the interpretative background for the subjective action-determining subjects (themas) and for the use of television symbolism.

(3) Television symbolism has consequences as far as content is concerned for the interpretation of action-determining subjects (themas).

(4) The thematically successful use of television symbolism reinforces the significance of television as an influential medium. At least in the long term, it locks the children - through a system of group relationships - in with the media and consumer network.

\section{Sphere of inquiry: The creative and expressive ability in the media and consumer network}

\section{Illustrative questions}

Are children capable of representing and possibly acting out their actiondetermining subjects (themas) in spite of television experiences and in spite of television symbolism? Do they reproduce only a stereotypical plot structure from a 
television series? Are they - as a result of group interaction - capable of giving shape to an idea or topic from the starting point of their action-determining subjects (themas)? Does the well-known television series "Captain Future" offer the children possibilities for communication and dialogue?

\section{Hypotheses}

Central to these questions are issues of children's subjective expression and subjective creativitiy. Expression and creativity are essentially dependent on cultural symbolism for their symbolic representation. Television symbolism (including issues of production and direction) has an important thematic expressive and creative function, ${ }^{12}$ especially in group situations:

(5) The symbolism of television as a highly significant medium together with its production and direction modes have an expressive function for the topics chosen by individual children and for the topics of groups of children.

(6) Children use the symbolism of television and its production/direction modes in a creative and formative fashion within complex communication processes.

(7) The symbolism and production/direction modes of television underpin the successful symbolic representation of action-determining subjects (themas). It therefore forms a successful basis for understanding (which then locks children into the media and consumer network).

(8) If children fail in the representation of their action-determining subjects (themas) by resorting to television symbolism or television production modes, then the cause lies in their individual biographies.

(9) Television experiences and television symbolism stimulate interaction and communication in children's groups (which stabilizes the powerful influence of television in the media and consumer network).

\subsection{The reconstruction of the symbolic mediation in the situational context}

\section{Gaining experiences for life and seeking "media traces"}

The subject of television reception research is communication in everyday life not the isolated media. Expressed graphically, this means that, rather than setting down a model of variables for television reception, it is a question of discovering the effects of television on the day-to-day lives of the children and of asking what communicative significance the "media traces" have. (The term "communicative" is used here in its widest sense and includes the interaction in groups, the current situational context and individual lines of biographical development.)

Participatory observation is the most appropriate method for analysing experience and behaviour, and for describing and discerning events and their complex 
relationship with the "world of the media". This method is especially suited for dealing with phenomena where little theoretical knowledge is available. The aim of the participatory observation is to provide situational documentation. For this purpose, audio recordings are made in the various children's groups. Selected sections of these (so-called "episodes") are then transcribed. The transcribed episodes form the analytical as well as the empirical material for this piece of research. The choice as to which episodes are transcribed is based upon the observer's frame of the reference and his/her situational and empirical report. This report, together with its frame of reference, is also linked back to situational documentation. Group discussions involving all the observers is here an important method for effecting this linking back process. ${ }^{13}$

Research object: symbolic representation in the context of symbolic mediation ${ }^{14}$ The question as to how children create, interpret and express themselves in an everyday situation (school, play-group) is linked up with the definition of communication as a symbolic mediation. An important point here is the assumption that objective, subjective and situational components overlap each other in what is a unique and focussed pattern of actions. ${ }^{15}$ The objective component here is television as the major medium in the media and consumer network, which appears in the form of media experiences or media symbolism in the symbolic representations of the children. Symbolic representations are all communicable expressions, e.g. statements, props, play models. ${ }^{16}$

The subjective component is established in the action-determining subjects (themas) of the children. They are the result of their particular biography in the context of the particular circumstances of their daily lives. The action-determining subjects (themas) appear also to be objectivised in the symbolic representation of the children.

The situational context plays a decisive role in the interpretation of the symbolic representations and of the subjective-objective mediation which appears in them. That means that the symbolic representations of the children are to be localised in the open teaching situations, each of which has its own group dynamic and educational objective. It was in this classroom context that the interpretational and creative processes of the children are identified by referring to their symbolic representations and by examining how these are related to television.

\section{Integrated and analytical perspectives of investigation}

In order to determine the meaning of the "media traces" in the symbolic representations of the children, these "traces" must be 'situated' in the respective sphere of action and development (school, peer group, teaching project encouraging free association, "Space Travel" project as an opportunity for creative expression and 
action). These then provide integrated perspectives of investigation. For the purposes of investigation, the researcher considers the perspective of events, or the development of the plot. The functional relationship of these events and their development are traced with the help of the observation documents (audiorecordings of role-playing situations or transcriptions of these in the form of selected episodes, and the reports made by the observers): Why do the boys initiate their wild war play? What situation in the group precedes this? How does the teacher intervene? What function does the expression "Monster of Megara" have in the play? etc.

The observational documents are then analysed from the point of view of communication theory (analytical investigation perspectives). In this way the relationship of symbolic representations, action-determining subjects (themas) and mass communications can be studied, with a view to discovering which functional relations are relevant from the aspect of communication theory. In a concrete sense this is done by seeking to establish "media traces". Here, it is a question of finding indicators which point to "media experiences". In addition it is important to identify these "media traces" as indicators within the symbolic representations of the children of media symbolism and of clusters of media production/direction modes.

\section{Methodological and associative-impressionistic investigation}

The specific methodological investigation of the empirical documents takes the form of textual analysis. The transcribed episodes are analysed from the standpoint of the functional relationships between the elements viewed from the perspective of communication theory (for example, action-determining subjects [themas], media symbolism etc.). The selected and transcribed episodes are thus related to situations and to plot development. Here the important question is whether the selected episodes are relevant and complete or whether they have already been interpreted. This process of linking back both the comprehensive interpretation of the documents and also the relevance and the completeness of the documents serves the function of a revision. This allows fundamentally new hypotheses and new pieces of evidence to be integrated into the dynamic of the interpretation process. It also allows new hypotheses and new documentation to be fed into the research process.

Furthermore, the episodes which contain references to the media ("media traces") are compared with the media to which they might be related. Here attention is focussed on such questions as: whether a child quotes from a scene from a film, whether there are striking similarities in terms of production and direction modes employed between the symbolic representations of that child and the film to which the "media traces" relate. 
As well as comparing selected and transcribed empirical documents with actual plot situations and individual media, there is also a subjectively guided group discussion involving observers and other members of the research team. The observers start by presenting their reports. These include: assessing the involvement of individual children, comparing plot situations with actual life experiences, discussing transmission mechanisms and sympathy evaluations etc. In this way the emotionally significant aspects of communication are introduced into the research process and become an inter-subjectively verifiable part of the research object. The associative and impressionistic elements of communication are thus integrated into the research process and are given objective status in the form of written documents. The processes of textual analysis or textual comparison are thus linked with impressionistic and associative processes. Under the heading "The dynamics of interpretation in the research process" the relationship of both evaluative methods is described with regard to their development within the framework of the research process.

\section{Space police - Playfully warding off threats and being aggressively superior}

\subsection{The emergence of an aggressive performance model in the conflict between boys and girls}

Two boys and two girls are put together by the teacher in a work and role-play group. Already on the first morning there is disagreement between the boys on the one hand and the girls on the other hand, a disagreement which is clearly triggered by the different work strategies employed. Götz and Christa are at the centre of this conflict. Götz is spontaneous, impulsive, is constantly running off to other groups, has no personal work aim. Christa on the other hand has a much clearer objective. She tries to get Götz involved in the group work. She also uses the teacher as the authority person to achieve her ends.

(Götz runs around with his radio receiver and tries to make contact)

Götz:

Christoph: (using his radio) Christoph, come in Christoph, I'm still working on my radio receiver. I can't make contact.

(Götz runs around again with his radio receiver)

(Teacher approaches the group)

Christa:

Teacher (T): (reproachfully) All he does is build radio receivers! That is not what we want! (to Gotz) You keep running round with a box, sticking a wire into it and then that's it. This is the third one you've made. 
Christa: Yes, you are only building the -

T.: Aren't you doing anything else?

Götz: If I haven't even got such a thing - this sort of lid

Christa: Yes, he said he would do more to that (pointing to the half-made rocket) and thought he could miss out a few.

T.: Then he cannot take part in the play later, he cannot take part. (to Götz) If you do absolutely nothing again. You cannot always let the others do the work for you.

Götz: That's not true (he points to the rocket). Up to now I have done everything!

Christa: Yes, you have botched them all. (She is referring to the building technique.) Götz has not stuck the links together well enough).

T.: Who is in your group, then. Who is it? Christa, Christoph, Isa. You three are working and Götz isn't?

Götz: Of course I am. I just don't know where where my thing is now.

T.: You keep showing me a box with a wire stuck into it and saying: Look at my super receiver set.

Götz: $\quad$ Should I stick something on like that - OK?

T.:

You can also make something other than a receiver set!

(Noise)

Isa: (to Götz) You can make something else, you could have made something different, for example, a robot, or something.

Götz (put out) That's marvellous! Before I made a robot and you all nagged. And now I am supposed to make another robot!

Christa: $\quad$ A real one! You have only got your R2 or whatever it is.

Götz: (with emphasis) R2D2 R2D2 - gosh!

(Götz spontaneously puts two cardboard boxes together.)

Christa: Götz! We don't want that silly thing there, we want a real robot!

Götz: (lost) How should I build it then?

In this episode what happens is that Götz is obviously enjoying playing with the radio receiver he has quickly put together (a box with a piece of wire) and making radio contact with the other children. Götz's idea of "R2D2" (Robot from the film "Starwars") was rejected by Christa. In order to get her own way, she uses the teacher as an authority figure. The second girl in the group reproaches Götz for having made "a robot or something". His suggestion to build a robot was previously, when the teacher was not present, rejected by the group as "silly". In this situation Götz and Christoph develop an associative chain which begins with the radio receiver and continues with head gear (the wire of the radio receiver is used for this), space helmet, laser pistol and "space police".

(Gobtz suddenly suggests going on an adventure to the girls)

Götz: The girls are attacked by the dragon and radio for help. The boys shoot the dragon with their pistols.

Christa: That is not a real story. 
(Christoph and Götz are playing at angels)

Christoph/Götz: I am an angel. I am an angel!

Isa: (to Götz in a pejorative voice) you (stressing the word) an angel!

(The children laugh)

Christoph/Götz: I am an angel. I am an angel. I am an angel. I am an angel!

(The children laugh)

Christoph/Götz: I am an angel. I am an angel. . . angel.

(Christoph and Götz flap their arms up and down like wings and run through the classroom. Götz stops first).

Götz: $\quad$ My wings are clapped out.

(Christoph keeps on "flying")

Christoph: I am an angel, I am an angel.

Isa: (irritated) Why don't you do something.

Christoph: Hey, Götz, I'm just thinking.

Götz: What then?

Christoph: Oh yes.

Götz: What then?

(Christoph moves away from the table and thinks to himself)

Christoph: Hey, Götz, come over here. Come over here!

(Christoph and Götz put their heads together)

Christoph: $\quad$ Götz, we can. . . we can be policemen, us ourselves, police, space police! Do you hear?

Götz: $\quad$ Yes, of course, I am a space policeman!

(Christoph and Götz whisper to each other excitedly about "Sheriff stars", which they are going to make out of the angel-headgear. Götz wants to get Christopher to come further away from the table).

Götz: $\quad$ Come away, come here!

Research observer: What do you want to do away from here, ay?

Christoph/Götz: Nothing! Nothing!

(They want to keep their plans secret. Next Christoph and Götz get involved in the hectic activity of making the police equipment.)

The chain of association from the angels to the space police

As the children continue playing, the "space police" turn into soldier-like space fighters, who ward off the "Megaras".

The girls succeed now in getting the teacher fully on their side in their disagreement with the boys, so that the boys are excluded from the group and form their own work group. The boys resolve this conflict for themselves, by building for 
themselves all-conquering machines and weapons of war, so that they can play space police warding off the "Monsters of Megara".

Presumably they are wanting - at an imaginative level - to enlist the aid of the space policemen, after the girls - in the real world of the classroom - have got the teacher on their side to resolve the conflict. Here the teacher is almost functioning as a classroom policewoman. In this way the boys are very successful in expressing their ideas and, through their play, further developing the relationships within the group. As space police they fend off aggressors time and again, until they have fully acted out their ideas in the role-play.

\subsection{The generation of an individual dynamic within the play model in the context of the action-determining subject (thema)}

The boys' play begins with their receiving orders from their boss to ward off the threat posed by the Monsters of Megara. To this purpose, they fly off in their space ships to the planets, where they shoot some Megara Monsters. They are then called back by radio to their base which is under threat of an attack by the Megara Monsters. On take-off, they throw more bombs at the Megara Monsters. The boys then fly in their space ship to the island where the Megaras have captured a spaceship. On the island one of the boys falls through a hidden trap door. He is freed. The space travellers victoriously ward off a constant series of threats (molten lava, enemy space ships, a hostile den, a shooting dragon and aggressive Megara Monsters) by dropping bombs, lighting explosive charges etc.). The boys end their play, after they have had a wild time, without however bringing the plot to a conclusion. Within the pattern they have established - warding off attack, fighting, attacking, killing - there are a series of variations. One of the reactions which occurs is 'flight'; a much rarer reaction is 'talk' or 'removing something' (a battery).

\section{Variations on the pattern: 'Warding off threat/fighting/attacking/killing'}

$\begin{array}{ll}\text { Alex: } & \text { A heavy landing! - ahrrrrrrrr - } \\ \text { Christoph: } & \text { Leave the craft! } \\ \text { Götz: } & \text { Take your radio receivers with you! } \\ \text { Christoph: } & \text { Take your masks with you! } \\ & \text { Come on - in rows of three! }\end{array}$

(They jump out of the space craft. Götz makes the wildest leaps) THREAT:

Alex: The Monsters of Megara! Monster 
Christoph: I'll look down here, you up there!

(Alex is crawling around on the floor)

Alex:

Here at base, here at base. Come in!

(Götz comes running)

I have discovered a clue!

Götz:

Here I am!

(Götz and Christoph run to the open window and shoot down into the parked teachers' cars)

DEFENCE:

Shooting

Götz: I'll take the one at the back, you take the one at

the front.

Christoph: OK! Fire! - psh-pshpsh-psh damn! (He) takes cover) - psh-psh

Götz:

- psh - pshpsh!

(In the middle of the play, there is a practice alarm of the town's sirens!)

T.: (to the boys) You did that. You started that off.

It is the same wave length!

Christoph: (frightened) - oooooooh!

Götz: The monsters! Stay on board!

THREAT:

Monster

(Götz runs with Alex to the window from which they both shoot.) DEFENCE:

Shooting

(Alex comes back to the spaceship and walks past Christa's rocket.)

Alex: Alien spaceship in sight!

THREAT:

Christoph: Alien spaceship in sight!

Spaceship

Götz: $\quad$ Shoot it down!

DEFENCE:

Shooting

Alex: No - make radio contact! Hello, alien space-

DEFENCE:

ship! What is your name?

Speaking

(T. has switched on the echo machine for Henning.

Henning makes an eerie gurgling and laughing sound.)

Christoph: They are interfering with our radio contact. What machine is that? Switch it off before they do anything which is dangerous for us.

THREAT:

Someone is

dangerous

Götz:

The trees are wobbling.

DEFENCE:

Christoph: That is very dangerous. We must land at once! Landing 
(Alex has taken a stick with bells on it out of the props and is waving it backwards and forwards over the table.)

Alex: $\quad$ That's a dragon rolling towards us - you must disappear!

Götz: That is a shooting dragon, do you know that?

THREAT:

Shooting

Christoph: Look out or it'll kill you!

dragon

(Götz and Christoph fetch their weapons. Götz shoots the dragon dead)

Götz:

It's gone. It is dead.

DEFENCE:

Shooting

(The spaceship flies in curves, rising and falling)

Christoph: What a landing!

Götz: Don't land! climb at once - enemy beings!

Dragons - they shoot gas from pistols

DEFENCE:

Aliens

Alex: $\quad$ Set off, as fast as possible!

DEFENCE:

Escape

Alex:

All men to headquarters! The monsters of Megara THREAT:

are attacking, a contact from earth! Out! Monsters

attacking

Christoph: We must set off at once!

DEFENCE:

Götz:

Set off at once!

Escape

Christoph: That's enough. Switch off!

Götz: $\quad$ Megara beings!

Christoph: Gosh, fire! Turn on the jets!

DEFENCE:

Alex: I'll chuck a gas bomb at the Megaras.

Throwing bombs

Götz: Mine too, here!

Alex: $\quad$ That's not a gas bomb! - Now we are flying to the island.

Christoph: News in of an attack last night on a spaceship with six Megaras - Take off!

THREAT:

Attack

Alex: Stop, look behind - look, our enemies!

(Alex and Götz get out. Götz takes the "time bomb".)

Christoph: I'll stay on board!

THREAT:

Götz: That's an enemy hideout, the entrance is walled up Being

walled up

(The boys light the fuse of a "time bomb".)

DEFENCE:

Alex and Götz: Booch - pshshshsh! -

Lighting

fuse 
There is an abundance of motifs here relating to fighting, attacking, killing, warding off attack: military action; emergency procedures and emergency landing, shooting down of alien spaceship; killing of the shooting dragon by gunfire; chucking a gas bomb at the Megaras; lighting the fuse of a time bomb; switching on the neutron canon; turning on the fire system.

The linguistic expressions (Spaceship Enterprise, emergency procedures, Megara Monsters, jet propulsion, time bomb, back-up electrical apparatus etc.) together with the motif (warding off threats by fighting) allow for extensive variation within this performance type (action) and are, with some modification, built into similar action sequences. The generating potential of the play reinforces the patterning process.

\subsection{The plot model and quotations from the mass media, especially from "Captain Future"}

The individual linguistic elements within the action and the play (emergency procedures, jet propulsion, Megara Monsters etc.) introduce a connection which is typical of science fiction films, that of "battle" and "technology". It is of no great significance here whether the talk is of "time bomb" or "gas bomb". What is important is that technological weaponry is being referred to. The same goes for details such as "back-up electrical apparatus", "jet propulsion", they too must be technical. Although the individual connections are interchangeable, they are to do with fighting and technology. In this way, the boys align themselves with the category of 'aggressively technical' science fiction media, such as among others "Spaceship Enterprise". "Starwars Galactica", "Captain Future”.

The linguistic set expressions with their aggressively warlike and technical meanings are likewise embedded in an aggressive context. The action is one of war and adventure in which threat is warded off by the destruction of the attacker. This plot model, mixed with aggressive and technical details, appears in films like "Captain Future", in which the protagonist battles as a shining hero against the threat, only escaping destruction himself by destroying others. The boys' play is more directly connected with "Captain Future", however, than merely through the general motif of 'aggressively warding off danger'. The "Monster of Megara", which play such an important part in the play, originate from - or are almost quoted from - the three-part "Captain Future" series "Lord of Megara". Word for word parallels appear in the following commands such as: "Prepare the proton canon", ". . . fire well", "attack", "counter attack". The expressions are nevertheless on the whole products of the common, general motif 'aggressively warding off danger'. 


\subsection{Conclusions about the creative, expressive and interpretative possibilities}

Group conflict, the school situation, media experiences, and the boys' 'media symbolism" appear as an integrated framework, which is thematically structured (hypothesis 1). The boys work intensively towards creating their symbolic solution of the conflict with the girls, by employing, as they think fit, the symbolism of a current television series, its presentational style and mode (hypothesis 5). The boys make the most of a very important creative and representational opportunity, in that they produce a joint strategy for the play by following a chain of associations (hypothesis 7,9 ). In this way they can act out their action-determining subjects (themas) in a comprehensible fashion. Through their play they succeed in overcoming their failure in working together with the girls (hypotheses $2,5,6$ ). In this way, the symbolism of their play overlaps with the symbolism of the media, in particular, with the symbolism of "Captain Future" (hypothesis 5). This seems particularly likely, because the way they handled the topic in the group has important similarities with the "Captain Future" series (hypothesis 5). The reference to "Captain Future" also makes it easier for the 'underdogs' to communicate, because they know the basic outline of the series and also many of its details (hypothesis 4). What is always to the fore are solutions with aggressive symbolism, although the solution of the conflict is free of violence. Nevertheless the solution is acted out in such a way that it is experienced as disturbing or aggressive by a third party (hypotheses 3,5 ). Occasionally the boys also attempt to find other than aggressive solutions in relation to the threat which they experience. They do not, however, free themselves from the pattern constituted by the group interest, that of 'fending off danger together'. It then becomes very easy always to generate a solution for this problem, because they can keep on developing new and successful play motifs as a result of establishing common ground between their play and the story of "Captain Future". These are motifs which they have at their disposal, almost in the manner of a repertoire (hypotheses 7,9 ). In this way, the significance of the current television series should increase for this group of boys.

\section{The function of television for a child that is disapproved of or difficult: television quotations as a message}

\subsection{Media set pieces in a situation that is non-specific and where one encounters contact and defence mechanism}

Götz is one of the protagonists of the action play "Space police" and fights against the "Monsters of Megara". It is characteristic of him, however, that there seem to be no recognizable distinctions for him between the situation of school and play. Thus, in the play, he treats the rocket that a girl of another group has made as a prop or the cars of the teachers as objects that are to be shot down. 
(Alex goes back to the spaceship and walks past Christa's rocket)

Alex:

Christoph:

Götz:

Alex:
Alien spaceship in sight!

Alien spaceship in sight!

Shoot it down!

No - make radio contact with it! Hello, alien spaceship! What is your name?

When a neighbouring group is looking for a name for a robot, Götz brings his scrap book "The black hole" along and comes out with film titles, names of film characters and scenes:

Götz:

Starwars, Battle star Galactica, Starwars (faltering, excited, staccato, irrepressible)

Nicola:

What do you want to be called, Markus?

Götz: R2D2! R2D2! - Eh Markus, you could also call him Graig, from "Captain Future"

Markus: Have you got one of those comics here?

Götz: $\quad$ No, I have one at home, the one where he fell down from above (excitedly) - below his computer crashed down - then a machine was set off boooommmm!

Götz uses an abundance of expressions and actions taken from the media. One has the impression of a stream of expressions and actions based on a generative framework. In this way - mostly regardless of situational changes - he establishes the same sorts of relationship by means of aggressive contacts, demeaning utterance and by effecting behaviour intended to impress (for example "I am a very dangerous guy"). Or he reacts in the same way to a series of different relational situations. The important thing is, that there seems to be no situation in which he is prevented from speaking of film titles, film characters, film experiences or of other media.

This argues against the hypothesis which sees the context of the situation or rather of the group situation as the interpretational background for both plot-determining subjects and media symbolism (hypothesis 2). The origin of this is that aspect of his role-playing which is the desire to stay at the centre of attention. He succeeded in this too, though with a negative effect, throughout the whole of his primary school life. He is actively rejected by the other children. This is the view of the teacher who despite intensive efforts has never succeeded in establishing a different sort of group relationship. Media experiences and media referencs - that is Götz's references to the media and consumer network - have an enormous communicative significance for him, which is based on the familiarity of all the children with this media and consumer network (hypothesis 9). With his constant references to the media, he creates opportunities for communication and in so doing partly fulfils his objective. However, this has the negative result that he is 
actively rejected - which has the effect of making him seek more opportunities for communication from the media, or at least, that is the supposition.

Götz's situationally unspecific use of media symbolism usually remains without content, that is, has no specific expressive function (in opposition to hypothesis 5). This is why, within the context of group relationship, it is not a suitable basis for communication and conversation.

\subsection{Putting across the message by means of film quotations}

As has already been stated, Götz receives a lot of rejection, resistance and outright criticism from his fellow pupils on account of these, so to speak, empty utterances and actions. Although the structure of his attempts at role playing in many respects hardly differs from the performance model of "Space police", he is showered with reproaches by his fellow pupils (on the fifth school morning during the discussion of their performances). It was his fault, they said, that his group put on a totally unsuitable performance. Comments were made like: "I found it so stupid, that Götz always so, so, so . . . um . . . he was always so . . . he overacted so much. He was . . . what he did was such a lot of rubbish" (The origin of this is the disagreement between the theme of Götz and the themes of the other children and Götz's resulting use of media symbolism).

Götz goes quiet in the face of all these reproaches. In the discussion about "Captain Future", however, he soon starts shouting out the names of film titles and characters, often at the most inappropriate moments. In the course of the discussion, when one girl from the group wants to know who Captain Future ist, an explanation is given which focusses on the murder of Captain Future's parents, of his revenge and of the crime of Kim Iwan and Kuolun. Götz recounts the story from a sequence of "Captain Future".

Götz comments are given alongside what happens in the course of the film:

\section{Götz's comments}

One thing I found great was when ... and then the dogs hid with Captain Future. . . eh?

Then they iced 'em in.

I don't know how that was ... .
Description of the storyline of the film

The two animals in the Future crew, an iron-eating dog and a tortoise capable of transforming itself, had disguised themselves as technical equipment and transformed themselves again into dog and tortoise.

Captain Future and his crew are locked in coffin-like glass cases in a standing position and frozen by means of a gas. 
He bit a sort of hole near Captain Future, he made some sort of a thing and then he bit it to bits. And he did it somehow. And then the dog ate something, eh.

And then he did it again. I don't know how he did it.

Then the dog came and ate everything up!

Then he was able to move his foot. Then he put his foot in hard and everything was bust.

Markus: He did it with his fist.

Götz: With his foot!

Markus: And then, then he freed the others

Götz: Yes, but this, this speaking brain, Dr. Simon - that funny creature there, what he got up to, that electric charge.

Andreas: That was it. Funny stuff. You couldn't move.

Götz: I know.

Girl: It's gas.

Götz: Gas.
Captain Future calls the dog by means of telepathy.

The dog bites into the base of the glass case, turns away because he does not like the taste of the material;

is called again and admonished.

then bites a hole in the glass at the base of the case, near Captain Future's foot.

The anaesthetic surges out explosively.

Captain Future can move again and smashes the glass with his fists.

Captain Future frees his team by smashing the glass cases with his fists.

Dr. Simon, who was caught earlier with an electrical whip by the villain, tortured and tied up, is freed by Joan. She unties him.

Götz is referring here to an episode from the three-part sequal to "Captain Future" ("The Black Planet", Part 2), which had been on about 6 weeks before. In the film episode, Future and his entire crew were overpowered by gas and put into coffin-like glass cases. By using telepathy Captain Future is able to summon a small iron-eating dog, and with its help and by using his fists escapes.

By comparing the comments and the film, it is striking that Götz can remember the film scene down to the smallest details. His reduced language: "somehow he somehow. . ." is deceptive in terms of content. There is nevertheless a lot in the episode which is hard to fathom and difficult to express in language, for example, the telepathy incident and the transformation of a piece of technical apparatus into two animals. Nevertheless, Götz has understood the essence of the scene and gives an exact rendering. 
What has to be asked is: Why does Götz remember this film scene about 6 weeks after the broadcast? Why does this scene not disappear in the daily welter of television experiences? It is to be assumed that the symbolism and the central message of this scene connects with his own action-determining subject (thema) of 'feeling rejected' and 'aggressively freeing himself'.

Central to Götz's comments is the symbolism of 'being frozen in' which he exemplifies by the immobility of Captain Future in the glass case/ glass coffin. This 'being frozen in' corresponds to his social situation in the class during the discussion session, when he is isolated and 'torn off a strip'. He is in one of the few situations in which he keeps quiet and retreats into his shell, as if in resignation. This is a state of social immobility. It is through the symbolism of this "Captain Future" scene that he depicts how and what he feels.

Because such scenes correspond to his topic, he also experiences them as important when he watches them on television. This topic forms the framework of relevance for how he reads the film scenes and how he verbally reproduces them. Added to this is the fact that the symbolism of the television scene fits nicely in with his personal preoccupation.

Alongside the symbolism of immobility and of being frozen in, there are in the film and also in Götz's performance two further important figures or narrative strands which are common to both. These are the helpful animals, which Captain Future summons by means of telepathy, produced as it were by a conjurer out of a hat. Such loyal companions are the prerequisite for the act of liberation. One could ask whether he sees the two school companions from the game "Space police" as having a similar function to that of Captain Future's helping animals.

After the small animal in the film has released Captain Future from his paralysis, the latter smashes his glass case/glass coffin and those of his crew. Here again is the symbolism of aggressive liberation: smashing. This symbolism is immediately taken up by the boys who quickly go over the means of escape with him: What was the instrument used for smashing? This film scene then opens up a short communicative situation. In this way, his sensitive comments about small helpers (dogs, tortoises) and thinking helpers (Dr Simon) become insignificant, because they ultimately do not fit in with the plot of "Captain Future", namely aggressive warding-off of threats. Although the closeness of contact is immediately present following the quotation from the "Captain Future" film (hypothesis 9), Götz's thematic message of 'being frozen in, help' has no chance, because the battle symbolism of the film scenes works against this message (hypothesis 3). It is once again the battle symbolism to which the fellow pupils refer. It is the same sort of symbolism which the pupils in his class latched on to in their strong rejection of his behaviour. Again he is the one talking of fighting. It can only be supposed that this is not the only time that he has been locked into the circle of self-affirmation: i.e. 
representing a subject or idea by means of television symbolism but being misunderstood or even rejected in the process (hypothesis 5 , in opposition to hypothesis 7).

Conversations with Götz's teacher beyond the immediate context of the observational study lead one to assume that this circle, in which his ideas and his potential for expressing them have become enclosed, has its roots in his family history (hypothesis 8).

\subsection{Conclusions about creative, expressive and interpretative possibilities}

In the case of Götz, two interconnected links with television and the mass media are evident. There is first of all the sheer number of attempts at communication, which he undertakes by means of media symbolism, thereby providing a successful thematic context within the boys' group (hypotheses 2,9 ). With regards to his individual thematic preoccupations, which aim, among other things, at gaining attention and at remaining at the centre of attention, this way of communicating nevertheless fails despite the high communicative density. This is because his use of media experiences and of media symbolism is situationally non-specific and is subsequently aggressively rejected by his fellow pupils (hypothesis 2 ). $\mathrm{He}$ is probably unsuccessful in his media-related attempts at communication, because his way of communication appears devoid of content (in opposition to hypothesis 5, affirmation of hypothesis 1). Possibly the range of dramatic presentation with the media and consumer network is partly responsible for this failure in communication (hypothesis 7). This is especially because symbolic representation and actions are interchangeable and consequently have no concrete expressive function. The constant repetition of media symbolism may result in a high communicative density, even if content is lacking. This may account for Götz's attempt - no doubt prompted by his experience in life hitherto - to keep playing through his topic in the same way, by taking 'material' from the media (hypothesis 4).

In his second link with television he uses a television quotation which is not just situationally and thematically appropriate, but is indeed extremely sensitive (hypothesis 5 ). The problem is that the television symbolism conceals its message in the situation which is understood as aggressive by the other pupils. Along with the communicative success of the aggressive symbolism, the sensitive, 'soft' part of his message is lost (hypothesis 7). Although the television symbolism has here an expressive and creative function which corresponds with his underlying topic (hypothesis 5), the communication fails a result of the explicit television reference (reference to hypothesis 7). The failure lies in the message, which implies the relationship to the "Captain Future" television series. Who can expect a sensitive message to come out of this series with its basic motif of 'Warding off threats by fighting, destroying'! 
A further reason, why Götz fails in his use of a television quotation to put across a message, lies in his subtle knowledge of the series, which would presuppose an intensive involvement in the media and consumer network on the part of his listeners. The majority of the children and the adults did not have this sophisticated knowledge of this series. (Nevertheless, one might presume that certain mechanisms exist with reference to hypotheses 4 and 9.)

\section{Flight from destruction - disguised television symbolism}

In a group consisting of two girls and three boys, the boys have an increasingly decisive influence on the atmosphere of the group. They cooperate with each other, but yet each one resolutely follows his own ideas and develops his own storyline. In this way, it is difficult to pin them down to one line of development, namely to that of their planned performance.

Karola is dominant from the beginning. It is taken for granted that she will take on the role of leader. She puts herself out to ensure that the group puts on a successful performance. She only succeeds, however, after much effort. She is always threatened with failure, because the boys insist on their own ideas and take little part in working out and preparing the play in a straightforward and clear fashion. Nevertheless, Karola remains in the centre, directing and determining the structure. Through her the confused narrative strands which the other children have contributed to the performance come together. This task demands of her an enormous amount of coordinating skill and ability to empathise and carry things through. She overtaxes herself, in order on the one hand to be and to remain the group leader and on the other hand to produce a space play, which is a 'hit' with the class and the teacher.

Karola's overtaxing herself appears in the story which she has developed in the form of catastrophe and escape motifs, in the form of stress and panic. The motifs of catastrophe and escape as well as those of the panic and the hectic rush of the production are the expression of her action-determining subject (thema), which she also portrays using the symbolism of the "Captain Future" television series.

4.1 Motifs and structure of the "space travel" play: the dramatic portrayal of threat and flight.

After the group has spent two days making props, Karola begins to direct a play which deals with the threat of catastrophes and with hectic flight. When the development of the plot is discussed, Karola suggests the following motif: 


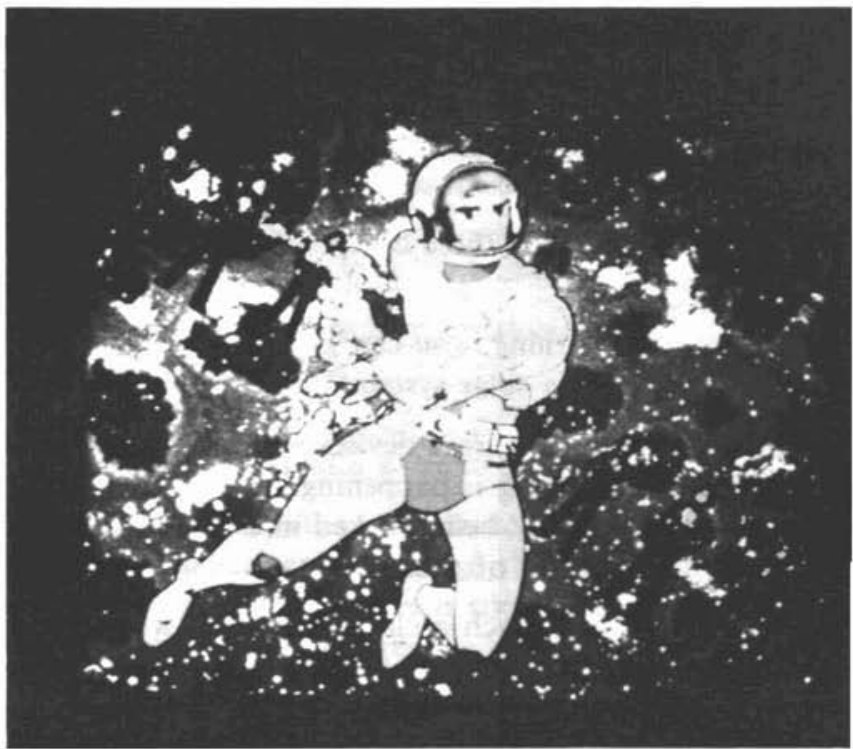

4

Captain Future, the radiant white hero

Children making properties for the game "Space Travel" $\nabla$

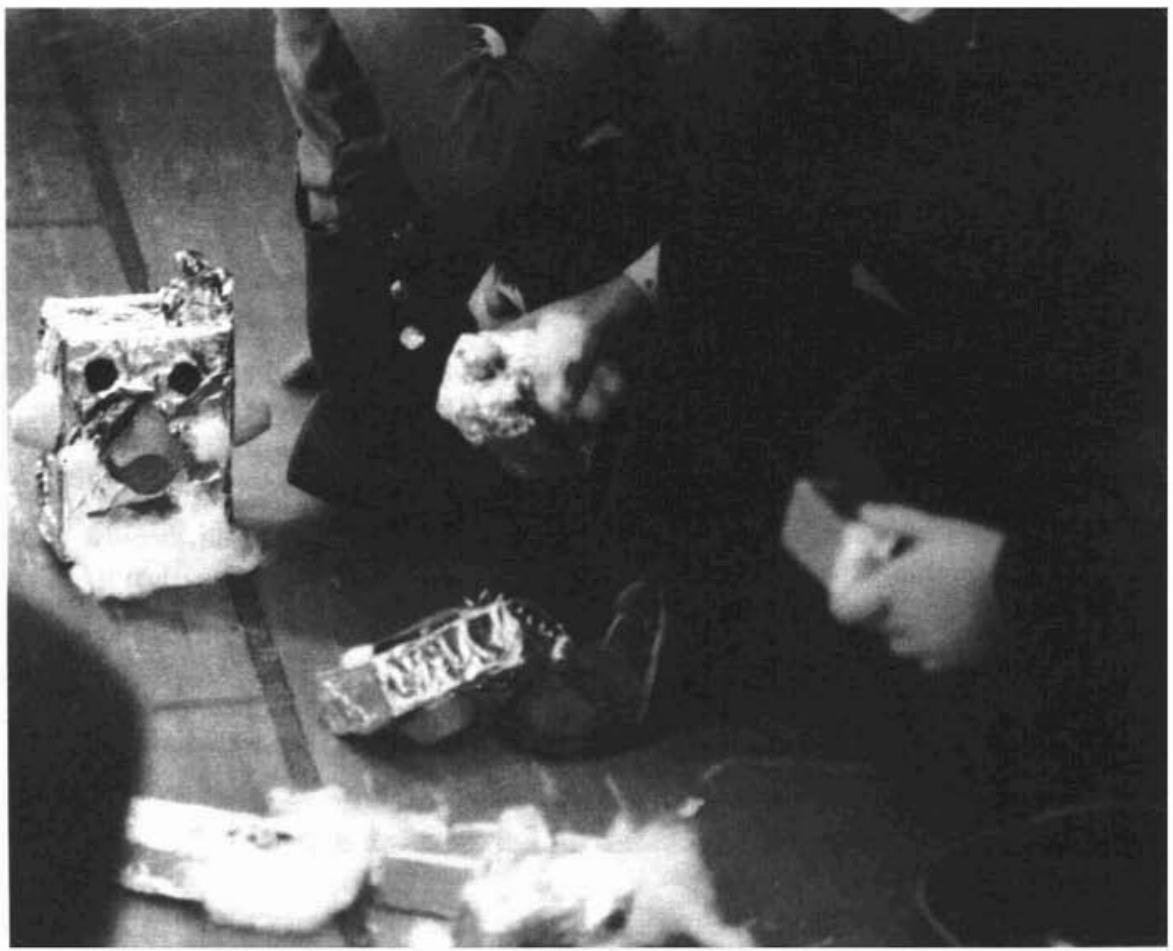


" ... With that sort of thing that you can . . . kill someone with and send them to a solar system.

...

With this thing there, you can kill someone and get him into a solar system. Then he'll go all yellow. Then you can burn him or something like that."

If one looks more closely at these comments, three components can be seen:

- deadly threat: "killing", "burning"

- anonymous threat: "with that sort of thing, you can kill someone"

- Getting to dangerous places: "send to a solar system", "get him there".

This subject forms the material from which Karola devises various catastrophes in various places: planets colliding/ something is happening/ accidents/ rockets crashing/ ice planet/ falling into stone caves/ being locked into caves/ crashing down/ in the water in the cave/ in a current of gas.

The catastrophes come thick and fast and reach a climax into 'the water-filled cave in the quarry, as planets crash together': the super catastrophe looms. - Why this threat must be, or what is behind it, is not stated by Karola. The escalating catastrophe appears to have no purpose, no cause, no reason.

Here are some examples of comments, some of which were made at very different times from others:

- the planets should crash together and we must blow something up. Then something would have happened. Somehow, there would have been an accident after that ..

- and that would have made the rocket crash, and then us down here; we would've really had to build something new, right?

- yes, and the rockets would've fallen into the stone cave, and we'd have had to blow up everything and we've had we'd have had to use all the tools and bore through everthing and ...

...

- Yea, and then we would've crashed, and then we'd be taking off again, because we'd have found nothing, then we'd have gone into the water, then that came, then we'd 've been in a cave. Oh man!

...

- Then we'd have had to go down below through the gas. And then that would 've happened, then we'd have set off again, 'cause we still could, and then we'd have, aah, fallen into the water with the cave, Yes? 
Threat and catastrophe achieve further dynamism because of time pressure:

Karola: Can you help us? In two months and 65 seconds there is going to be an explos ... .

Child: Weeks.

Child: Days

Karola: Mmmm, day-, days, in two days and 65 seconds the planet is going to explode on the Kelvis, and we must -

This subject of the imminent super-catastrophe reaches its dramatic climax in the downfall of the world:

Karola:

... you see, explosive doesn't help, otherwise our whole, our whole world is going to be destroyed.

What function does the symbolism of catastrophe and escape have? What is Karola wanting to put across by using it? Is there a topic, which corresponds with these motifs? It is clear that there is some connection. Karola can extend her position as leader in a group of creative children by the use of this symbolism.

\subsection{Motifs of catastrophe and flight as the symbolic representation of an action-determining subject (thema)}

The driving and coordinating force in the group is Karola. She has the role of the responsible group leader and acts virtually as the teacher's representative. She is thereby attempting to carry through the requirement that the group itself does justice to the task. In this role, Karola pushes the "lazy" boys on or motivates them:

Karola is criticising, for example, Sven and Andreas:

Karola: Andreas hasn't made a single thing. And I have already made so much! And you're doing absolutely nothing. At first you did something to the rocket, and now you're stuck again as to what to do!

Sven: $\quad$ So what, I've already made two robots!

Karola: I'm on the third one now and I've already made the tools and everything.

She turns to the teacher for help:

Karola: $\quad$ T. - I've realized that Andreas still hasn't finished anything!

She complains:

Karola: $\quad$ Start making things again! You're just sitting around and telling others what to do! Now you do something! Lazy thing! 
Karola is trying to motivate Katrin:

Karola: Is it going OK, Kati? Fun, isn't it? Do you think so? Are you having fun as well?

Katrin: $\quad$ No!

Karola: Why not?

Katrin: Because I don't like it!

Karola: No?

Katrin: $\quad \mathrm{Ah}$, it keeps all falling apart.

Even the beginning of the play as they developed ideas for the plot was not easy for Karola. If one looks at the end of the play, one can see that the group did indeed produce a performance, but the final scene is nothing more than chaos. The boys fool about and sabotage the seriousness of the play. Karola tries to bring about a minimum of discipline, then acts out the final scene mainly on her own, a scene which is barely comprehensible to the spectators.

The play ends with the successful escape from the mega catastrophe. So what does the situation look like for Karola as group leader? In this final scene, she is clearly pulled down from her position by the boys. She doesn't succeed in making the end of the play comprehensible and does not attain her goal of putting on a successful play. To use Karola's own symbolic expression, she has landed in the water, in the marsh or in some other uncertain place. She is in danger of sinking into the morass as far as the dynamics of the group are concerned. She is constantly in such danger. Even during the rehearsal of the play she has to impose order by quelling the boys' disruptive actions. For Karola this means constantly being concerned about the outcome of the group work. She has to work continually towards her aim of putting on a play. She has to struggle for recognition as the group leader.

She uses a story of crisis and catastrophe, the content and thrust of which underpins her position as leader. This can be seen in the following situation:

Karola: $\quad$ Please lie down, Andreas!

(Drumming sounds, shouting)

10-9-8-7-6-5-4-3-2-1 Take off! Pchch. Pch!

Got you!

The boys spoil Karola's idea:

Andreas: They are blowing up the shoes. (He is referring to the shoes of the observer.) (Drumming, laughing)

Andreas: I'm going out now in the rocket.

Eckhard: What else? We should blow up the shoes. I've already ...

(Shouting)

Karola: Nol 
Katrin! That's no good. You must burn through the fuse. How should we do it?

Andreas: ... Now all at once she starts going slowly.

Karola's annoyance combined with a desire for relevance:

Karola: The planet? In a month we must. . . (mumbles) hrr, he really is a fool, (Whistling)

Andreas: Aaaah!

Katrin introduces a new plot thread:

Katrin: I've got a great question. Can we have your.. your Wickie for a bit? Eckhard: Ja.

Katrin: $\quad$ Thanks

Eckhard: (disguised voice, angry) But don't kill him!

Katrin: No,no!

Eckhard: (angry voice) Otherwise I'll kill you.

Katrin: (playing with the figure) Wickie, Wickie! Wickie! fly off to the - to the rocket.

(disguised, squeaky voice:) Have you got it?

(Normal voice) Wickieeee! Take off! Pchch. We're coming down at once.

Andreas: $\quad$ Yes, get in!

Karola is frustrated. Again wants to introduce a sense of relevance:

Karola: (Groans softly to herself:) Aaah, I'm having a heart attack.

Katrin: Oh, he's here again!

Karola: Cut through the fuse! Give me the small animal. I'll cut through the fuse!

Eckhard: $\quad$ Down here is a stupid box.

Karola's catastrophe motifs are not effective. The other children act their own stories, or their own characters. The confusion is complete. Here she is saying: "Now he should be on the planet and he could never get away again. (And to herself). Now keep calm!" By "he" she possibly means the main character of the play "Captain Future". It is true that Andreas is playing this leading male character: but he demotes "Captain Future" from being a manly hero and makes him into a funny minor character. Karola, on the other hand, continues to play the leading male character. Here one could argue that Karola is identifying herself with this male character ("he"). Seen in this way, her picture of a captured hero: "and then he could never again get away" would also be true of her. She would be locked in her position as 'leader':, because she wants to direct a play with children who will not allow themselves to be involved. Like the hero of her play, she tries to escape from the catastrophes. In the play she follows two paths to this end. 
One that is $(+)$ aggressive: and involves explosives, freeing by force etc; the other is $(+)$ constructive: and involves building something new, using tools, boring etc. Her way of behaving as group leader and director fits in with this pattern. She uses an authoritarian and aggressive manner with Sven, the uncooperative outsider:

Sven you're not joining in again.

(to Andreas) Bash him one!

After this aggressive solution to the group crisis, she again uses her catastrophe story, almost as a tool. She involves the boys, by telling them they should prevent the planets crashing and the ensuing world destruction. She stresses the seriousness of the situation not only by referring to the catastrophe of world destruction, but also by emphasising time pressure, caused by the imminent nature of the catastrophe.

Mmm. Day- days-, in two days and 65 seconds the planet is going to explode on the Kelvis, and we must -

But first of all you have to act properly, Andreas!

You see explosives don't help, otherwise our entire - our entire - our entire universe will be destroyed.

The more important the catastrophe and escape stories become for Karola, the more she has to bring the other children to her way of thinking and to exclude other ideas. The harder she fights for group cooperation, the more use she makes of her catastrophe and escape symbolism, which she presents as a communal danger. By doing this, she enforces a greater sense of togetherness in the group.

\subsection{The correspondence between the television series and the subjective themes of catastrophe and escape.}

There are several points of contact and similarity between the theatrical activity of Karola's group and the TV series "Captain Future". There is first of all the hectic nature of the film series, the action-packed narrative, so characteristic of "Captain Future" and similar adventure series. Secondly there are the motifs of catastrophe and escape, which in part take the form of quotations from the television series. ${ }^{17}$

\section{Hectic activitiy and stress}

The television series "Captain Future" is structured in such a way as to give the impression of hectic activity. Every episode consists of a rapid succession and mixing of very short shots, comprising dramatic music and brief verbal comments, all of which signal hectic activity and stress. This corresponds to Karola's strate- 
gy, in which the origins of catastrophe virtually crowd in on each other. The pressure is intensified through the abundance of theatrical subjects, which are reinforced by linguistic expressions of compulsion ("now we must", "we simply must" "very fast"). The hectic activity or stress which ensues from this can be seen in the following example:

Karola:

We just have to hope that it does not crash, otherwise we'll be in the cave.

Andreas: It has crashed!

Karola: Jea, uumm, we haven't even taken off yet.

Andreas: Well, we've crashed, because one too many got -

Karola: We simply must take off first, we've got to fly - to fly through there. And if - and not until then can there be an earthquake. We simply must take off very quickly.

Andreas: $\quad$ Oh yes, take off quickly, psh, psh.

Karola: That could happen even in a couple of hours.

Hurry. Quick.

Eckhard: In a few seconds, too. Beep, beep.

Andreas: Hay, you, Oskar!

Eckhard: $\quad$ My name's Otto, you fool.

Andreas: Hay, Otto!

Eckhard: Yes.

Andreas:

Eckhard:

Karola:

Can you feel something?

Andreas:

Eckhard:

Karola:

Andreas:

Karola:

Andreas:

Yes, I can feel a power cut. The moon is exploding even

Karola: It could happen in a few seconds!

Danger of moon excession, in how many minutes or hours? In ten thousand minutes! deet-deet-deet.

10-9-8-

No!

\section{-5-4-3-2-1-Start!}

$\mathrm{Ah}$, the rocket is climbing.

Now we must be in the cave, Yes? OK, now we must all get out, we could all get out on time. Quick, get out. It could be destroyed in a few minutes. Quick. Get out!

\section{The motifs from "Captain Future" in Karola's story}

In addition, Karola uses an abundance of motifs which also come up in the television series. The motifs are in varying degrees concrete, and are sometimes so general that they appear in many comparable media forms, and are therefore characteristic of stories - also found in the media - of adventure, catastrophe and escape. In the following section we have selected two catastrophe motifs which have a connection with "Captain Future". 
Karola's motifs belong to the following story: The rocket falls on a water planet and is submerged. Under the water there is a cave which leads to the "Solar system at the Kelvis". There is a danger of the "Kelvis" exploding in the cave and destroying the planet. The motifs of 'being locked in'/ 'being submerged' and 'destroyed'/ 'exploding' appear in an internal connection here (explosion in a cave under water) and all develop into a super catastrophe.

Karola's motif of "Collision and Explosion":

Moons and planets collide, the planet "Kelvis" explodes

Corresponding "Captain Future" motifs and sources in "Captain Future":

- The earth is threatened by a collision of the planets.

Images: cracking earth surface, volcano eruption, explosion, destroyed cities, people in a panic, fire.

Source: "The Black Planet, Episodes 1-3.

- The Future crew has made an emergency landing on a planet threatened with explosion. Images: fire, molten lava, earthquake, exploding planet.

Source: "Capture in the Universe", Episode 2.

- Planet description Celbes (="Kelvis") in an explosive plot context. Source: "The Black Planet", "Capture in the Universe".

- As a result of a blasting, a part of a planet's surface explodes

Images: volcanic eruption, explosion, earthquake, molten lava engulfs a human being and destroys buildings, fire.

Source: "The Fight for the Gravium Mines". Episode 1.

Karola's motif: 'Being submerged and locked in':

The rocket is submerged and they are stuck in a cave under water.

Corresponding "Captain Future" motifs:

- Captain Future is caught under water in a mine shaft which is collapsing.

Images: cracking walls, masses of water pouring in, whirlpools, rising water level, surface of the planet covered with water, spaceships under water.

Source: "The Fight for the Gravium Mines", Episode 2.

- Captain Future is transformed into a fish and held prisoner in a cage in an underwater cavern.

Images: Cavern, water, the path to the water leads through a cavern.

Source: "The Fight for the Gravium Mines", Episode 3.

- The spaceship of the Future crew has made an emergency landing on a planet threatened with explosion and sinks into a pool of lava.

Images: exploding planets, earthquake, volcano eruptions,molten lava, fire.

Source: "Prisoners in Outer Space", end of Episode 1, Episode 2.

\subsection{Conclusion about creativity, expressive and interpretative possibilities}

What is striking here is the correspondence between the television series and the behaviour in a group situation, in which the symbolism or the dramatic expression employed in the series overlaps with the ideas and topics which the girl in this si- 
tuation is trying to convey (hypothesis 1). Although the relationship with the television series is blurred, the contours of the series (threat, time pressure etc.) form a strategic background against which the girl manages the relationship within the group. In this way she succeeds in bringing together her own ideas (function of leader, being threatened, being under stress), the group situation and the dramatic expressions from the series (hypotheses 2,7). She makes use of an abundance of quotations from various episodes in the series, which make it possible for the detached observer to recognize their specific and current location (hypothesis 5). The dramatic expressions used by the girl, however, prevent the other children from perceiving the underlying expressive function (otherwise they would realize what was happening in terms of group dynamics).

The blurring of television experiences and television symbolism intensifies the strain under which the girl is operating and this probably increases the tension which forms the basis of what she is seeking to convey. It can be assumed, on the other hand, that this promotes symbolic and fantasising attempts to resolve matters in a more positive, that is less exhausting, manner than was possible in the children's group. She finds one such a solution in the media, especially in those action-packed presentations which lead to a high emotional tension in the spectators, but which do not at the same time, trigger off confusion in group relationships (reference to hypothesis 4).

\section{Notes}

1 Preceding this was a kindergarten study (Bachmair 1984 and 1989). This was followed by a study of the relationship between the mass media and the daily lives of young people (Bachmair et.al. 1988). Although various studies go beyond a consideration of that age group, a comparability of the symbolic mediation processes in relation to the mass media can be ascertained.

2 The pedagogic concept of the associative sphere of fantasy and creativity is directed at the symbolic processing of television experiences, television symbolism and subjective actiondetermining subjects'. Cf. Bettelheim 1977, Erikson 1978. Media pedagogic concretisation by Bachmair 1990.

3 Research report relating to this study (Bachmair et.al. 1984). This report first of all emphasises the results of observation descriptively and chronologically under the categories of behavioural development of the children and the context of group dynamics. Within this context the 'media traces' are identified. Using a systematisation based on communication theory, the observation data are combined under the category of the situational and didactic intention of the symbolic processing of media experiences and media symbolism.

References to studies of receptivity (children/television) can be found, among others, in the following:

Allouche-Benayoun, B.J., 1975

Arbeitsgemeinschaft Rundfunkwerbung (Ed.), 1981, p. $297 \mathrm{ff}$

Baacke, D., 1979 
Barthelmes, J., 1987

Boeckmann, K./Hipfl, B./Stotz, G., 1985

Darschin, W., 1976, 1977

Egeri, U., 1983

Ekrut, p., 1977

Feilitzen, C.v., 1975

Hengst, H., 1973

Horn, I., 1976

Jensen, K., 1980

Kübler, D., 1980

Leifer, A.D., 1975

Luger, K., 1985, p. $85 f f$

Nevius, J.R., Jr., 1980

Platner, G., 1981

Prokop, D. (Ed.), 1985

Reid, L.N./Frazer, Ch.F., 1980

Riedel, K.V., 1966, p. 46ff

Röhner, Ch., 1987

Rogge, J..U., 1984

Saxer, U./Bonfadelli, H./Hättenschwiler, W., 1980, p. 3-45, p. 159-220, p. 231-235

Schmidt, C. et al. 1989 , p. $171 \mathrm{ff}$

Tsadarkis, D., 1981, p. $105 \mathrm{ff}$

4 These are the theories and studies, the paradigmatic basis of which was formulated by Lasswell (1948) with his well known question: "Who says what to whom through which channel with what effect?". Summary in Langenbucher et al. 1978.

5 For the argument being developed here, Berger and Iuckmann's theory is important. This theory describes the cultural and objective side of symbolic acquisition within the socialisation process, with particular reference to language. Further reading in Bachmair 1979a and b.

6 Cf. H. Blumer's summary, 1973.

7 Cf. Hans Mayer, 1980.

8 Bettelheim, 1977

9 Cf.J.Israel's "Einführung in die Sozialpsychologie (Introduction to Social Psychology). 1976

10 See the systematic consideration of this in Bachmair 1989b.

The question of symbolic mediation, for example, in the direction of media 'shaping' is investigated in an empirical study with young people: Bachmair / van den Hövel et. al.: Research report 1988 and Bachmair $1989 \mathrm{~b}$.

11 Concept of the television includes the following phenomena:

- the reception situation, e.g. arguments concerning television

- television symbolism, film motifs, narrative sequences, styles of film production among other things. The important point is that television symbolism is used by children, without this having to be based upon television experiences.

The reception situation remains mostly outside the sphere of investigation, because within the school context they only have a role as a frame of reference, dealing for example with such questions as: "Did you watch that on Saturday?" (The investigation of Bachmair $1989 \mathrm{a}$ is concerned with reception situations.)

2 This relationship can be depicted using the following metaphor: The children take what they need out of all the television rubbish, in order then to create their own works of art.

13 A.V.Cicourel's methodical suggestion of triangulation was stimulating here.

$14 \mathrm{Cf}$, the hypothesis of the communicative correspondence between research object and research method: Bachmair 1989c and 1989d. 
In order to distinguish media experiences from media symbolism, it is important to note that media experiences do not necessarily need media symbolism as a means of presentation. Likewise the use of media symbolism does not have to be seen as following on from media experiences.

17 A further connection between the pupils' performance and the television series is found in relation to the character of Captain Future. This is, however, very difficult to verify and then only with the help of extensive textual comparisons. The reason for this lies in Karola's 'blurring' tactics.

\section{References}

Allouche-Benayoun, B. Joelle: Der Einfluß des bewegten Bildes auf Kinder und Jugendliche. In: Fernsehen und Bildung, 9/1975/2-3, p. 229-247.

Arbeitsgemeinschaft Rundfunkwerbung (Ed.): Media Perspektiven. Kinder - Medien Werbung, Frankfurt/M. 1981.

Baacke, Dieter: Realitätserfahrung und Ich-Findung durch Erzählen im Fernsehen. In: Fernsehen und Bildung, 13/1979/3, p. 222-242.

Bachmair, Ben: Medienverwendung in der Schule, Berlin 1979a.

Bachmair, B.: Ethnomethodologie als handlungstheoretische Grundlage einer Didaktik der Kommunikation. In: Bildung und Erziehung, 1979b/3, p. 229-240.

Bachmair, B.: Mit eigenen Augen sehen - der Versuch, Fernsehen didaktisch zu zähmen. In: Medien und Erziehung, 24/1980/4, p. 194-204.

Bachmair, B.; Thüne-Schoenborn, B.: Symbolische Verarbeitung von Fernseherlebnissen in assoziativen Freiräumen. Forschungsbericht vol. 1, Kassel 1984.

Bachmair, B.; Klinger, M.; Thüne-Schoenborn, B.: Symbolische Verarbeitung . . . vol. 2, Kassel 1984.

Bachmair, B.; v.d. Hövel, M.; v. Waasen, M.; Hofmann, B.: Dynamik symbolischer Vermittlung von Alltagshandeln und Massenkommunikation. Forschungsbericht (Manuscript) 1988.

Bachmair, B.: Thematisch und situativ integrierte Fernsehrezeption im Kindergarten. In: Erlinger, H.-D. (Ed.): Kinderfernsehen II (in preparation), 1989a.

Bachmair, B.: Mobilität und Medienförmigkeit - Kulturhistorische Skizzen zur Erziehung im Medien- und Konsumnetz. In: Mann, M.; Zacharias, W. (Ed.): Medien und Pädagogik 2001, München 1989b (in preparation).

Bachmair, B.: Symbolische Vermittlung - Argumente, Beispiele und Stichworte zu einer Handlungs-, Kommunikations- und Medientheorie. In: Conrady, P.: Literatur-Erwerb, Frankfurt 1989c (in preparation).

Bachmair, B.: Analyse symbolischer Vermittlungsprozesse am Beispiel von Kindergruppen; Überlegungen zum Zusammenhang von Forschungsgegenstand und Forschungsmethoden. In: Baacke, D.; Kübler, H.D. (Ed.): Qualitative Medienforschung, Tübingen 1989d (in preparation). 
Bachmair, B.: Folgen kommunikationstechnologischer Innovationen aus pädagogischer Sicht. In: Deutsches Jugendinstitut (Ed.): Medien im Alltag von Kindern und Jugendlichen. Methoden, Konzepte, Projekte, Weinheim/München 1988, p. 141-158.

Bachmair, B.: Gestaltungsräume inszenieren. In: Schill, W.; Tulodziecki, G. et al. (Ed.): Medienpädagogik in der Schule (in preparation), 1990.

Barthelmes, Jürgen: Kindliche Weltbilder und Medien. Eine Literaturanalyse zur Mediensozialisation, München 1987.

Berger, P.; Luckmann, T.: Gesellschaftliche Konstruktion der Wirklichkeit, Frankfurt 1970.

Bettelheim, Bruno: The uses of enchantment. New York 1975. (German edition: Kinder brauchen Märchen, Stuttgart 1977.)

Blumer, H.: Der methodologische Standort des symbolischen Interaktionismus. In: Arbeitsgruppe Bielefelder Soziologen (Ed.): Alltagswissen, Interaktion und gesellschaftliche Wirklichkeit, vol. 1: Symbolischer Interaktionismus und Ethnomethodologie, Reinbek 1973.

Boeckmann, Klaus; Hipfl, Brigitte; Stotz, Günther: Auswirkungen des Kabelfernsehens auf die Mediennutzung von Kindern und Jugendlichen, Bericht über die qualitative Teilstudie, Klagenfurt 1985 (unpublished manuscript).

Cicourel, A.V.: Sprache in der sozialen Interaktion, München 1975.

Darschin, Wolfgang: Kinder vor dem Bildschirm. Erste Ergebnisse der teleskopieFernsehforschung. In: Media Perspektiven 8/76, p. 366-370.

Darschin, Wolfgang: Veränderungen im Fernsehkonsum der Kinder. Neue Ergebnisse aus der kontinuierlichen Zuschauerforschung. In: Media Perspektiven 11/77, p. 613-624.

Egeri, Ursula: Mediennutzungsverhalten als bewußtes Handeln, Frankfurt/M. 1983.

Ekrut, Sybille: „Lassie“. Ein Beispiel der Identifikationsangebote in fiktionalen Fernsehdarstellungen für Kinder. In: Praxis Deutsch 25/77/-, p. 19-23.

Elias, N.: Über den Prozeß der Zivilisation, 2 vols., Frankfurt 1976.

Erikson, E.H.: Kinderspiel und politische Phantasie, Frankfurt 1978.

Feilitzen, Cecilia v.: Ergebnisse skandinavischer Forschungen zum Thema Kind und Fernsehen im Sozialisationsprozeß. In: Fernsehen und Bildung, 9/1975/2-3, p. 143-173. Hengst, Heinz: Schallplatten und Kassetten für Kinder. In: Medien und Erziehung, 23/1973/3, p. $149-160$.

Horn, Imme: Kinder und Fernsehen. Neuere Untersuchungen zum Fernsehverhalten von 3bis 9jährigen. In: Media Perspektiven, 8/76, p. 357-367.

Israel, J.: Sozialpsychologie, Stuttgart 1976.

Jensen, Klaus: Der kindliche Umgang mit Massenmedien. In: Zeitschrift für Pädagogik, 26/1980/3, p. $383-399$.

Kübler, Dieter: Kinder und Fernsehen. Ein Literaturbericht. In: Zeitschrift für Literaturwissenschaft und Linguistik, 1980, Beiheft 11, p. 136-204.

Langenbucher, W.; Räder, G.; Weiß, H.-J.: Zur Notwendigkeit einer neuen Konzeption der Massenkommunikationsforschung in der Bundesrepublik. In: Berg, K.; Kiefer, M.L. (Ed.): Massenkommunikation. Eine Langzeitstudie zur Mediennutzung und Medienbewertung, Mainz 1978, p. 9-39.

Lasswell, H.D.: The Structure and the Function of Communication in Society. In: Bryson, L.: The Communication of Ideas, New York 1948. 
Leifer, Aimée Dorr: Untersuchungen über die Sozialisationseinflüsse des Fernsehèns in den Vereinigten Staaten. In: Fernsehen und Bildung, 9/1975/2-3, p. 111-141.

Luger, Kurt: Medien im Jugendalltag, Wien/Köln/Graz 1985.

Mayer, Hans: Das unglückliche Bewußtsein. Zur Literaturgeschichte von Lessing bis Heine. Frankfurt 1986.

Nevius, John R., Jr.: The „,Cookie Monster“ and Cognitive Enculturation. In: Educational Technology, Bd. 20, 1980, Nr. 9, p. 57-60.

Platner, Geert: ,,So leben wie die Serienhelden: öfters mal Denkpause". Schüler erkunden die Fernsehgewohnheiten ihrer Mitschüler. In: päd. extra, 12/1981/-, p. 35-39.

Prokop, Dieter (Ed.): Medienforschung, vol. 3. Analysen - Kritiken - Ästhetik, Frankfurt/M. 1985.

Reid, Leonard N.; Frazer, Charles F.: Television at Play. In: Journal of Communication, 30/1980/4.

Riedel, Karl Veit: Jugend und Fernsehen. Untersuchungen und Überlegungen zur Jugendeignung von Fernsehprogrammen, Neuwied 1966.

Röhner, Charlotte: Stark wie ein ,,Master" und bildschön wie „Barbie“. Die Medienwelt der Kinder wahrnehmen. In: Die Grundschulzeitschrift, 9/1987/-, p. 19-23.

Rogge, Jan-Uwe: Mediengewohnheiten und Medienhandeln ausländischer Kinder. In: Wittemann, Peter (Ed.): In der Fremde zu Haus, Stuttgart 1984, p. 71-86.

Saxer, Ulrich; Bonfadelli, Heinz; Hättenschwiler, Walter: Die Massenmedien im Leben der Kinder und Jugendlichen, Zug 1980.

Schmidt, Claudia; Bruns, Christoph; Schöwer, Christiane; Seeger, Christoph: Endstation Seh-Sucht?, Stuttgart 1989.

Tsadarkis, Dimitrios: Die Rolle des Fernsehens im Sozialisationsprozess unter besonderer Berücksichtigung griechischer Kinder, Frankfurt/M. 1981. 
Ben Bachmair, Burkhard Hofmann, Michaela van Waasen, Martina van den Hövel

\section{Media analysis within an activity-context - Understanding a girl's activities and verbal images}

In the following case study, a film is used as an aid to interpretation, in order to decipher the meaning of a girl's statements and to discover how this girl perceives an activity-context. We are dealing here with an example taken from a media education research project which examines the communicative mediation between the everyday activities of young people and mass communication. ${ }^{1}$

\section{Verbal image and media trace - from the "smiling witch" to the film "The Fall of the Roman Empire"}

\subsection{The verbal image "smiling witch" within the context of an educational 'event'}

In the context of an educational project at an exhibition of contemporary avantgarde art, a Turkish girl (Melek) recounts that she is a smiling witch and describes a scene of torture and death. In so doing, she makes reference to a television film. How did she arrive at these statements? In what activity-context can they be placed and to what characters do they refer? ${ }^{2}$

Melek is about 17 years old. She comes from Turkey but her German is almost that of a native speaker. She spends a large amount of her leisure time in a youth club. Whenever she shows up, brimming over with energy, there is always something going on. She speaks to people in an open and uninhibited manner. She comes across as self-assured and, because of her various friendships, she is well integrated into the group. In the educational project in which Melek is taking part, the young people take the exhibited works of art as symbolic material for their own creative products. These they will present with other young people on the occasion of a public 'happening'. For this purpose audio recordings and photographs are made at the exhibition. After an initial rejection of art (" . . it's all just crap" "), Melek takes up two ideas. One of them is an idea she herself has when she looks at her photo of a sarcophagus (an exhibit by Jenny Holzer). She says: "We should have quite simply lain down upon it". Another idea, not her own, is that of a funeral pyre. This links in with an exhibit by Tadashi Kawamata situated in a boarded-up ruined church which is made up of 'fluid' wooden slats (= funeral pyre). 
Both events are photographed with a view to making a sound-and-slide performance for all the young people's 'happening'. During the first event, Melek lies down, a 'beautiful dead woman', on Jenny Holzer's black sarcophagus. She wears a flowing, bright yellow dress and has a rose and a plastic gun in her hand. Melek has carefully prepared for this event, for example, she has brought along the props. She knows what she wants and how the event should run.

The second event, on the other hand, proceeds in an unstructured manner. The only thing that is clear to all those present is that Melek is to be photographed as a witch in the slatted wooden structure in the church ruin. A whole host of ideas is produced on the spot, many different photographic poses are tried out. Finally this event merges into one about the burning witch who is dragged onto the funeral pyre by the torturer. The group, young people and tutors, project a lot of ideas onto Melek, some of which she takes on board. Melek is there in turn as a witch figure, a photographic model, an attractive, lively young woman, the centre of the group's attention.

When the photographic event 'Torturer/Witch' is nearly finished, Melek states that she is the "Witch with the smile", a point which is not taken seriously, however, by the tutor. She thus repeats her statement, referring then to a television film. A short conversation follows, of which the following is a transcription:

$\begin{array}{lll}\text { Melek: } & 264 & \text { Yes, but still, there are witches who } \\ \text { Erika: } & 265 & \text { smile,aren't there? } \\ \text { Melek: } & 266 & \text { (prob.: because they're witches, Melek) } \\ & 267 & \text { Yes but there was just now a film on television, } \\ & 268 & \text { yea? And there he, there he, } \\ & 269 & \text { they kept burning this man's hand. When was it on, } \\ & 270 & \text { the day before yesterday, } \\ & & \text { or sometime. And they kept on and on burning the } \\ & 271 & \text { and he didn't cry out once, he } \\ & 272 & \text { only screwed up his face.// And grinned. } \\ & 273 & \text { // Things like that happen, you know.// Long ago, be- } \\ & & \text { fore } \\ & 274 & \text { Christ, just imagine all the things that happened. } \\ & 275 & \text { // Hey, what's he staring at? } \\ & 276 & \text { (laughs) } \\ & 277 & \text { (Name of tutor), he's surprised, that's all. (laughs) } \\ \text { tutor: } & 278 & \text { Yes. I was only surprised just then. What } \\ \text { female tutor } & \text { film was it you saw then? It was that Roman } \\ \text { tutor: } & 279 & \text { film, wasn't it? }\end{array}$


Melek: $281 \quad$ Yes. He just kept on screwing up (his face) and

282 looking up and he opened his mouth

283 and said something like Ugh, Ugh, and cried

284 out.

Erika: $285 \quad$ Pleasure in suffering.

Melek: 286 And when the arrow hit him as well,

287 yea, at the end, then he still just //

288 he still just stood there and, yea, it just

289 hit him and he held his hand in there

290 and. /It's true, isn't it.

The photographic event ends here.

What happened in this confused situation? How did Melek experience this situation? What does she want to express by means of the image of the smiling witch. Is she trying to underpin this image by referring to a television film? What meaning does the reference to torture have: "And they kept on and on burning the man's hand"' (270). The important point is that Melek, with her statement about the smiling witch (250) moves on, within the situation, to a new and original form of representation, which those around her do not take on board and do not understand. When the young girl then speaks of a television film, her listeners take as little notice of the content of this statement as they did before of the image of the smiling witch. Although Melek gets the attention of the educationalists with her reference to the television film and presumably also with the violence element of her story, Melek nevertheless is, in the first instance, not understood.

\subsection{A film as the interpretative background to understanding the activity- context and the verbal image}

The assumption of this work is that both the statements of the young Turkish girl and also the activity-context become understandable in retrospect, when the girl's reference to the television film is subjected to further media analysis. The television film thus takes on the function of an interpretative background for the understanding of Melek's statements in the activity-context. Put theoretically, it is a question of relating Melek's statements as symbolic representations ${ }^{4}$ in an activity-context to the film which is seen as the source of this symbolism and of using the thus ascertained meaning of the statements relating to the film to interpret the activity-context.

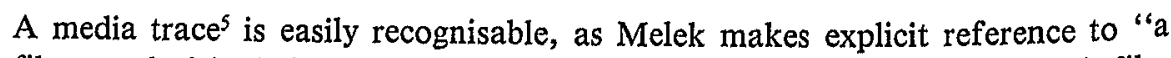
film on television" (267f). The further comment of Melek about the time this film was on ("When was it on, the day before yesterday, or sometime", 269) also makes it possible to determine the title of the film. The film in question is one lasting about $21 / 2$ hours entitled "The Fall of the Roman Empire", U.S.A, 1963, 


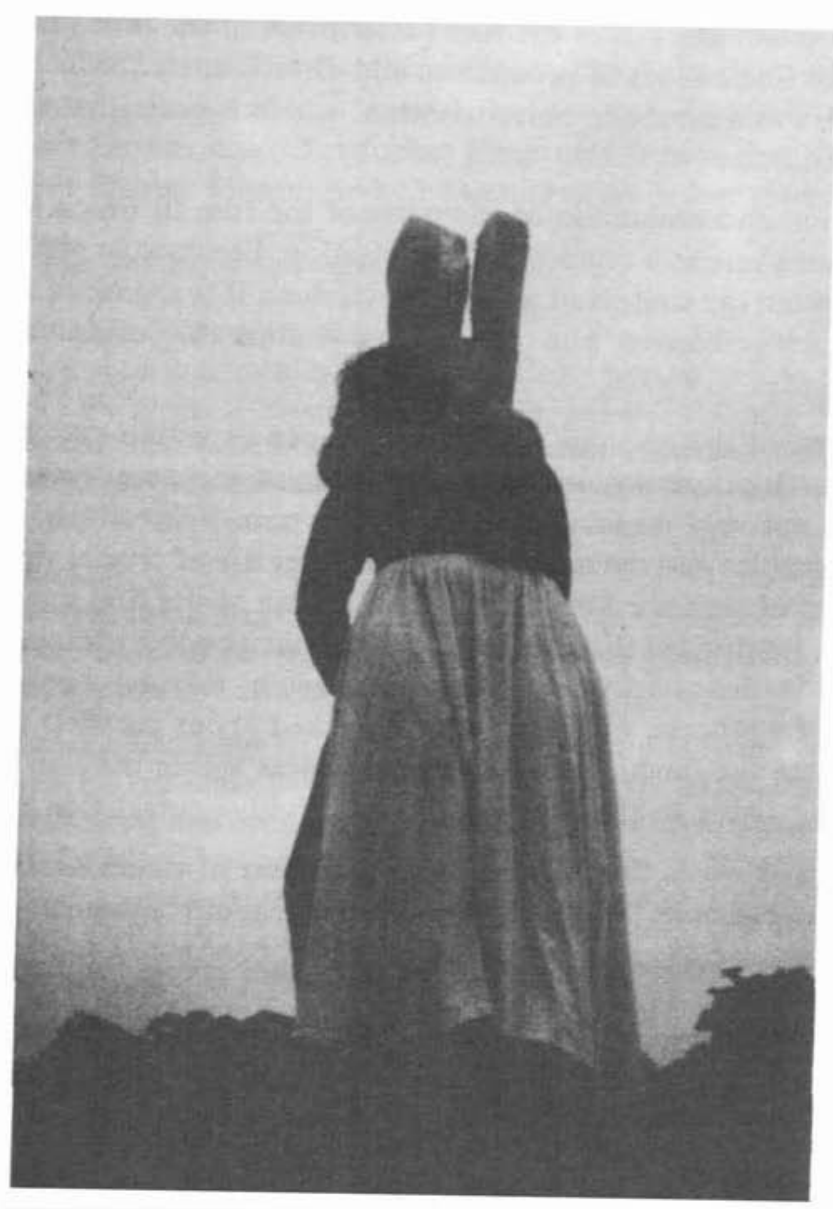

Melek explains her idea of the 'smiling witch'

Director: Anthony Mann), which had been screened a few days previously by ZDF ("Zweites Deutsches Fernsehen"', Second German Television). ${ }^{6}$ One of the tutors had already recognised the film during the activity-context: "It was that Roman film, wasn't it?" 279 f.) Melek confirms that his assumption is right.

Because the significance of Melek's comments about the film is not immediately apparent, first the film as a whole then the film sequences to which Melek refers will be reconstructed and presented in written form. In total, the work will be divided into three stages (see also section 4.2): 
- Examination and analysis of the film (description of the film's thematic complexes, story lines, issues of production and direction, etc.). The film is reconstructed here as a symbolic objectivisation, which is basically independent of its reception.

- Identification and evaluation of the parts of the film to which Melek refers. The film, seen here as a symbolic objectivisation, becomes an object which has meaning within the context of an activity-context. It is examined as something communicated, received and experienced within this communication and activity-context.

- Bringing out of the meaning of the film sequences within the context of the whole film. This is particularly important, because these sequences, seen in isolation, are not very meaningful. However, in terms respectively of the film's thematic complex and the narrative strands, they are of crucial significance (in anticipation of such a result). From the meaning of the film sequences which has been reconstructed through film analysis, the possible meaning of Melek's statements in the activity-context (smiling witch, torture, death) can be inferred. In the process, questions must be asked about parallels or contradictions between the function of the film sequences within the film and Melek's statements relating to the film within the activitiy-context (see Section 3.2)

In this area of work, the film is again the subject of examination, seen as an autonomous symbolic objectivisation independent of the manner of reception.

These areas of work are heuristic subdivisions: they create the framework of a methodical procedure. Depending on the activity-context, on the media trace, on the medium itself, these sections are to be converted into different work phases or sequences of work phases.

\section{Conducting the media analysis against the background of the activity-context}

\subsection{Summary of the story lines, the characters and the thematic complex of the film}

"The Fall of the Roman Empire" is a typical epic film. The broadly structured story, produced in a somewhat shorter television version of about $21 / 2$ hours, increases its spectacular appeal by the use of huge armies of film extras, crowd scenes, lavish costumes, magnificent buildings and scenery.

What is already advertised in the title of the film is immediately confirmed in the introductory background commentary: the subject is historical; what is going to be described is the beginning of the end of the Roman Empire. The causes of this 
historic development are presented in the form of personification which takes place against a background of conflict between the main characters. These are Emperor Marcus Aurelius (Alec Guiness), his daughter Lucilla (Sophia Loren), his son and heir Commodus (Christopher Plummer), Timonides, the close friend of the Emperor (James Mason) and Livius, the army leader (Stephen Boyd).

\section{a. The story threads which run through the film:}

- Political and historic development

The Roman Empire is in conflict with enemies from without, especially the Teutons. The policy of the Emperor Marc Aurel is directed towards civilising the Teutons and towards peaceful coexistence with the subjugated tribes. After the death of Marcus Aurelius his successor, Commodus, abandons this policy for selfish reasons and this finally leads to the fall of the Roman Empire.

\section{- Unfulfilled love}

The love between Livius and Lucilla remains unfulfilled throughout almost the whole story, because reasons of state demand this sacrifice (to safeguard freedom) and because Commodus foils this love through anger and revenge.

\section{- Involved family relationships}

It transpires at the end of the film that Commodus is not the natural son of Marcus Aurelius. He is therefore also not the lawful heir to the throne. Commodus kills his natural father (when the latter gives away the secret). The relationship between Lucilla and her brother, who is actually the step-brother, is characterised by life-threatening hatred.

\section{b. The constellation of the protagonists:}

The events of world history are presented in personified form as conflicts between the principal characters. Aurelius, Timonides, Livius and Lucilla form a group who are struggling for the well-being and continued existence of the Roman Empire, with Commodus as their opponent. In these characters, or this group of characters, the following principles oppose each other: morality, reason, a sense of duty, civilisation, peaceful progress versus amorality, the pleasure principle, selfishness, a hunger for power, luxury and decadence.

- The Emperor Marcus Aurelius, the person who is paving the way for peaceful coexistence with the peoples who are to be civilised, is poisoned by his son's close friend.

- Lucilla, Marcus Aurelius's daughter, represents the political heritage of her father.

- Livius is the army leader of high morals, intimate friend and foster-son of the Emperor, a person who behaves with integrity. Lucilla and Livius are lovers.

- Timonides, a Greek philosopher and close friend of Marcus Aurelius, continues, after the latter's death, the Emperor's commitment to civilisation, at the cost of much personal sacrifice. In so doing, he builds and relies upon reason and peaceful progress.

- Commodus, the egoistic and hedonistic son of Marcus Aurelius, goes mad and finally brings the Roman Empire to its knees. 


\section{c. The constellation of themes:}

The theme of sacrifice, of being sacrificed, is central. It is directly connected with the aims of civilisation, with peaceful coexistence and with the preservation of the Empire. Behaviour based on moral principles is inseparable from sacrifice which has existential significance for the individual who makes it. The protagonists become victims of power and state policy. Standing as they do for a higher ideal (humanism, reason) and for the general good, demands of them a readiness to renounce personal happiness and well-being. They are thus raised to the exalted status of victorious champions and heroes.

This thematic complex of readiness to make sacrifices and the exaltation to superhuman status is of fundamental importance, when Melek refers to torture in talking about the film.

The following thematic constellations are also discernible: male friendship / male rivalry; peaceful progress / violence; civilisation / barbarism.

\subsection{The film sequences described by Melek}

An examination of the film clearly shows that Melek is referring to two sequences:

- the film sequence 'Torture':

Timonides is tortured before a sort of 'Divine Tribunal' by the Teutons whom he wants to persuade to live in peaceful coexistence with the Roman people. (Analysis see 2.2.1)

- the film sequence 'Death':

Timonides is killed by Roman soldiers during a feast which he is sharing with the now peace-loving Teutons who have in the meanwhile taken up his ideas of peace and humanity. $\mathrm{He}$ is hit by a javelin while he is appealing to the murdering soldiers to show a desire for peace. (Analysis result, see 2.2.2).

\subsubsection{Analysis of the film sequence 'Torture'}

The film sequence takes place in a big cave, a sort of place of worship for the Teutons who are captured and held there by the Romans. In this cave there stands a statue of the Teuton god Wotan. The protagonists are Balomar, leader of the Teutons, and Timonides.

Running time of film: 1 hour, 35 minutes; length of the film sequence: about 3 minutes, 20 seconds.

a. The film sequence consists of the following six segments:

(1.) Speech of Timonides to the prisoners. Timonides invites the prisoners to live together in peaceful coexistence.

(2.) The Teutons overpower the unsuspecting Timonides. The leader of the Teutons forces Timonides, as representative of the Roman gods, to take hold of a burning torch, so 
as to determine the superiority either of the Roman gods or of the Teuton god Wotan. If Timonides submits to the statue of Wotan then the torture will be stopped.

(3.) Timonides argues as a philosopher. He rejects physical suffering as a test.

(4.) Timonides is tortured three times by Balomar thrusting his hand into a torch. As this is happening, the camera shows Timonides's distorted face. Timonides could call to the Roman soldiers for help, but he does not do this, however, as the latter would kill the Teutons. During the torture Timonides changes the form of his spoken resistance: from humanitarian arguments to verbal expression of human vulnerability, to aggression and the admission of helplessness.

Melek's statement refers to this segment: "And there he, there he, they kept burning this man's hand ... And they kept on and on burning the man's hand, and he didn't cry out once, he only screwed up his face.// And grinned" (268-272) - "He just kept screwing up (his face) and looking up and he opened his mouth and said something like Ugh, Ugh. . ." (281-283)

The following is a detailed description of an excerpt from the shooting script of segment 4 of the film sequence:

\begin{tabular}{|c|c|c|c|c|}
\hline \multicolumn{2}{|c|}{$\begin{array}{l}\text { Shot sequence/ } \\
\text { Length of film } \\
\text { sequence in } \\
\text { seconds }\end{array}$} & $\begin{array}{l}\text { Type of } \\
\text { shot }\end{array}$ & Image & Sound \\
\hline 8 & $3 "$ & $\begin{array}{l}\text { Medium } \\
\text { long } \\
\text { shot }\end{array}$ & $\begin{array}{l}\text { In the foreground is the } \\
\text { torch, which Balomar is } \\
\text { moving towards Timoni- } \\
\text { des's left hand }\end{array}$ & \\
\hline 9 & $2 "$ & $\begin{array}{l}\text { Medium } \\
\text { close } \\
\text { shot }\end{array}$ & $\begin{array}{l}\text { Timonides's fist opens as } \\
\text { torch gets nearer }\end{array}$ & \\
\hline 10 & $3^{\prime \prime}$ & $\begin{array}{l}\text { Medium } \\
\text { close } \\
\text { shot }\end{array}$ & $\begin{array}{l}\text { Timonides, covered in } \\
\text { sweat, horrified expression } \\
\text { on face }\end{array}$ & \\
\hline 11 & $1 / 10^{\prime \prime}$ & $\begin{array}{l}\text { Medium } \\
\text { close } \\
\text { shot }\end{array}$ & Balomar & \\
\hline 12 & $4 "$ & $\begin{array}{l}\text { Medium } \\
\text { close } \\
\text { shot } \\
\text { Medium } \\
\text { close } \\
\text { shot }\end{array}$ & $\begin{array}{l}\text { Hand } \\
\text { (quick panning shot) } \\
\text { Timonides opens mouth } \\
\text { distorted with pain }\end{array}$ & \\
\hline
\end{tabular}




\begin{tabular}{|c|c|c|c|c|}
\hline \multicolumn{2}{|c|}{$\begin{array}{l}\text { Shot sequence/ } \\
\text { Length of film } \\
\text { sequence in } \\
\text { seconds }\end{array}$} & \multirow{2}{*}{\begin{tabular}{|c}
$\begin{array}{c}\text { Type of } \\
\text { shot }\end{array}$ \\
$\begin{array}{c}\text { Medium } \\
\text { close } \\
\text { shot }\end{array}$ \\
\end{tabular}} & \multirow{2}{*}{\begin{tabular}{l}
\multicolumn{1}{c}{ Image } \\
Balomar looks \\
Timonides in the face
\end{tabular}} & \multirow[t]{2}{*}{ Sound } \\
\hline 13 & 3" & & & \\
\hline 14 & $19 "$ & $\begin{array}{c}\text { Medium } \\
\text { long } \\
\text { shot }\end{array}$ & $\begin{array}{l}\text { Torch taken away from } \\
\text { Timonides hand and re- } \\
\text { mains in foreground } \\
\text { Torch moved nearer to the } \\
\text { hand }\end{array}$ & $\begin{array}{l}\text { Timonides (breathes out): "I } \\
\text { would like to help you to be } \\
\text { free but you would have to die } \\
\text { if I cried out." } \\
\text { Timonides groans loudly }\end{array}$ \\
\hline 15 & $3 "$ & $\begin{array}{c}\text { Medium } \\
\text { close } \\
\text { shot }\end{array}$ & Balomar & \\
\hline 16 & $12 "$ & $\begin{array}{c}\text { Medium } \\
\text { close } \\
\text { shot }\end{array}$ & $\begin{array}{l}\text { Timonides, distorted with } \\
\text { pain }\end{array}$ & $\begin{array}{l}\text { Timonides: "Although I was on- } \\
\text { ce a slave, I am not used to en- } \\
\text { during pain. Although I am a } \\
\text { philosopher, I am weak". }\end{array}$ \\
\hline 17 & $3 "$ & $\begin{array}{c}\text { Medium } \\
\text { close } \\
\text { shot }\end{array}$ & Balomar & \\
\hline 18 & 6" & $\begin{array}{c}\text { Medium } \\
\text { long } \\
\text { shot }\end{array}$ & $\begin{array}{l}\text { Timonides, distorted with } \\
\text { pain }\end{array}$ & Timonides groans \\
\hline 19 & $25^{\prime \prime}$ & $\begin{array}{c}\text { Medium } \\
\text { long } \\
\text { shot }\end{array}$ & $\begin{array}{l}\text { Balomar is thrown a new } \\
\text { torch and goes towards Ti- } \\
\text { monides again } \\
\text { Balomar pushes the torch } \\
\text { onto Timonides's hand. }\end{array}$ & $\begin{array}{l}\text { Timonides: "You are not worth } \\
\text { the sacrifice. (screams) Barba- } \\
\text { rians. Monsters (even louder) } \\
\text { cannibals. Balomar. "Touch Wo- } \\
\text { tan, and we'll know that your } \\
\text { Gods are weak." }\end{array}$ \\
\hline 20 & $3 "$ & $\begin{array}{c}\text { Medium } \\
\text { close } \\
\text { shot }\end{array}$ & Balomar & \\
\hline
\end{tabular}


(5.) Timonides capitulates, by throwing himself down in front of the statue of Wotan. Humiliated, he makes excuses to himself for his failure and then reproaches himself for this failure.

(6.) Timonides's humanitarian success. Balomar is so impressed, that Timonides did not scream, thus preventing the destruction of the Teutons, that he submits to the Roman gods.

\section{b. Plot pattern and plot of the film sequence 'Torture' (Summary of the analysis findings)}

In the foreground is the suffering of Timonides, the protagonist of civilisation and humanity. He demands superhuman responses of himself and fails. That does not alter the fact that he becomes a victor through his incredible ability to endure suffering and he is thus exalted. Timonides behaves as the precursor of a civilised, humane evolution. He must endure the torture in order not to betray his own principles. He could end the torture, if he were to shout out and thus call to the soldiers for support. However, his torturers would then be massacred by the soldiers. Moreover, he cannot submit to the Teuton god of war because he would not then be able to lead the Teutons/barbarians out of their blindness and open up to them the path to civilisation. This dilemma, together with the will to preach on the part of the man who is being tortured, is portrayed in the film sequence by means

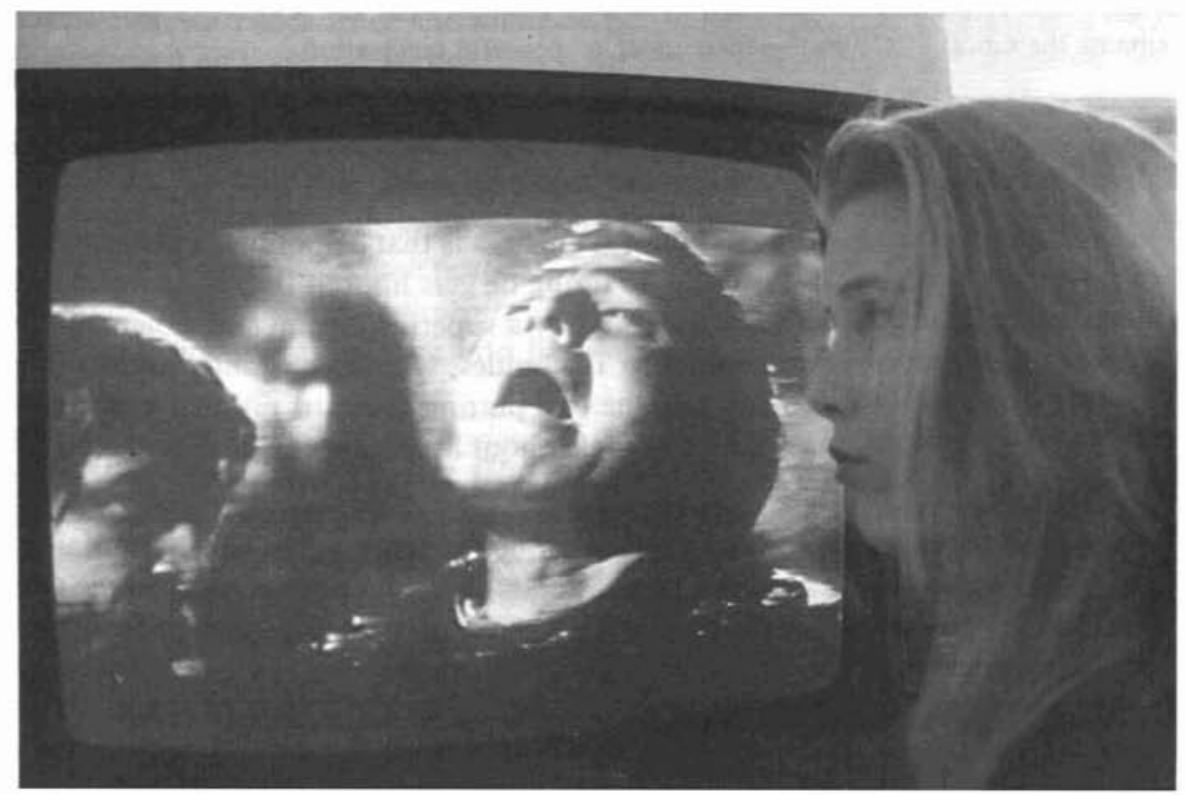

The media symbols cited by Melek from the section 'Torture' in the film "The Fall of the Roman Empire" 
of the following dynamics: the preaching of humanitarian principles, being taken prisoner, torture and self-denial for humanitarian reasons, remaining true to one's own principles and beliefs, sacrificing oneself in pain in order to redeem others from blindness and barbarism. This progression of events makes superhuman demands on the protagonist. This superhuman effort is symbolised by Timonides's having to endure repeated torture ( $=$ his hand being burnt). Going together with his failure - he cannot bear the pain of torture once more - he is exalted as a victor. The exaltation into a superhuman state is supported by the camera showing the suffering and pained facial expressions of the protagonist. The exaltation as victor is also communicated by an element of the narrative (the leader declares Timonides as a victor, the torturer and the victorious victim stand side by side at the same level) and by the mode of presentation (camera shots from above and from below).

\subsubsection{Summary of the film sequence 'Death'}

Melek talks about the fourth and fifth segment: "And when the arrow hit him as well, yea, at the end, then he still just, he still just stood there and, yea, it just hit him and he held his hand in there and /..."(286-289).

With a brutal attack by the Roman soldiers on the feasting Teutons, Timonides appears exposed and unprotected while championing the cause of civilisation, reason and peaceful coexistence. In order to save the lives of the Teutons, he risks his own. The film shows him as the exponent of a general and humanitarian idea. This readiness to support this cause unconditionally ends in his death. His representation as a dead man is, however, devoid of any form of exaltation. Although he dies as a simple man and a loser, he nevertheless remains the moral victor as the forerunner of peaceful civilisation.

\subsection{The film sequences 'Torture' and 'Death' within the context of the film}

\subsubsection{The relationship between the two film sequences}

The common factor between both film sequences is that Timonides intercedes for humanity by risking his own life. In so doing he gets himself into life-threatening situations, each of which is brought about by a superior, brutal and violent group of people. Both groups remain deaf to Timonides, who is constantly putting forward arguments. In this position of the one putting forward rational arguments and preaching to a group of violent people about humanitarian aims and motives by putting his own life on the line, Timonides is exalted.

In contrast, nevertheless, to the first film sequence 'Torture' in which Timonides remains victorious because of his superhuman ability to endure pain, in the second film sequence 'Death' he is destroyed as the victim of an anonymous, barbarous and murderous group. 


\subsubsection{The central issues of production and direction in the film sequences 'Torture' and 'Death'}

Within the film narrative, the film sequence 'Torture' has the function of showing that the Teutons are ready for civilisation and that consequently peace can be brought about in the north of the Roman Empire. Thus the political plan of the late Emperor Marc Aurel is realized. After the Teutons had become civilised, which would not have been possible without Timonides's capacity to endure physical pain and to show proof of superhuman strength, there begins for Timonides a phase in which his philosophical ideas and ideals are actually put into practice. When the mad, power-hungry Emperor Commodus gives his order that the Teutons be annihilated, Timonides's life aim and life work are brought to nought (as shown in the second film sequence 'Death' and described by Melek). With that, the fall of the Roman Empire takes its course. For the time being, the development towards civilisation and peaceful coexistence is brought to an end.

The torture and death of Timonides play an important function in the total structure of the film and also in relation to the linking of the themes 'Sacrifice and Exaltation': confronted with the pagan Teutons, Timonides is successful, because he is a suffering, noble victim. By contrast confronted with the politics of the Roman Empire that are based on power and the exercise of force, and that are also interwoven with decadence and madness (personified by Commodus), Timonides is destroyed as a victim, without his destruction attracting much attention. But while the pagan culture is already overtaken by the forces of civilisation, the culture of the Romans is on the threshold of a historical transition, beyond which Timonides, with his humanitarian principles, cannot yet venture, and he is killed. What the process of civilisation could be like is shown in the film shortly before Timonides's death, when the peaceful Teutons dance and celebrate at their feasts. By contrast, the Roman culture, as shown in the scene with the murdering soldiers, has already fallen back into barbarism.

\section{Using the results of the film analysis as an interpretative guideline in studying the activity-context and verbal image}

Is there a connection between the three central points of the film and the activitycontext? Are the themes of sacrifice, suffering and exaltation to be found again in the activity-context?

In theoretical terms, it is a question of understanding Melek's statements about the film as a symbolic representation in an activity-context which uses film symbolism. The meaning of the symbolic representation, which is, as it uses film symbolism, incomprehensible in the activity-context, can be reconstructed from the 
context of the film. In the following, we will be teasing out the situational significance of Melek's symbolic representation within the context of the 'event', whereby the film is used to help provide clarification. ${ }^{7}$

There then follows, as part of the investigation, a detailed analysis of activities which will then be linked with our film analysis to provide guidelines for interpretation. The following section will summarise the results of this phase of the work.

The key finding is that Melek wishes to be understood (see 3.1) in the situation which is both confused and imaginatively charged (see 3.3). She therefore describes both of the film sequences in order to explain the verbal image of the smiling witch (3.2). Being understood is of great importance to her because in the situation she is being made an object of group fantasy.

\subsection{Wanting to be understood}

During the entire photographic event in the church ruin, Melek has difficulty in putting across her ideas about a 'witch performance' in spite of very considerable group pressure. Only towards the end of the photographic event does she assert her witch image with the statement "I am the witch with the smile", a comment which is not understood by the group. Now she brings in the description of the two film sequences 'Torture' and 'Death'.

The first segment of her film description 'Torture' (from line 268) is presumably aimed at helping her impose her witch image and also her own 'witch performance', against the different ideas and images of the group. As she does not achieve this by using her own words and her own 'performance' by the end of the activitycontext, she finally falls back upon the mass media, upon a television film. In so doing, she fits in with the verbal images and the communication style of the group (e.g. allusions to film titles, borrowings from production techniques of film making).$^{8}$

\subsection{The parallel between the verbal image of the smiling witch and the film character Timonides}

Melek is unsuccessful in her attempt to impose her witch image. The reason for this is surely that the image of a witch standing on the funeral pyre and smiling is a contradictory one. The central character in her description of the film, that is to say the sequence she alludes to, has the function of showing that there are people or characters with such incompatible characteristics and behaviour patterns. The reference to a current film turns her description into something for which there is verifiable evidence. The television film is brought in, so to speak, as a piece of evidence. 
The film character Timonides is committed to the causes of humanity and civilisation. In his exposed position and with his humanitarian objectives, he is tormented by the group for whom he is speaking up. Because he endures superhuman suffering, he is exalted to the position of moral victor.

The parallel between the smiling witch and the film character Timonides suggests an analogy between the group situations in which the smiling witch and the film character Timonides occur: just as with Timonides, the smiling witch's aims and objectives are not recognised and she too is tortured. The people surrounding $\mathrm{Me}-$ lek could understand how to react, if they only understood the aims of the two characters of the witch and Timonides, who are linked together in Melek's mind. A further indication that Melek is connecting the film character Timonides with her verbal image in order to clarify what she is saying and what she is doing is the way in which her portrayal of the film sequence 'Torture' deviates from what is in the film. Melek says that the man (Timonides), who is tortured in the film grinned ("And grinned",272). Actually, however, Timonides makes no facial movement in the film sequence alluded to here which can be seen as a 'laugh' or a 'grinning. Melek has therefore 'changed' the film at this point.

How can this deviation be explained? In modifying the film sequence Melek is emphasising that, in the film character, incompatible elements come together. In so doing, she exaggerates the film character's ability to endure pain to a superhuman extent. Since her 'witch performance' is characterised by the coming together of apparently incompatible elements (smiling witch on the funeral pyre), the supplementary words "and grinned" have the function of emphasising in a particular way that which is apparently incompatible and making it comprehensible."

\subsection{Melek as an object of group fantasy and how she copes with it}

Melek has got into a group situation in which the group makes her an object of its fantasy. The outer framework of this is the media production. Melek, who is being photographed, is indeed the centre of attention as a photographic model. Nevertheless, the group members who are onlooking are clearly directing the production. They give instructions as to how Melek is to represent the character of the witch, how she should stand, how she should look etc. Melek picks up these ideas and directions. She has, however - and this is clearly shown by the analysis of the activity-context - little opportunity to develop or carry out her own modes of expression (in comparison with her first performance in which she actively plays the part and portrays herself as a dead beauty on the sarcophagus). In the process, she experiences the admiration of the group in her role as an actress to be directed. Comments are made like "Melek is the perfect film star for witches." The entire group action revolves around Melek. At the same time erotic fantasies are projected onto her. 
Hypothesis: This situation with herself as the object is experienced by her in exactly the same way. She interprets this situation for herself and the group with the help of the character of Timonides. In so doing, she emphasises the dimension of suffering. This is made especially clear through the second divergence between the film description and the 'Torture' film sequence. Melek says that Timonides screwed up his face, looked up "and cried out" (283 f). This description does indeed refer to Timonides' surrender after the torture. In fact the utterances he makes at this point can be interpreted as whimpers and sobs but not as crying out. Melek's added comment "and cried out" ( $283 \mathrm{f}$ ) can be understood as an indication of the fact that it is above all the victim in Timonides that interests her. She describes him in the position of abasement ("He just kept . . . looking up", $281 \mathrm{f}$ ) and, following that, as crying out. This interpretation is reinforced by the fact that Melek in her film description leaves out the end of the film sequence each time. So Timonides gets as little mention as someone whom the Teutons acknowledge as victor in the first film sequence as does his death in the second film sequence. Both these omissions, as well as the addition that Timonides cried out, are an indication that Melek sees him above all as a suffering human.

Despite the stress on suffering the young girl's film description repeats the cinematic representational aspects of Timonides which link suffering and exaltation. In describing the film sequence 'Torture', she stresses resistance and activity: "and he didn't cry out once, he only screwed up his face. // And grinned." (271 f.). In her description of the 'Death' film sequence, she picks out those representational aspects of the film which stress the dying man's heroic gesture: "And when the arrow hit him as well . . he still just stood there" . . (286-288).

\section{Arguments which can be used as a basis and categorisation of an audience-oriented analysis}

\subsection{Notes on the further analysis of the media trace: interpretative function of the communicative mediation}

Up to now the results of the media analysis and the analysis of the activity-context were presented in such as way as to explain the events within the context of the photographic event. Over and above this, the film analysis, nevertheless, offers further help with interpretation, allowing us for example, to decipher the actiondetermining subjects (themas) which are represented in the Turkish girl's forms of expression. This is prefaced by an important assumption: that there is a more general relationship than only the specificially situational one between the film or film genre and the symbolism appearing in the activity-context. Since films, film series and film genres today belong to the everyday experience of young people, 
an increasing number of recurrent film images and sequences take on a general communicative and interpretative function. The case under consideration shows that mass media experiences have an interpretative function within the context of everyday activity: media experiences become the basis for helping to interpret social situations. This interpretative connection needs not be linked to a specific media experience.

Melek also offers an example of an indirectly communicated relationship between a subjective symbolic representation and a media representation. This concerns the amazing similarity between the way in which Melek (through pose, clothes etc.) presents herself on the stone sarcophagus of Jenny Holzer's exhibit (see Section 1.1) and a film representation in which Lucilla is shown in exactly the same pose lying on her bed waiting for her lover. The reasonable assumption that Melek has taken this from the film is not acceptable, as Melek had expressed the creative idea for her performance before the film had been shown. If one does not wish to see these parallels as having occurred by chance, then the origin of the similarity between Melek's mode of presentation and the film presentation is to be sought in a third common source. This could be, for example, stereotypes, clichés or other archetypes which are taken up, modified, circulated and even developed. For Melek there is presumably here a close link with the genres of historical and epic film which aim at monumental effects. The description and analysis of the use of this cinematic mode of presentation in Melek's performance could yield indicators with whose help it would be possible to make statements about Melek's personality and about Melek's action-determining subjects (themas). This line of questioning or method of working would go beyond the elucidation of the interactive context as it is presented here. The hypothesis about the interpretative function of the mediated relationship nevertheless holds good for this question too.

\subsection{Arguments based on communication theory}

If one takes this approach, two of the basic assumptions of communication theory must be used extensively. Communication is the mediation process between subject, action and symbolic objectivisation. ${ }^{10}$

This communicative mediation is also valid in the case of mass communications. Since the technical media were invented, activities, language and experience have been mediated by mass communications.

The concept of communicational mediation of action and symbolic objectivisation is decisive for the link between the analysis of the activities and the analysis of the media, the methodological aim of which is to avoid, by using appropriate research, the loss of contact between media production, media distribution and media reception, which is characteristic of today's industrial society. The methods 
of producing an integrated analysis of media and activities take into account communicative mediation which is basically indissoluble.

The research method involves an investigation of the everyday lives of people in order to uncover the typical links and connections between media experiences, media symbolism and action. The mass media which have 'disappeared' as a result of this research method have then to be reconstructed by media analysis. In addition, there is the methodological task of discovering and presenting this medium by means of the media traces in the subjective symbolic representations of the activity-context. This reconstruction has two central points: firstly the medium is analysed as a received symbolic objectivisation. In the case under consideration, two film sequences are in the foreground. Then the medium is analysed so to speak as a medium in its own right, that is, as a symbolic objectivisation which is basically independent of its reception.

The concept of mass media mediation is of decisive importance for the line of questioning which concerns itself with the analysis of media and activity. The fact that mass communication has become a feature of everyday life has led to the linking together of the symbolic representation and action-determining subjects (themas) of individuals with the symbolism and topics of mass communications in a way specific to the media. The case under consideration offers a simple example. The symbolism, which is not comprehensible to the listeners (that of the smiling witch) is explained with the help of a film description. This presupposes that television films and their symbolism are ubiquitous, which is why they provide the necessary framework of experience for successful understanding and explanation. The methodological consequence of this mass media mediation now consists in always perceiving the symbolism of mass communication and the experiences linked with its reception as something in common with and basically connected with symbolic representations and experiences of people. The identification of media traces in the activity-context is thus the first step in an integrated analysis of media and activities. The aims of media analysis within the context of activities are to achieve - over and above the practical connection - insights into the dynamic developmental process of communication and action, which is significant to the mass media. ${ }^{11}$

\subsection{Media analysis within the context of activities - a comparison with film analysis methods}

In the following section, the development of some of the most commonly used models of film analysis are reconstructed and used as a background for describing the procedures of media analysis within an activity-context.

Right up to the early sixties, the analytical debate about the medium film was almost exclusively the concern of the arts disciplines. Its contributions were specula- 
tive, normative-aesthetic or historical in approach, and presented using the descriptive methods of the essay (e.g. Everschor 1964, cf. Kuchenbuch 1978, p. 181).

The beginning of 'scientific' film analysis in the Federal Republic is generally considered to date from the publication of Albrecht's essay "Die Filmanalyse - Ziele und Methoden" ("Film Analysis - Aims and Methods") of 1964. The article, with its social-psychological orientation contains not only precise details of the film-making process, but over and above that, attempts to achieve a systematic film content analysis, using the quantitative methods borrowed from the AngloSaxon "Content Analysis". In his historical overview "Kleine Geschichte der 'Filmanalyse' in Deutschland" ("Short History of Film Analysis in Germany"), Faulstich (1988) comes up with about 60 titles, which appeared in the following period and whose publication he divides into three phases: the first goes up to 1976 and is described as "Diversity of Methods". The second lasts till 1980 and is characterised by the dominance of "Analyses of Individual Works" and in the third phase, which stretches up to the present day, are gathered together titles with the common feature "Theory Orientation".

Even if the first phase, with its very varied attempts to produce a film analysis satisfying a scientific standard, is rightly characterised by its "Diversity of Methods", there are nevertheless two rival concepts of analysis which have determined the discussion and which still have influence today. These are the two methods of "Systematic Content Analysis" and of "Statistical Style Analysis" on the one hand, and the "Rhetorical and Dramatic Analytical Model" on the other. The first two owe their emergence to the study of Journalism which was becoming established at that time and which aims at achieving the most exact and objective results possible. Relying on the empirical methods of American social research, the semantic or syntactic elements of a film (or of several) were operationalised and the resultant details were statistically evaluated (cf, among others, Silbermann 1980, p. 26 ff.) The objective of the analysis was "to move from the contents to an analysis of the effects of the film (Silbermann, 1980, p. 28). In contrast, the rhetorical-dramatic analytical models tried to grasp the intended meaning of the film and are thus "generically related to the dialectic-hermeneutic methods of interpreting the meaning of a text (Kuchenbuch 1978 p. 172). Its central categories are, among others, story, topic, characters, conflict, plot development and plot presentation. It aims also to find an answer to the quest for "the presumed effect of communication" (Kuchenbuch 1978, p. 171). ${ }^{12}$

Despite all differences, both have the common aim to come to a conclusion as to the possible effect on the public. On the other hand, the media analysis which considers the context of activities concerns itself with films which are discovered within the framework of field studies (identifying media traces) and whose functional 
meaning for the recipient is empirically established. The film analysis takes place, in the first instance, using the categories of the dramatical analytical model. Since, however, the rather remote reconstruction of the film story is not sufficient to do justice to the multi-layered meaning of the filmic symbols ("the most complex of the arts", Seeßlen 1988a, p. 5), it is backed up by an associative-impressionistic meaning analysis. The object of this investigation are the film sequences which are indicated by the media traces. Since these film sequences are, however, not isolated but come within the context of a story, their function within the plot has to be worked out using the dramatic-analytic model and to be compared with the results of the associative-impressionistic meaning analysis. Only then does one obtain the relevant film analysis material, with which activities and film can be mutually set against each other, as part of the interpretative process.

Summary of the step-by-step process or area of work in media analysis within a context of activities

The analysis develops as a process of bringing together the film and the events in the activity-context. Despite all the complexity and ambiguity of interpretation relating to the individual case, three relevant areas of work can be described:

- Area of work: identifying the media traces

A prerequisite is a text, which describes the dynamic process of the activitycontext in its entirety. Within this text, indicators of explicit or implicit media traces are sought. (Explicit media traces are indications of media experiences and reception situations, use of media symbolism, description of a film etc. Implicit media traces are, among others, common features of production and direction. In the case under discussion, the media production is imitated and interspersed with elements of show.) Starting from these indicators, the film is acquired, observed and relevant excerpts, components of production and directions etc. are isolated and described.

- Area of work: the transcription of the film and of the activity-contexttexts of the film and the activities

In order to do justice to the criterion of inter-subjective comprehensibility of the analysis, selected written documents of the activity-context and the film must be available. The documents accompanying the media or the activitycontext can never be completely analysed and investigated. Nevertheless, they concretize the object of research from the point of view of the respective line of questioning. The transcription of the activity-context and the media presupposes a hermeneutic sequencing process. This sequencing is to be developed from the point of view of a description of connections. In the case under discussion, the following film texts were drawn up: description of the film's plot development/ description of the production and direction of the film / descrip- 
tion of the shooting script of several film sequences/ the placing of the film sequences within the context of the film.

- Area of work: comparison of the film text and the text of the activity-context Important for the comparison is the quest for correspondences and differences or contradictions between the film text and the text of the activity-context. The establishing of affinities and differences forms the basis of looking for connections in interpretation and perspective: How does the film help in the interpretation of the activity-context? / How does the activity-context help in the interpretation of the film?

\section{Notes}

1 In this research project "The Dynamics of Symbolic Mediation between Everyday Activities and Mass Communication", the concept of "Creative Spaces" is tested, among other things. Cf. Bachmair, v.d. Hövel 1988, Bachmair 1987 and 1990.

2 For this question it is not important in the first instance to establish where the verbal image of the smiling witch comes from, e.g. from a Turkish fairy tale or perhaps a video. Within the context of the investigation of the observation transcript, the question of the possible origin of the verbal image is nevertheless examined if only with the hope of obtaining further interpretative help of the source of the symbolism, perhaps even to find the key to Melek's action-determining subjects. However, nothing could be found in the observational material which gave any indication as to the source of this symbolism.

3 The word-for-word quotations are taken from the audio tape transcripts. Within the framework of the participatory observation, audio-tape documents were drawn up alongside subjective reports based on personal experience. The transcript excerpts which are reproduced here are numbered by the line as in the research report. Extracts from this transcript excerpt are reproduced with line numbers, e.g. $(270)=$ line 270 . All other quotations are printed without reference to the transcript line number, in the interests of clarity.

The transcipt markings have the following meaning:

Numeral = line number of the research report; / = short pause; $/ /=$ longer pause; ()$=$ beginning or end of a comment; prob. = probably the following comment is the basis of the taped excerpt.

4 Symbolic representations are significant comments or gestures of a subject. In this way the subjectively renounced part of the communication process is indicated, cf. Bachmair 1989.

5 For further media traces see the Sections of 3.3 and Section 4.1.

6 Details of the film "The Fall of the Roman Empire": USA Production 1963, running time of the original 175 minutes, direction Anthony Mann, camera Robert Krasker, music Dimitrie Tiomkin, actors among others Sophia Loren, Stephen Boyd, Alec Guiness, Christopher Plummer, James Mason.

7 Over and above the activity-context, the use of film symbolism can be identified also as a symbolic representation with regard to Melek's personality, her communicative and interactive style, as well as her action-determining subjects (themas). It is a question, here, of the relationship between mass communications and object. This is outlined in Section 4.1.

8 Here is it a question of investigating which media specific components underpin Melek's efforts to be understood, for example, the classification of the moral positions of the characters. 
9 Smiling as a feature of the witch and grinning as a feature of Timonides strengthens the compatibility of the two figures and supports the explanatory function which Timonides has or could have in the activity-context.

10 Important literature here is, among others, Berger/Luckmann, 1966, G.H. Mead, 1934.

11 Here the concept of the media shaping of language and action-determining subjects (themas) can be helpful.

12 For a critique of both approaches, see, among others, Seeßlen 1986, p. 5 ff.

\section{References}

Albrecht, Gerd: Die Filmanalyse - Ziele und Methoden.In: Everschor, Franz (Ed.): Filmanalysen 2. Düsseldorf 1964.

Bachmair, Ben: Aneignungsversuche. In: Medien praktisch - /1987/4, p. 56-59.

Bachmair, Ben.: Symbolische Vermittlung - Argumente, Beispiele und Stichworte zu einer Handlungs-, Kommunikations- und Medientheorie. In: Conrady, P.: Literatur-Erwerb. Kinder lesen Texte und Bilder. Frankfurt 1989.

Bachmair, Ben.: Gestaltungsräume inszenieren. In: Schill, W.; Tulodziecki, G. et al. (Ed.): Medienpädagogik in der Schule. Opladen 1990.

Bachmair, Ben; v.d. Hövel, Martina: Medienpädagogische Beratung - Professionalisierung und Erziehung im Medien- und Konsumnetz. In: Medien und Erziehung 32/1988/4, p. 196-204.

Berger, Peter L.; Luckmann, Thomas: Die gesellschaftliche Konstruktion der Wirklichkeit. Eine Theorie der Wissenstheorie. Frankfurt 1970. American Original New York 1966.

Faulstich, Werner: Kleine Geschichte der ,Filmanalyse in Deutschland' In: Korte, Helmut;

Faulstich, Werner: Filmanalyse interdisziplinär. Göttingen 1988.

Kuchenbuch, Thomas: Filmanalyse. Theorien, Modelle, Kritik. Köln 1978.

Mead, George M.: Mind, Self and Society. Chicago 1934.

German: Geist, Identität und Gesellschaft. Frankfurt 1973.

Seeßlen, Georg: Probleme der Filmanalyse heute. Einwände, Notizen und Vorschläge zu einem Anspruch, der mit seinem Gegenstand in die Krise geraten ist. In: Medien und Erziehung, 30/1986/1, p. 2-13.

Seeßlen, Georg: Kategorien der Filmanalyse. Zu ihren Methoden und ihrer Geschichte. In: Medien praktisch, $-/ 1986 / 1$, p. 4-9.

Silbermann, Alphons: Zur soziologischen und sozialpsychologischen Analyse des Films. In: Silbermann, Alphons; Schaaf, Michael; Adam, Gerhard: Filmanalyse. Grundlagen, Methoden, Didaktik. Oldenburg 1980. 


\section{Media symbols and self-symbolisation - Steps taken by the child to overcome anxiety}

\section{Introduction}

Using a case study as an example, we intend below to investigate the thesis that children find figures or scenes in television films which can stand them in good stead for coping with their everyday life. According to this idea, media symbols represent offers of meanings in which the child finds himself or the activities of his environment interpreted. By occupying himself with these media figures it becomes possible for the child to understand his own needs and feelings better. In a further step the child can, with the aid of this self-symbolisation, manage to discover ways of integrating into his own personality feelings which he had previously warded off.

We want to show, on the one hand, that not only the classic myths and fairy tales provide this kind of potential for self-interpretation. But even rather trivial television films, such as, for example, the "Pumuckl" films produced by Bavarian Commercial Television, can be used by children for this purpose. The success or failure of a television series can certainly be explained to quite a considerable extent by how far viewers' prototypical areas of experience are addressed and appropriately dealt with.

On the other hand, however, it should be realised that children as viewers can understand television stories in a way that deviates completely from what the author intended, and they can change them to suit their own requirements. Our case of developmental psychology proves that the significance of a television figure for a child can undergo great changes when the viewer progresses in the development of his personality.

\section{Case study: Paul takes a close look at the television imp Pumuckl}

As part of the "Freiburg Longitudinal Study of Media Reception by Pre-school Children in the Family Context" (for more details of this study cf. Charlton/ Neumann in this book) six children were visited during play contacts and joint media use over a period of two years.

One of the children, whom we shall call Paul here, has long taken a keen interest in a certain media figure, well known to most children: the television imp $\mathrm{Pu}$ - 


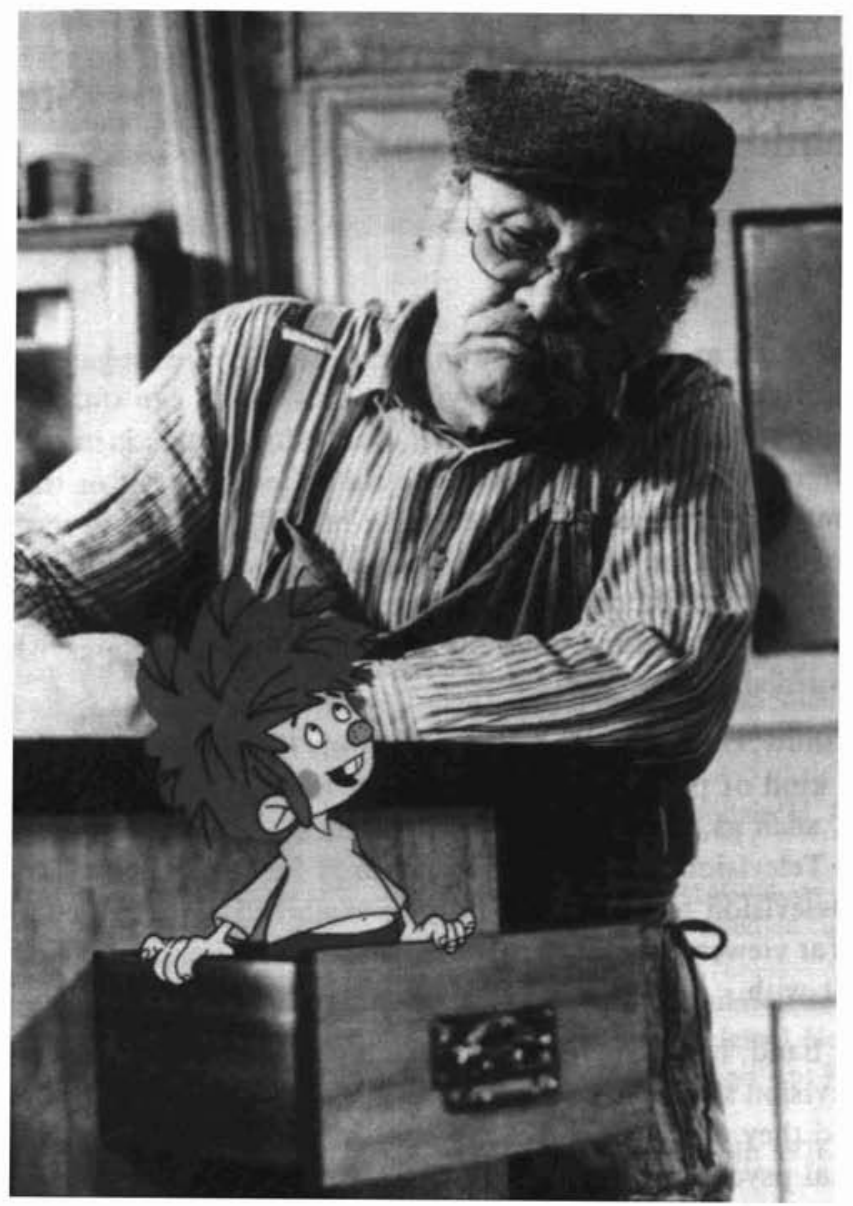

"Master Eder and his Pumuckl" (photo of a scene)

muckl. While talking and playing with the observers ${ }^{1} \mathrm{Paul}$ also mentioned $\mathrm{Pu}-$ muckl several times.

Parts of the case material have already been interpreted in works by Charlton and Neumann (1968, pp. 1-8) and Braun et al. (1988). Now that the longitudinal study has been completed the case material is available in its entirety (see Braun et al. 1989, Vol: II: The Case of Christian), so that the interpretation begun can be deepened and expanded into a comprehensive longitudinal consideration of Paul's preoccupation with the media. 
Paul's favourite television series, the "Pumuckl" films, was not being shown at the time of the study. Nevertheless, the television imp is present in the world of Paul's own room: a Pumuckl poster is hanging on the wall, and a wooden Pumuckl doll is sitting on a shelf. As we shall show below, the imp also plays an important part in Paul's world of fantasy.

At the age of five years and two months, during a play contact, Paul begins to talk about Pumuckl quite unexpectedly while he is playing with his wooden train together with the two psychologists. As the level-crossing gates sometimes open of their own accord he fixes them with wooden bricks. He explains this:

Transcript (1) ${ }^{2}$ : Paul talks about Pumuckl and the wolves

101 it'll hold better like that (,) won't it (,) clamped down like that (?)

2 P actually they can go onto the bricks (,) but I do it like that (,) because (,) because otherwise they keep on opening (,) don't they (,) because of the Pumuckl (,) and the wolf (.)

3 O2 because of the Pumuckl (?) (P: $\mathrm{mhm}$ ) why that (,) what do they do (?)

$4 \mathrm{P}$ they have a party every time (,) every day they have a party (.) when I don't (,) when I want something (,) then they do it differently (,) and from the

$5 \mathrm{O} 2$ you must (,) you must tell me more about that (,) (P: $\mathrm{mhm})$ that interests me (.) what do they do with that (?) they simply push that up (?)

6 P yes (,) they simply put the (,) points up (,) but of course they can't do it like that (,) the gates (O2: $\mathrm{mhm}$ ) when it's like this (,) I mean the (,) the wolf $($,) because they're very light(,) and when they put them together (,) they still can't do it (.)

701 so that you can trick the Pumuckl like that (?)

8 P mhm (,) then they can't (,) do it like that (,) (O1: $\mathrm{mhm})$ can they (,) you see and then (,) then the engine has nothing to run into (.) (O1: aha)

9 O2 do they do that to annoy you or only (,) because they have fun doing it (?)

$10 \mathrm{P}$ no (,) they try to make me (,) so that I (,) I get terribly angry (.) (O2: mhm) that's why they want to do it (.) (O2: $\mathrm{mhm})$

11 O1 do they come often (,) or are they always here (?)

$12 \mathrm{P}$ they're always here (,) they hide (.)

13 O1 the Pumuckls (,) (P: $\mathrm{mhm}$ ) how many are there then (?)

$14 \mathrm{P}$ very (,) very many

15 O1 can they be counted (?)

$16 \mathrm{P} \mathrm{mhm}($,) there are (,) because (,) because they hide (,) and I don't know (,) (O1: ah) how many of them are hiding (.)

$17 \mathrm{O} 1$ all you know is (,) that there are very (,) very many of them (P: $\mathrm{mhm}$ ) aha (,) and you have to keep looking (,) ehm (,) to see that they don't try (,) to annoy you (?)

$18 \mathrm{P}$ yes (,) but they hide themselves (,) and they do it the Pumuckls (very quickly) they share their (,) the wolves come as well (,) and the wolves(,) they frighten me then in the night $($,$) you see (O2: yes) so that I have bad dreams (,) crazy things (,) you$ see $(\mathrm{O} 1+2: \mathrm{mhm})$ and that annoys $\mathrm{me}($, $)(\mathrm{O} 1: \mathrm{mhm})$ and they make the Pumuckls invisible by magic (.)

19 O1 ah that's what the Pumuckls do as well (?) (P: $\mathrm{mhm}$ ) mhm (.) 
$20 \mathrm{O} 2$ are they there at the moment (,) just like that (,) (P: mhm) now (,) invisible (?) $21 \mathrm{P} \mathrm{mhm}($.$) 'cause in the (,) in the bright air they're invisible (.)$

$22 \mathrm{O} 2 \mathrm{mhm}(\mathrm{O} 1: \mathrm{mhm})$ do you sometimes play with them as well (,) or do they always play against you (?)

23 P they only play (,) against me (,) I never play with them (,) because I don't like them (O2: yes) $\mathrm{mhm}($,) that's why I never play with them (.)

$24 \mathrm{O} 2 \mathrm{mhm}($,$) and do you play any tricks on them (?)$

$25 \mathrm{P}$ but that doesn't work (,) because I can't make myself invisible by magic (.)

$26 \mathrm{O} 2 \mathrm{mhm}($ ) that's silly (,) isn't it (?)

$27 \mathrm{P} \quad \mathrm{mhm}($,) really silly (,) that I'm not a Pumuckl (.) (laughs)

Here Paul fantasises Pumuckls that are really present in large numbers and frightening him. Can these fantasies be explained as a consequence of watching television?

In the media model Pumuckl is a small, red-headed imp, who is not visible to people and who constantly plays tricks on them. Only the master carpenter Eder once discovered Pumuckl by chance, and so he can see him and has taken him into his home.

Master Eder is often annoyed by Pumuckl's tricks, but because of the imp's innocent, childlike charm he is never angry with him for long. Nor does Pumuckl's remorse last very long after Eder's reprimands - he quickly reverts to his impish nature again. But there is never any permanent damage caused, since in the end Master Eder intervenes with help and explanations in spite of his annoyance.

The Pumuckls in Paul's day fantasy lack not only an adult counterpart to Master Eder to keep them in check but also the saucy amiability of the original figure. For Paul they are an unpredictable horde who annoy and threaten him in a malicious way. Their power extends beyond the invisible manipulation of objects: through their allies, the wolves, they even force their way into Paul's dream world and frighten him. He goes on to talk about this dream world when one of the observers asks him about it:

Transcript (2) ${ }^{3}$ : Paul dreams of octopuses that want to eat him up

1 O2 tell me (,) you said (,) you said before (,) you (,) you (,) dream (,) that (noise) (the Pumuckls?) sometimes send some sort of dreams (.) would you like to tell us one of the dreams (,) or would you rather not (?)

2 P no you know otherwise I dream (,) you know that comes (,) that all comes from telly (.) (O1: yes?) then I dream about it in the night (,) you see (.)

3 O1 what sort of things do you dream then for example (?)

4 P and today I dreamt (,) last night I dreamt (,) about octopuses (,) one was really big (,) of course it eats me up (,) because it followed me from behind (,) wanted to catch hold of me and eat me up (,) (very quickly) but of course I knew (,) that octopuses don't $\left(_{(}\right)$of course I knew that octopuses eat plant(s)(.) 
5 O1 of course you knew that didn't you (?)

6 O2 yes (,) and of course you aren't a plant (,) are you (?)

$7 \mathrm{P}$ and then I thought (,) it wanted to eat me $(\mathrm{O} 1+2: \mathrm{mhm})$ and there were (,) the water turned into a person (O1: ah) as quick as lightning in the water (,) you see $(\mathrm{O} 1+2: \mathrm{mhm})$ and the whole thing (,) is somewhere where only octopuses live $(\ldots)$ full of water (,) you see $(01: \mathrm{mhm})($.$) and then I dreamt first of my room$ here (,) where a gutter went down here from the roof $($,$) and then there was the$ lake (.)

$8 \quad \mathrm{O} 2$ and there everything was full of octopuses (?)

$9 \mathrm{P}$ mhm (,) down there (.)

Here Paul himself puts his anxiety dreams down to television. Of course, it cannot be ruled out that Paul once saw a frightening film about octopuses. The extent of his emotional involvement and the specific shaping of his fantasy, i.e. the particular integration of the magic figure of the imp and animal shapes tend, however, to indicate - that is the thesis - anxiety fantasies which already existed before the beginning of the media reception. We should therefore like to examine below how Paul experiences a fear of animal and imp figures in connection with the development of his ego.

\section{Excursus: Animal symbols in dream and fantasy}

In the relevant literature on developmental psychology discussion centres on children's fears of animal figures. Fears of concrete or fantasised animal forms are not rare, especially at Paul's age: according to the epidemiological study by Shepherd, Oppenheim and Mitchell (1973), the fear of animals is typical, particularly in the case of five-year-olds. With increasing age the fear contents change, while the general anxiety remains almost unaltered.

A similar development also emerges in the case of dream contents: all the dream researchers referred to by Strunz (1988) report an increased incidence of animal symbols in children's dreams. Van de Castle, who made an empirical study of the frequency of animal dreams depending on age, states: "With regard to children's dreams, an inverse relationship exists between chronological age and the frequency of animal dreams; as a child gets older, animal dreams decrease" (1983, p. 172). In the the dreams he evaluated the percentage of animal contents drops from $39.4 \%$ in the four-year-olds to $7.5 \%$ in adults.

Since a fear of animals (either in dreams or in reality) in children cannot be fully explained in its extent and its frequency by their experiences - although these certainly exist - with real-life animals, it must have a certain psychological function. 
Animal figures are intepreted by most of the dream researchers fairly unanimously as the symbolisations of children's vitality (cf. Strunz 1988, p. 178). The feelings of helplessness and fear which children experience in their dreams when confronted with animals are triggered in their everyday life by the multiplicity of emotional demands made on them both by their psychological inner world and their external environment. Children often feel they are at the mercy of their own feelings, which descend upon them like the forces of nature, and they are afraid.

Coming to grips with animal figures represents an important step in developing the ability to overcome this fear. As Zulliger put it: "Nobody can live in fear. He tries to fight it, to overcome it, to protect himself against it by certain measures. The young child very frequently does so by attaching his original diffuse (= diverse, unfounded) fear to an object. He takes fright at cows, for example, or dark rooms such as the cellar or attic. As soon as a child succeeds in fixing his fear onto an object in the way described, this already signifies considerable progress in handling fear, in fighting fear. For now he only needs to go out of the way of the fear object, to avoid it in order to be free of fear again." (Zulliger, p. 70; underlining in the original)

Symbolisation renders previously vague, threatening feelings tangible. This provides the prerequisite for the child to deal actively with his impulses. It now puts him in a position to conduct this dispute outside himself, as it were. If he finds a 'language' for his feelings he can play with it: symbolisations can serve to test strategies for overcoming his fears in his fantasy by varying them and integrating them into fantasy stories. The function of this playing is not primarily to build up distance to his own explosive emotionality, but a gradual approach and integration. "Moreover, the older children become, the greater the tendency to establish a more harmonious balance, in the normal course of development, between the demands coming from the outside world and the impulses from within. Animals thus lose their threatening function." (Strunz 1988, p. 179)

A similar attitude is adopted by Bettelheim, who has dealt in great detail with magic figures in fairy tales. In his opinion the child has to "understand what is happening in his conscious mind, so that he can also cope with what takes place in his unconscious mind. This understanding and this ability is not acquired by the child by rationally comprehending his unconscious mind, but only by becoming familiar with it: by brooding over the relevant elements from stories as a reaction to unconscious tensions, assembling them anew and fantasising about them. In doing so, the child turns unconscious contents into conscious fantasies, which then make it possible for him to come to grips with these contents." (Bettelheim 1975; German edition 1980, p. 13) 


\section{Paul and his symbols}

Paul's wolves and octopuses are still very simply structured, "handy" symbols. Children, in the course of their development, however, select more complex, more differentiated symbolisations to grapple with, which are in keeping with their increasing psychical differentiation. A very suitable fund of these are provided by media stories - from the parents' good-night story to stories from their own books, cassettes and television.

For five-year-old Paul the animal symbols of octopuses and wolves are still important. But he is no longer helplessly at the mercy of his fear of them. He can overcome it by, for example, exercising his intellect: "Of course, I knew that octopuses eat plants." (Transcript 2, Interact 4)

In the course of his development Paul begins at the same time to occupy himself with Pumuckl. The latter, too, just like the fantasised wolves and octopuses, is bound up with Paul's feelings of helplessness, but represents a differentiated symbol: a symbol of vitality as well, the imp additionally represents the character of what is hidden and uncontrollable. On the one hand, Paul is fascinated by him, but, on the other, feels subordinate to him especially on account of his magic abilities: "But that doesn't work, because I can't make myself invisible by magic."' (Transcript 1, Interact 25)

He therefore processes his preoccupation with the media figure, by integrating it into his existing anxiety scenario. He adapts the character of the Pumuckl he has fantasised to that of the octopuses and wolves by turning them into omnipresent, impersonal beings which might overwhelm him. Only in the course of his next year will Paul find his way to a more productive pre-occupation with Pumuckl this will be examined later.

If one now asks why it is precisely Pumuckl that has become for Paul a significant symbol, Paul's understanding of symbols must be considered against the background of the world in which he lives. In the course of the 2-year study period we had an opportunity to meet him and his family at play and in conversation. We have reconstructed the significance of Paul's fears in the family context as follows:

Paul and his younger sister are growing up in a family which endeavours to create a harmonious, affectively related family life. Both parents are often at home and clearly take their children into consideration when organising their leisure time. Important family values are responsibility towards oneself and the social environment, solicitousness and mutual helpfulness (extending to charitable work by the parents), and control - as a strategy for overcoming anxiety and maintaining the myth of family happiness. This is the "reverse of the coin", for living together 
in a closely knit family - incidentally, in a comfortable flat, but about the size of a doll's house - involves the danger of mutual over-control and tabooing the needs of individual members of the family to relieve each other and keep at a distance from one another.

Paul exhibits a very specific social competence apart from cognitive abilities that developed at an early stage. He is a loving, gentle child with a good ability to empathise, which seems to adults to be almost unchildlike. Accordingly, Paul has trouble with the feelings of anger and aggression, which are less embedded in the family. Paul's anxiety-laden day and night dreams, too, are to be understood in connection with the necessity to control his fierce and "unsocial" outbursts: his own unintegrated, threatening internal impulses are personified as anxiety figures which are directed against him in his fantasies.

In this context it is possible to understand the special significance that the figure of Pumuckl possesses for Paul: as he cannot fully develop his own unadapted, cheeky aspects in his family, he is attracted by the imp's ability to 'act while hidden away' through his magic powers. In his own words: "Really silly that I'm not a Pumuckl." (Transcript 1, Interact 27). This desire to be close to Pumuck1 is, however, as we have seen above, connected with the fear of not being a match for the imp - i.e. not being able to control his own impish impulses and being overwhelmed by them.

\section{A good one year later: Paul's relationship to Pumuckl has changed}

At 5 years 2 months Paul answered the question as to his relationship to Pumuckl ("Do you sometimes play with them as well, or do they always play against you?" see Transcript 1, Interact 22): "They only play against me, I never play with them, because I don't like them, that's why I never play with them" (Transcript 1, Interact 23). A good one year later - Paul is now 6 years 4 months old - the observer asks almost the same question again when Paul fantasises about an imp that was really present after they had both seen a "Pumuckl" film together. She asks:

Transcript (3) ${ }^{4}$ : Pumuckl plays tricks for Paul

$1 \mathrm{O} 2$ and does he stick by you (') or does he play against you (?)

2 P if he wants to (,) actually he always stays with me (') and then (,) we don't bother each other (,) only (,) only sometimes (,) he does does silly things with me (.)

3 O1 yes (?)

4 P yes (,) I once discovered him on my flowers for example (.)

5 O2 what (.) inside the flowers (?)

$6 \mathrm{P}$ yes (.) 
7 O1 yeees (?)

8 P yes (,) just as they were open and he (,) then he sat inside them until (,) until late in the night (,) and then in the (,) in the night $($,$) it was closed and then I had to$ unfold the flower (.)

901 well would you ever (.)

1002 so that he can get out hm (') (,) and then he (,) he was almost like in a mousetrap wasn't he (')

1101 wouldn't he have managed (-) to come out again on his own (?)

$12 \mathrm{P}$ no (') (,) then he thanked me (') for that (,) he said (,) he said (,) he (,) he (,) was going to a shop next day to steal something there (.)

1301 what (.)

1402 and what would he have stolen (?)

$15 \mathrm{P}$ if he (,) hadn't (,) if (,) if he hadn't come back to me (,) and said (,) he was too frightened (') and then he would have (,) would have (,) fetched me a doughnut (.) (O2 laughs) and that's why (,) and then he would (,) he would only have left me the ja (,) jam (.)

$16 \mathrm{O} 2$ ahh (.) he gobbled up everything round the outside (?)

$17 \mathrm{P}$ yes (,) he would have (,) (O2: yes) if if he wasn't so frightened by it (.) (quietly) but then he would have been too frightened by it after all (.) I'm sure (.)

1802 what was he afraid of (?) of getting caught (?)

$19 \mathrm{P}$ no (.) yes of that as well and (,) that $\underline{\mathrm{I}}$ have to (,) go off later to be punished (.)

2001 aha (')

2102 so that (,) so that then (,) everyone thinks it was you (.) yes (.) so he doesn't want that to happen (.) does he (?)

$22 \mathrm{P}$ mhm (')

It is no longer possible to detect anything like a threat to Paul by sinister Pumuckls; Paul's Pumuckl has become very close to the original and has a friendly relationship with him.

The reason for this is partly that Paul refers in his fantasy to the film he had seen previously "Der große Krach und seine Folgen" (The Big Row and its Consequences): in the film Pumuckl stole a girl's ornamental chain and is thrown out by Master Eder for doing so, because the latter sees his reputation as an honest man being put at risk. Pumuckl thereupon terrorises a mechanic's house, but the latter shows no understanding for these impish tricks. When he even plans to catch Pumuckl in a mousetrap, Pumuckl returns to his Master Eder, who has forgiven him in the meantime.

In his story Paul now seems to have taken over Master Eder's role: Pumuckl always stays with him (Interact 2), Paul can see him (Interact 4) and has to rescue him from a trap (Interact 8 ). The core of the media story - Pumuckl's theft and punishment - is, however, clearly taken up by Paul in different ways: whereas the "real" Pumuckl plays tricks on his own childlike, playful initiative, Paul's 


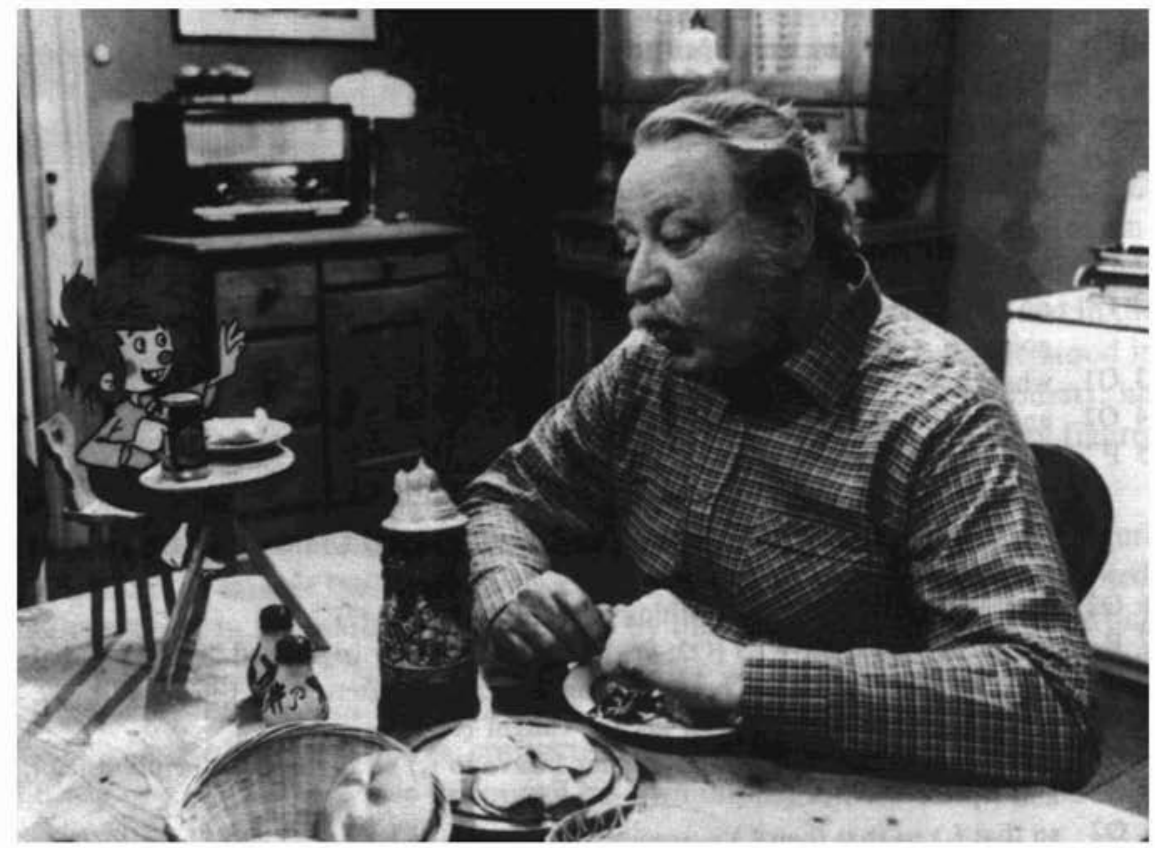

"Master Eder and his Pumuckl" (photo of a scene)

Pumuckl wants to steal for him (Paul); whereas Master Eder receives no understanding for the concern about his good reputation, Paul's Pumuckl is worried that Paul could be punished because of him. Paul therefore establishes a special cross-connection between himself (in the adult's role) and the imp.

For Paul to come to grips with his own impish, aggressive impulses this means a big step towards integration. Paul approaches this part of his personality by fantasising himself as the person to whom Pumuckl relates, his super-ego, as it were, thus ensuring Pumuckl's loyalty. This enables him to maintain the necessary internal distance to the imp and still to take pleasure in his tricks vicariously without having to acknowledge these impulses directly. At the same time, the Pumuckl he has fantasised is no longer just sinister and uncontrollable (cf. Transcript 1), but also accessible to external demands. The fact that the imp now accepts a 'reasonable' partner reflects Paul's advanced ego-development: his super-ego has become so strong that it can allow the impishness without too much of a threat.

As a remnant of earlier fears, however, Paul remains conscious of the insecurity of his arrangement with the imp: Pumuckl only stands by him "if he wants to", and sometimes still plays the odd trick on him (Transcript 3, Interact 2). 
As the play session proceeds, this remaining feeling of insecurity is also lost, and Pumuckl even gains the function of an auxiliary ego for Paul:

In another story Paul clearly refers to the family context:

Pumuckl had caused a short circuit in the television precisely during one of the so rare children's programmes. He lets the observers guess which programme was involved, and finally decides it was the "Programme with the Mouse" (Sendung mit der Maus). The observer asks:

Transcript (4) ${ }^{5}$ : Paul gives instructions to Pumuckl

1 O1 what has he got against the "Programme with the Mouse" (?)

2 P actually $(-)$ no (.) it wasn't the film after all (.)

3 O1 so it wasn't (.)

$4 \mathrm{P}$ after the Mouse (.) (...) news (.)

5 O2 he turned your news off (.)

$6 \mathrm{P}$ mhm (')

$7 \mathrm{O} 2$ would your parents do that too (?) when you were watching children's programmes (,) do they also switch off the telly then (?)

8 P $\mathrm{m}-\mathrm{m}().(\mathrm{O} 2$ unintelligible) we'll do (,) something quite different (.) (O2 unintelligible) $\mathrm{m}-\mathrm{m}(-)($, ) then we would $(. .$.$) watch telly ($,$) they would take us by the arm$ (,) chuck us into the children's room so that we would (,) land on our matresses $(-)$ (giggles) and then (,) slam the door to (.)

902 close the door (') (,) and then the grown-ups watch telly (,) and you have to sit on the bed (.) (P: $\mathrm{m}-\mathrm{m})$ and you have to get over it first (.)

$10 \mathrm{P}$ then we rush like lightning to the door (') (,) (O2: $\mathrm{mhm})$ lightning and dash out (.) (,) but I usually dash round the corner (') (O2: $\mathrm{mhm}$ ) shall I tell you why (?)

11 O2 why (?)

12 P (giggles) because I want to do something sillier (,) 'cause I want to talk to Pumuckl (,) 'cause he always hides in the kitchen then.

$13 \mathrm{O} 2$ aha (.) and what tricks do you think up between you in the kitchen (?) (whispered) (what do you tell him?)

$14 \mathrm{P}$ I arrange with him (,) what nonsense (,) what nonsense he should do next time (.) $15 \mathrm{O} 2$ oh I see he carries out your orders (.)

$16 \mathrm{P}$ but that business (,) that with the news that was (,) that wasn't (,) he (,) he (,) thought that up himself $().(),(01$ : that wasn't your idea) but once he did arrange to do something silly (.) and it was (,) was my idea (.)

17 O1 yes (') what was it then (?)

1802 what (?)

$19 \mathrm{P}$ he took the beer bottle and drank everything up (,) all the juices (,) everything we had (.) only (,) beer (,) Cola (,) he drank up (,) everything (.)

Paul gives this story a decisive turn by making Pumuckl carry out his trick with the news, that is his parent's programme, but not with the children's broadcast, and in the end he even gives him instructions.

Paul's symbolically mediated occupation with the media figure has now advanced 
so far that it is possible for him not only to feel his impulses more clearly but also to direct them to the outside: against his parents. The measures described by Paul to prevent him and his sister from watching television do not provide a true picture of the parents' educational behaviour, but reflect, first and foremost, Paul's feeling that he is being refused something. "How does it come about that loved parents are changed into monsters in their children's eyes? If we project ourselves into the child's life, we notice that such changes tend to take place when we are forced to put an end to the child's pleasure, to interrupt an enjoyable activity, to refuse a wish or to shatter the child's desires or demands in some way." (Fraiberg 1972, pp. 19/20)

Refusals trigger helplessness and anger. These are feelings that he can hardly give vent to in the context of his reasonable family concerned about harmony. On the other hand, he finds an appropriate expression in fantasy and role play. Paul, with a giggle and with great pleasure, gives an account of the (fantasised) drastic measures of his parents and thus takes up an important component of the "Pumuckl" story, namely humour.

Haas et al. (1984) assigns the "Pumuckl" stories to a certain type of comic and fanciful story which exhibits the qualities of vigorous childlikeness by using fantastical individual figures. The egocentric, animistic and prelogical characteristics of these figures " - in their close connection to the fantastic - are judged by the tendency displayed by their comic qualities. The childlike aspect can appear to be something infantile, egocentric, limited, which is incompatible with the reasonable standards of adults, or to be something fresh, young and unbroken, which tends not only to make fun of the boring and conventionalised adult society, but also to revitalise it." (p. 286) The fantastic elements of this type of story "testify to a sense of humour which (. . .) could bolster not reason but the feeling for life and self-assurance. Childlikeness is not something limited that has to be overcome, but something enlivening that has to be sustained." (p. 289)

Paul accepts this aspect of the story that is offered to him and almost becomes a 'Pumuckl' himself when he impishly takes pleasure in his fantasised trick. But then he takes fright of himself and waters down the trick by directing it not against his parents' watching television but against the whole family, which is deprived of beverages. But the underlying theme remains the same: coming to grips with his own needs, which are only partially fulfilled.

\section{Summary of the presentation of the case}

Paul occupies himself with the media figure of Pumuckl as part of his identity development. The magic figure of an imp provides him with an opportunity to 
symbolise his cheeky, unadapted aspects through the character traits provided by the media story; Paul, however, goes further and fantasises him according to his own needs.

As a 5-year-old, Paul is still at the mercy of his own impulses to a large extent; he therefore integrates the figure of Pumuckl into his existing anxiety scenario and connects him up with his fear-cathected animal figures.

But, as a 6-year-old, he can largely go along with the original story and take pleasure in Pumuckl's tricks. That he is at the same time still occupied with controlling his impulses can be seen from the fact that he is particularly concerned about Pumuckl's punishment. He first identifies himself not, like most of the other children, with the imp himself but with the adult person who could be compromised by Pumuckl's tricks.

As the story carries on, Paul approaches the Pumuckl more closely. He fantasises himself as the person who gives him instructions and thus uses him as an auxiliary ego. It now becomes clear against whom he needs the imp's help: against his parents, whom he experiences as a failure. The liberating feeling of giving vent to his aggressions is only possible for Paul by immersing himself deeply in the world of fantasy and is also quickly toned down by him again. It will no doubt be some time before Paul can completely accept and integrate Pumuckl in himself.

\section{Conclusion: The confluence of a child's development and his understanding for symbols}

We have therefore seen that Paul's coming to grips with Pumuckl cannot be explained as a one-directional impact of the media story, but that it represents a meaningful action that can only be understood in the context of his everyday life.

That does not mean that this aspect of the media programme should be neglected; media stories certainly provide a framework that determines the subject and situation and thus make certain demands on the child. Within this framework, however, there are a wide variety of possibilities for processing.

Paul 'reads' the "Pumuckl" stories on each occasion to suit his current situation in life. As he does so, his interpretation of Pumuckl's character traits is based to a varying extent on the media model and thus reflects Paul's identity development: the more he can perceive his own "Pumuckl parts" free of anxiety, the more he can devote himself to the media figure without making any changes to it.

Coming to grips with Pumuckl gives Paul scope in dealing with his fears. At the same time, however, he also gains scope in dealing with the media programme: 
he can vary and interpret it according to his needs. The acquisition of this internal scope goes hand in hand with the differentiation of his fantasy activities.

Schäfer (1986) ascribes to fantasy an important connectional function between 'inside' and 'outside', between ego and non-ego, between self and reality: 'Fantasies contain a reference to one's self. This is always incorporated in a relation to the non-ego world, which also has an effect in the fantasies, promoting or limiting them. Fantasies can in the end be seen as an attempt to establish the subjective, internal reality in some kind of non-ego reality that is more or less suitable for this purpose, to join up with it and to locate the subject within a reality." (p. 273)

He differentiates between this constructive term fantasy and fantasising that escapes reality, which he calls 'illusion', as follows: “. . . that fantasies exhibit a relation to real, present life and make it easier to cope with this reality, whereas illusions remove energy from it, produce isolation towards it and invest it in a past reality from which they cannot detach themselves.' (pp. 287/288)

So the media can be used to escape into illusions, but also become an important means for occupying oneself actively, reflexively with (internal and external) realities. "A child that uses its fantasy to solve its problems is working on its own mental health. It can maintain its human ties and its good contact with reality and at the same time with its world of fantasy. What is more, it can be seen that the child's contact with the proper world is strengthened by its periodic flights of fantasy. It becomes easier to withstand the disappointments of reality and to fulfil the demands of reality if one can occasionally enter a world in which one's fondest wishes come true." (Fraiberg 1972, p. 26)

Now whether a certain child uses media stories to fantasise and thus cope with life or escapes into worlds of illusions, is not determined alone by either the symbols that are provided or by the structure of the child's personality and of its social environment. It seems to be far more important whether a child can itself place confidence in its own ability to cope with the world and can shape its arrangement for doing so accordingly. The supportive actions of the people the child relates to can be a critical factor in contributing to this confidence.

Bittner (1981) calls for appropriate suggestions of symbols to be made available to children: "If it is admitted that the formation of self-symbols represents a necessary component of becoming oneself, and if it also holds good that this formation of self-symbols does not take place in the vacuum of a psychological introspectiveness, but that it depends on an accommodating, external reality capable of symbolisation, this results in an educational task: to introduce the children to 'world' that 'speaks', i.e. that is capable of interpretation and from which children can learn something about themselves." (ibid, p. 203) 
This kind of 'speaking world' certainly includes, in our days, the characters and stories presented in such a wide variety in the mass media.

\section{Notes}

1 The field observations were carried out by Ruth Franck and Ruthild Rapp.

${ }^{2}(\mathrm{P}=$ Paul, $\mathrm{O} 1$ or $\mathrm{O} 2=$ observer 1 or 2 , consecutive numbering of the interacts)

All the transcripts have been carried out according to the system of Kallmeyer and Schutze (1976, p. 6 et seq.). As spoken sentences contain no punctuation, the sentence construction is indicated in the conversation analysis by special transcription signs. The following signs were taken from the transcription system:

(,) = very brief interruption of an utterance

… = pause

$\mathrm{mhm}=$ pause-filler, reception signal, dual peaked

(.) = lowering the voice

$(-) \quad=$ voice hanging in the air

(') = raising the voice

(?) = question intonation

always $=$ marked stress

(laughing), (goes out), (fast) = indication of non-verbal processes or way of speaking, intonation

$(.) \quad=$. incomprehensible

(comes?) $=$ not properly understood, suspected words

Simultaneous speaking characterised by shifting parallel lines towards each other.

${ }^{3}$ See note 2

4 See note 2

${ }^{5}$ See note 2

\section{References}

Bettelheim, Bruno: The uses of enchantment. New York 1975. (Kinder brauchen Märchen. München: dtv 1980. German ed.).

Bittner, Günther: Die Selbst-Symbolisierung des Kindes im pädagogischen Kontext. In: Bittner, Günther (Ed.): Selbstwerden des Kindes. Ein neues tiefenpsychologisches Konzept. Fellbach: Bonz 1981, p. 200-205.

Braun, Barbara; Charlton, Michael; Neumann, Klaus; Orlik, Waltraud; Rapp, Ruthild: Medienkonsum zur Lebensbewältigung. In: Heyse, H.; Wichterich, H. (Ed.): Alte Schule

- neue Medien. Bonn: Dtsch. Psych. Verl. 1988, p. 59-65. 
Braun, Barbara; Charlton, Michael; Neumann, Klaus; Orlik, Waltraud; Rapp, Ruthild: Freiburger Längsschnittuntersuchung der Medienrezeption durch Vorschulkinder im familialen Kontext (Text-Kontext-Korpus). Forschungsarbeiten des Psychologischen Instituts der Universität Freiburg, 1989.

Charlton, Michael; Neumann Klaus: Medienkonsum und Lebensbewältigung in der Familie. Methoden und Ergebnisse der strukturanalytischen Rezeptionsforschung - mit fünf Falldarstellungen. München; Weinheim: Psychologie Verlags Union 1986.

Fraiberg, Selma: Die magischen Jahre in der Persönlichkeitsentwicklung des Vorschulkindes. Psychoanalytische Erziehungsberatung. Reinbek: Rowohlt 1972.

Haas, Gerhard; Klingberg, Göte; Tabbert, Reinbert: Phantastische Kinder- und Jugendliteratur. In: Haas, Gerhard (Ed.): Kinder- und Jugendliteratur: Ein Handbuch. Stuttgart: Reclam 1984, p. 267-295.

Kallmeyer, W.; Schütze, Fritz: Konversationsanalyse. In: Studium Linguistik 1/1976, p. 1-28.

Schäfer, Gerd E.: Spiel, Spieiraum und Verständigung. Untersuchungen zur Entwicklung von Spiel und Phantasie im Kindes- und Jugendalter. Weinheim, München: Juventa 1986.

Shepherd, M.; Oppenheim, B.; Mitchell, S.: Auffälliges Verhalten bei Kindern. Göttingen: Vandenhoeck u. Ruprecht 1973.

Strunz, Franz: Die Träume der Kinder. In: Psychother. med. Psychol. 38/1988/-, p. $175-184$.

Van de Castle, R.L.: Animal figures in fantasy and dreams. In: Katcher, A.H.; Beck, A.M. (Ed.): New perspectives on our lives with companion animals. Philadelphia: University of Pennsylvania Press 1983, p. 148-173.

Zulliger, Hans: Die Angst unserer Kinder. Stuttgart: Klett 1966. 
Heinz Hengst

\section{Change of scene \\ The scripts of the media industry in children's culture}

\section{Changed contexts}

The reference points of research which thematises children's media actions cannot be just the concrete environments in which these actions are embedded. A development dimension should also be taken into consideration. The specific forms of children's occupation with the media and the children's media competences emerge under conditions in which the context of childhood, the relation of childhood and adulthood, vary in the same way as the media system itself is subject to constant change.

\section{Differentiation of the context of childhood}

The description of the change in the life-world(s) of children is difficult inasfar as the pertinent research knows little about the factors relevant to socialisation in the traditional institutions, the complex interaction of these institutions and their relations to new factors. Added to this is the fact that prejudices in one's own socialisation experience distort the way one sees new conditions and make it difficult to assess them. Nevertheless some changes in childhood conditions are obvious. A decisive change in the context of childhood lies in the fact that it has become more complex and more heterogeneous in its composition (than twenty years ago). The children who are currently growing up in highly industrialised societies gather their experience in a very wide variety of areas of reality.

Firstly, more experience-relevant groups, institutions and systems enter into children's everyday life, secondly, each of these has become differentiated, and, thirdly, the different changes result in a new environment which is more than the sum of its parts. It cannot be understood with zero sum games, colonising and loss models. Thus children spend more time in institutions. On the whole there is more public childhood. There is more media and commercial childhood. And there is no less family childhood. But the context of the family has changed, some reasons being that parents see and treat one another and their children more like individual partners, that more mothers go to work, the marital relations have become less stable, that children have more opportunities to withdraw (for example, by having a room of their own at home) and have become more independent. Moreover, peers have gained in importance as socialisation authorities at school institutions and in the extra-mural area. School has become more and, at the same time, 
less important: more important because under the condition of expanding education job prospects shrink to a minimum without having passed the final examinations; less important because the training sector has been detached more and more from the employment system. In spite of the 'inhospitableness' and 'unreality' of the towns in which functions have become segregated and which are dominated by the motor-car, in spite of a trend towards making childhood more 'domestic', 'street socialisation' and 'playing outside' (broadly understood) continue to be as many studies show - relevant aspects of children's leisure-time organisation and environmental experience (cf., among others, the study by Lang 1985). We therefore have to start from the assumption of complex environments which confront children with very diverse situations and which make possible for them or demand from them new kinds of integration achievements.

\section{Expansion and erosion of the media system}

This complexity and heterogeneity characteristic of the present-day context of childhood finds a parallel or special expression in the media system. That it is made up of many media and many channels has consequences for acting with and everyday knowledge of the media. The selective fixation on individual, dominant or new media should therefore be replaced by consideration of a dynamic media ensemble. The development of the last two decades has led to a multiplication of media and media offerings. This has implied a number of other (qualitative) changes, which have entailed, among other things, an increased blurring of the contours of the individual media. Quite obviously it is first the print media, but then the sound media (for example, commercial radio plays for children) that have made sacrifices to television. In many different ways (for example, by borrowing material, reducing everything to 'action', restricting the vocabulary, simplifying sentence construction etc.) they have become, so to speak, 'tele-visualised'. The latest changes emerging in the media and leisure-time area can no longer (in spite of the spread of video and private television) be understood in this sense as a mere differentiation of television culture.

It is noticeable that an obvious tendency to break down contours and structures is not restricted to the intermedial area but has also increasingly blurred the borders between the medial and non-medial sectors. The media sector has been merged together with other areas of the world of goods and the services sector. This tendency has been and is being forced above all by the creation of constantly new variants of the multi-media system, that is the simultaneous, multi-medial and multi-channel gaining acceptance for a symbol or script (script here in the sense of producer's directions, matching stage properties, prescribed scenery and plots for media communication and leisure-time organisation) on the market. 
A constitutive element of the expanding and eroding media world is also to be seen in the fact that it is subject to faster and faster circulation in the relevant, or at any rate frequented, areas.

These changes - especially the increasing spread of 'interactive' media should also be mentioned - make it necessary, when attempting to reconstruct media experience, to refer to a dynamic quantity that has become diffuse.

Children are directly affected by all these developments. And it should be clear that a media world of the type outlined is received and processed differently to a small media ensemble in which the individual media have distinct contours. The meanings which children ascribe to individual media and their offerings, deliberately or automatically, can, it is true, in the end only be opened up by considering the changed context of childhood, their concrete socio-cultural environments and their personalities, but they also depend on their experience with an expanded media ensemble even in the early years of life.

Although on this point there is little systematic research, it will be possible to assume that those who are growing up in and with a multi-medial world attach differences between the various media not only to their (typical) contents and product structures, but also ascribe different meanings to the individual media, construct meanings in which the situative contexts and the 'side' activities which they permit, the attention they command, the personal arrangements in space and time they make possible play a decisive part. The selection of, the occupation with, the distancing from and the judgement of media are always answers as well to the structure of the whole media ensemble experienced.

These answers - as the growing attractiveness of sound cassettes and other audiomedia, and also the specific use by children and adolescents of video films, computer games and certain elements in multi-media systems show - are cohortand/or generation-specific accesses to a differentiated media ensemble.

\section{Between producer's directions and script manipulations or activity enclaves in the shadow of the family, school and television}

In view of such developments the study (of the structures) of subjective correlates, of the typical activity bundles which the adolescents, simultaneously, in the long and short term, realise in their occupation with the changed media ensemble emerges as an important theme of qualitative (children's) media research. Here the non-media-centred share of the activities must not be regarded as a mere remaining quantity. A more open relation between use of and influence by the media has to be assumed. Such a way of looking at the situation takes into consideration 
the erosions of the media system, which confronts in particular the children more and more frequently with impulses and scripts in the acquisition of which the pure media reception is distributed over not only different media (audio-visual, auditive, 'interactive' and print media) but also becomes one moment among many. It also harmonises with the fact that non-medial activities and forms of communication have by no means been ousted from children's and adolescents' everyday life in the course of an advancing mediatisation (cf. for children, among others, Arbeitsgemeinschaft Rundfunkwerbung 1981, Feilitzen 1984, Lang 1985, for adolescents, among others, Jugend und Medien 1986, Jugendliche + Erwachsene '85).

It is to be assumed, if the findings of the available representative studies are taken seriously, that there are various forms of coexistence and mediation of medial and non-medial elements and activities. One subject of empirical studies that suggests itself is, for example, an attempt to reconstruct the modes and the sense of children's (new) structurisation and integration efforts.

The increased importance of such reconstructions is connected with the following: in societies which are subject to rapid and comprehensive structural change, such as are indicated currently by, among other things, the demographic developments, fundamental technological changes, market expansion and individualisation tendencies, children (and young people) are to an increasing extent referred to "socialisation on their own". They are the early adapters, the population and age group which is especially susceptible to new cultural elements, and (doubtless also) the most strongly influenced by them. Whoever takes them seriously as subjects does not only and not primarily inquire after the determination of their actions through the conditions that they find, but understands the world they are coming to grips with as a children's culture, which they themselves (help to) construct by processing what they find. An analysis of children's culture then becomes an analysis of culture by children (cf. Daun 1982, Hengst 1989), comprehensible in the activities and interpretations of the children.

The experience they gather in their dealings with the totality of culture, especially with the media ensemble, with new technologies and commercial culture, are possibly more relevant for the future than what they learn under supervision of their teachers. The adolescents" "new kinds of access" (Mannheim 1965) to the available cultural stock are nowadays no longer just those which the generation change generally entails and without which cultural change would be quite unthinkable.

Because children's present time is no longer, as in more static societies, largely identical with the adults' past, and their present time no longer represents the children's future, a new kind of generation-relationship must be taken as a starting point. 
If research into childhood and children's media is, under such conditions, not concerned - as Margaret Mead (1974) provocatively put it - with children about which it "knows nothing", it is concerned with a generation of children whose experiences are less well known than those of earlier generations of children and who also have a different relation to the future. They cannot easily, for example, be subsumed in the "not-yet" category.

\section{Remarks on the research method}

The methodological consequence that suggests itself with a preliminary understanding of this kind is an ethnologising of research. Ethnologising means the attempt to trace empirical social worlds as they exist for the addressees/those being studied (and not as the researcher imagines them). In the given context it is therefore a matter of creating research processes about children's media experience so that they are really discovery processes. Ethnologising means, among other things, that no hypotheses are imposed on social reality. It means restraint when resorting to basic theories, to psychological developmental theories, to identity theories and curriculum vitae concepts etc.. It should go hand in hand (see above) with the task of a solely media-centred perspective, because the latter runs the risk of giving the wrong weighting to the media influence. Research must (however) be open to new elements of learning, to what is alien in children's media culture, must be aware of the danger that the adult researchers' prejudices also make them blind to new conditions and judgements through their own socialisation history.

What can be empirically (in its entirety) recorded most easily in highly differentiated societies are excerpts, areas of reality, which often first take shape in context with certain thematic complexes. They should be excerpts which correspond to the changed context of childhood as they do to the the changed structures of the media ensemble.

\section{The reference group of children's peers}

In the study to which I shall refer below, certain age cohorts were laid down, the nine- to thirteen-year-olds. In the given connection the following facts favour this selection: at this age children are very mobile, and they come to terms with the media in a variety of social situations. Children in this age group take part in a comparatively large number of cultural activities in very different institutions. It is especially in the time outside school that considerable importance attaches to relations to their peers. In their relations to their peers, in the joint activities with them, which are characterised by symmetry, norms and rules of social actions are generalised and differentiated, interests and competences are harmonised and compared, rules of behaviour are tested and re-negotiated. In view of the fact that many innovations in the areas of technology and the media are new not only for 
the children and that therefore there is a lack of conventions for dealing with them, group experience with these excerpts gain a special importance.

To examine their experience as common (cultural) experience of peers therefore suggests itself. Thematically, attempts to come to grips with the media are preferred in which fascinating impulses from the media system, the arsenal of the leisure and culture industries, play a part, or are evoked by such impulses. The choice of a theme/object also depends on whether it has practical importance for large sections of the age group.

At the same time the age group is subdivided into two types of reference groups. There is the reference group towards which the children (only) orientate themselves (virtual reference group), and there is the one they belong to, in which they become active, interact and communicate (real-life reference group).

The former (virtual) group is also the instance in the establishing of which the media and consumption industries have a considerable share. In coming to terms with its offerings preferences, action patterns and mentality structures develop which the industries (a kind of circular process) take up with constantly new productions.

\section{Educationally rarefied zones}

With regard to the context (the natural setting) in which empirical studies should be carried out the following applies: generalised restrictions to certain social venues are not sensible. The choice should, however, be made so that the control by teachers or social workers is ruled out (as far as possible); for the research object intended is "socialisation on their own" or under anonymous control: as an interplay of the given media/market conditions and (independent) group actions.

The social venue that is emphasised is (put colloquially) the "educationally rarefied zone'. The term 'zone' is here not only or primarily to be understood as being in space but also to a certain extent four-dimensional, as being in time. (If the rapid and constantly accelerating circulation is a constitutive element of the media and consumption sphere, then the dimension of time must be included in a subject-orientated research.)

Such a space of time is given reality, for example, in connection with a leisuretime script launched by the media and culture industries. (That is shown by the observation of this excerpt of children's culture over many years.) Certain scripts created by the media meet with a good response in certain spatial surroundings in the peer group for some time. 


\section{On integrating medial, sense-active and group-related actions into educationally rarefied zones - a model study}

Research objects of the type outlined are complex fields which are made up of very different elements and whose structures are not laid down from the beginning. The scientific penetration of such a field therefore raises special methodological problems.

They are concerned with access, observation, analysis, systematisation and presentation. It is necessary to translate the 'ethnological view' into appropriate methods.

I should like to go into this in more detail taking as an example the study of the Bremen children's computer scene. Methods were chosen to carry out this study which allow the experience to be reconstructed which nine- to thirteen-year-old Bremen children had in a typical context for the study period (last quarter of 1983, first quarter of 1984) in the computer departments of large stores and specialist shops. The point of time chosen and the period available for the study favoured this field of study just as much as the fact that the latter largely complied with the criteria outlined above. Computers and computer games are attractive innovations in the media world. They cannot be simply included in the phalanx of the screen media. The screen is, it is true, an integral and fascinating constituent part of the (media) ensemble that is played with, and screen and television experience is good preparation for handling computers and computer games. Thus the American media psychologist Greenfield understands the computer game competences of adolescents as the results of their television socialisation. She supposes that the rules of the computer games demand above all television literality, that is the ability to be able to process dynamised visual information (Greenfield 1987, pp. 91 ff.).

These rules - unlike those of chess and other board, card and party games must be primarily learnt by observation. Movement and speed are integral parts of the games; speed is absolutely essential. Most computer games require the ability to process different and various kinds of information at the same time. They presuppose a strategy of information processing which psychologists call 'parallel processing' (ibid., p. 104).

More decisive than the visual dimensions is, however, the novelty that the games make 'interactive computer microworlds" accessible. "Video games are the first medium to connect visual dynamics with an active participant's role for the child." (Ibid., p. 95) In the last analysis, computer games are a new type of integrated media system. The conventional form of the integrated media system suggests or admits of a separate use of the individual elements that is split up in time. (For example, you first see the film, then the script is performed in another way 
with the relevant figures or properties, later you read a book version or hear a sound cassette version - with "Batman", for instance.) What is new about the 'integrated media system of the computer game' is that it integrates various elements in such a way that they can/have to be acquired simultaneously. The computer game occupies the sensorium more intensively and more activatingly than electronic entertainment media have done hitherto.

The departments of the big stores, where many West German children and young people had their first experience of computers and computer scripts, were educationally rarefied zones, a part of the semi-public sphere which has long played an important role in the explorations of children living in (large) towns (cf. Ward 1977, Köhler 1981, Harms/Preissing 1988).

\section{On the methodological instruments}

To research the typical activities in this field a multi-method approach was chosen which allows the individual methods to be supplemented and mutually corrected. At the centre of the methodological instruments were the classical ethnomethod, the participatory unstandardised observation and open questioning. It was, in the end, a matter of mediating the children's practical experience with field-relevant data of all kinds. The unstructured participatory observation was chosen because it ties down the observer least of all, giving him the chance to record complex situations and actions. Although this method is combined with a lack of control, it does have the advantage that the perspective can be continuously adapted to new circumstances and knowledge.

Participation means within the framework of the project that those conducting the study introduced themselves into the scene so that they could understand it better or ask after the meaning of actions with more insight. Whereas observations are principally suitable for registering action patterns, interviews make it possible to record the inside views and the subjectively available knowledge ascertainable by questioning.

While exploring the computer scene in department stores, open, or unstructured, interviews supplemented the unstructured participatory observation. The interviews - individual and group questioning as well as a number of short conversations - were usually conducted 'on the spot', in the departments and cafeterias of the stores. To achieve more perspectivity not only children but also other people involved in the field and the subjects were interviewed. These mainly included young people who moved in the scene. In addition conversations were also carried on with adults concerned, such as sales assistants, representatives of companies and teachers who ran computer working parties. The lists of the children's game programmes and technical journals that circulate in the scene were also evaluated as further sources of information. 
The analyses of contents and pictures were found to be a promising method of reconstructing the scene as an ideological reality.

It took 18 months to carry out the whole project, and the field phase lasted about seven months. Although at the beginning it was certain that empirical research into the subject of children and the media should be carried out, it was not certain into which object.

The interest in a study of the department store computer scene developed in connection with observations in the urban consumption zone. Expanding the field to 'night bar phenomena', or rather, the inclusion of two other scenes into the study (BMX and breakdance, see below) resulted as a reaction to the orientations and reorientations of the children from the computer scene. (It becomes clear from these reorientations, which also entailed the necessity to expand the samples, that for reasons of flexibility appropriate to the research object it is not a good idea to lay down the samples precisely beforehand.)

The presentation of the results of ethnographical studies aims to bring out clearly the typical actions and meanings which characterise a cultural field. This means that in the final reports and publications sections are quoted from observation records and interviews which bring out what is typical about the particular excerpt from reality. The advantage of this manner of presentation is its colourfulness and closeness to everyday life. (Cf., among others, Geertz 1983 and Girtler 1984. $)^{1}$

I should like to comply with the requirement of clarity in this report at least in the initial stages, and to do this I refer to a single aspect, to what was mentioned in the material analyses of the 'Change of Scene' project.

The motives and causes for a 'change of scene' can contribute in particular to a knowledge of the linkages of the ephemeral and the constant in the children's orientations, and thus of the determinants of structuration processes.

\section{Change of scene}

At the beginning of 1984 some children announced their departure from the computer scene, giving as the reason that the latter and the computer had 'lost its attraction' for them. The interviews showed that this 'loss of attraction' is not tantamount to satiation in the case of all children, but that many boys preferred to join in the majority interests in their clique, because it was especially important for them to spend a lot of time with the familiar group. Some cliques planned a more intensive occupation with BMX cycles. Others toyed with the idea of going in for breakdance. The observation of an increasing interest in these two scripts contributed in no small way to the physically active dimension in their dealings with computers, the children's most widespread computer-centred activity, gaining in significance in the analyses. 
The conversations provided evidence that some boys regarded playing as a new sport variant. The fact that, in the case of some children, BMX and breakdance could advance to follow-up scripts of computer games was connected with the fact that they stood for new body experience. (Sherry Turkle points out an affinity between sporting activity and playing with computers $(1985$, p. 78).) She bases her findings on relevant reports of her interview partners' experiences. The fact that they (like the majority of their peers, cf. Kabel 1987) mentioned sports when they were asked what their favourite hobbies were also indicates a marked interest of the children interviewed in body experience. In the phase of their most intensive preoccupation with the computer scene, too, (several times a week for several hours) they regularly went in for at least one kind of sport in a club.

It was also possible to find explanations for the 'loss of attraction' in the material. Both observations and questioning showed that the actual programme which fascinated the boys was a very wide range of games which could be constantly added to. (The interest in this programme motivated the exchanging, buying and selling of games, which after a few months became a matter of course, furthering new main activities such as copying, collecting and cataloguing programmes (at the expense of playing computer-centred games)). A broad programme of games was guaranteed for a time (for reasons of profit, which did not remain hidden from the children) by the conditions in the department stores. As from the beginning of 1984 the stores' personnel (not in all stores at the same time) stopped allowing many activities and communication opportunities which in the prolongued Christmas business in 1983 were the order of the day and were encouraged. (For example, no defective computers and peripheral units were repaired or replaced by new ones, and hardly any games were made available. Copying was also not allowed.) Now it was no longer possible for the children to play off the department stores (and specialist shops) against one another by simply boycotting the departments where conditions got more difficult for them, sales assistants were unfriendly, etc. The computer games also 'lost their attraction' for some of the children because in coming to terms with the scripts of the media and leisure industries it has become a habit for them to expect rapid changes. And, finally, the computer games had also 'lost their attraction' because the (virtual) reference system of their peers was already 'testing' the new scripts breakdance and BMX (BMX = bicyclemoto-X (cross)). The possibilities and the importance of BMX had become clear to the children of this age group through a brief episode in Steven Spielberg's film "E.T.".

In "E.T." there is a wild and dramatic chase between a group of children on cross-country bikes and adults (police officers and NASA people) in police cars and armoured vehicles. The children, being very mobile with their bikes, can throw off their pursuers for a while. But then they are faced with a road block and there is no chance of escape. Just before the seemingly inevitable collision, 
however, E.T., who is riding in a basket on 10-year-old Elliot's bicycle, raises a finger, the bicycles take off from the ground and fly over the roofs of the cars and the heads of the pursuers towards the safety of the woods. This scene only lasts a few minutes.

Those of the researchers who had already seen the film before their exploration of the BMX scene had not paid any particular attention to this episode. (It is, incidentally, not mentioned one single time in the many reviews of the "E.T." film.) $)^{2}$ It was the children who first enlightened those involved in the project on the significance of this scene. They provided the impulse for the research which makes clear why it was possible for this episode to trigger a run on a new type of bicycle among children (worldwide) and the multi-channel success of a new script. ${ }^{3}$

The description may make it clear that very different motives and interests enter into the acquisition of scripts mediated by the culture industry. It may also make it possible to understand along which lines in the project the categorisations and systematisations had to run. They concerned interests, motives, activities and communication forms. -

The material (finally) furnished a bundle (of categories) in which being together with peers and like-minded children, the interest in new and extraordinary physical experience and/or in physical self-portrayal, in conquering semi-public rooms and places, in rapid script changes are constant, and - like the children's lack of financial resources - decisively mark out the scope for script manipulations, for changing the uses and independent forms of acquisition and thus the limits of steering by the culture industry as well.

The material suggested the distinction of two types of child: those orientated to fashion and the subculture and the experts/specialists. In the case of the latter coming to terms with the media is centred on and conforms with the script, and it was clearly to the fore. (Their leisure-time organisation took place in a scriptcentred way. They not only mastered the particular central activity and technical jargon noticeably better than the others, but they also purposefully sought contacts to other experts in the scene, were less group- and fashion-orientated, as a rule somewhat older than the majority of those observed and interviewed. They were a small minority. All the considerations in this article refer to the first type.)

The conception of the study does not give any explanation for the orientation of the children in one or the other direction. Only few biographical data were obtained.

The demographic data collected indicate a wide dispersion. The children (and adolescents) in the computer and BMX scenes are recruited from a very broad range of the population strata and urban districts. They were distributed over all types 
of school. Only in the breakdance scene were children from the lower strata overrepresented. Those actively involved were almost exclusively boys.

\section{New kinds of mixtures?}

My concluding remarks apply to what is possibly new which emerges in the children's coming to terms, in the three scenes, with the three scripts. Anyone who wants to record something new has to make comparisons. In the given context the question arises, however, as to what can be compared when cultural practices in dealing with new and very complex phenomena develop. The mere fact that phenomena are new does not per se result in new kinds of processing and acquisition patterns.

In the concluding discussions on the project an attempt was made to first bring out the new features with regard to the distinction between child-specific, cohort/generation-specific accesses and, over and beyond this, period effects in the orientations and activity patterns. Such activities which the children use to process new elements in a traditional way were subsumed in the term child-specific. In this sense the collecting, cataloguing as well as exchanging, selling and buying are phenomena which enter into many areas of past and present children's culture. Here, therefore, an assimilation of what is new about traditional children's culture activities takes place. Nevertheless, the fact that many of these activities no longer evolve in dealing with media and materials produced specially for children cannot be disregarded. Nor are they practised in children's reservations but in the (one) consumption sphere. They lack the traditional 'as-if' dimension.

In the case of the script-central acitivities allocation to one of the categories named becomes even more difficult. The computer is a 'marginal object' (Turkle 1984) inasfar as it is not a toy in the conventional sense. The English technical terminology (computer, breakdance and BMX jargon) do not have the significance of (children's) old secret languages. The journals in all three scenes do not speak children's language (if only because they address themselves to adolescents all the time as well). Breakdancing and riding BMX bikes are not activities which are followed by more elaborate ones at an adult age, they are not therefore preliminary stages to jogging, therapeutic fasting, triathlon or bodybuilding (either). On the other hand, no adults get involved in these scripts.

The mixture of ages in the scenes indicates a tendency towards the destructurising of (at least) specific children's and adolescents' activities. An expression of a period trend is the interest in physical experience and physical self-portrayal. The adolescents often go their own way in the framework of this period trend. Of considerable importance are attempts at a new kind of integration of medial, sensualactive, body- and group-related actions in educationally rarefied zones. The deci- 
sive script manipulation is aimed at establishing this integration. As soon as it is no longer possible, media-created scripts lose in importance.

It should be examined to what extent the integration interest outlined here and the appropriate integration attempts are generalisable, whether and how they find expression in the forms of structurisation and organisation of the totality of leisuretime activities. Moreover, it ought to be clarified whether in the case of girls similar practices of linking media activities, physical and group experience are widespread, and which kind of integrated activities they favour in dealing with the scripts of the media industry and leisure industries.

\section{Notes}

1 I have presented the main results of the study of the computer scene in, among others, the following publications: Tuscheln, Handeln, Tauschen. Das heimliche Programm am Kaufhauscomputer. In: Bildschirm. Faszination oder Information (Annual Edition No. III of the Friedrich Verlag), Velber 1985, pp. 8-11; Soziales Lernen in der Konsumzone. Kinder im Umgang mit Kaufhauscomputern. In: Medium, No. 7/1985, pp. 13-20.

2 Here it is by no means, as the skateboard revival among children following Zemecki's film "Back to the Future" (1985) shows (also produced by Spielberg), a matter of a negligible, one-off attempt to push through a script via the cinema with a large-scale impact in children's culture. In Zemecki's film daring skateboard runs by young heroes play a similar role to that in the "E.T." scene described.

3 Compare my essay on the "E.T"-launched BMX script and the typical script manipulations of the children: Selbstbehauptung in der Medienkultur. In: Medien praktisch, No. 4/1985, pp. $19-22$.

\section{References}

Arbeitsgemeinschaft Rundfunkwerbung (Ed.): Fernsehen im Alltag von Kindern, (Schriftenreihe Media Perspektiven 1) Frankfurt 1981, p. 297-601.

Daun, A.: Ethnological Research on Children. In: Ethnologica Scandinavica 1982, p. $42-52$.

Feilitzen von, C.: Passiv eller aktiv? Om barns tv-tittande, bokläsning och fritid. In: PuP - Forskning om Radio och TV, Stockholm 1984, p. 56-74.

Filstead, W.J.: Soziale Welten aus erster Hand. In: Gerdes, K. (Ed.): Explorative Sozialforschung, Stuttgart 1979, p. 29ff.

Geertz, C.: Dichte Beschreibung. Beiträge zum Verstehen kultureller Systeme, Frankfurt 1983.

Girtler, R.: Methoden der qualitativen Sozialforschung, Wien/Koln/Graz 1984.

Greenfield, P.M.: Kinder und neue Medien. Die Wirkungen von Fernsehen, Videospielen und Computern, Munchen/Weinheim 1987. 
Harms, G.; Preissing, C.: Kinderöffentlichkeit und Straßensozialisation. Überlegungen zu städtischer Kindheit heute. In: Harms, G.; Preissing, C. (Ed.): Kinderalltag, Berlin 1988, p. $91-108$.

Hengst, H. Tendenzen der Liquidierung von Kindheit. In: Hengst, H.; Köhler, M.; Riedmüller, B.; Wambach, M.: Kindheit als Fiktion, Frankfurt 1981, p. 11-72.

Hengst, H.: Tuscheln, Handeln, Tauschen. Das heimliche Programm am Kaufhauscomputer. In: Bildschirm. Faszination oder Information (Jahresheft III des Friedrich Verlages), Velber 1985, p. 8-11.

Hengst, H.: Perspektiven einer subjektorientierten Kinderkulturforschung. In: Hengst, H. (Ed.): Kindheit in Europa, Frankfurt 1985, p. 301-315.

Hengst, H.: Soziales Lernen in der Konsumzone. Kinder im Umgang mit Kaufhauscomputern. In: Medium, No. 7/1985, p. 13-20.

Hengst, H.: Selbstbehauptung in der Medienkultur. In: Medien praktisch, No. 4/1985, p. $19-22$.

Hengst, H.: Kinderkultur im Wandel. Neue Erfahrungen in pädagogisch verdünnten Zonen. In: Geulen, D. (Ed.): Kindheit. Neue Realitäten und Aspekte, Weinheim 1989, p. 86-107.

Jugend und Medien. Eine Studie der ARD/ZDF-Medienkommission und der Bertelsmann Stiftung, Frankfurt 1986.

Jugendwerk der Deutschen Shell (Ed.): Jugendliche + Erwachsene, Opladen 1985.

Kabel, R. et al.: Jugend der 80er Jahre im Spiegel von Umfragen, Berlin 1987.

Kiefer, M.-L.: Massenkommunikation 1964-1985. In: Media Perspektiven 3/1987, p. $137-148$.

Köhler, M.: Unterhaltung als Botschaft und Kauf als Erfahrung: Die Equipierung der Kindheit. In: Hengst, H. et al. (Ed.): Kindheit als Fiktion, Frankfurt 1981, p. 73-131. Lang, S.: Lebensbedingungen und Lebensqualität von Kindern, Frankfurt/New York 1985. Mannheim, K.: Das Problem der Generationen. In: Friedeburg von, L. (Ed.): Jugend in der modernen Gesellschaft, Köln/Berlin 1965, p. 23-45.

Mast, C.: Medien und Alltag im Wandel, Konstanz 1985.

Mead, M.: Der Konflikt der Generationen. Jugend ohne Vorbild, München 1974.

Rittner, V.: Sportvereine und gewandelte Bedürfnisse. In: Pilz, G.A. (Ed.): Sport und Verein, Reinbek 1986, p. 43-55.

Ronge, V.: Mediennutzung versus personale Kommunikation. In: Rundfunk und Fernsehen 35/1987/4, p. $461-477$.

Turkle, S.: Die Wunschmaschine. Vom Entstehen der Computerkultur, Reinbek 1984.

Ward, C.: Das Kind in der Stadt, Frankfurt 1977. 


\section{Hermeneutic case reconstruction in media research}

Events are unforeseeable as long as they have not occurred. When they have taken place one can try to understand them, to explain them. One can link events with one another and retrospectively understand the logic of this linkage. In the present time there is nothing that has allowed one to predict what, under so many possible, imaginable and other completely unimaginable constellations, will finally occur."

(Claude Lévi-Strauss, “De Près et de Loin", 1988)

\section{Stating the problem}

German-language research into the effects of the media in the last few decades was, and is still to a large extent, orientated rather one-sidedly towards simple theoretical models and standardised empirical research methods. The Commission of the Deutsche Forschungsgemeinschaft DFG (German Science Foundation) was also forced to acknowledge this in its review (DFG 1986). Thus in some cases it was even demanded that only those studies could be scientifically recognised which exhibit a causal proof of effects. The procedures of collecting data and especially of data evaluation used in this connection give rise, however, to considerable doubts as to whether this proof can be furnished at all in this way. Moreover, the question also arises as to whether the assumption of effects from the point of view of causality is an appropriate prerequisite for the object area of the social sciences - and they include the media. It is not only that the field to be examined is very complex and that it appears almost impossible to isolate all the relevant factors, but the whole epistemological gain of such a research strategy becomes debatable. For if we take a closer look at the studies from the field of research, hardly any new knowledge about the object itself can be produced from the point of view of research logic. Thus the classic design, for example, first demands that a theoretical position on the object to be studied should first be taken up from which hypotheses to be examined are deduced. What the empirical phase that then follows can produce is either the confirmation or the rejection of the hypothesis advanced. In these approaches, too, reality is subject to prescribed categories, i.e. it is asked whether certain events fit patterns laid down previously. The process of generating hypotheses and forming theories here takes place outside the empirical research process and is based on the interpretation of the connections that are statistically demonstrated. From this point of view new knowledge cannot be generated on the object. 
To distinguish this methodology which registers reality with categories, here a reconstructive approach is represented. ${ }^{1}$ Central for this position is the assumption, based on anthropology and action theory, that human actions and thoughts are guided by rules. Unlike the term ' $l a w$ ' in natural science, the term 'rule' is regarded as being more appropriate for the social scientific object area. The reason given for this is the linguistic make-up of our consciousness and the structuredness of sociality in terms of meaning. Through language we produce social reality and through that we also communicate about this reality. The concept of meaning refers to the rule-governed connection between the object and its symbolisation on the one hand and the symbol and situation on the other. Adopting the meaning concept after the American social philosopher George Herbert Mead (1973) also implies that there are two levels, namely that of objective meaning structures and that of the subjective representation of these strucutures. The objective structuredness of reality means that the cooperative participation in society is dependent on intersubjectively available symbols which claim validity to make possible 'reasonable' actions and understanding between subjects. In this connection language, which contains this meaning structuredness, is to be regarded as a prominent means of communication (Habermas 1981).

Now the reconstructive approach would like to disclose the rules which generate these meaning structures. In doing so it uses hermeneutic procedures, that is, the way of opening up meaning. In expanding philological hermeneutics orientated to the literary text, the methodological approach which it is necessary to adopt sees itself as a social scientific one which extends the definition of the concept of text. By social reality appearing as being meaning-structured it gains the form of a text whose sense can in principle be opened up. ${ }^{2}$

It is precisely these meaning structures that structural hermeneutics wants to reconstruct. In order to disclose the appropriate meaning contents it avails itself of the implicit knowledge which we ourselves always use in our actions and speech acts to produce meaningful relations. It concerns those systems of rules which determine the pragmatics of our actions and speaking. So when these rules condition our actions and speech we can use it in exactly the same way to judge the pragmatic embedment, that is, the meaningful constitution of actions and speech in social reality. For the hermeneutic interpretation records are produced from this social reality, the interaction text, and these serve as a material basis for the reconstructive method (cf. Oevermann 1979 and 1986). 


\section{Hermeneutic case reconstruction}

\subsection{The character of case reconstruction}

Whereas in the case study an effort is made to give an accurate description of all possible factors, data and conditions of the case so as subsequently to seek for a theory which can be applied to this constellation, that is, to advance an explanation from the outside, the case reconstruction claims to reconstruct the genesis of the case from inside, in the language of the case itself. Here it is assumed that each case contains a specific logic of its development and that the latter can be defined as a certain structuration logic. If this logic is disclosed by the hermeneuticreconstructive access, then the case is 'understood' (verstanden) and hypotheses can be advanced about its further course. So case reconstruction is a matter of answering the question of how something has become what it is. Since the hermeneutic process is one of disclosing or approaching the structures hidden beneath the surface, the result of the reconstruction must always be seen as a hypothesis which has to be examined by further analyses.

While the case study is orientated towards a more typological description of its object and would like to reveal what is individually typical, case reconstruction is interested in what is general about the case. The dialectics of the particular and the general is a central, basic assumption of reconstructive hermeneutics. While the case study tries to understand the case with a theory to be brought in from the outside and thus proceeds with subsumption logic, the case reconstructive procedure claims to open up hermeneutically the meaning content and thus what is typical about the case. The latter means working out from the case itself those structural moments in which the particular appears as a principle possibility of the general and, conversely, the general arises as a specific individual variant.

\subsection{The object of the case reconstruction in media research}

Now, in media research case reconstruction can be applied in many areas. The formulation of the problem of a media research that proceeds reconstructivehermeneutically can, for example, concentrate on the structural contents of media or media systems, of actions in dealing with media, thinking about media or about the influence of media on thinking. Since a reconstructive-hermeneutic method of procedure can thus aim at different object areas, it is important before every analysis to coordinate and formulate the problem and the analysis area. It is therefore a matter of what is actually the case to be interpreted in the case reconstruction. This may, for example in a film analysis, be the structural meaning content of the features of the movie, the interactions of the persons performing or the form of address to the recipients. But also the manner of dealing with certain media, the inner wishes and motivations as well as specific meaning patterns with regard to 
the media can be hermeneutically reconstructed in this way. An interpretation example is taken below to make clear the connection of different perspectives and the interrelation of various case structures. The general theme is a media reception situation composed of several elements. Thus the medium, on the one hand, and the recipient, on the other, are central for such an analysis. But over and beyond this $I$ am also interested in the socialisation background of the receiving subject to obtain elucidation on the manner of reception.

\subsection{Concrete steps in the analysis}

Using an example I should like to clarify the way the case reconstruction approach is applied in media research. I shall, however, restrict myself to questions which arise in connection with the media reception process. To analyse reception questions of this kind I have developed a method of procedure which comprises three different steps:

In the first step the objective meaning content of the medium or the medial presentation is analysed; i.e., for example, of the book or television programme. Here, too, it is important to lay down the analysis level in the selection of the case. It is also often sufficient to analyse the whole plot structure of a film or story. This step is based on the above-mentioned assumption that all social structures are characterised by an objective meaning content which can be reconstructed. Only in very rare cases is this meaning content directly accessible to the recipient, as it first has to be opened up interpretively. But it reflects those interpretation options which are principally available to the receiving subject.

The second step is directed towards the receiving subject. Interest is concentrated on the subjective way of reception. As interpreting is an understanding process, this step can also be described as the one in which it is a matter of understanding what the receiving subject understands. To this end the recipient is asked about his understanding of the plot or the characters in the story. His answers are, in turn, hermeneutically reconstructed with regard to their meaning contents. What is revealed in this phase are the meaning and interpretations which the receiving subject attaches to the medium. Now this second step does not stop at the interpretation of the recipient's understanding achievement: against the background of the analysis undertaken in the first step, the recipient's subjective interpretation is now confronted with the objective meaning contents of the medial presentation. Of course, this can give rise to differences, but it is precisely these differences which are interesting for the analysis. For if the subjective interpretation of a film, for example, deviates from the interpretation of the objective meaning contents, then this requires an explanation, since it must be suspected that here other criteria than intersubjectively valid ones are being applied to assess meaning contents. They might be discovered in the third step. In this second step of the analysis, 
however, what interests us are the recipient's interpretation achievements and his or her subjective way of looking at the media contents in relation to the reconstruction of the objective meaning contents.

Now the third step examines how the subjective meanings of media and the specific motivations to turn to certain contents might have come about against the background of socialisation processes and socio-cultural influences. Here the familial socialisation processes, which in early childhood influence the formation of specific ways of interpreting the world, are likely to play a special role. For this reason here the socialisation conditions have to be ascertained. But these conditions can, at the very best, only be obtained by a special study for this purpose which goes into the receiving subject's family of origin. But as this, in practical research, is only feasible in very rare cases, one has to fall back on these data by means of biographical parts of the interviews and to open up the aspects of the family dynamics of the family of origin. Over and beyond this, however, aspects relating to the life-world and situation play a crucial role. They, too, have to be taken into account in the case reconstruction. So the purpose of this third step is to be able to understand the differences discovered in the second step between the objective and the subjective interpretations and motivations for turning to the media.

Now, the order of the steps presented here is, however, based on an experimental research design, as described elsewhere. ${ }^{3}$ First a film is analysed and subsequently the specific ways of reception by the subject are examined. In an everyday manner of proceeding one will, of course, come across a certain medium or certain media contents which, through utterances during an interview or through the observation of an interaction scene, may be of importance for the interviewee. In this case it is advisable to first take a closer look at the contents of the medium, that is, carry out the first step described above, so that, in a subsequent phase, it is possible to ask specific questions on this, which are then evaluated in the second step.

In the following Diagram the different levels - not steps - are represented on which the case reconstruction operates. The film and the interview are available as material on the lowest level. Only a summary of the plot and a scene from the film are selected. The material represents, on the one hand, the medium and, on the other, the recipient and, in our case, the socialisation history as well, that is, the question as to how the manner of reception might have come about. The middle level represents the statement of the problem: What makes a certain subject (recipient) turn to a certain medium and how can this fact of his turning to it be explained specifically with regard to the situation or socialisation? The interpretations of the individual steps on the different levels must, in the end, join together in a case structure description which embraces the whole case. On the basis 
of the individual interpretation steps and their combination, it must contain an answer to the question which must not be seen as a theoretical access to the case, but it should result from this itself. But subsequently, concepts can be taken out from other theoretical approaches to arrange the case structure into a more general framework.

\section{Diagram}

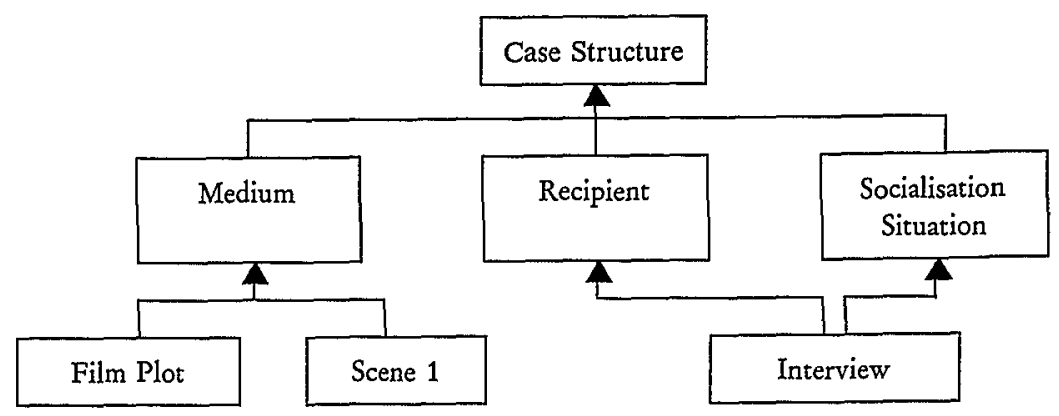

\section{Example of an interpretation}

I should like to present the necessary steps and the concrete analysis process using an example. It is concerned with an excerpt from a larger project on the question of how recipients understand and interpret media contents and how these interpretations have come about by socialisation-conditioned effects. This approach is based on the assumption that, on account of inner motivations, we turn to certain media contents and these motivations themselves are in turn characterised by conditions which are specific to the life-world or relevant to socialisation. The latter aspect is, however, not discussed in the example, as no data are as yet available on it.

The following analysis refers to the question of what might have actually motivated young people to watch horror films. In the last few years viewing such films has become a very popular leisure-time activity among a considerable number of young people, which, however, is condemned by adults. The phenomenon of interest in such films usually arises at an age of between 14 and 17 years and disappears between 18 and 20 . Only very few adolescents continue to enjoy this kind of film after this age threshold. Only in very rare cases did the debate on the consumption of horror by young people conducted in public by those interested in media education result in a closer examination of the reasons for such preferen- 
ces. The following case reconstruction would like, however, to come a little closer to this phenomenon and make it understandable.

The case at issue ${ }^{4}$ is concerned with the specific interest of a 19-year-old young man in the horror film "The Evil Dead I", which is available as a video and which has been banned in Germany for some time. These videos play a decisive role in the everyday life of some young people for their leisure-time organisation and are frequently consumed in groups of friends of the same age. Although girls also look at such films, it is mainly male adolescents who are interested in horror films. As became clear from an interview with the young man, he had already seen the video film six times and this can be regarded as his favourite (horror) film. The example was selected for the following analysis not only because of the clearness of the method of case reconstruction, but also because of the age of the respondent, who at 19 is not altogether typical of the usual group interested in these films. It is thus all the more likely that a hermeneutic case reconstruction might bring out factors which suggest an inner motivation for his preference rather than outer reasons conditioned by the peer group.

In accordance with the steps described above, the film was first interpreted in detail and then the interview was dealt with. Since not only the interview is very extensive, but also the film, which lasts 90 minutes, does not admit of a detailed presentation, I have restricted myself to a small aspect, which in my opinion is, however, central for formulating the question. Nor is it possible here, for reasons of space, to make a precise interpretation of the whole film with its component parts, such as camerawork, editing or the interactions of the performers. ${ }^{5}$ I shall therefore only refer to the character of the plot of the whole film and one short scene, which was chosen by the interviewee in the interview excerpt that follows as a point of reference. It is the scene which the young man describes as the worst in the film. The reason given for selecting this part is that this scene must contain something that might give indications of his motivation for seeing the film. For if he has seen the film so often and each time accepts a cruel and ugly scene, then it must symbolically contain something which unconsciously fascinates him. Before I interpret this scene, the whole plot of the film should first be described.

On the methodological procedure in interpreting the film plot: The plot of the film is interpreted as if it were a real-life action, i.e. the fact that it is a film is ignored. From this perspective even the supposedly subjective view of a recipient plays no part, but only that of an objective third person who observes the scene. This observer represents the view of a reasonably acting subject or the rules of appropriate action. During interpretation scenes are looked for from everyday life which are similar to those presented, according to the motto "That's like..." or "What does that mean when ...?" and are judged according to the rules or structure they are based on. Thus the structural content of a plot has been worked 


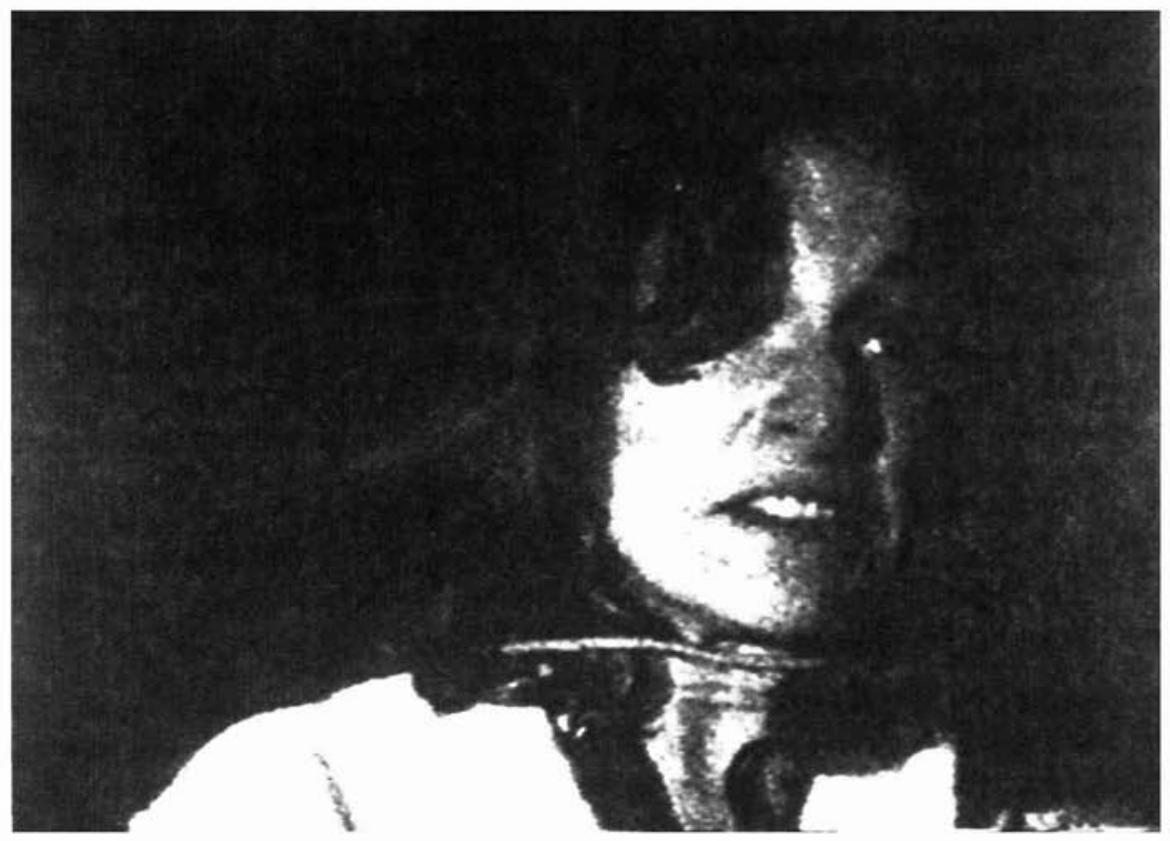

"The Evil Dead I": The root twines itself around the young woman's neck

out. Afterwards an attempt is made to generalise this structure, i.e. to work out more general meaning contents which are to be seen in connection with other parts of the film.

\subsection{Summary of the plot of the film "The Evil Dead I"}

Two couples and a woman, five people in all, drive off together for a weekend in a lonely hut, far away in the forest. During the ride and also on arrival some mysterious things happen. On the first evening in the hut, a door in the floor suddenly opens. There the visitors discover a book with strange writing in it and a tape recorder on which a scientist recounts uncanny events and says the forest is alive. He also claims to know the spell which can revive the dead. In the course of the evening the woman who had come along alone is enticed by something unknown into the forest. There trees fall over and roots begin to twine around her. Parts of her clothing are torn from her body by these roots, and she is thrown to the ground. As if it were a rape, the roots force her legs apart, while she utters groans. Afterwards she releases herself and runs back to the house. Here the cam- 


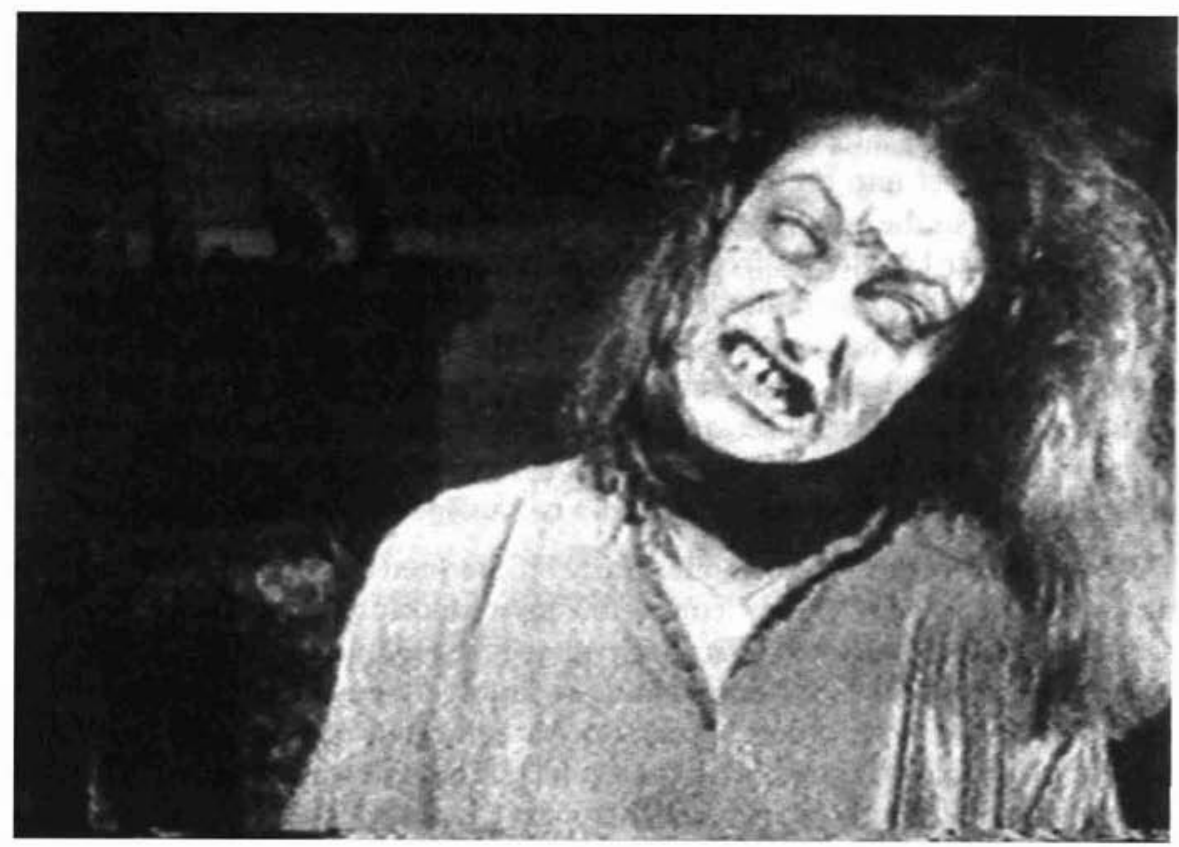

"The Evil Dead I": The young woman's face after the transformation

era perspective shown is always that of a pursuer. In the house she tells the others that the trees are alive. She wants to go home at once. As all the routes for a return have been blocked in the meantime they all have to spend the night in the hut. Now the women, one after the other, all begin to be transformed into eerie beings which threaten the men. By cutting up the women the men try to defend themselves, but the women repeatedly return to life and continue to pursue the two men. After one is already dead the other is threatened by all three women. In the end he manages to save himself by throwing the book with the strange writing that was found in the cellar into the fire. After that the corpses of the women decay and the man goes outside where the day is breaking. There he believes he has survived the horrifying night, but in the end he is also killed by the unknown something, represented by a subjective camera.

The structure of the plot and the subject of the film can be briefly summed up: A woman is changed by an invisible power into a man-hunting 'witch', infects the other women, and together they threaten the men, who can only defend themselves by trying to destroy the women. 
I shall now turn to the presentation and interpretation of that excerpt from the film which is referred to in the interview excerpt that follows. It is the scene mentioned at the beginning of the story in which the third woman who had come without a man is lured into the forest by something magic. She wanders aimlessly deeper and deeper into the forest, branches strike her face and more and more roots come out of the ground and try to grasp her. They slowly entwine themselves around her, tear her clothes from her body and throw her to the ground. While she is pinned to the ground, her legs are pushed apart by the roots, and the camera, which up to now has been observing events with a certain distance, moves up towards the opened legs. At the same time a strong root penetrates into her body. At this moment the fearful screams of the woman mix with pleasurable groans. Shortly afterwards she manages to release herself from the roots and flees back to the house. There she is the woman who is transformed and threatens the men.

This excerpt from the film can quite clearly be interpreted as a rape scene in which the woman appears to be the victim of the mysterious powers of the woods. The action is, however, directed in such a way as if she allows herself to be seduced because she goes deeper and deeper into the forest, although the signs of impending evil are growing. She thus appears to share the guilt for her rape, i.e. in this way the victim also becomes in part the culprit. This ambivalence also emerges in her groaning during the scene, which is meant to indicate that the whole event gives her pleasure.

What can be concluded from this? By making the rape of the woman at the same time appear to be a willingness to be seduced violence is equated with lust or sexuality. Indirectly female sexuality and thus that of the woman in the film appears to be debased, since sexuality is no longer something alive and life-promoting, but also something destructive. If we now look at the overall plot of the film, this represents the beginning of the change in the woman. She had come along as a single woman with the other two couples and thus almost appears to be a saint who would not abandon herself to the passions a partnership involves. But this scene completes her transformation into a whore, who abandons herself to the unknown something which takes her by force. Thus once again the aspect of the debasement of the woman is brought up structurally.

What is significant about the scene is also the camerawork, which changes from a distanced to a subjective view. While her legs are being opened by the roots, the camera moves up to the woman's genital area so that the viewer not only becomes a voyeur of the events but can also place himself in the perspective of the imaginary rapist. The film pretends that the viewer is the rapist.

If we now detach ourselves from the concrete interpretation and ask generalisingly what significance such a structure can have, then the following in particular becomes clear: this scene, of course, creates an identification potential which 
might possibly gain inestimable importance for the reception. A mingling of the perspectives of the imaginary something which rapes the woman and those of the viewer takes place. But as the woman went almost voluntarily into the forest and even experienced pleasure during the rape, this act can be more easily justified, and this also makes an identification with the imaginary something easier. Because the camera pretends that the viewer is the rapist, that is, it acts on his behalf, but at the same time no concrete person appears, this scene offers both distancing and identification. Thus this scene's central structural meaning content, which debases the woman on the level of the film plot, appears to be partly responsible for her transformation and offers identification and distancing through the formal camerawork, seems to be deciphered. If these two aspects are combined, it is possible to set up the first hypothesis on a motivation for the reception of this film. This film is likely to be of interest mainly to those recipients who see their own relationship to women reflected in the debasement of women and in a rape that is desired and accompanies it.

This working out of the meaning contents of the film, or a certain excerpt from it, now allows us to pass on to the selected interview in which the latter scene is mentioned. ${ }^{6}$ This concerns the above-mentioned, second step in the case reconstruction. In the interview interpretation the same procedure is actually adopted in principle as for the picture or film interpretation. Here, too, it is a matter of examining the question as to what an utterance actually expresses. The reference point for assessing the appropriateness is, however, not, as in the case of the interaction, the context, but the facts of the case that are described. When we interpret an interview we ask what the relationship of what is said is to how it is said. In interviews it is also important to analyse the interviewer's question as well, since a particular question also results in corresponding answer options. Here, too, it is important to compare the interviewee's answer with the intention behind the question. Then part of the structure which represents the motivation is already revealed in a possible deviation from what can be expected.

\subsection{Interview ${ }^{7}$}

\section{Q: Which scene in "The Evil Dead" do you find the worst?}

The question is directed at the interviewee's assessment of the film. Finding something 'bad' can refer to both cognitive and to affective aspects. This statement represents a cognitive judgement if it says something about the way the film is made, the expression contents or prejudices coming up in the contents or stereotypes. The term 'bad', however, is also used when the emotional consternation is to be expressed by the scene. It may involve being stirred up inwardly, disgusted or also being frightened with reference to the presentation or the course of the plot. For 
a horror film the cognitively-orientated assessment can only be taken as a standard when this film is seen from a distanced, aesthetic point of view. The horror occurring in such a film would then leave one cold.

\section{A: When the woman changes, when she goes out and changes because of the roots that are touching her.}

That it is precisely that scene in which the single woman changes that is described as the worst is, at first sight, surprising, when the dreadful scenes of the rest of the film are known. The 'bad' refers to the change in the woman who had gone into the forest and was raped there by the roots. This scene is also the starting point for the transformation in the women, who then threaten the men. So what can be so especially frightening about the change in a woman? An empathetic reaction for the woman's situation can be ruled out, since no passive is used (e.g. "How she was changed"). The stress is on the active aspect, the change. But this can be hardly noticed outwardly, but concerns the relationship to the men. It thus becomes clear that the threatening of the men that accompanies the change in the woman is felt to be 'bad'.

I shall therefore try to make a first structure description: An utterance, like the one in which it is said that that scene is the worst in which the woman changes, can only be seen as 'meaningful' if the change itself can be understood as something threatening or similar.

Which motivation might be the basis for such an utterance is to be followed up below. Thus a first structure hypothesis on the case, i.e. on possible reasons for turning to horror films, could be set up.

Since the woman does not change outwardly in the film, but inwardly, in that a friendly relationship to the men and the other women turns into a threat for the others, possible reasons must be sought in the symbolics of such a change, which can be understood as a transformation.

Since the woman in the film does not threaten the viewer but the male partners in the plot, a strong indentification with the men in the film by the interviewee must be assumed. Being threatened by women when they are no longer the people they once were or as they are known is experienced as something real. But now the question as to whether the transformation as such or the transformed woman is understood as threatening still remains open. Assuming the first aspect would mean that the woman withdraws from the control of the man through a transformation. He no longer knows where he stands. This way of looking at it would lead to the conclusion that the interviewee has a very stereotype attitude to women: women have to be predictable for him, otherwise the situation becomes a threat for him. The assumption of the second aspect would lead to the conclusion that his relationship to women is disturbed, which, although not unusual during 
puberty in men, does make one take notice. Both hypotheses do not rule one another out, they even complement each other.

Methodologically, in interpreting the interviewee's first answer a procedure was adopted so that a sensible reason for such an answer was sought. As it does not fall within the area of normality implied by the question, I have looked for motivations for such an answer. They are no more than hypotheses which aim at giving an explanation of how an answer like the one that followed the preceding question might have come about and makes sense.

The previous interpretation will be checked by another point in the interview at which the above-quoted point of the change in the woman is again dealt with.

$Q:$ When you see, for example, the scene in which the woman changes, where the roots come, when you ask yourself, "What kind of feelings do I have or what occurs to me?"'

The question is now aimed more precisely at the feelings that the interviewee has when he sees the scene mentioned. Thus the cognitive component of the assessment is cut out and the affective one is called for. The interviewee has to concentrate on his emotional experience.

A: Yes, I have thought about it from the point of view of feelings, how hard that is for the other man when his girlfriend changes. How hard it must be, what he goes through, what nerves he needs and so on. The man, who certainly likes his girlfriend and doesn't know how much he loves her. And then he has to see her change, suddenly turned into a monster. He'll think, "What kind of a girlfriend have I got?" or thinks to himself, "Didn't she ever tell me that she turns into a monster at full moon?"

Again the interviewee emphasises the change in the woman as especially threatening, but relates the emotional assessment demanded not to this woman but to her friend. ${ }^{8}$ He thus again avoids the request for an emotional assessment. He himself does not comment on it, but he has 'thought about' what feelings the man in the film must have. It is not the woman who suffers but the man. If this utterance is related to the situation shown in the film, this one-sided empathy for the man's situation and less for the woman's is what is surprising. This can only be said by someone who has no time for the woman at all. The man is pitied, because the transformation of the woman takes place unannounced. The expectation that a girlfriend should tell her boyfriend about her imminent transformation is, of course, absurd. Reproaching the woman in this way is to ascribe to her indirectly some of the responsibility for her transformation and thus for the rape that occurs - at any rate from the point of view of the interviewee.

The interpretation up to now again shows the interviewee's identification with the 
man in the film and his suffering. It is not the woman who suffers by becoming a witch, but her friend, who cannot influence this transformation. This utterance also indicates a very object-related relation to women, for it is only possible to keep control of things. Here again the fear of the loss of control over women becomes clear. In addition, the threat of the man by the woman is again the central theme. Thus the structure hypothesis advanced on the basis of the interpretation of the first answer has been confirmed in the case of the analysis of this answer as well.

From methodological points of view the interview ought to be further interpreted to support this structure hypothesis or to find points which refute it or make a revision necessary. These points can be selected according to two alternative modes of procedure when the interview is too detailed and one does not want to interpret everything. The first way is that of the random selection of further interview sequences; the second that of the contrast principle. The latter says that on reading the interview those parts are to be interpreted in detail in which a contradiction to the structure hypothesis advanced is intuitively noticed. If in both cases - the random and contrastive selections - this hypothesis is, however, confirmed, in that the same structure description was obtained, then the previous interpretation can be regarded as consolidated and other questions can be pursued. This situation is assumed in the analysis under discussion.

I shall sum up the previous interpretations of the two interview excerpts. The interviewee identifies very strongly with men in the film, who are threatened by the women. This threatening aspect is especially expressed in the transformation of the women, which means the men are no longer able to control it. The interviewee's sympathies are accordingly not directed at the women who are transformed but at the men who are taken by surprise by this transformation. This indicates that the film here touches on a theme which must be regarded as an inner problem for the interviewee. Only in this way is the motivation to be understood for the answers given which can find a direct relation to the meaning contents of the film.

Below I should like to compare the result of the interpretation of the film plot and of the short interview excerpt, that is, the result of the first step in the method with the second. What the film expresses in the structure of its plot and what was recorded as the result of the intepretation above - the threatening of the men by the women - is, it is true, understood as the contents in terms of meaning of the film by the interviewee, but it gains in personal importance by reason of the identification with the male figures. Thus the interviewee's answers can consequently only be understood as an expression of projections of inner problems onto the plot. The interpretations so far indicate that these inner problems can be tied down in the area of the interviewee's relations to women. It is to be suspected that the interviewee has a problematical relationship to women, so that utterances by 
him on this subject might be particularly informative. To check this furtherreaching hypothesis additional interview passages are included below which thematise the interviewee's relation to women. The first passage is one in which his mother is mentioned. I shall quote these passages in detail so that I can subsequently present an interpretation.

Seen methodologically, here the transition to the third step in the case reconstruction takes place by using situation- and socialisation-related data of the interview. This further analysis serves to help to discover better possible reasons for the motivation for watching such horror films as "The Evil Dead" assumed in the first structure hypothesis.

Q: You said before that you once scared your mother. Can you explain to me how you did that?

A: Yes, I bought one of those masks, a white one, yea, that covers up everything.

Q: Like in "Friday the 13th"?"

A: Yes. Then I drew scars on it with a waterproof felt pen, or cut the mouth out afterwards and the eyes, yea? . . . And I made slit-eyes in it, so that it wouldn't be so obvious, yea? . . . And then I put in Dracula teeth, and a black coat or like Dracula himself, there were two, teeth like Dracula and the mask like Frankenstein, yea? . . And here gloves, white ones, yea? . . and at one place I had an arm, which has a kind of hook or like the pirates, and then I walked like that across the street, yea? . . .

$Q:$ And then you went to your mother. . .?

A: Yes, opened the door and went into the bedroom, made noises, Mother woke up my father, she turned on the light. I went down like this, the sirup was running out of my mouth and she went, "Ahhhh" (scream). A scream, and I ran into my room and laughed. That's something I enjoy doing, giving women a fright.

Q: Why women especially?

A: Because they are the most afraid.

What is very astonishing about the interviewee's story is his transformation into a monster, a phenomenon which he felt was threatening in the film. Forcing his way into his parents' bedroom ${ }^{10}$ resembles an oedipal situation, especially since he relates his description to his mother and not to his father as well. To startle one's own mother in the bedroom in the guise of a Dracula indicates a great lack of respect towards women. But what can it now mean when someone enjoys terrifying women and particularly one's mother in the bedroom? If we take the young 
man's age into account and consider a certain retarded development in his case, which showed itself, for example, purely cognitively in his difficulty in giving a full account of the film without mixing it up with the second film "The Evil Dead II" ", then the assumptions about the problems of the adolescent phase would apply to him. Here the development task is above all the severance from his parents and especially from reference persons of the opposite sex and the reorientation towards women outside the family. In this phase ambivalent feelings towards the mother as well as towards other women have to be dealt with. The beloved mother cannot remain the object of oedipal wishes, but she has to be replaced by other women. Such an action as the interviewee describes can actually only be carried out when one has aggressive feelings towards one's mother.

The reason he gives, namely that he enjoys terrifying women because they are afraid, shows up another aspect of his personality. It is, of course, simple to terrify those people who are afraid, because one has nothing to fear from them. So by seeking out weak points in others one can appear to be strong oneself. But since his idea of women is based on sterotypes, he will, of course, be all the more disappointed when women act differently from what he expected. This consideration also makes his fear of the transformation of women in the film understandable, since transformed women no longer react as expected.

The fact that he can put his supposed strength to the test vis-á-vis his mother of all people while dressed up in a Dracula costume indicates a weak mother, who fails to interpret his behaviour appropriately and thus does not react to it in the proper way. The almost grown-up son forcing his way into his parents' bedroom ought actually to call for a reprimand for his behaviour, but it seems - which does not emerge very clearly from his account - that it does not take place. So there is likely to be an unresolved tension in his relationship between him and his mother and women in general, which is to be examined in the further course of the interview. To do this, other places are taken up in which his relationship to his girlfriend is thematised. They are now reported on in conclusion.

A: My mother, my mother always says, hmmm, "You can never be without women. You always have women on your mind." Then I say, hmm, "That's fine, er, if you have the harem, you have to have it," is what I always tell her. She says, er, "Go on with you, Dad will be mad." . . (incomprehensible), $\mathrm{hm}$, At the weekend I bring three of them home, always different girls. . . He says, hm, "How many have you got? I thought you had one girlfriend." Yes, I do have only one. These are replacements, in case the other one breaks it off...

In this account the boy poses as a lady-killer. The treatment of women from an object-related point of view (three girls) also confirms his relationship to women worked out above. 
A: That's something I simply can't understand. Always these women. When a woman is in love with you and then another man comes along, makes eyes at her, bye-bye, you can go, she goes off to the other man...

Q: Do you feel that's how it is?

A: Yes, not all of them, but some. I know a lot who are like that. It's best to be alone. Then you don't have any problems. Always going out with your girlfriend, and when you go away you have to ring her up. I always go and fetch her on Friday. And when I go away otherwise, she says no, stay with me . . .

In these sections he now criticises precisely that aspect of women's behaviour which he shortly before had claimed for himself. Whereas he had previously mentioned the large number of his girlfriends and referred to them as 'replacements', this is now the point which he does not like about girls. His very one-sided point of view in his relation to women is also reproduced. When women act independently he regards this as a threat and would like to flee. The latter is expressed in his desire to be alone.

\subsection{Summary}

In the summary an attempt is to be made to reconstruct and generalise the case of the media reception of horror films, examined in the light of the example of the horror film "The Evil Dead I" and a 19-year-old young man. It is a matter of bringing together the lower levels shown in the Diagram into a comprehensive description of the case structure. Over and beyond this, further-reaching hypotheses are to be made on how the case came about, i.e. the motivation for reception, and theoretical approaches are to be quoted which are capable of theoretically describing the case.

The interpretation of the film or a film scene and an interview with a 19-year-old who describes this horror film as his favourite film has brought out interesting connections between the meaning contents of the film and the inner problems of the interviewee. While in the film the threat to the men by transformed women is taken as the subject, the recipient's disturbed relationship to women in everyday life seems to find here a corresponding confirmation. Subjective perspectives presented in a film, such as the rape scene at the beginning of the film and the aggressive and destructive resistance by the men in response to the women's threat, constitute further possibilities of identification. The horror film offers themes on which the recipient can act vicariously out his unresolved problems in dealing with women. Thus these themes of the film correspond to the interviewee's inner themes. From this comes the answer to the question as to what constitutes the motivation for watching the film. The adolescent finds a possible way of coping 
with his problems in his relation to women in the symbolic presentation of the relationship of the two sexes.

Wagner-Winterhager (1984) has interpreted these problems generally and against the background of theory elements in depth psychology. According to this, this kind of horror film is so attractive to adolescents "because and inasfar as these adolescents find in the sadistic-sexually tinged sections of the plot possible ways of living out inner conflict tensions of a sexual kind in a harmless way voyeuristically" (p. 363). The authoress refers above all to the aim-shifted actions offered in the film by the actions of certain figures. This means that the viewer, for example in the projection to a murderer of women, can see him as 'not-me' and thus does not come into a conflict of conscience if this ambivalent attitude to women is his or her theme. This is also one of the findings of our interpretation. On account of the dramatics of the film plot, this plot then even undergoes a moral justification. In our film "The Evil Dead" this comes about through the transformation of the woman into a witch, which she is partly responsible for causing - she allowed herself to be seduced - and through the threatening of the men by the women, which can only be warded off by using force. The - probably unconsciously motivated - preference for such films suggests, according to Wagner-Winterhager, that the psycho-sexual process of severance in adolescence has been inadequately coped with. This interpretation also applies to our case. His unresolved themes - his relation to women - become symbolically resoluble for the interviewee in the film.

On the basis of the available data little can be said, of course, about the familydynamic conditions of coping so inadequately with the adolescent process of severance. But it should be asked whether there are not also societal reasons for the development that took place on the video market in the 70s and 80s with the great demand for horror films. In our interpreted case there are, in my opinion, some indications that the emancipation movement of women causes difficulties precisely for those men who in their thinking are closely attached to traditional and stereotype role patterns. The transformation of women in society into self-confident and independent human beings must seem frightening to precisely these men. The media offer these men a projection sheet for their fears of women, in that in horror films they can symbolically defend themselves against the transformation of women.

By including considerations from the viewpoint of depth psychology I have tried to theoretically describe and not to explain the interpretation result of the hermeneutic case reconstruction. This assumption has not been placed like a kind of sheet over the case at the very beginning, but was first brought in at the conclusion. The structural elements of the case have appeared through the hermeneutic interpretation of the case itself. 


\section{Conclusions}

As the present hermeneutic case reconstruction should have shown, in media research a qualitative mode of procedure which is orientated towards the individual case can be carried out so that it results in gaining knowledge. The way presented tries to do justice to the complex phenomenon of media reception and of its possible reasons, by including and relating to one another different factors, such as the film and processes of understanding in the recipient. What distinguishes traditional individual case studies from case reconstruction is that the latter tries without theoretical categories but solely with the aid of the interpreters' everyday knowledge to understand the case. Using the case-reconstructive approach, processes and dynamics at a lower level can be deciphered more precisely than with other methods. In spite of the reference to an individual case, statements are obtained during interpretation which extend beyond what is particular about the case, since when interpreting an action or an interview utterance the normal case, i.e the general, has to be reconstructed. In this sense the dialectics of the particular and the general are to be seen in case reconstruction, since it always contains both at the same time.

One question that is still open for hermeneutic case reconstruction is the generalisation of the results, which is expressed in the term structure generalisation. In order to be able to place the results obtained in the individual case reconstruction on a broad basis further case reconstructions have to be undertaken, which should be pursued exactly as suggested here. In doing so the selection of the further cases should be made according to the principle of 'theoretical sampling' of Glaser/Strauss (1967). The theoretically conducted search starts with the interpretation result of the first case and looks for further cases which help to generalise the structure hypothesis or case description advanced. In the case under discussion this search would have to be carried out in two directions: firstly, the assumption of a disturbed relationship of men to women as a possible motivation for the reception of horror films should be examined; secondly, the question must also be asked as to which reasons girls or young women might have for receiving such films. By using a strategy of this kind the phenomenon of media reception described in this article could be further clarified and thus make a contribution to an understanding of dealing with the media in our everyday life. 


\section{Notes:}

1 For the reconstructive approach compare the two essays by Jürgen Habermas: “Die Philosophie als Platzhalter und Interpret" and "Rekonstruktive vs. verstehende Sozialwissenschaften", both in: Moralbewußtsein und kommunikatives Handeln. Frankfurt 1983, pp. 9-28 and 29-52.

2 The text concept of this structural hermeneutics was worked out by Ulrich Oevermann (1986).

3 Compare Stefan Aufenanger, Stephanie Ester and Barbara Ludewig: Das kindliche Verstehen verstehen. Erste Versuche zu einer qualitativen Analyse von Rezeptionsweisen und -bedingungen bei Kindern anhand von Fernsehfilmen. Oldenburg 1989, pp. 111-128.

4 I am indebted to Denise Chervet for making the interview available and for the joint interpretation.

5 An example of a detailed structural-hermeneutic interpretation of a television scene using a film script can be found in Margrit Lenssen; Stefan Aufenanger: Zur Rekonstruktion von Interaktionsstrukturen. Neue Wege zur Fernsehanalyse. In: St. Aufenanger; M. Lenssen (edit.): Handlung und Sinnstruktur. Bedeutung und Anwendung der objektiven Hermeneutik. München 1986 (Kindt).

6 The interview was conducted in Swiss German, so that some words used had to be commented on.

7 The interviewer's question is abbreviated below with ' $Q$ ' and the interviewee's answer with 'A'.

8 Here too the scenes have again been mixed up. The woman in the film who was transformed by the roots had come alone, but later she transformed the other two women as well. These three women then fought together against the men. The description therefore refers to a later scene and not to the forest scene.

9 "Friday the 13th" and "Mother's Day" are two of the best-known horror films.

10 At another point in the interview he narrated the same scene, but does not mention his father: “. . . and afterwards I woke up Mother with this mask. She got a real shock. She didn't go to sleep all night"'.

11 This confusion arose right at the beginning of the interview when he was asked to give an account of the contents of the film. In his description, scenes from the first film ("The Evil Dead I") were mixed up with the second film ("The Evil Dead II"). The plots of both films are, however, very similar. 


\section{References}

Deutsche Forschungsgemeinschaft (Ed.): Medienwirkungsforschung in der Bundesrepublik Deutschland, Weinheim 1986.

Glaser, Barney; Strauss, Anselm: The discovery of grounded theory. Strategies for qualitative research. Chicago 1967.

Habermas, Jürgen: Theorie des kommunikativen Handelns, vol. 2, Frankfurt 1981.

Oevermann, Ulrich: Sozialisationstheorie. Ansätze zu einer soziologischen Sozialisationstheorie und ihre Konsequenzen für die allgemeine soziologische Analyse. In: Lüschen, G. (Ed.): Deutsche Soziologie seit 1945. Opladen 1979, p. 143-168.

Oevermann, Ulrich: Kontroversen über sinnverstehende Soziologie. Einige wiederkehrende Probleme und Mißverständnisse in der Rezeption der ,objektiven Hermeneutik'. In: Aufenanger, St.; Lenssen, M. (Ed.): Handlung und Sinnstruktur. Bedeutung und Anwendung der objektiven Hermeneutik. München 1986, p. 19-83.

Mead, George Herbert: Geist, Identität und Gesellschaft. Frankfurt 1973.

Wagner-Winterhager, Luise: Warum haben Jugendliche Lust zu grausamen Filmen? In: Neue Sammlung, 24/1984/-, p. 356-370. 
Michael Charlton, Klaus Neumann, Mara Niemann

\section{Children write viewers' letters}

\section{An example of mediating between mass and individual communication ${ }^{1}$}

\section{Viewers' letters as a form of communication between producer and recipient}

Not only the broadcasting stations but also the media researchers are interested in mail from listeners and viewers. Solicited and/or unsolicited feedback in writing from the media consumers to the broadcasting organisations provide, as it were, "natural" insight, not provoked for purposes of research, into the reception of the broadcasts by the listener or viewer concerned. The media-users produce a special kind of communication connection with their letter writing, namely the mediation between mass and individual communication. In the course of communication by listening/viewing - writing - receiving an answer producers and consumers enter into a direct dialogue, which, for obvious reasons, leads to the idea, within the framework of the participation debate, of regarding writing letters to broadcasting stations as a form of active participation by the public in the production of mass communication.

Although the programme producers, the broadcasters' internal research and the universities' media research in communication sciences have dealt with "followon communication", the analyses up to now have yielded anything but satisfactory results. The broadcasting houses frequently consider the letters to be only a kind of ballot paper on the acceptance of a programme (pro or contra) or they even regard the viewers' letters - at any rate in public statements - as completely meaningless, which does not mean, however, that in isolated cases an editor does perhaps think that viewers' letters are an important source of information. The research in communication sciences, too, has so far not fully exhausted the information potential of such letters, when it tries, for example, to ascertain the typologies of letter-writing viewers or endeavours to answer the question of the representativeness of viewers' mail (to examine the relevant literature see Huth and Krzeminski 1981; Scheuch 1986). The letters from the media recipients, however, contain more, and it is certainly worthwhile and profitable to take a closer look at them.

In this paper a plea is made to see and to analyse with greater differentiation the media consumers' letters as, so to speak, minutes of the reception process. The recipients' statements may contain indications of which needs the viewer wanted 
to satisfy by watching the programme, which expectations he had with regard to the product and whether they were met. It may also be possible to obtain information on why the recipient wants to enter into an active dialogue with the producer, which communicative needs were therefore not satisfied by merely viewing and listening.

\subsection{Viewers' mail as follow-on communication}

In a differentiated treatise on the subject of viewers' mail the two authors Huth and Krzeminski (1981) place the writing activity into a wider reception context. Unsolicited, programme-related letters are seen as a continuation of a communication process between the recipient and the media performer. Unlike the example of another form of follow-on communication, for example the "two-step communication" within the framework of everyday communication, in the case of the activity of writing the communicator is maintained. The para-social interaction with the media performer (programmatic: Teichert 1973; see also: Neumann and Chariton 1989), that is the mass communication, is continued within the framework of direct communication through contact by letter. Certain forms of programme (e.g. shows, discussion broadcasts, but no doubt also family serials) lead, in the case of the recipient, to a definition of a situation "in which programmes are experienced as dialogues and the writing of letters appears as a 'natural' opportunity to continue the "conversation"' (Huth and Krzeminski 1981, p. 62). The letters to the broadcasting stations are evidence of the dialogue structure of both the media reception and the connecting communication: many letters are explicitly written as contributions to the continuation of the interactions and conversation begun in the programmes.

The prospect of understanding media reception as a dialogue process which can find a continuation, a follow-on communication, in the form of everyday conversation and writing activity (inter-communication), but also in the form of a conversation with oneself (intra-communication) emphasises that sound radio and television are integrated without any break into everyday life and the individual's process of coping with life. The question which continues to be of interest in this connection is why recipients write unsolicited letters to the editorial boards of broadcasting stations.

\subsection{Follow-on communication and gratifications}

Huth and Krzeminski (1981), in trying to answer this question, resort to the "uses and gratifications approach", although their attitude to it is critical and they offer - also with regard to the general formation of theory in communication sciences - a promising reformulation of this approach. One of the central problems of the uses and gratifications approach is, as is known, to be seen in the fact that 
the theoretical derivation of the "needs" and "gratifications" is inadequate: catalogues of needs and requirements are compiled, expanded and shortened relatively variably and arbitrarily. On the one hand, basic human needs are postulated to which specific possibilities of gratifying them are assigned, and, on the other, certain types of gratification are derived from empirical observations in a quasiinductive way. The problems of the two methods of proceeding are obvious: the first has to come to terms with the limits and scope of the discussion of philosophical anthropology, the second with the shortcomings of ad hoc systematisations.

Huth and Krzeminski propose, on the other hand, that one should not start from general anthropological considerations on nature and the essence of man, but, instead, make the specific point of reference of human communication the starting point of a systematisation of gratifications which can be achieved by using the media: "It (seems) reasonable to proceed from those needs which are satisfied by the social functions of communication" (Huth and Krzeminski 1981, p. 96). Taking up and further developing Bühler's linguistic psychology, the authors distinguish between (a) an I-directed, (b) a contact-directed and (c) a world-directed function (analogous to Bühler's "bases of reality" provided by language: one - to the other - about things), to which individual gratifications can be assigned.

This synopsis of gratification classes and types is not to be regarded as complete. It is possible to imagine with regard to the gratification types, within the classes mentioned, additions and differentiations which are connected with the specific nature of certain programme forms or groups of viewers (see Table 1).

An attempt has been repeatedly made in various works to give a sound theoretical basis to the uses and gratifications approach: sometimes a plea is made to expand the uses and gratifications approach by adding elements of symbolic interactionism (e.g. Renckstorf 1977, 1980), sometimes, in the opposite direction, the integration of the uses and gratifications approach in symbolic interactionism is favoured (e.g. Altheide 1985), and, finally, a cognitive system theory is used to substantiate the uses and gratifications approach (e.g. Palmgreen 1984). All these discussion variants are, however, faced with serious problems, so that taking the linguisticpsychological and linguistic approach to reformulate the uses and gratifications approach adopted by Huth and Krzeminski can be regarded as a promising way that can compete with the others.

Interestingly enough, the classification classes and types laid down by Huth and Krzeminski agree with the classification of media reception actions which were developed by Charlton and Neumann from the viewpoint of a subject and action theory (1986; Braun, Charlton, Neumann et al. 1989): the use of mass media and the examination of media contents are placed within the framework of the reci- 
Table 1: Classes and types of gratifications in writing viewers' letters

\begin{tabular}{|c|c|c|}
\hline \multirow{2}{*}{$\begin{array}{l}\text { GRATIFICATION } \\
\text { CLASSES }\end{array}$} & \multicolumn{2}{|c|}{ GRATIFICATION TYPES } \\
\hline & Reception gratifications & Writing gratifications \\
\hline \multirow[t]{3}{*}{ I-directed } & diversion & \\
\hline & affect & affect \\
\hline & $\begin{array}{l}\text { identity } \\
\text { expression }\end{array}$ & identity \\
\hline \multirow[t]{5}{*}{ contact-directed } & companionship & \multirow[t]{2}{*}{ companionship } \\
\hline & social utility & \\
\hline & sharing & sharing \\
\hline & $\begin{array}{l}\text { to be represented } \\
\text { - representative }\end{array}$ & $\begin{array}{l}\text { to be represented } \\
\text { - representative }\end{array}$ \\
\hline & - advocativ & \multirow{2}{*}{$\begin{array}{l}\text { - advocativ } \\
\text { mediation } \\
\text { action knowledge }\end{array}$} \\
\hline \multirow[t]{2}{*}{ world-directed } & action knowledge & \\
\hline & orientation knowledge & orientation knowledge \\
\hline
\end{tabular}

From: L. Huth and M. Krzeminski: Zuschauerpost - ein Folge-Problem massenmedialer Kommunikation. Tübingen: Niemeyer 1981, p. 114

pient's coming to terms with himself, society and his situation. The reason for this compatibility can be seen in the fact that in both approaches the human ability to communicate and act are made the starting point of the systematisation (in Huth and Krzeminski Bühler's function of language communication, and in Charlton and Neuman the canon of the general theories of social action). But whereas Huth and Krzeminski give preference to a functionalistic way of thinking, the latter stress the constructivistic character of media reception actions (for discussion of functionalism vs. action theory see, for example, Joas 1986) and plead for a division of the uses and gratifications approach and the (media) action theory by categories (Neumann and Charlton 1989).

\subsection{Methods of analysing gratifications}

In an empirical study on viewers' mail received on the German Television ZDF programme "Spielraum" Huth and Krzeminski examine the question posed at the beginning in great detail and with methodical creativity. Who writes what to whom and why? The core of the analysis of the gratifications is the evaluation of 
the letters according to categories with an analysis of the contents. The authors assign certain text passages from the viewers' letters to the above-mentioned gratification classes and types. This assignment procedure based on an analysis of the contents - even if it is generally always carried out carefully by the authors cannot avoid the problem of the validity of the needs and motives expressed in the letters: there is always the danger of making subjective judgements, of distorting messages or even of passing over information at a deeper level.

Oevermann (1981) makes a methodically interesting proposal when he pleads for an analysis of letters using the method of objective or structural hermeneutics. In the example of the case of a letter from the management of a firm to a female employee he brings out the manifest information (request to the employee to change her behaviour), but also the letter's latent messages (for example, the exercise of power by using language formulas which result in making the recipient, i.e. the employee, appear infantile).

\section{Analysis material and the question posed by this study}

Our analysis is based on all the viewers' letters which the responsible television editorial board 'Young Children's Programme' in the Norddeutscher Rundfunk (NDR) received on its series "Hallo Spencer" in the first six years of its transmission. The letters were only available to us in an anonymous version, i.e. we have no personal information whatsoever on the letter writers.

In each of the half-hour transmissions of the NDR's Children's Television series "Hallo Spencer" two scenes are combined with one another. One shows a television studio in which a (puppet figure) presenter called Spencer guides the viewers through the programme: he welcomes them, he comments on the action as it occurs, converses with the puppet performers and at the end says goodbye to the viewers on behalf of them all.

The other eleven puppet performers live in a "village" in a kind of extended family: each member of the puppet community has his own place to live and - what is important - his own role and his own character. Funny stories, which are intended to entertain, develop from particular events (e.g. a village refuse collection is organised) or as a result of socio-dynamics in the group (e.g. petty jealousies). The programme is conceived in such a way that the viewer soon comes to know the performers and their world. Through the presenter, who addresses the viewers directly and continuously involves them in the action, the recipient is all the time integrated in the puppet world of "Hallo Spencer". A communication structure is produced which is clearly conceived as a dialogue (for details see Charlton and Neumann 1982). 
The questions our study wanted to answer were: How is the communication that is offered received by the target group of child viewers? How do they take up this offer of a relationship made by the puppet presenter? What are the motives and needs which induced the viewers to write?

In addition to these questions of contents, we also pursued a methodological objective with our study. We wanted to establish which additional benefit can be achieved with the help of the method of structural hermeneutics according to Oevermann compared with a quantitive contents analysis according to categories.

\section{Quantitative analysis of the viewers' mail}

\subsection{Analysis of the contents of the letters}

All 183 letters which reached the editorial board of the NDR's Young Children's Programme/Television between 1980 (transmission of the first 5 pilot sequences) and 1986 on the series "Hallo Spencer" were included in the first, quantitative evaluation.

About two-thirds of the letter writers were children $(\mathrm{n}=123)$; the remaining letters were written by parents at the request of children. Some writers gave more precise information on their ages $(n=64)$. They were between 6 and 15 years of age $($ median $=9$ years). Just over half of the letters written by children themselves were from boys $(n=77)$.

With regard to the addressing of the letters roughly two groups can be distinguished. The majority were sent to the institution television or a certain department (editorial board) ( $n=113$ ). A considerable number of the letter writers, however, wrote "direct" to Spencer $(n=70)$ or reproduced the words regularly used by Spencer to greet the viewers ("Dear people", "Hallo, dear people" or "Hallo friends from A to Z, from 1 to 100, from east to west"). Here children and adults do not differ in their choice of address (37.4\% vs. $35.0 \%$ of the letters to Spencer).

The subjects, too, with which the writers deal can be divided up into subjects which are more institution- and product-related and those which are more personrelated (the person being the writer or Spencer as a puppet person). The first group includes general opinions on the series, requests and questions concerning repeats or new transmission times and requests for advertising material (particularly frequent are requests for stickers with pictures of puppets $(n=35)$ ).

A second group of statements differs quite clearly from these comments and enquiries. Here it was the writer's intention either to relate something personal about himself (e.g. information about an illness he had just recovered from, a holiday trip or simply the remark that the writer himself is well); or the writer ask- 
ed Spencer how he was ("How are you?", "I hope you are feeling better"), asked for a personal answer ("Write to me some time") or sent greetings to other puppets. One child asked Spencer for the text of a certain song, another wanted to learn how to snap his fingers just like Spencer; one child requested Spencer to turn himself into a hand puppet and to send it to him; and some letter writers asked whether they might visit Spencer one day. Quite a few letters contained personal gifts (e.g. pictures they had painted, photos of the sender etc.). Table 2 shows which empirical relationship can be deduced between the letter writer, the receiver of the letter and the subject:

Table 2: Subjects (product-related vs. person-related statements) depending on the author of the letter and the addressee $(n=308)^{*}$

\begin{tabular}{|l|c|c|c|c|}
\hline Writer: & \multicolumn{2}{|c|}{ Child } & \multicolumn{2}{c|}{ Adult for child } \\
\hline Adressee: & Institution & Puppet & Institution & Puppet \\
\hline Subjects: & & & & \\
product-related & 91 & 44 & 48 & 23 \\
person-related & 19 & 52 & 9 & 22 \\
\hline
\end{tabular}

"Each self-contained piece of information, question or request was evaluated as a single statement. Most of the 183 letters contained more than one statement and/or subject.

There is a clear connection between addressee and subject $\left(\chi^{2}=42.5\right.$, df $=1$, $\mathrm{p} \leq 0.001$ ), but no connection between the letter writer and choice of subject $\left(\chi^{2}=0.34\right.$, df $=1$, n.s.). Children and adults who write for children thus address themselves in the same way to different subjects, depending on whether they write to Spencer or to television as an institution.

\subsection{The summary and interpretation of the results of the quantitative analysis}

(1) The phenomenon of follow-on communication can also be found among the viewers of children's programmes. In altogether 183 letters children have continued the para-social interaction with their vis-à-vis in the medium of television by writing letters.

(2) Here 35-40\% of the letter writers (children and parents writing for children) addressed the puppet figure Spencer directly. The clearly listener-related form of address used by the "presenter" Spencer was therefore "answered" by a considerable proportion of the writers.

(3) Adults who wrote on behalf of their children directly addressed the puppet Spencer percentagewise just as frequently as the children who wrote their own letters. So the parents apparently acted in fact as spokesmen for their children. 
(4) Of the 141 requests, questions and pieces of information to Spencer 74 are worded in a personal way. The viewers take up the "presenter's" friendly "offer of a relationship" not only in the manner of address but also in the contents. As a hypothesis for a closer examination of the individual case it could be assumed that this behaviour of the viewers - in Huth and Krzeminski's system - is motivated by the types of gratification "identity", "companionship" and "sharing" (cf. Table 1). That it is precisely these aspects which are of paramount importance could be put down to the form of the programme and the particular viewer-population.

(5) In the viewers' mail that tends to be product-related the request for stickers plays a major role. These stickers can be used to give a catchword in contact with their peers and as objects to be exchanged. So they are presumably asked for - as Huth and Krzeminski would say - for reasons of "social utility".

\section{Intermediate consideration: television as a "magic window"}

The analysis of the viewers' letters shows that children, too, occupy themselves continuously with television media programmes. They do so even actively, too, in the sense that they reach for pen and paper and address themselves in letters to the editorial boards or the presenter of a programme they have received. $67 \%$ of the letter statements were written with a product-orientated intention (wish for stickers etc.). In the other $33 \%$ of the letter statements the letter writers of both sexes address themselves directly to the programme presenter, the puppet Spencer, with their requests, questions and information. In doing so they give personal details about themselves or enter into a friendly dialogue with Spencer. How can this personal build-up of contact between a puppet and a recipient be explained? Is it because children of this age cannot yet distinguish "properly" between reality and medial fiction?

A look at the literature on the subject of "television as a "magic window" (the question being here: From which age are children in a position to understand the fictional character of television reality? From which cognitive stage of development do children no longer believe that television is a "magic window" through which one can look out into the actual everyday world of real people?) produces the following picture:

The cognitive level of development proves to be an essential predictor for the perception of media reality by children. Children in the pre-operational stage (up to about 7 years) often experience television as a kind of magic window onto the everyday world, with the help of which they can in fact observe events as they are taking place in life (Bonfadelli 1981; Dorr 1983; Hawkins 1977). Up to the age of 5 it is, besides this, only possible for children to believe they are in some mysterious way actually in contact with people on television, 
which expresses itself in the fact that they address these people and believe that they can be heard and seen by them (Böhme-Dürr 1987, 1988; Dorr 1980; Rydin 1984; Singer and Singer 1981). For preschool children there is quite generally a physical proximity between the world of television and the everyday world, and it is regarded as an important development task to separate them (Jaglom and Garner 1981). When they enter the stage of concrete operations children show clear changes in almost all the areas examined. They now realise that different television programmes may have a different reality content, and thus they show a differentiated understanding of the term "real" (Dorr 1983). Now they also manage to distinguish between animated cartoon figures, puppets and human performers on television (Baron 1980; Brown et al. 1979; Quarforth 1979), and their understanding of the fact that some of the people on television are represented by actors grows (Baron 1980; Fernie 1980, 1981).

Children of all ages judge the reality of television contents not by applying one criterion, but by using complex strategies, which contain not only comparisons between these contents and their everyday reality but also a knowledge of the technical and economic aspects of the medium (Kelly 1981; Morison et al. 1978, 1981). This knowledge, however, develops relatively late, is hardly present in younger children and can only be regarded as fairly advanced from the age of 10 to 12 (Baron 1980). From the age of 8 , however, children already understand that television programmes are made, and they can use this to judge television reality (Dorr 1983; Fernie 1981; Hawkins 1977).

Apart from the cognitive development, the knowledge of the medium just-mentioned (Baron 1980; Dorr 1983; Kelly 1981; Morison et al. 1978) and the judgement of the media reality by important persons to whom the child relates (Greenberg and Reeves 1976; Messaris and Kerr 1984) prove to be important predictors for the perception of media reality, far too little attention having so far been paid to the latter by research. With regard to the experience with the medium, the findings available are contradictory (Greenberg and Reeves 1976; Morison et al. 1978). A higher $I Q$ appears to guarantee a differentiated understanding of the reality of different television contents (Greenberg and Reeves 1976), and media educational programmes are capable of influencing the way children judge reality and of producing "more mature" judgements in preschool children (Rapaczynski et al. 1982).

Studies of the concept of subjectively perceived media reality show that different dimensions can be distinguished (Hawkins 1977). Whereas younger children tend to base their judgement on crass infringements of physical reality and, when making a comparison with the everyday world, look to see whether something actually does exist in it or not, older children prefer to form their judgements in the light of an assessment of the characters' plausibility and of a critical opinion of the author's intention, and are guided by infringements of psychological and social reality (Morison et al. 1981).

Children in the pre-operational stage are generally not in a position to explain what they mean when they refer to something on television as "real" (Dorr 1983). A distinction between reality and fantasy is not yet of importance for them, and so they still cannot imagine what the question about reality means (Bonfadelli 1981), and this has important consequences for media studies at this age. Thus direct questions as to the reality content of certain contents, characters etc. cannot be asked. In the concrete-operational stage children use the 
category "reality/fantasy" more frequently and usually mean "possible" by "real" (Dorr 1983). Judgements given especially by younger children on television contents are always situation-specific and are never consistent with regard to the whole programme. Generalisations extending to other contents and to television as a whole are thus not possible (Bonfadelli 1981; Klapper 1981).

The studies referred to clearly indicate the age of $7 / 8$ years as an important turning point in the perceptual development: magical and animistic thinking declines, and reality and fiction are increasingly differentiated.

Many questions of detail still remain open, however, and criticism can also be levelled at the above-mentioned studies on perception: (a) although the theory and method of many studies are based on Piaget's work, they do not come up to the level of the methods that he achieved. Piaget knew that much of what children say does not have to be "true" at all. To avoid methodological traps and thus errors he therefore distinguished between specific types of reaction in children (the "I-couldn't-care-less" attitude, spinning a yarn, conviction induced by suggestion, triggered conviction, spontaneous conviction), which he checked in his interviews with the children. None of the studies mentioned reflects these types of reactions in children, and this restricts the validity of the works. (b) In all the studies the term "(un-)real" is not clear - not clear in particular for the children questioned, either. (c) Often an attempt is made to bring out a clear "either - or", a clear "before - after" from the perceptual performances. But here it turns out that what is supposed to be an unequivocal "yes or no" distorts the relevant research perspective: but the point that should be studied more intensively is not a matter of reality and fiction, magic and animism after one another but in one another (Lurcat 1982; see also the following detailed analysis of the 3rd statement of the child viewer's letter).

The children who wrote the viewers' letters are between 6 and 15 years of age (median: 9 years). Many of the writers were thus, at the time when they wrote the letters, in a position to distinguish between reality and fiction. What is more and it is important to stress this - adults, just like children, write personally to the puppet Spencer, i.e. they write just as if Spencer were a "proper" human being. There is therefore little point in trying to explain the reason for writing these letters to Spencer with the thesis of any shortcoming in the recipients' perceptual performance: a lack of perceptual capability - resulting from the children's development - would lead to mistaking puppets for humans and vice versa. If such a lack is therefore not the reason for writing letters in this way, what is it that motivates children and adults to do so?

Against the background of the concept of mass communication as a dialogue (Kohli 1977), writing viewers' letters becomes intelligible as an element for mediating between individual and mass communication: within the framework of a para-social dialogue with a medium performer the recipient comes to terms with himself, with the social and physical world. The para-social dialogue between both is subsequently, i.e. after the transmission, continued, in this case by letter. 
The gratifications which a recipient can obtain in the process of media reception have already been dealt with above in the discussion of Huth's and Krzeminski's concept.

In our special case we are concerned with a puppet presenter in a children's series. His appearance, like that of the other puppet performers in the series, is aesthetically that of a "crossbreed", half animal, half human. For children - but also for adults (!) - crossbreeds of this kind have a special significance: they transcend the borders and levels between reality and fiction. Mythical creatures (for example, a mermaid) mediate between reality and supernatural spheres, little people mediate between youth and old age, between the world of children and that of adults (Weinraub and Putney 1978) - as happened in the ZDF children's series "Anderland". This status of a mediator especially predestines such figures to be partners for children (but also adults) to speak to - precisely partners for a private communication with an obviously personal slant. What form such a followon dialogue between a child and a puppet presenter can take will be pointed out below within the framework of an analysis, carried out reconstructively, of an individual viewer's letter.

\section{Structural analysis of a selected viewer's letter}

\subsection{The method of structural hermeneutics}

As already mentioned above, an analysis of the motives for writing by means of the method of structural hermeneutics (Oevermann et al. 1979) produces a greater degree of accuracy than using that of Huth and Krzeminski (1981). However, this additional precision is at the expense of the number of letters that can be analysed, since Oevermann's method is very complex in its empirical application. Representative analyses of the motives thus cannot be carried out, although the close examination of an individual case can result in theoretically useful hypotheses.

Objective hermeneutics recognises two methods of analysis: "detailed analysis" (cf. Oevermann et al. 1979, p. 394 et seq.) and the "context search" (Oevermann et al. 1979, p. 415 et seq. and Oevermann 1986, p. 38 et seq.). In the case of the context method used here for each statement and/or text unit those situations are searched for extensively in which the statement can be understood as following rules and containing sense. The criterion for the appropriateness is the tacit knowledge of the (group of) interpreters. In the case of the analysis of a letter, it is additionally possible to resort to explicitly stated rules to be applied to letter writing (model letters, writing aids such as are available on the market in large numbers) and to the findings of literary research into different sorts of texts (cf. Bürgel 1979; Emert 1979; Ettel 1984). ${ }^{2}$ 
Finding the context takes place sequentially, i.e. earlier statements are placed in fictitious contexts without taking subsequent passages into consideration. Later versions, however, must be compatible with previous context descriptions. In this way, as the analysis proceeds, a (funnel-shaped) reduction of the diversity of the versions emerges. The success of this method depends entirely on the extensiveness of the initial context selection. For this reason it was not possible to omit some versions which made a rather funny (exotic) or trivial (self-evident) impression.

\subsection{Determining the case structure to be analysed}

A letter was selected for further analysis which can be classified in the quantitative contents analysis as "child to puppet, person-related subjects".

The text of the viewer's letter ${ }^{3}$

(Translator's note: each word misspelt in German has also been misspelt in English)

$\begin{array}{ll}\text { Lieber Spencer } & \text { Dear Spencer } \\ \text { Hier schike ich } & \text { Here I am senting } \\ \text { dir ein par } & \text { you a fu } \\ \text { Hustenbonbons } & \text { cough sweets } \\ \text { dein heisere } & \text { yor hoarse } \\ \text { stime soll balt } & \text { voise is to } \\ \text { vorübergehen } & \text { go away sun } \\ \text { ach eines habe } & \text { Oh one thing } \\ \text { ich ja ganz fergesen } & \text { I have quite forgoten } \\ \text { ich sehe dich jedes } & \text { I see you every } \\ \text { mall tschüs } & \text { tim bye-bye } \\ \text { from (first and last name of a male letter writer) }\end{array}$

The letter to be examined is an unsolicited viewer's letter to the editorial board of the NDR's "Young Children's Programme" in Hamburg. What is to be examined in particular are the motives and needs which the author of the letter had when writing his letter to the broadcasting station. The question is also asked as to which relationship-structure is established between the viewer and letter writer, on the one hand, and the addressee and editorial board, on the other.

The knowledge that the written document to be examined is an unsolicited letter to a broadcasting station at first restricts the framework of action in which the letter was written and received (for example, the framework of action clearly changes if we are dealing with a correspondence between the management of a firm and an employee, such as Oevermann (1981) analysed).

On close examination, however, there remains a very large spectrum of action for the letter writer: he can write a letter on the basis of a close and familiar relation- 


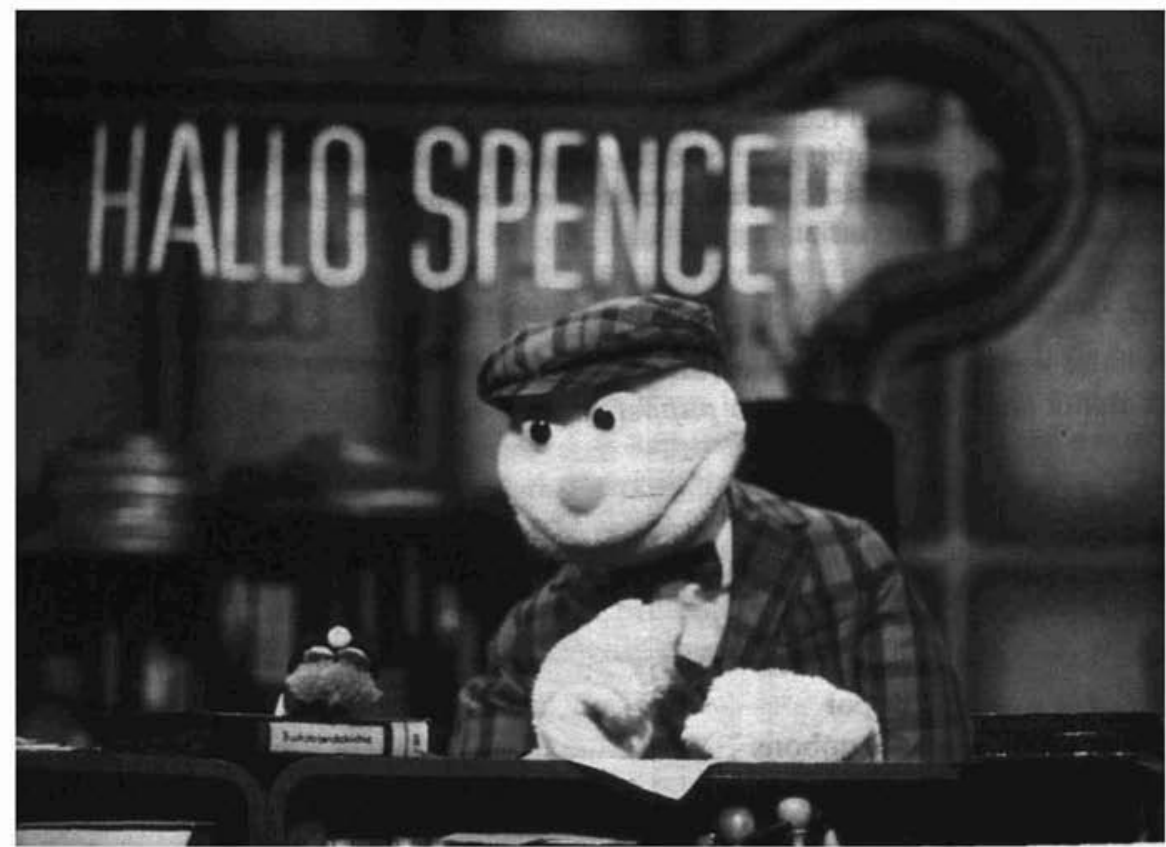

The puppet presenter Spencer from the series "Hallo Spencer"

ship (e.g. letter to an agony column or a "love letter" to an actor or puppet figure). But he can also write a letter as part of a distanced relationship (e.g. a formal request or a complaint).

The unstructured nature of the follow-on communication between a viewer and an editorial board therefore opens up a wide scope for action. For this reason, the interpretation of the text will be carried out more extensively: text and context variants which at first sight perhaps appear improbable will be listed and discussed.

\subsection{Sequential analysis of the text of the letter}

\section{Ist statement: "Dear Spencer"}

(1) This part of the text is a common formula for beginning a letter. To bring out the specific nature of this form of address the usual address patterns in letters are first listed: A distinction can be made between the forms of address "lieber. . " and "sehr geehrter. ..". (Translator's note: This difference is made in English by the use of "Dear 


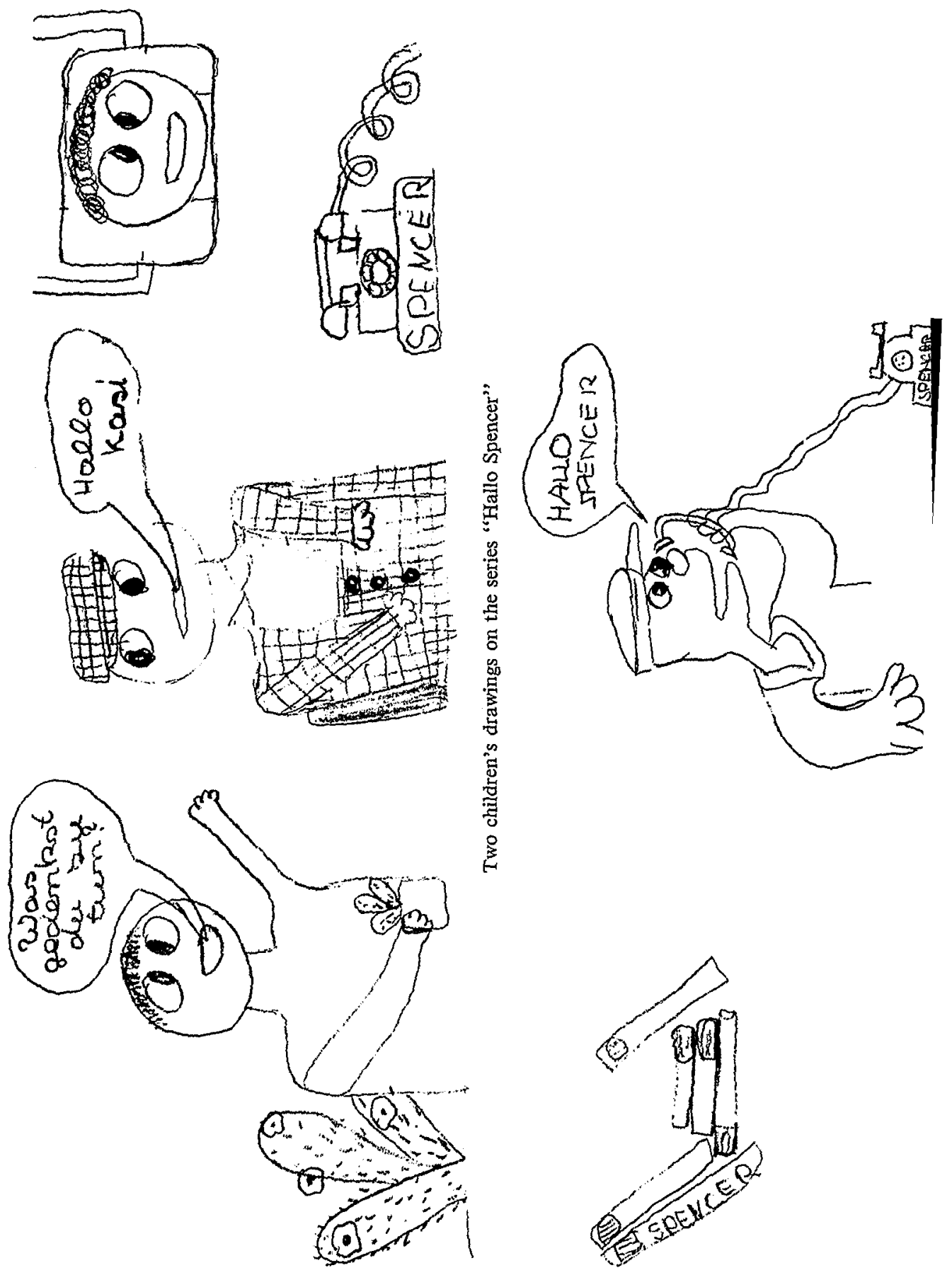


John" and "Dear Mr. Smith" respectively.) "Lieber. . ." is a form of expression which indicates a more familiar relationship between the writer and the addressee. The use of "lieber. . ." signals a relationship of "medium closeness". This way of opening a letter generally rules out - that is at any rate the tendency - an especially close and intimate relationship (an appropriate formulation here would be "mein Schatz" (My treasure")). The form of address "sehr geehrter. .." is, on the other hand, far more distanced. The form "lieber. .." can be combined with a first and/or last name, and it can also be joined up with, for example, the address pattern "Herr" ("Mr.") or "Frau" ("Mrs.") plus name. It is also possible to imagine an indication of a function in conjunction with "lieber. . ." (e.g "lieber (Herr) Briefträger" ("Dear (Mr.) Postman"). In our statement we find the combination "lieber. . " and a name ("Spencer"). It is not clear whether the name is a first or last name, either would be possible. In the world of the upper strata of society the use of the combination of "lieber. . ." and surname is not at all unusual (e.g towards servants). But this combination is also used between manual workers, for example when they call one another.

Nevertheless, it appears more probable to assume within the framework of a follow-on communication that the form of address "lieber. . ." has been combined here with the first name of a male person.

(2) The form of address "lieber. . " combined with a first name indicates - as explained - a more familiar relationship between the letter writer and the addressee. The question has to be asked as to which mutually exclusive action contexts such a statement could refer:

(2.1) The form of greeting is routinely used within the framework of a relationship regulated by belonging to an organisation (e.g. contact between colleagues, trade union contact).

(2.2) There is indeed a personal acquaintance and friendship between the letter writer and the addressee.

(2.3) A closeness and familiarity between the two is assumed by the letter writer contrary to the facts. This may

(2.3.1) be meant jocularly;

(2.3.2) be a form of humouring the addressee or of trying to force an intimate relationship on him; here the variants (a) strategic closeness ("dear fellowcitizens") and (b) individually communicative nearness (as the personality feature of an individual) can be distinguished;

(2.3.3) but this can also be the expression of the dialogue-like relationship between the author and reader of a text ("Dear Reader"; "intimacy at a distance", Horton and Wohl 1956).

(2.4) It can also be imagined that the writer does not know the form of address in a letter. This applies in cases in which

(2.4.1) a younger child or even a person of low intelligence writes a letter;

(2.4.2) a foreigner not yet well versed in the German language writes such a text. 
(2.5) Finally, the variant should be mentioned that such a letter is written within the framework of a relationship to a transcendent being ("Dear God", "Dear Santa"; for the event of a follow-on communication: e.g. "Dear Fairy").

(3) Against the background of the structure of this case it seems obvious to assume that a letter writer who uses a form of address expressing closeness and familiarity within the framework of an I-you (du) relationship is writing to a male person who is addressed by his first name in the editorial board of the children's programme of a broadcasting station.

\section{2nd statement: "Here I am senting you a fu cough sweets"'}

Paraphrase: "With this letter I am sending you a few cough sweets

(1) The author of the letter addresses the addressee with "du" (you), which fits in completely with the form of address "Dear Spencer" (lieber Spencer).

(2) The action reported - the performer of it is sending the receiver of the letter, Spencer, some cough sweets - implies that the letter is an accompanying letter. It will have to be checked whether the object that is being sent is what is actually the important aspect of the letter contact or whether the writing itself is the core of the contact, since the object sent would strengthen or weaken the letter's statements in a non-verbal way.

(3) The object being sent is "a few cough sweets". Cough sweets can generally be bought anywhere; they are a non-prescription medicine which provides a certain degree of enjoyment. As it is not very practical to send them by letter, the question arises as to why our letter writer is sending cough sweets to his addressee.

(3.1) It first has to be clarified whether there has been an explicit cause for this action: Was there (a) a request made by the addressee to which the letter writer is responding? (b) Are the motives egoistic (a strategic motive here would be, for example, to send a sample packet; a communicative but egoistic motive would be, for example, within the framework of an overprotective relationship, to bind the communication partner by sending the sweets [concrete situation: a mother sends her adult son cough sweets]) or are the motives which activate the letter writer altruistic (the addressee wishes to be sent such cough sweets or the sender knows that the addressee will be pleased about this gesture)?

If one goes more deeply into the question as to the possible motives for the action of sending someone cough sweets the following variants can be imagined:

(3.1.1) The sender possesses cough sweets, while the receiver does not on account of an actual scarcity (for example, the receiver lives in a town where they are in short supply).

(3.1.2) The sender sends the addressee the sweets on the basis of continuous or sporadic solicitousness and attention. Here one could further ask whether (a) this is necessary at present (the addressee is ill and does not have any cough sweets), (b) the sender is acting solicitously (the addressee might become ill), (c) the sender is acting, for example, overprotectively (a mother sends cough sweets to her healthy adult son). 
(3.1.3) The sender is acting on the basis of friendship and familiarity in the sense that he sends cough sweets without there being any pressures inherent in the situation (no shortage, no illness existing) according to the motto: "Small gifts keep up a friendship". In this case the gesture would be of paramount importance, not the object that is sent.

(3.1.4) The sender could, however, have a joke or some nonsense in mind, or be acting cynically (e.g. sending cough sweets to a bad opera singer).

(3.1.5) It also has to be asked for whom the solicitousness, friendship or joke is intended: (a) a close, very important person (significant other person) or (b) a less close and important person.

(4) The quantity stated - "a few" - is not precise. The letter says neither "cough sweets" nor "a packet of cough sweets". The quantity given instead ("a few") is a casual, imprecise formualtion: the exact number is not important, but it seems to be the gesture that counts.

(5) The sentence construction and writing style show the following special features: (a) The text is written in an oral style (Koch and Oesterreicher 1985) (for example, the use of the word "here" at the beginning of the sentence). (b) In accordance with the aims of the tuition in the primary school the following characteristics and mistakes are typical of a pupil of average intelligence in the first or at the beginning of the second school year in Germany: (i) Size of the writing (the letter is written in very large handwriting), (ii) spelling mistakes (the words "fu" and "senting" are written wrongly, and the word for "you" ("dir") should be capitalised). In the light of these features the author of the letter is most probably a 7-8-year-old child.

(6) Knowing that the author of the letter is very probably a schoolchild, it is possible to ask specifically whether certain alternative actions listed above can thus be ruled out. The following motives for the action are less probable:

(6.1) Variant (3.1a): reacting to a request (such a request was not made);

variant (3.1b): sending a sample, action within the framework of an overprotective mother-child relationship;

variant (3.1.1): the sender does not know the conditions in which the addressee lives in this respect;

variant (3.1.2): continuous, responsible care for the health of someone else who is not being cared for is generally something that a child of this age cannot yet accept.

(6.2) Variant (3.1.2): selective solicitiousness and attention, variant (3.1.3): friendship and familiarity and variant (3.1.4): practical joke may be feasible for a child of this age. Sending cough sweets can be used as a gesture to "cultivate" a relationship or to consolidate it ("Small gifts give pleasure"). 


\section{3rd statement: "Your hoarse voise is to go away sun"}

This statement is, at first sight, easy to understand. But difficulties arise when an effort is made to paraphrase it. For this reason an attempt should be made to look for action contexts in which such a statement has become a rule.

Paraphrase / adult language: "I want your hoarseness to disappear soon."

Paraphrase / child's language: "I order: hoarse voice, go away soon"

(1) Such a sentence construction conforms to a rule within the framework of a mother-child relationship which is characterised by a basal complementarity of support performances: the child expects the mother to support it to the best of her ability and to perform such activities as the child cannot (or does not want to) carry out itself yet. Here the mother frequently takes over the function of an auxiliary ego for the child (Martens 1979; Neumann 1983). A typical action situation would be, for example: A man unknown to the child enters the room where the mother and child are, and the child then says to the mother after a while, "The strange man ought to leave, Mummy." The mother is obliged imperatively by the child, instead of the child seeing to it that the man leaves.

(2) Another variant of this imperative sentence structure ("You are not to. ..") is to be found when children say, "The stove is not to burn me." Here, too, an imperative to act is expressed, although the addressee is not a person but a material thing, the stove. In this case the child's thinking is characterised by animism. "To be" and "ought" are not yet adequately separated, and natural events or objects are put into the "to be" modality of social action: the stove becomes a performer, which ought to behave or act according to the child's demand.

(3) In the viewer's third statement to be interpreted it is possible to detect a mixture of animistic and realistic thinking in the child that is writing the letter. The child chooses the imperative sentence construction known to it from the interaction with its mother (a performer ought to do something); secondly, a natural event is redefined as a social event (the performer is the hoarse voice), and, thirdly, it becomes clear in the time perspective which the child expresses in the modal auxiliary and the verb (something is to go away soon) that the child is not completely the slave of animistic thinking: the child knows that recovering from an illness takes a certain time. Even a strong command - the child realises this - cannot avoid this time factor. So the sentence construction contains a mixture of animistic and realistic thinking, which, incidentally, is by no means unusual for a 7-8-year-old child. Children of this age are at the transition point between animism and realism (Piaget 1980; Buggle 1988). So on the basis of this deduction the above paraphrase in a child's language has a claim to validity. 
(4) Peculiarities in the way of writing: the linguistic characteristics of the statement are appropriate to the performance level of a 7-8-year-old child.

(5) What significance does this statement have in the context of a viewer's letter? In a conventional way, the aim of this sentence is to rationalise the action of the letter writer in sending cough sweets to the receiver. The justification connection which emerges is: the addressee (Spencer) is hoarse, and the sender is sending him a few cough sweets as a form of gesture of friendship or solicitousness, so that he can use them to do something about it.

(6) Why should "Spencer" do something about his hoarse voice? Reference has already been made to the motjves of solicitousness, friendship and a joke. But other motive variants are imaginable:

(6.1) It could be imagined that the child is complaining about the normality of a voice that is not hoarse: a voice that has been perceived as unfamiliar is to become "normal", or familiar, again. Or: a voice perceived as unpleasant is to become more pleasant; a voice that is difficult to understand is to become easier to hear.

(6.2) There is the worry on the part of the letter writer that he will have to do without the addressee because his illness has got worse (fear of the loss of a significant other (media) person).

\section{4th statement: "Oh one thing I have quite forgoten"}

Paraphrase: "Oh, one thing I have quite forgotten"

(1) This statement follows a conventional language rule to indicate a change of subject in a letter. It becomes clear that the actual letter is finished and a kind of postscript is beginning. The contents of the letter, namely to be a letter accompanying the cough sweets, is confirmed: there are no further statements in the actual letter apart from the one that cough sweets are being sent to cure the receiver of his illness. The use of the introductory formula additionally intensifies the reader's expectation of the second part of the statement that follows.

(2) The writer announces another thought which he apparently had intended to inform the reader of before writing, but had then failed to really do so. This thought appears to be very important for the author of the letter. The use of the added formulation " $O$ h, one thing 1 have quite forgotten" in this case also stresses the importance of the message that follows.

(3) Again the formulation stems from the spoken language, the language of closeness. The further linguistic peculiarities also characterise the performance level of a 7-8-year-old child. 
5th statement: "I see you every tim"

Paraphrase: "I see you in each of (your) programmes"

(1) The author of the letter informs the addressee that he watches his programmes regularly, or sees him in every programme in which he appears.

(2) The statement shows that the author of the letter adheres to a realistic way of thinking rather than an animistic one: he knows that the editors, actors or puppets cannot know per se that he always sees the programmes (see Böhme-Dürr 1987).

(3) What significance does this statement have for the dialogue between the sender and receiver?

(3.1) This information can be understood as praise for "Spencer" roughly in the sense of: "It is always worth my while to watch your programme, because it is super";

(3.2) it can be an expression of admiration for the idol "Spencer";

(3.3) it can be a reference to the fact that the sender would like to tell the receiver that he is a "loyal" viewer, who never misses one of his programmes;

(3.4) but it can also be understood as a kind of reassurance of a positive association which is of significance especially in the event of illness (hoarseness) ("You mean a lot to me').

(3.5) It is also imaginable that this information may be meant not only retrospectively but also prospectively - this (a) also in connection with the cough sweets: "I see every programme, so I can also see whether the cough sweets have the desired effect and "Spencer's" voice improves." (b) With regard to a possible answer from "Spencer" to the sender's letter it might be expected that the latter could assume: (i) "There is no need for you to reply to me by letter, because I can see on television how your voice is getting on"; (ii) "It would be nice if you could let me know on the screen whether the sweets have helped"; (iii) "But perhaps you could also thank me "live' for my letter." All these sense variants bring out the latent request of the sender to the addressee as an intention to continue, within the framework of the follow-on communication, the para-social communication between the media performer and the viewer that has begun.

(4) Linguistic peculiarities: the performance level of a 7-8-year-old is again revealed.

6th statement: "Bye-bye from (first and last name of a male letter writer)

Paraphrase: "Goodbye. This letter was written by (. . .)."

(1) The expression "Bye-bye" is a common way for - not only - children to end letters; it stems from direct face-to-face contact (spoken language) and is a shortened form of "goodbye" used here to indicate the end of the letter. The German expression ("Tschüß") is used when bidding farewell, especially in North Germany. 
(2) The programme "Hallo Spencer" also ends with the presenter taking leave of the viewers with the word "Tschüß". The repetition of the presenter's usage by the child would indicate (a) the action circle of a follow-on communication (the repetition of language patterns as a sign of mutuality of interests); it can, however, also be interpreted as an expression of the child's media competence: the letter writer reproduces, like a mirror image, the interaction between the show performer and the viewer.

(3) This is followed, as is also usual in letters, by the name of the sender, here in the form: "from...", the first and last name being given. This is conspicuous, too: giving the last name indicates that the sender and the addressee are at least not so familiar that the first name is sufficient for purposes of recognition; so the author of the letter must already know about the feature of anonymity within the framework of follow-on communicataion. The "from", too, is unusual, if it is in a letter to a familiar person. This ending to the letter has to be paraphrased as follows: "This letter was written by (. . .)", which is inconsistent with a close relationship between two people in which there are regular contacts (thus in a pen friendship as well). The letter is therefore ended in a tension of closeness and distance.

\subsection{Summary of the results of the detailed analysis}

The child who wrote the selected viewer's letter is preoccupied with the puppet presenter "Spencer" and his hoarse voice. In a film sequence it was shown that Spencer had caught a cold and now has a bad voice. This event in the story interests the boy so much that he sends "his" presenter "Spencer" cough sweets shortly after the sequence was transmitted. Here feelings of friendship, sympathy and solicitousness for the health of the media vis-à-vis, who in spite of his puppet appearance is addressed as a human vis-à-vis, are mixed together. The child's letter is a clear example of how a para-social dialogue between the medium performer and the viewer within the framework of the follow-on communication is transformed into a social dialogue. All the same, the boy goes to the trouble, which should not be underestimated, to write and send cough sweets; his wish to continue the dialogue can be clearly seen. In doing so the letter writer is sure about the technical conditions of this special form of dialogue. He knows that, although Spencer cannot see him himself through his television set, the contact can be maintained by both sides. Television is not a 'magic window' for the writer, but nor is it an insurmountable barrier to communication. The child overcomes this communication situation in a specific mixture of animistic and realistic strategies of thought and action.

\section{Concluding discussion of the methods of analysis}

What additional benefits have now been gained by the extensive structural analysis? Has the work been worthwhile? 
The letter, the structural analytical evaluation of which was presented in Section 5 , was placed into the category "child to puppet, person-related subject" in the course of the quantitative analysis. This kind of categorisation provides only little information on the peculiarities of the form of communication 'a viewer's letter written by a child'. Without more extensive, interpretative evaluation it is not possible to make any more extensive statements about either the prerequisites of the follow-on communication interesting from the point of view of the theory of communication, or about the child's understanding of media reality that is informative from the point of view of development psychology, or about this individual child's motives and expectations.

A contents analysis that is more strongly interpretative might represent a compromise between the purely quantitative and the structural-hermeneutical method. If one wanted to evaluate the letter in this way, for example with the help of the procedure which, although interpretative, is still based on categories, to determine Huth and Krzeminski's (1981) gratification classes and types, one would only be able to make a few categorisations on account of the brevity of the letter: (in particular) "companionship" (cf. Table 1), (but also) "sharing" are possible as contact-directed gratifications; perhaps the category "social utility" would also be relevant in the expanded variant that the writer can use his activity within the framework of everyday communication. The gratification "identity" could be pointed out in a generalised perspective as an I-directed gratification. Although it would be posssible using these categorisations to give the letter subjects an adequate statement direction, many points would still remain unclear: the categorisations themselves would not become very transparent and much of what was explicitly stated in the above structural analysis would not have been taken into account or mentioned.

The extensive letter analysis we have presented can show that the effort needed to carry out the method of objective or structural hermeneutics is worthwhile in many respects:

(1) The first advantage is of a methodological kind:

The structural analysis furnishes an intersubjective access to the subjective conditions of social behaviour (here: the example of mass communication). As we saw in the discussion of the literature on the 'magic window', there is not a great deal of sense in asking children how real television reality is for them. Children have great difficulties in understanding the sense of questions like this. But is the situation any different when we - as happened in many works on the uses and gratifications approach - ask adults what their motives are for using the media? Huth and Krzeminski answer this question in the negative. Introspection does not open up for the persons concerned a privileged access to the motives for their actions. 
In this situation the linguistic-pragmatically orientated philosophy promises a way out (Habermas 1988). When someone speaks he always expresses by what he says what he considers to be the truth, which communicative rules he regards as appropriate to the situation and how he subjectively assesses the circumstances. The speaker's motives and expectations are always contained in the act of speaking. Whoever analyses a performer's act of speaking for its implicit conditions thus directly obtains access to the speaker's motives and convictions.

Over and beyond this, the texts analysed represent a special kind of reality by which different interpreters can understand each other intersubjectively. If a reader of the case reconstruction presented in Section 5 should have objections at certain points to the sense versions explicitly stated above (which is quite possible, as for reasons of space it was not possible here to comprehensively present the listing of the versions and the elimination process of sense variants), this is a point in favour of the interpretation process presented: interpretations are in principle presented in complete transparency, and the advantages and disadvantages of any argumentation can be checked directly by a reader if he is prepared to participate in the differentiated and complex interpretation work.

Neither the speaker himself (here the letter writer) nor the researcher who submits the evaluation can claim to be right in the face of this critical authority of the reader who refers to knowledge shared by the speech community about the meaning of texts!

(2) The second advantage is of a psychological kind:

The extensive letter analysis has managed to shed light on what may be behind the categories "companionship", "sharing", "social utility" and "identity" in the way of quite concrete happenings in a relationship and the writer's subjective concern. A "detailed analysis" or a "context search" explicitly represents the nature or the shaping of actions in the appropriate breadth and depth. It became very clear what the letter writer's motives were for initiating the dialogue with the puppet presenter.

Wherever alternative reasons or versions had to be left open, it would certainly have been possible to specify the statements further if more contexts had been available. (This was prevented by the preservation of the writer's anonymity required by data protection.) However, in our analysis we were not concerned to completely elucidate this one, special case. But, rather, the one analysis is intended to provide insight into the general conditions of media reception and of follow-on communication. This brings us to the third advantage. 
(3) The third advantage is of a theoretical kind:

Although the detailed analysis was only carried out on one single letter it does allow us to find answers to general, theoretical questions, in the case under discussion, on the basic assumptions of a theory of para-social interaction with media and on the question of children's perception of reality when watching television.

(3a) Justifying the term 'follow-on communication':

With 'follow-on communication', it was assumed, the viewer continues a communcative process. Media reception itself, too, has been understood by him as a communicative happening. Is this assumption right? In the research into the effects of the media one is used to regarding the recipient as a subject processing stimuli or information. Which model of the recipient should one prefer? Is the recipient an automaton controlled by stimuli, a subject who adopts a strategic attitude to search the environment for information in order to act successfully, or does the recipient enter into a social relationship with the media producer? Our case reconstruction shows that the young viewer's letter can only be understood meaningfully from the latter point of view. Media reception therefore has to be described at least as para-social interaction as well.

If we also look at the participation debate, our findings once again underscore the fact that viewers' letters represent a medium for mediating between mass and individual communication which should no longer be held in such low esteem. The para-social communication is expanded by means of the follow-on communication to become direct communication. This leads to the obvious demand to pay more attention to the media recipients' needs for contact and dialogue (see the still relevant discussion between Huth and Krzeminski, on the one hand, and the broadcasting stations, on the other: Huth and Krzeminski 1981, appendix).

(3b) The perception of media reality by children:

Finally, the structural letter analysis brings some light into the debate on children's ideas of the reality of what is shown on television. At least in the case of the writer of the one letter analysed, the dichotomy 'real' vs. 'not real' does not make much sense. But, rather, this child's letter can only be understood if we assume realism and animism are inside one another in perception . But this form of perception will no longer seem so alien to us adults if we realise that we can only understand the actions of a cloth puppet if we set aside our critical consciousness of reality and pretend, at least temporarily, that the puppet is a vis-à-vis just as if we wanted to enter into a dialogue with the puppet. 


\section{Notes}

1 This work was partly financed by the DFG, Bonn (SFB 321, Project B7). - We are especially indebted to the NDR editorial board for "Young Children's Programmes/Television" for kindly putting the letter material, with the names of the writers removed, at our disposal for our scientific study.

2 Our thanks are due to Peter Koch for references to the literature available on the sort of text.

3 The text was written in large handwriting with a blue ballpoint pen. It completely fills up one page of white paper measuring $21 \times 15 \mathrm{~cm}$ (DIN-A5). All the writing mistakes etc. were reproduced as they were found.

\section{References}

Altheide, D.L.: Symbolic interaction and „,uses and gratifications" ${ }^{4}$ : Towards a theoretical integration. In: Communications $11 / 1985 / 3$. p. $73-82$.

Baron, L.J.: What do children really see on television? Paper presented at the Annual Meeting of the American Educational Research Association, Boston, Mass., April 7-11, 1980. American Educational Research Association (Ed.). Boston, Mass.: AERA 1980.

Böhme-Dürr, K.: Was Kinder wirklich von ihren Medien halten. Unpublished manuscript. Universität München 1987.

Böhme-Dürr, K.: Die kleinen Plastikleute im Fernsehen: Wie Kinder Fernsehrealität wahrnehmen. In: Medienwirklichkeit - Wirklichkeit. Kreisjugendring Nürnberg-Stadt, (Ed.). Nürnberg: Selbstverlag 1988. p. 61-80.

Bonfadelli, H.: Die Sozialisationsperspektive in der Massenkommunikation. Berlin: Spiess 1981.

Braun, B.; Charlton, M.; Neumann, K.; Orlik, W. and Rapp, R.: Freiburger Längsschnittuntersuchung der Medienrezeption durch Vorschulkinder (Text-Kontext-Korpus). Forschungsberichte des Psychologischen Instituts der Universität Freiburg. No. 53, 7 vols. Freiburg 1989.

Brown, M.H.; Skeen, P.; Osborn, K.D.: Young children's perception of the reality of television. In: Contemporary Education, 50/1979/3, p. 129-133.

Bürgel, P.: Brief. In: Kritische Stichwörter. Faulstich, W. (Ed.). München: Fink 1979, p. 26-47.

Buggle, F.: Untersuchung zum Animismus bei 5-8jährigen Kindern. Zeitschrift für Entwicklungspsychologie und Pädagogische Psychologie 20/1988/-, p. 3-14.

Charlton, M.; Neumann, K.: Fernsehen und die verborgenen Wünsche des Kindes. Weinheim: Beltz 1982.

Charlton, M.; Neumann, K.: Medienkonsum und Lebensbewaltigung in der Familie. Weinheim/München: Psychologie Verlags Union 1986.

Dorr, A.: When I was a child, I thought as a child. In: Television and social behaviour. Hillsdale, N.J.: Erlbaum 1980, p. $191-230$. 
Dorr, A.: No shortcuts of judging reality. In: Children's understanding of television. Research on attention and comprehension. Bryant, J.; Anderson, D.R. (Ed.). New York, N.Y.: Academic Press 1983, p. 199-220.

Ermert, K.: Briefsorten. Tübingen: Niemeyer 1979.

Ettl, S.: Anleitungen zu schriftlicher Kommunikation. Tübingen: Niemeyer 1984.

Fernie, D.: Who flies, who cries? Children's understanding of people from television and real life. Paper presented at the Annual Meeting of the American Psychological Association, 88th, Montreal, Canada, September 1-5, 1980. American Psychological Association (Ed.). Montreal, Canada: APA 1980.

Fernie, D.: Ordinary and extraordinary people. Children's understanding of television and real life models. In: Viewing children through television. Kelly, Hope; Gardner, Howard (Ed.). London: Jossey-Bass 1981, p. 47-58.

Greenberg, B. S.; Reeves, B.: Children and the perceived reality of television. In: Journal of Social Issues, 32/1976/4, p. 86-97.

Habermas, J.: Nachmetaphysisches Denken. Frankfurt: Suhrkamp, 1988.

Hawkins, R.P.: The dimensional structure of children's perceptions of television reality. In: Communication Research, 4/1977/3, p. 299-320.

Horton, D.; Wohl, R.R.: Mass communication and para-social interaction. Observations on intimacy at a distance. Psychiatry 19/1956/-, p. 215-229.

Huth, L.; Krzeminski, M.: Zuschauerpost - ein Folgeproblem massenmedialer Kommunikation. Tübingen: Niemeyer 1981.

Jaglom, L.M.; Wilder, P.G.; Fagre, A.: How preschoolers explore the relationship between television and the real world. Harvard University, Cambridge, Mass., Graduate School of Education (Ed.). Cambridge, Mass.: Harvard Univ. 1979.

Jaglom, L.M.; Gardner, H.: The preschool television viewer as anthropologist. In: Viewing children through television. Kelly, H.; Gardner, H. (Ed.). London: Jossey-Bass 1981, p. $9-30$.

Joas, H.: Die unglückliche Ehe von Hermeneutik und Funktionalismus. In: Kommunikatives Handeln. Honneth, A.; Joas, H. (Ed.). Frankfurt: Suhrkamp 1986. p. 144-176.

Kelly, H.: Reasoning about realities: Children's evaluation of television and books. In: Viewing children through television. Kelly, H.; Gardner, H. (Ed.).London: Jossey-Bass 1981 , p. $59-71$.

Klapper, H.L.: Children's perceptions of the realism of televised fiction. New wine in old bottles. In: Television advertising and children. New York, N.Y.: Child Research Service 1981, p. 55-82.

Koch, P.; Oesterreicher, W.: Sprache der Nähe - Sprache der Distanz. Romanistisches Jahrbuch. vol. 36. 1985. Berlin: de Gruyter 1986, p. 15-43.

Kohli, M.: Fernsehen und Alltagswelt. Rundfunk und Fernsehen 25/1977/1-2, p. 70-85.

Lurcat, L.: A cinq ans, seul avec Goldorak. Le jeune enfant et la télévision. Paris: Syros Collection Contre-Poisons 1982.

Martens, K. (Ed.): Kindliche Kommunikation. Frankfurt: Suhrkamp 1979.

Messaris, P.; Kerr, D.: TV-related mother-child interaction and children's perceptions of TV-characters. In: Journalism Quartertly, 61/1984/3, p. 662-666.

Morison, P.; MacCarthy, M.; Gardner, H.: Exploring the realities of television with Children. Harvard University, Cambridge, Mass. (Ed.). Cambridge, Mass.: Harvard Univ. 1978. 
Morison, P.; Kelly H.; Gardner, H.: Reasoning about the realities on television. A developmental study. In: Journal of Broadcasting, 25/1981/3, p. 229-242.

Neumann, K.: Der Beginn der Kommunikation zwischen Mutter und Kind. Bad Heilbrunn: Klinkhardt 1983.

Neumann, K.; Charlton, M.: Massenkommunikation als Dialog: Zum aktuellen Diskussionsstand der handlungstheoretisch orientierten Rezeptionsforschung. In: Communications, 14/1988/3, p. 7-38.

Neumann, K.; Charlton, M.: Massen- und interpersonale Kommunikation im Alltag von Kind und Familie. In: Massenkommunikation. Kaase, M.; Schulz, W. (Ed.). Sonderheft der KöIner Zeitschrift für Soziologie und Sozialpsychologie. Opladen: Westdeutscher Verlag 1989, p. 364-378.

Oevermann, U.: Probleme der hermeneutischen Sozialforschung. Vortrag. Universität Osnabrück. (manuscript) 1981.

Oevermann, U.: Kontroversen über sinnverstehende Soziologie. Einige wiederkehrende Probleme und Mißverständnisse in der Rezeption der ",objektiven Hermeneutik". In: Handlung und Sinnstruktur. Aufenanger, St.; Lenssen, M. (Ed.). München: Kindt, 1986, p. $19-83$.

Oevermann, U.; Allert, T.; Konau, E. et al.: Die Methodologie einer ,,objektiven Hermeneutik" und ihre allgemeine forschungslogische Bedeutung in den Sozialwissenschaften. In: Interpretative Verfahren in den Sozial- und Textwissenschaften. Soeffner, H.-G. (Ed.). Stuttgart: Metzler 1979, p. 352- 434.

Palmgreen, Ph.: Der „Uses and Gratifications Approach", Theoretische Perspektiven und praktische Relevanz. In: Rundfunk und Fernsehen 32/1984/1. p. 51-62.

Piaget, J.: Das Weltbild des Kindes. Frankfurt: Ullstein 1980. (Original 1926).

Quarfoth, J.M.: Children's understanding of the nature of television characters. In: Journal of Communication, $29 / 1979 / 3$, p. 210-218.

Rapaczynski, W.; Singer, D.G.; Singer, J.L.: Teaching television: a curriculum for young children. In: Journal of Communication, 32/1982/2, p. 46-55.

Renckstorf, K.: Neue Perspektiven in der Massenkommunikationsforschung. Berlin: Spiess 1977.

Renckstorf, K.: Nachrichtensendungen im Fernsehen. Vol. 2. Berlin: Spiess 1980.

Rydin, K.: Wie Kinder Fernsehsendungen verstehen und daraus lernen. In: Wie verstehen Kinder Fernsehprogramme? Forschungsergebnisse zur Wirkung formaler Gestaltungselemente des Fernsehens. Meyer, M. (Ed.). München: Saur 1984, p. 158-177.

Scheuch, U.K.: Wechselwirkungen zwischen Programm-Machern und Hörern. Krefeld: Mund-M-Wissenschaftsverlag 1986.

Singer, D.G.; Singer, J.L.: Television and the developing imagination of the child. In: Journal of Broadcasting, 25/1981/4, p. 373-387.

Teichert, W.: „Fernsehen“" als soziales Handeln (II). In: Rundfunk und Fernsehen $21 / 1973 / 4$, p. $356-382$.

Weinraub, M.; Putney, E.: The effects of height on infants' social responses to unfamiliar persons. Child Development 49/1978/-, p. 598-603. 


\section{Media-related education for parents and family counselling as an aid to socialisation in practical life - Some essentials}

The media- and communication-pedagogical counselling of parents and forming a family can be described as an aid to socialisation that is close to life and which is determined by three central points of view:

1. For an experience- and subject-orientated educational and counselling conception it is first a matter of reconstructing subjective interpretation patterns and the way in which everyday knowledge is acquired and takes effect. This also applies to the media, media use and the communication-pedagogical action concepts. The families or parents come to a relevant meeting with a mixture of everyday knowledge and elements of scientific knowledge, elements of knowledge which are almost always based on a simplified stimulus-response model: they put the hyperactivitiy of their children on Monday morning down to the excessive consumption of television at the weekend; they interpret children's aggressive actions as an imitation of television examples; they see the increase in potential aggression and anxiety in children as the direct consequence of television; they interpret the relation between "television and child" as a stimulus-response mechanism, they regard the children's lack of imagination as the result of media consumption, or the adolescents' inability to use language and to play is explained monocausally by a preference for television. Now it is not a matter of unmasking "false" interpretation patterns (about the media). The aim is, rather, to replace or to supplement interpretation patterns that have begun to break up and to be questioned by those that are thought out and expanded. The understanding-interpretative counselling gives an impetus to learning and experience processes and accompanies them, structures experiences, offers alternative interpretation patterns.

2. This presupposes moulding the process of learning and of counselling as an experience process, or put in other words: it is firstly a question of recognising the participants' inner perspective, but at the same time also of taking the participants' interpretation patterns seriously as relevant factors in counselling. (Media-related) everyday knowledge has relevance for the families' actions; this is meant to mean: the available interpretation patterns contain, for example, not only (stereotyped) views and (simplified) interpretations of children's actions ("That only comes from television, you know." "This damn television, what is there I can do about it?") but also orientation and justification 
patterns ("Children see enough television, that's why I refuse to talk about it all." "One should give other parents a bad conscience about seeing too much television, perhaps something would change then.') for the particular pedagogical action. Imparting knowledge and expanding action competences begins with the participants' biographically characterised interpretation patterns and everyday experience, names them clearly and tries to systematise and differentiate them. What is decisive here is the counsellor's professional and ethical responsibility. Although the process of education and counselling takes up the parents' experience, the scope of the intervention (in interpretation patterns or pedagogical everyday actions) remains open. The parents have an opportunity for withdrawal and resistance. The point of reference of this professional and ethical responsibility "is the awareness of man's biological and social structure. It is an ethic which originates in human reflection and which places the reflection which constitutes what is human in the centre as a constitutive social phenomenon. When we know that our world is necessarily a world which we produce together with others, then we cannot, in the event of a conflict with another human being with whom we want to continue to coexist, insist on what is certain for us (on an absolute truth), as that would negate the other person. If we want to coexist with the other person we have to see to it that his certainty - however undesirable it may appear to us - is just as legitimate and valid as our own. Like our certainty the other person's certainty is also an expression of his retention of the structure linkage in an existence area - however unenticing this area may appear to be to us. The only chance for coexistence is therefore the search for a more comprehensive perspective, an existence area in which both parties come together to produce a common world. (. . .) A knowledge of this knowledge is the social imperative of every ethic based on what is human." (Maturana/Varela 1987, pp. 264/65)

3. The counselling concept is aimed at action orientation. It takes the requirements of the participants for help and support seriously, in that it not only tests identity designs in view of a crisis experience or provides appropriate interpretation patterns. The conception at the same time contributes to reflecting on everyday practice in life and education, to reaching agreement with other parents or to check back in view of new experiences.

\section{Subject orientation and transferability}

Practical education and counselling orientated to the families' interpretation patterns offers three advantages:

- subject orientation

- the differentiation of the interpretation patterns and 
- the transferability to family education of the principles experienced in counselling.

An indisputable advantage of the approach is the subject orientation. The individual is at the centre with his wishes and communication claims. This experience has been confirmed by the families in their feedback. But subject orientation also entails the recognition of a perception of reality with perspectives. Put in another way: the perception of reality always takes place against the background of subjective everyday experience.

This implies that the life-worlds of every person, every family, every child (and that applies especially to the media worlds, the media-related use patterns, television and reading behaviour, the preference for certain genres, the way of a total media use etc.) can always be perceived only relatively, only approximately. Medial realities do not exist in themselves, but only for themselves; they are always interpreted against the background of available interpretation patterns. It is precisely this aspect that is all too quickly overlooked in the public discussion about the effects of the media. That is why many discussions remain abstract and appear to be an alibi. For the interpretation of other media worlds, the interpretation of other people's media use, is always to be described only as a gradual approximation and should therefore take place with great care and caution. Rashly branding and stigmatising them as well as creating problems should be avoided.

This is at the same time a plea for a casuistic argumentation and for case-related interpretations. The parents are given to understand how relevant subjective interpretation patterns are. But whoever only goes on from everyday knowledge in order to unmask interpretation patterns blocks access to other life-worlds and everyday worlds. That is the reason why the differentiation of interpretation patterns does not mean that the counsellor's paramount interests are imposed. Differentiation always takes place by dialogue, and it can only be described as a negotiating process. Thus a further perspective of media-related education and counselling as a practical socialisation help has been described.

The dialogue about possible structurisation aids or about alternative interpretation patterns does not mean that parents are deprived of their autonomy and responsibility or that their initiative is suppressed - dialogue means encouragement, stimulation and giving back responsibility to those acting pedagogically. It can also lead to personal fears and uncertainties being expressed, when, for example, it is a matter of testing new action orientations.

A conception that begins with the parents' interpretation patterns is characterised by its transferability. By the families experiencing in the process of counselling how seriously I take interpretation patterns, yet at the same time work with them and try to differentiate and expand them, they experience a procedure that can 
be transferred to their pedagogical practice and applied in their field of action. This holds true especially for the work with children.

\section{(Media) science and daily (media) routine}

Unlike many media-pedagogical conceptions I was not concerned with the "pedagogical" mediation or putting media-scientific theory formation into practice (for example, on the theory of media violence, on the theory of emotionalising through media etc.). But, rather, media-scientific knowledge, including that which has been obtained by means of qualitative methods, must reveal itself in its specific relevance in practical everyday life, i.e. such knowledge must at the same time be plausible to the participants and contribute to extending everyday awareness and interpretation patterns. The approach I practised was based on two important fundamental considerations:

- the relationship of scientific knowledge to everyday knowledge and

- the responsibility of the counsellor or educator.

Scientific knoweldge is not per se more valuable than everyday knowledge. Both differ, however, in some segments: while (media) scientific theories are characterised by intersubjectivity, complexity-extension and differentiation, the typical features of everyday theories are subjective plausibility, complexity reduction and simplification. Thus media effects from the point of view of everyday theories are interpreted so that they agree with everyday observations and practised action patterns. The children's Monday morning activity is put down to television; the loud behaviour of the children is thus plausibly and simply explained. At the same time the complexity of the problem is reduced to a dimension that makes it correspondingly easy to act and intervene, for example in not allowing a conversation on the subject of television, in suppressing the acting of television-related scenes etc.

Taking the participants' everyday worlds and life-worlds seriously means at the same time taking seriously their fundamental experience and their orientation patterns in keeping with consistency in everday actions . This does not mean transferring responsibility to an expert with his theoretical knowledge (e.g. the researcher, the further education course teacher), but, rather, the responsibility is given back to the societal subjects and those acting pedagogically, and their observations and experience are not debased, but expanded and structured against the background of scientific knowledge, inasfar as it is relevant to the actions. Feedback from families shows that they were encouraged by the manner of proceeding to try out other ways of acting and proceeding.

Transferring qualitative research findings to societal and individual practice calls for forms of transfer that are more differentiated and closer to everyday life than 
lectures or presentations tailored to the expert, since it is a matter of making knowledge available that can be transferred into practice. On the other hand, I see myself as a presenter who calls on the participants to introduce their individual and specific everyday media-related problems, who organises and supports communicative processes in the counselling sessions and who tries to structure the problems of the particular fields of practice and to solve them in a way that is close to everyday life. This also includes my bringing in my knowledge of the specific problems. A prerequisite for this structuring process is, however, the capability of pedagogical understanding and the ethical obligation not to shatter the participants' confidence in the force of their own interpretation patterns, to respect and not to break resistance to expanded media-related interpretation patterns.

\section{Individual case and overall connection - between idealism and objectivism}

Now family counselling and the education of parents have, however, not only a social-psychological-compensatory aspect, it is for me also a matter of imparting systematic knowledge. Points of departure are here never scientific explanation models or methods of proceeding. Thus in the case of the theme "media violence" it is for me not a question of listing, comparing or providing the pariticpants with all the hypotheses on the effects of television. In order to inform themselves appropriately the family members are given relevant thematic working sheets at the end. More important (in the process of counselling and educating) are for me the parents' respective interpretation patterns and their relevance for interpreting situations. I am concerned that the parents acquire more sensibility for - in this case - communication situations that are taken up by aggression, are given interpretation patterns to help them deal more successfully with situations, i.e. with aggressive actions by the children. I provide a framework within which the participants can process the information they have heard and worked out with greater reflection. The aim is not to impart everything that research knows and has documented on the subject of aggression. What is more important for me is a methodological, but not an ontological, reduction of scientific knowledge, and its application to the particular field of practice.

Only in this way will it be possible for the expanded and differentiated interpretation patterns to become relevant to actions. Added to this is a further aspect. It is not rare for scientific methods to be characterised by (necessary) abstractions, leading to the loss of the concrete nature of experiences, the qualities in terms of meaning of the findings of the study. The uniqueness of every action (for example, of media use) is sacrificed to generalisation. I work, on the other hand, with 
individual cases, take everyday situations as the starting point, discuss problems orientated to cases and encourage casuistic argumentation. In doing so, points of view also show up in each individual case which can be transferred to other cases or represent more general connections. But what remains decisive for the practical counselling is dealing with the individual case, since it is not a matter of helping "all" children (for example, with regard to media-related problems), but the child which shows the problematical symptoms here and now as it reveals itself to the parents and children present. And only in this way is the transfer to everyday life possible at any time. A father put it like this: "It was a good thing that we always discussed individual cases. This made it possible for me to tackle other cases I had experienced as well. What use to me are some average figures? I am concerned with my own particular child and my own concrete problems."

\section{Autobiographical reflections}

Everyday knowledge is firmly rooted in the subjects' biographies. This applies equally to both media-related interpretation patterns which develop in the course of somebody's life and which then decisively influence the (pedagogical) actions in the present. Parents frequently judge their children's media-related actions by those values which they acquired in their original family or surroundings. Their own attitudes are not seldom fixed absolutely, and the other people's attitudes characterised by their life-history are judged accordingly, but are frequently misjudged. (Media-related) further education thus always touches on the biographical continuity of interpretation patterns as well and are possibly able to disclose the "secret" messages and symbols contained in everyday knowledge.

The way to the interpretation patterns of children and families only goes via the media-biographical reflection and reconstruction, via the search for answers to questions addressed to one's own life history and media history. I have endeavoured to achieve this subjective access in the first phase of counselling and education in two ways: on the one hand, through appraising, considering and reflecting on one's own media-biography, and, on the other, by the attempt to impart possible ways of opening up latent interpretation patterns which hinder or block one's own educational work. To put this in concrete terms: I get parents to re-enact mediarelated problem situations, reconstruct their media-biography or draw or model their own favourite heroes. By this way of proceeding it is possible to make (conscious and unconscious) emotions, wishes and needs bound up in the media more conscious for the parents and family members, i.e. to make them available to them.

The vehemence with which media influence everyday life and communication is also shown, for example, by the kinds of feelings with which media users accom- 
pany the actions of the heroes in the media: they perform what one does not allow oneself to do perhaps, and one can put into them those feelings which may be suppressed. So whoever talks about popular television series or cinema stars always talks about their (own) communication needs tied up in them. Whoever - with all the justified criticism - condemns the trivial series of television ("That's a lot of stupid nonsense') also judges and condemns the feelings which accompany the reception of such programmes. Whoever makes this kind of general criticism the starting point of his media-pedagogical actions bars his access to the everyday worlds of the specific users: there is active ("That's not true. I like it.") or passive ("Let him have his say, at home I watch what I enjoy anyway") resistance or even refusal ("I shan't tell him anything again"). Conversations about dealing with the media and their heroes are always conversations about one's own feelings. They call for a lot of sensitivity. That applies in the same way to work with parents. If one fails to take parents' needs and interests seriously one quite frequently produces defensive attitudes and barriers. If only for this reason it appears important to me to reveal the relevance of one's own media-related interpretation patterns and the way in which they arise and take effect. By working on a wide variety of material it may, on the one hand, involve the description of the inner perspective of one's own interpretation patterns (How did they arise? How are they to be structured? How can they be changed?); on the other hand, understanding the interpretation patterns as factors to be taken seriously in the process of counselling and imparting knowledge (Which importance do the media-related interpretation patterns have for me, for my pedagogical actions, for my perception and for the acceptance of other interpretation patterns?). The aim of an autobiographical reflection is thus the openness and consciousness vis-à-vis one's own experience as well as a more distanced and better considered way of dealing with one's own media and life history.

But that alone is not enough. It is also the task of parents' media-related education and family counselling to recognise, by the method of empathic understanding, one's own interpretation patterns, so that one can then deal with them with more reflection. However, when working with interpretation patterns it is a matter of providing the families with an appropriate and practice-orientated action knowledge for the individual specific field of practice. It is important to support the families by providing and further developing alternative and above all viable interpretation patterns. I cannot demonstrate to the families the helplessness of a stimulus-response scheme from research into the effects of the media without at the same time offering more practicable possibilities of interpretation and orientation for actions. That is now an outline of a crucial condition for counselling work orientated towards interpretation patterns: the familes are prepared to open up only if the intervention process attempted by the counsellor has practical consequences. The families must not fall into a hole; they should not be given the 
feeling of hopelessness and powerlessness. That is why I begin with the everyday life of children and families in the communication-pedagogical counselling. It is within the scope of those concerned to change everyday structures.

\section{Continuity and change}

Families need time to agree to a subject-orientated access: they have to be certain that it has productive consequences in practical life and will prove to be viable and applicable for the field of practice. Otherwise interpretation patterns remain resistant to changes, differentiations and structuring (however reasonable, wellfounded and well intentioned they may be).

Wishes for expansions and differentiations of interpretation patterns arise especially in crisis situations. This results in the need for counselling and education to change a situation experienced as unsatisfactory. On the basis of the feedback two forms of crisis can be formulated for the families with the help of a model project I have carried out:

- On the one hand, the feeling prevails that one is no longer able to do justice to existing everyday knowledge, media experience and the everyday media routine or that one reacts helplessly to children's media-related activities.

- On the other hand, many families (especially mothers) found themselves in a life phase or a family cycle in which they were seeking for expanded and differentiated action offerings from a diffuse feeling of dissatisfaction. Changes in interpretation patterns are therefore permitted in situations of radical change, when the existing store of knowledge and the action concepts applied hitherto are no longer adequate for dealing successfully with educational situations. It was noticeable that such crisis experience was not equated with helplessness and hopelessness, but it was understood as a chance to learn more about oneself, one's family and a specific pedagogical problem - in this case the use of the media by children and families. Media (-related) counselling is thus also a medium for transforming parental and educational identity; counselling thus also serves to provide aid in educational crises and critical phases in life.

\section{Reference:}

Maturana, H.; Varela, F.: Der Baum der Erkenntnis. Bern: Scherz 1987. (Original title: El arbol del conocimiento. 1984.) 


\section{The authors}

Stefan Aufenanger, Ph.D., born in 1950, studied education, sociology, psychology and the history of art at Mainz; was last assistant professor at the Institute for Education at Mainz University. At present DFG research scholarship holder for the area of media pedagogics. Main fields of research are socialisation research, moral education, qualitative research methods, media research and media pedagogics.

Ben Bachmair, Ph.D., born in 1943, is Professor for Education, Media Pedagogics and Media Didactics at the University of Kassel. Media-related research at the Institut für Film und Bild, Munich, was followed by the study of systematic theory on the embedment of media-pedagogical and media-didactical questions (key word: symbolic mediation), and this led to empirical studies on the connection between mass communication and actions - in the course of life. His work is at present directed towards developing a frame of reference in cultural history for interpreting mass communication (key word: everyday culture).

Michael Charlton, Ph.D., born in 1943, is Professor for Psychology at Freiburg University. In charge of part of the project in the Special Research Area 321 ('linguistic representation and written representation'). Work has concentrated on developmental psychology, cultural psychology and interpretative research methods.

Heinz Hengst, born in 1941, studied philosophy, sociology and (modern) German; received his doctorate in 1970, became a qualified universiy lecturer in 1982 (Habilitation); Professor of Social Pedagogics at the University of Bremen. Work has concentrated on socialisation, media communication, children's culture; member of the Institut für Popularkultur at the University of Bremen.

Martina van den Hövel, Ph.D., born in 1952, after training as a teacher studied education and philosophy. First worked as a teacher of German and social studies and then, together with Ben Bachmair, ran the project "Media-Pedagogical Counselling" at the University of Kassel. At present she is evaluating the project "The Dynamics of the Symbolic Mediation of Everyday Actions and Mass Communication".

Burkhard Hofmann, graduate in social pedagogics, born in 1956, studied social pedagogics at the University of Kassel, runs a programme cinema and is working on studies of the media history and cultural history of photography. In addition he is evaluating the results of the project "The Dynamics of the Symbolic Mediation of Everyday Actions and Mass Communication". 
Paul Löhr, born in 1938, studied pedagogics at the University of Munich. Since 1965 a member of the staff and since 1980 head of the International Zentralinstitut für das Jugend- und Bildungsfernsehen. Editor and author of numerous publications on television for children and young people.

Stefan Müller-Doohm, Ph.D., born in 1942, Professor of Sociology, with the main emphasis on interaction and communication theory, at the Institute for Sociology at the University of Oldenburg. Publications in the area of the theory of society and research into culture and the media.

Klaus Neumann, Ph.D. in sociology, born in 1952. Assistant professor and in charge of part of a project in the Special Research Area 321 ('linguistic and written representation') at Freiburg University. Research fields are socialisation research, communication sociology and interpretative research methods.

Mara Niemann, teacher and psychology graduate, born in 1951, lives and works in South Baden as an educational counsellor.

Waltraud Orlik, psychology graduate, born in 1961. Studied psychology at Saarbrücken and Freiburg; since 1986 a member of the Freiburg project team 'Structure-analytical Reception Research' in the SRA 321.

Jan-Uwe Rogge, Ph.D., born in 1947. Studied German, political and cultural sciences. From 1976 to 1986 various research works on the subjects of 'children's culture' and 'media and the family' at the University of Tübingen. Since 1986 free-lance cultural scientist, at present working as a family therapist and adult educationalist; in charge of a model experiment on family counselling and media education.

Michaela van Waasen, born in 1959, qualified as a secondary school teacher (English and French), after teaching worked as a member of the academic staff on the project "Media-pedagogical Counselling" at the University of Kassel. At present she is a teacher on a project for youth unemployment. 